\title{
Algoritmo de Otimização Híbrido para a Coordenação de Relés Direcionais de Sobrecorrente em um Sistema Elétrico Malhado
}

Dissertação apresentada à Escola de Engenharia de São Carlos da Universidade de São Paulo como parte dos requisitos para obtenção do título de Mestre em Ciências, Programa de Engenharia Elétrica.

Área de Concentração:

Sistemas Elétricos de Potência

Orientador:

Prof. Dr. Mário Oleskovicz

\section{São Carlos}




\section{AUTORIZO A REPRODUČ̃̃ TOTAL OU PARCIAL DESTE TRABALHO, POR QUALQUER MEIO CONVENCIONAL OU ELETRÔNICO, PARA FINS DE ESTUDO E PESQUISA, DESDE QUE CITADA A FONTE.}

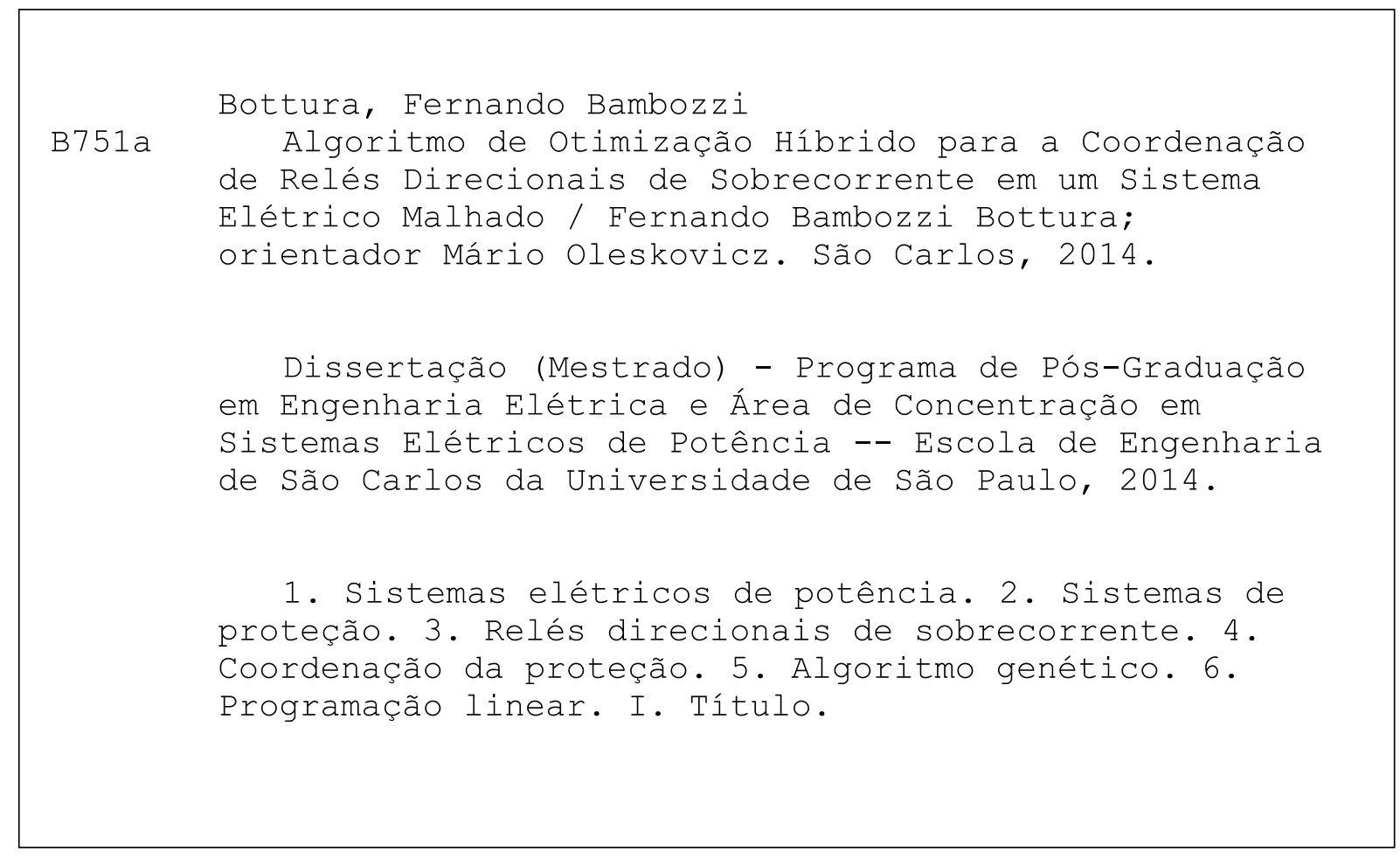




\section{FOLHA DE JULGAMENTO}

Candidato: Engenheiro FERNANDO BAMBOZZI BOTTURA.

Título da dissertação: "Algoritmo de otimização híbrido para a coordenação de relés direcionais de sobrecorrente em um sistema elétrico malhado".

Data da defesa: 29/01/2014

Comissão Julgadora:

Resultado:

Prof. Dr. Mário Oleskovicz (Orientador)

APROVADO

(Escola de Engenharia de São Carlos/EESC)

Prof. Dr. Marcos Julio Rider Flores

APROVADO

(Universidade Estadual Paulista "Júlio de Mesquita Filho"/UNESP- Ilha Solteira)

Dr. Silvio Aparecido de Souza

(Companhia de Transmissão de Energia Elétrica Paulista/CTEEP)

Coordenador do Programa de Pós-Graduação em Engenharia Elétrica e Presidente da Comissão de Pós-Graduação:

Prof. Titular Denis Vinicius Coury 

Para meus pais Maria Teresa e Herbert. 



\section{AGRADECIMENTOS}

Agradeço ao Prof. Dr. Mário Oleskovicz pela cuidadosa orientação em todas as etapas do desenvolvimento desta pesquisa, desde as mais corriqueiras às mais desafiadoras. Muito obrigado pela confiança, incentivo, parceria e por todos os ensinamentos transmitidos nesta fase de importante e essencial aprofundamento acadêmico.

Agradeço ao Prof. Dr. Eduardo Nobuhiro Asada, Prof. Dr. José Carlos de Melo Vieira Júnior e ao Prof. Tit. Denis Vinicius Coury pelas sugestões, discussões e contribuições para esta pesquisa, resultantes, principalmente, do envolvimento constante nos trabalhos do projeto de Pesquisa e Desenvolvimento PD-0068-0020/2011.

Obrigado aos engenheiros da Divisão de Análise da Operação da Companhia de Transmissão de Energia Elétrica Paulista (CTEEP) pela contribuição com os dados e informações técnicas do sistema elétrico estudado. Agradeço também à CTEEP pelo auxílio financeiro prestado durante o desenvolvimento deste trabalho.

Aos amigos do Departamento de Engenharia Elétrica e de Computação, Áthila Q. Santos, Alexandre V. Festa, Daniel A. P. Ferreira, Daniel Motter, Danilo L. A. Negrão, Jáder F. D. Breda, Juliana A. Paludo, Luciano C. M. de Andrade, Marcelo A. A. Lima, Renato M. Monaro, Rui B. Junior, Thais R. Kempner, Ulisses C. Netto, Vinicius de C. Moro, Wellington M. S. Bernardes, agradeço por serem companheiros nas horas de trabalho no Laboratório de Sistemas de Energia Elétrica (LSEE), nos eventos científicos, nos momentos de reabastecimento de energias no restaurante universitário, no movimentado espaço do café e nas horas de descontração.

Também do Departamento de Engenharia Elétrica e de Computação, agradeço aos prestativos funcionários da secretaria de pós-graduação Marisa H. R. V. Fortulan e Leonardo E. S. de Oliveira pelo apoio técnico.

Agradeço aos meus pais, e minha irmã, Eleonora B. Bottura, pelo amplo e amoroso suporte de uma família querida, indispensável e semeador de bons momentos e oportunidades.

Expresso meus agradecimentos também à Silvana M. L. Andrade, pelo respeito e dedicação, e ao Victor S. Fares, pela amizade e ensinamentos, fundamentais para a conclusão desta importante etapa em minha vida ("mens sana in corpore sano”). 



\section{RESUMO}

BOTTURA, F. B. Algoritmo de otimização híbrido para a coordenação de relés direcionais de sobrecorrente em um sistema elétrico malhado. 2013. 156f. Dissertação (Mestrado) - Escola de Engenharia de São Carlos, Universidade de São Paulo, São Carlos, 2013.

Esta pesquisa tem como objetivo apresentar um método para a coordenação dos Relés Direcionais de Sobrecorrente (RDS) associados ao sistema de proteção de um Sistema Elétrico de Potência (SEP) malhado. O SEP malhado, referente a uma parte do sistema de subtransmissão da rede básica brasileira, em concessão da Companhia de Transmissão de Energia Elétrica Paulista (CTEEP), foi simulado via o software CAPE (Computer-Aided Protection Engineering) a partir da base de dados, para estudos de curtos-circuitos, disponibilizada pelo Operador Nacional do Sistema (ONS). Dada a topologia e a operação do SEP malhado em análise, um método de otimização híbrido foi implementado baseado na combinação e aplicação de Programação Linear (PL) e Algoritmo Genético (AG). O algoritmo desenvolvido permitiu a realização de diversos estudos de curtos-circuitos necessários para a obtenção e avaliação da coordenação dos pares de RDS, tanto para a topologia principal do SEP em análise, como para outras configurações de operação caracterizadas, principalmente, pela alteração topológica do SEP. Os resultados demonstram que o algoritmo foi capaz de fornecer uma coordenação adequada para os RDS, respeitando todas as restrições impostas pelo problema de coordenação.

Palavras-chave: Sistemas elétricos de potência, sistemas de proteção, relés direcionais de sobrecorrente, coordenação da proteção, algoritmo genético, programação linear. 



\begin{abstract}
BOTTURA, F. B. Hybrid optimization algorithm for directional overcurrent relay coordination in meshed power system. 2013. 156f.. Dissertação (Mestrado) - Escola de Engenharia de São Carlos, Universidade de São Paulo, São Carlos, 2013.

The aim of this work is to present a method for directional overcurrent relays coordination in a meshed power system which is part of the Brazilian power transmission system operated by São Paulo State Electric Power Transmission Company (CTEEP Companhia de Transmissão de Energia Elétrica Paulista). This power system was simulated by CAPE (Computer-Aided Protection Engineering) software using the database of short circuits studies which is provided by the Electric System National Operator (ONS - Operador Nacional do Sistema). Given a specific power system topology and its operating conditions, the hybrid algorithm was developed based on the combination and execution of linear programming and genetic algorithm. Several short circuits scenarios were evaluated in order to obtain and assess the coordination between the pairs of directional overcurrent relays. In such scenarios, it was considered the main network topology, as well as other network operating conditions, mainly caused by certain topological variations. The results show that the hybrid algorithm provided a feasible coordination solution for the considered directional overcurrent relays.
\end{abstract}

Keywords: Electrical power system, directional overcurrent relay coordination, power system protection, genetic algorithm, linear programming. 



\section{LISTA DE FigURAS}

Figura 1 - Sistemas com fontes geradoras interligadas por linhas de transmissão paralelas... 34

Figura 2 - Representação unifilar simplificada de um RDS.

Figura 3 - Diagrama fasorial para estudo da direcionalidade de um RDS

Figura 4 - Curvas de tempo do tipo normal inversa segundo a norma IEC 60255-3 (1989). .. 39

Figura 5 - Fluxograma referente à metodologia de parametrização e avaliação da coordenação do SP para a desejada operação da topologia principal.

Figura 6 - Fluxograma referente à metodologia de parametrização e avaliação da coordenação do SP para uma alteração na operação da topologia principal do SEP.

Figura 7 - Sistema elétrico malhado de 3 barras

Figura 8 - Ilustração de um cenário de curto-circuito para um par de RDS $\left(R_{1}\right.$ e $\left.R_{4}\right)$ em um SEP simplificado, evidenciando as correntes mensuradas pelos relés de PRL e PRR

Figura 9 - Limites dos múltiplos Mmin e $M \max$ sobre a curva do tipo normal inversa segundo a norma IEC 60255-3 (1989) para MT = 1.

Figura 10 - Fluxograma do algoritmo híbrido de coordenação.

Figura 11 - Funcionamento básico de um AG ilustrado por blocos funcionais.

Figura 12 - (a) Disposição das correntes de pick-up em um cromossomo; (b) Codificação binária das correntes de pick-up na estrutura cromossômica.

Figura 13 - Ilustração de um processo de crossover entre dois cromossomos de três genes $(g=3)$ e dois pontos de corte $(g-1)$.

Figura 14 - Efeito da mutação sobre um bit de um dos genes do cromossomo, (a) antes da mutação; (b) após a mutação.

Figura 15 - Diagrama unifilar do sistema teste referente à porção de um sistema de subtransmissão de $138 \mathrm{kV}$ conectado à rede básica brasileira sob concessão da CTEEP.

Figura 16 - Representação simplificada do diagrama unifilar do sistema teste em que se identificam as 11 LT e os 22 RDS envolvidos no processo de coordenação. 
Figura 17 - Comportamento de $S T$ (curva média) para as 30 execuções do algoritmo utilizando-se $P=50$, fator $\mu=50$ e $\lambda=1$.

Figura 18 - Gráfico contendo as curvas médias para as 30 execuções do algoritmo híbrido de coordenação variando-se o tamanho populacional de 50 a 300 cromossomos.

Figura 19 - Comportamento de $S T$ para 10.000 gerações utilizando-se $P=50$, fator $\mu=50$ e $\lambda=1$.

Figura 20 - Coordenogramas do relé R3 (PRL) e relé R2 (PRR).

Figura 21 - Coordenogramas do relé R6 (PRL) e relé R8 (PRR). 104

Figura 22 - Coordenogramas do relé R12 (PRL) e relés R13, R15 e R19 (PRR). 104

Figura 23 - Coordenogramas do relé R14 (PRL) e relés R11, R15 e R19 (PRR). 105

Figura 24 - Coordenogramas do relé R15 (PRL) e relé R17 (PRR).

Figura 25 - Comportamento de $S T$ para 10.000 gerações utilizando-se $P=50$, fator $\mu=50$ e $\lambda=1$, dada a alteração na topologia em relação à principal (saída de LT6). 


\section{LiSTA DE TABELAS}

Tabela 1 - Constantes de tempo inverso definidas pelos padrões ANSI e IEC.

Tabela 2 - Conjunto de pares de RDS definidos pela matriz MI para o sistema da Figura 7.. 53

Tabela 3 - Pares de RDS calculados para a topologia principal de operação do sistema teste.

Tabela 4 - Valores dos casos de curtos-circuitos obtidos via CAPE para a topologia principal de operação.

Tabela 5 - Condição mínima de sensibilização dos RDS para a topologia principal de operação.

Tabela 6 - Casos de curtos-circuitos obtidos via CAPE para a topologia principal de operação considerando a condição mínima de sensibilização dos RDS.

Tabela 7 - RTC de cada RDS, corrente mínima e máxima de partida que podem ser ajustadas.

Tabela 8 - Capacidades nominais das LT e seus respectivos bays. 88

Tabela 9 - Definição dos limites da faixa de ajuste da corrente de partida para a topologia principal de operação.

Tabela 10 - Definição dos limites da faixa de ajuste dos MT

Tabela 11 - Valores médios das variáveis monitoradas para estudo do fator $\mu$

Tabela 12 - Valores médios das variáveis monitoradas para estudo do fator $\lambda$

Tabela 13 - Variáveis monitoradas para a determinação do tamanho da população inicial de cromossomos.

Tabela 14 - Valores de tempo computacional e ST a cada

Tabela 15 - Ajustes da corrente de partida, ajustes dos MT e tempos

Tabela 16 - Pares de RDS, dada a condição mínima de sensibilização, e seus respectivos valores de ITC, tempo de atuação da PRL e da PRR e múltiplos máximo e mínimo da PRL e PRR

Tabela 17 - Relés de PRL e seus respectivos relés de PRR associados 
Tabela 18 - Valores dos casos de curtos-circuitos obtidos via CAPE para a topologia sem a operação da linha LT1.

Tabela 19 - Pares de RDS e seus respectivos valores de ITC, tempo de atuação da PRL e da PRR, múltiplos de máximo e mínimo da PRL e PRR, dada a parametrização principal frente à saída de LT1....

Tabela 20 - Valores dos casos de curtos-circuitos obtidos via CAPE para a topologia sem a operação de LT6.

Tabela 21 - Pares de RDS e seus respectivos valores de ITC, tempo de atuação da PRL e da PRR, múltiplos de máximo e mínimo da PRL e PRR, dada a parametrização principal frente à saída de LT6.

Tabela 22 - Definição dos limites da faixa de ajuste da corrente de partida para a topologia sem a LT6.

Tabela 23 - Definição dos limites da faixa de ajuste dos MT para a topologia sem LT6.

Tabela 24 - Condição mínima de sensibilização dos RDS para a topologia sem LT6.

Tabela 25 - Pares de RDS determinados via matriz de incidência para a topologia sem LT6.

Tabela 26 - Valores dos casos de curtos-circuitos obtidos via CAPE para a topologia sem LT6.

Tabela 27 - Valores de tempo computacional e ST a cada 1.000 gerações utilizando-se $P=50$, fator $\mu=50$ e $\lambda=1$ dada a saída da linha LT6.

Tabela 28 - Ajustes da corrente de partida e dos MT e tempos de atuação das PRL para a topologia sem a linha LT6.

Tabela 29 - Pares de RDS, dada a condição mínima de sensibilização, seus respectivos valores de ITC, tempo de atuação da PRL e da PRR e múltiplos de máximo e mínimo da PRL e PRR (saída de LT6).

Tabela 30 - Dados de linha do sistema teste reduzido de 43 barras.

Tabela 31 - Dados de barra do sistema equivalente de 43 barras

Tabela 32 - Dados das impedâncias mútuas do sistema reduzido de 43 barras

Tabela 33 - Correntes de curto-circuito observadas pela PRL e PRR em função da saída da linha LT2. 
Tabela 34 - Pares de RDS sensibilizados e seus respectivos valores de ITC, tempo de atuação da PRL e da PRR, múltiplos máximo e mínimo da PRL e PRR, dada a parametrização principal frente à saída de LT2

Tabela 35 - Correntes de curto-circuito observadas pela PRL e PRR em função da saída da linha LT3.

Tabela 36 - Pares de RDS sensibilizados e seus respectivos valores de ITC, tempo de atuação da PRL e da PRR, múltiplos máximo e mínimo da PRL e PRR, dada a parametrização principal frente à saída de LT3.

Tabela 37 - Correntes de curto-circuito observadas pela PRL e PRR em função da saída da linha LT4.

Tabela 38 - Pares de RDS sensibilizados e seus respectivos valores de ITC, tempo de atuação da PRL e da PRR, múltiplos máximo e mínimo da PRL e PRR, dada a parametrização principal frente à saída de LT4

Tabela 39 - Correntes de curto-circuito observadas pela PRL e PRR em função da saída da linha LT5.

Tabela 40 - Pares de RDS sensibilizados e seus respectivos valores de ITC, tempo de atuação da PRL e da PRR, múltiplos máximo e mínimo da PRL e PRR, dada a parametrização principal frente à saída de LT5

Tabela 41 - Nova parametrização calculada para a topologia de operação sem a linha LT5; valor do tempo de atuação da PRL e a respectiva soma dos mesmos.

Tabela 42 - Pares de RDS sensibilizados e seus respectivos valores de ITC, tempo de atuação da PRL e da PRR, múltiplos máximo e mínimo da PRL e PRR, dada a nova parametrização frente à saída de LT5.

Tabela 43 - Correntes de curto-circuito observadas pela PRL e PRR em função da saída da linha LT7.

Tabela 44 - Pares de RDS sensibilizados e seus respectivos valores de ITC, tempo de atuação da PRL e da PRR, múltiplos máximo e mínimo da PRL e PRR, dada a parametrização principal frente à saída de LT7

Tabela 45 - Nova parametrização calculada para a topologia de operação sem a linha LT7; valor do tempo de atuação da PRL e a respectiva soma dos mesmos.

Tabela 46 - Pares de RDS sensibilizados e seus respectivos valores de ITC, tempo de atuação da PRL e da PRR, múltiplos máximo e mínimo da PRL e PRR, dada a nova parametrização frente à saída de LT7. 
Tabela 47 - Correntes de curto-circuito observadas pela PRL e PRR em função da saída da linha LT8.

Tabela 48 - Pares de RDS sensibilizados e seus respectivos valores de ITC, tempo de atuação da PRL e da PRR, múltiplos máximo e mínimo da PRL e PRR, dada a parametrização principal frente à saída de LT8.

Tabela 49 - Nova parametrização calculada para a topologia de operação sem a linha LT8; valor do tempo de atuação da PRL e a respectiva soma dos mesmos.

Tabela 50 - Pares de RDS sensibilizados e seus respectivos valores de ITC, tempo de atuação da PRL e da PRR, múltiplos máximo e mínimo da PRL e PRR, dada a nova parametrização frente à saída de LT8.

Tabela 51 - Correntes de curto-circuito observadas pela PRL e PRR em função da saída da linha LT9.

Tabela 52 - Pares de RDS sensibilizados e seus respectivos valores de ITC, tempo de atuação da PRL e da PRR, múltiplos máximo e mínimo da PRL e PRR, dada a parametrização principal frente à saída de LT9.

Tabela 53 - Nova parametrização calculada para a topologia de operação sem a linha LT9; valor do tempo de atuação da PRL e a respectiva soma dos mesmos.

Tabela 54 - Pares de RDS sensibilizados e seus respectivos valores de ITC, tempo de atuação da PRL e da PRR, múltiplos máximo e mínimo da PRL e PRR, dada a nova parametrização frente à saída de LT9

Tabela 55 - Correntes de curto-circuito observadas pela PRL e PRR em função da saída da linha LT10.

Tabela 56 - Pares de RDS sensibilizados e seus respectivos valores de ITC, tempo de atuação da PRL e da PRR, múltiplos máximo e mínimo da PRL e PRR, dada a parametrização principal frente à saída de LT10.

Tabela 57 - Nova parametrização calculada para a topologia de operação sem a linha LT10; valor do tempo de atuação da PRL e a respectiva soma dos mesmos.

Tabela 58 - Pares de RDS sensibilizados e seus respectivos valores de ITC, tempo de atuação da PRL e da PRR, múltiplos máximo e mínimo da PRL e PRR, dada a nova parametrização frente à saída de LT10

Tabela 59 - Correntes de curto-circuito observadas pela PRL e PRR em função da saída da linha LT11. 
Tabela 60 - Pares de RDS sensibilizados e seus respectivos valores de ITC, tempo de atuação da PRL e da PRR, múltiplos máximo e mínimo da PRL e PRR, dada a parametrização principal frente à saída de LT11

Tabela 61 - Nova parametrização calculada para a topologia de operação sem a linha LT11; valor do tempo de atuação da PRL e a respectiva soma dos mesmos.

Tabela 62 - Pares de RDS sensibilizados e seus respectivos valores de ITC, tempo de atuação da PRL e da PRR, múltiplos máximo e mínimo da PRL e PRR, dada a nova parametrização frente à saída de LT11 



\section{LISTA DE SIGLAS}

AG

ANAFAS

ANSI

CAPE

CEPEL

CTEEP

EPSO

GAMS

ITC

IEC

IEEE

LT

MT

ONS

PSO

PL

PNL

PRL

PRR

RTC

RDS

SEP

SP

$S A$

TC

TP
Algoritmo Genético

Análise de Faltas Simultâneas

American National Standards Institute

Computer-Aided Protection Engineering

Centro de Pesquisa de Energia Elétrica

Companhia de Transmissão de Energia Elétrica Paulista

Evolutionary Particle Swarm Optimization

General Algebraic Modeling System

Intervalo de Tempo de Coordenação

International Electrotechnical Commission

Institute of Electrical and Electronics Engineers

Linhas de Transmissão

Múltiplo de Tempo

Operador Nacional do Sistema

Particle Swarm Optimization

Programação Linear

Programação Não Linear

Proteção de Retaguarda Local

Proteção de Retaguarda Remota

Relação de Transformação

Relés Direcionais de Sobrecorrente

Sistemas Elétricos de Potência

Sistema de Proteção

Simulated Annealing

Transformadores de Corrente

Transformadores de Potencial 



\section{SUMÁRIO}

1 - INTRODUÇÃO

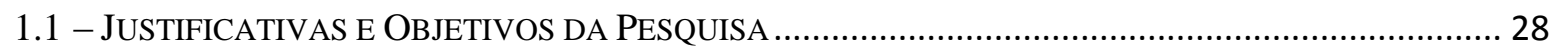

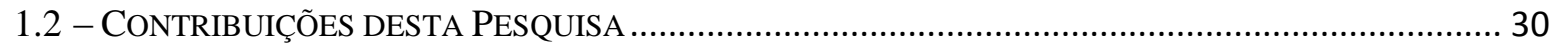

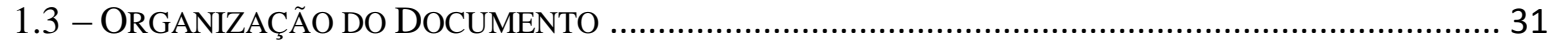

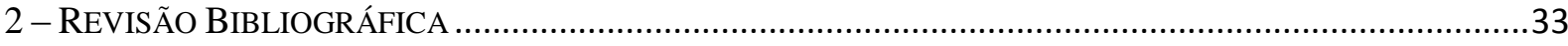

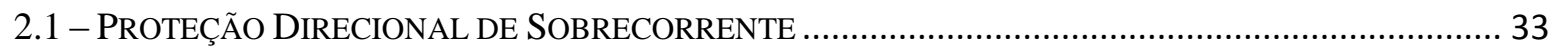

2.2 - COORdENAÇÃO DA PRoteÇÃo EM Sistemas MALHAdos UtiLIZANDO RDS ......................... 36

2.3 - Trabalhos Relacionados Ao Tema Desta PESQUISA........................................................ 40

3 - Metodologia de PARAMETRIZAÇÃo E AvaliaÇão da CoORdENAÇÃO........................................49

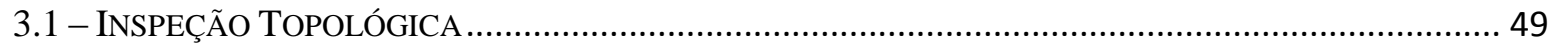

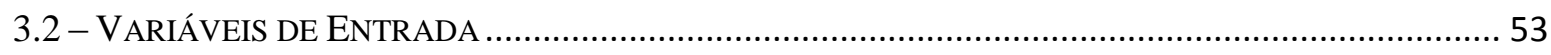

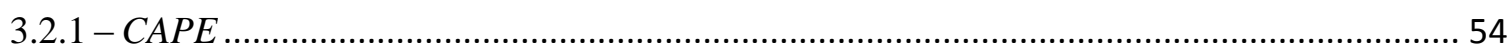

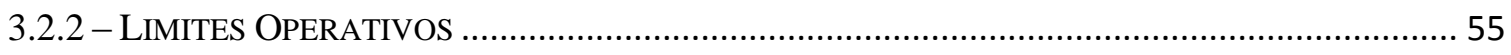

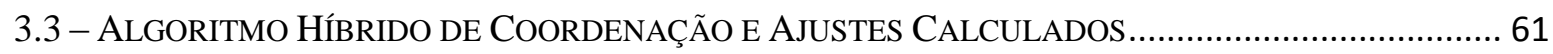

3.4 - VALIDAÇÃO DA COORDENAÇÃO E SISTEMA COORDENADO ….............................................. 62

3.5 - ALTERAÇÃO DA TOPOLOGIA EM RELAÇÃO À PRINCIPAL ...................................................... 63

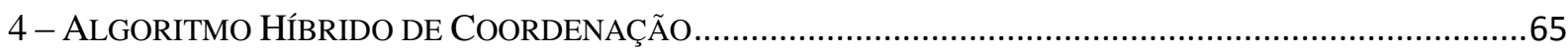

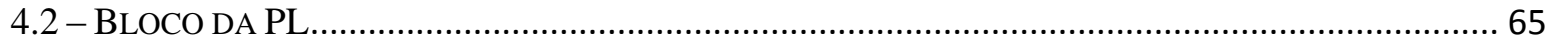

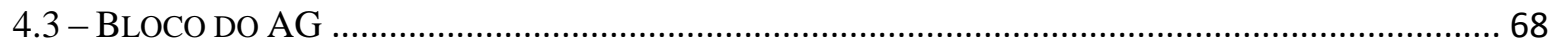

4.3.1 - REPRESENTAÇÃO CROMOSSÔMICA …………............................................................. 71

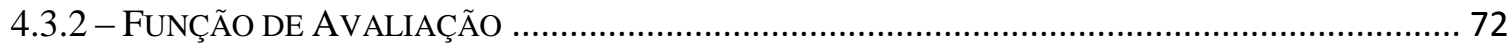

4.3.3 - SEleÇÃo, Elitismo, CRoSSOVER E MUTAÇÃO .............................................................. 74

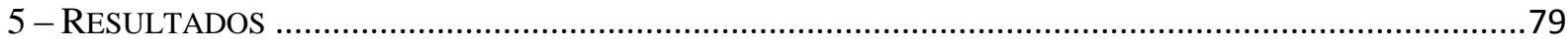

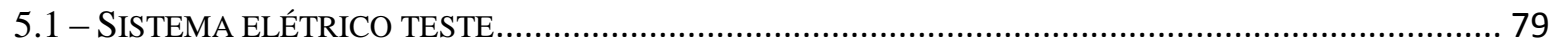

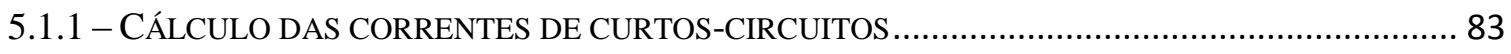

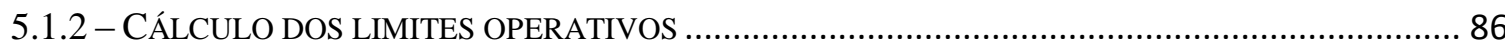


5.1.3 - PARÂMETROS DO ALGORITMO HÍBRIDO DE COORDENAÇÃO .............................................. 90

5.1.4 - COORDENAÇÃO OBTIDA ENTRE OS RDS PARA TOPOLOGIA PRINCIPAL DE OPERAÇÃO....... 98

5.1.5 - AVALIAÇÃO DA PARAMETRIZAÇÃO FRENTE A VARIAÇÕES TOPOLÓGICAS ......................... 106

5.1.6 - COORDENAÇÃO PARA UMA VARIAÇÃO TOPOLÓGICA EM RELAÇÃO À PARAMETRIZAÇÃO

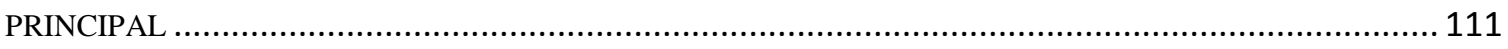

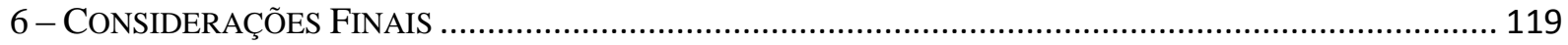

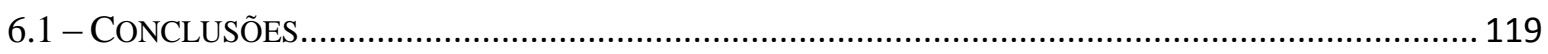

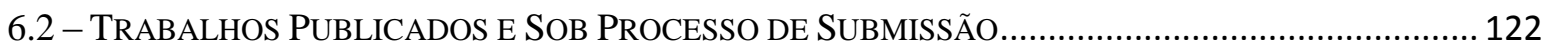

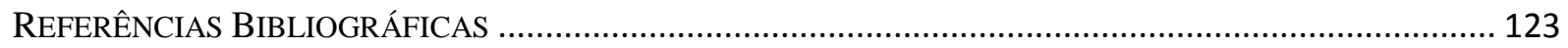

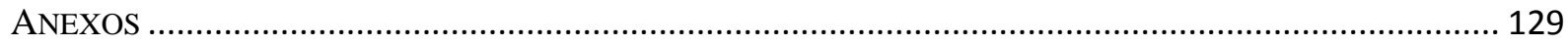

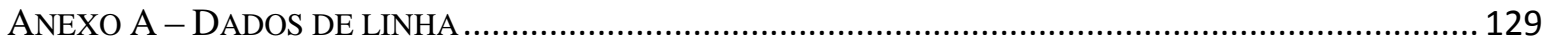

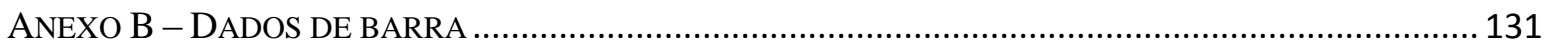

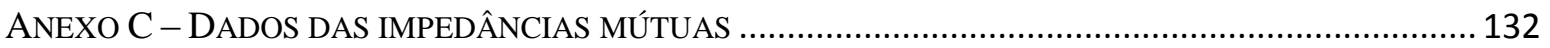

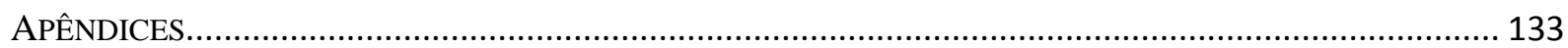

APÊNDICE A - TOPOLOGIA DE OPERAÇÃO SEM A LINHA LT2 …................................................. 133

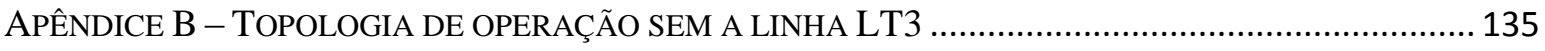

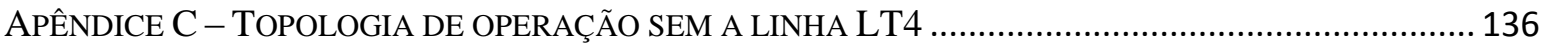

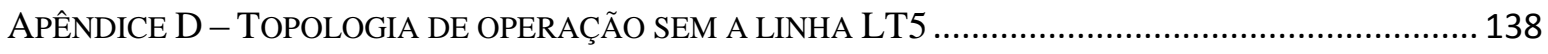

APÊNDICE E - TOPOLOGIA DE OPERAÇÃO SEM A LINHA LT7 ......................................................... 141

APÊNDICE F - TOPOLOGIA DE OPERAÇÃO SEM A LINHA LT T …....................................................... 144

APÊNDICE G - TOPOLOGIA DE OPERAÇÃO SEM A LINHA LT9 …................................................. 147

APÊNDICE H - TOPOLOGIA DE OPERAÇÃO SEM A LINHA LT10 ….............................................. 150

APÊNDICE I - TOPOLOGIA DE OPERAÇÃO SEM A LINHA LT11 ................................................. 153 


\section{1 - INTRODUÇÃO}

A proteção em Sistemas Elétricos de Potência (SEP) compreende uma ampla infraestrutura constituída por diversos elementos cujas atribuições e configurações de operação são bem definidas. É função primordial do Sistema de Proteção (SP) analisar e diagnosticar situações não desejáveis na operação do SEP e atuar com rapidez para iniciar ações corretivas que reestabeleçam as condições normais de operação o mais rápido possível. Além disso, é responsabilidade do SP salvaguardar toda a infraestrutura associada à área do SEP protegido.

A falha individual, parcial ou total dos elementos de proteção, assim como o ajuste (parametrização) incorreto dos mesmos, pode comprometer a integridade dos equipamentos protegidos, dos serviços e a continuidade do fornecimento de energia elétrica de consumidores locais num primeiro momento, e, numa situação mais severa, acarretar na propagação do distúrbio para todo o restante do SEP. As falhas incidentes sobre os sistemas elétricos podem ocorrer por inúmeros fatores, dentre os quais, citam-se: descargas atmosféricas, queimadas (alteração na rigidez dielétrica do ar), defeitos nos isoladores e surtos de chaveamento (COURY; OLESKOVICZ; GIOVANINI, 2007).

O SP é constituído, basicamente, pelos seguintes subsistemas: Transformadores de Corrente (TC), Transformadores de Potencial (TP), disjuntores, relés e banco de baterias.

O relé de proteção identifica a ocorrência de um defeito através dos transdutores de corrente e tensão (TC e TP, respectivamente) de maneira a produzir, quando necessário, um sinal de abertura ao disjuntor associado para que seja possível isolar (interromper a passagem da corrente) o elemento ou circuito com defeito. Neste sentido, um sinal de abertura é gerado somente quando valores de corrente e tensão previamente estabelecidos são detectados, indicando, por exemplo, a ocorrência de uma falta no sistema elétrico em análise, ou em parte deste. O banco de baterias tem a função de suprir o SP de energia de forma independente da alimentação externa disponibilizada pelo sistema elétrico.

Conforme mencionado, para o adequado funcionamento do SP, os relés devem possuir características funcionais que possibilitem uma atuação rápida o bastante e a preservação da integridade e a estabilidade do sistema elétrico remanescente. As principais características funcionais mencionadas são: (i) sensibilidade; (ii) seletividade; (iii) velocidade de atuação e (iv) confiabilidade (HEWITSON; BROWN; BALAKRISHNAN, 2005). 
A sensibilidade de um relé está associada com a capacidade da proteção em responder às anormalidades nas condições de operação e aos curtos-circuitos incidentes no SEP, tomando como parâmetro determinadas especificações de projeto (CAMINHA, 1977).

A seletividade caracteriza-se pela propriedade do sistema de proteção ser capaz de detectar e selecionar em quais situações é necessário uma rápida atuação, ou então, quando nenhuma operação, ou ainda, um retardo de atuação é exigido frente à ocorrência de defeito e/ou não conformidade na operação do SEP. Além disso, o SP deve ser capaz de isolar completamente o componente defeituoso respeitando a restrição de desconectar a menor parcela possível do SEP (HEWITSON; BROWN; BALAKRISHNAN, 2005; CAMINHA, 1977).

A característica funcional de velocidade de atuação refere-se ao quão rápido se dá a atuação da proteção quando esta é requerida. Esta propriedade tem por objetivo minimizar a extensão dos danos aos equipamentos do SEP e garantir a segurança do próprio pessoal envolvido em sua operação (HEWITSON; BROWN; BALAKRISHNAN, 2005).

Por fim, a confiabilidade está associada à probabilidade, em certas condições, de um componente e/ ou equipamento do SP em realizar adequadamente sua função conforme previsto em projeto (ANDERSON, 1999).

A responsabilidade da proteção sobre uma porção de um sistema elétrico é associada à zona de proteção, que consiste em uma área limite claramente definida sobre o diagrama unifilar do sistema elétrico e está intimamente relacionada ao conceito de seletividade anteriormente mencionado. Dada uma zona de proteção, os relés associados à mesma são responsáveis por remover todas as faltas que ocorram em seu domínio de forma a isolar a porção defeituosa pertencente a esta região. As zonas de proteção são normalmente definidas pela disposição adequada dos TC ao longo das porções do sistema. Através dos sinais disponibilizados pelos TC, referente a uma zona de proteção específica, os relés associados são capazes de comandar a abertura de disjuntores que irão isolar eletricamente o defeito que é detectado na respectiva zona de proteção (COURY; OLESKOVICZ; GIOVANINI, 2007).

Em muitos casos, a atuação de um SP se dá em dois níveis principais, conhecidos como proteção primária (ou principal) e proteção de retaguarda (ou de backup). A proteção primária deve atuar em caso de falta dentro de sua respectiva zona de proteção, isto é, deve ser a proteção a atuar de maneira prioritária na remoção do defeito. Já a proteção de retaguarda deve operar somente quando ocorrer uma falha por parte da proteção principal (PHADKE; THORP, 1990; HEWITSON; BROWN; BALAKRISHNAN, 2005). 
Em geral, o registro e análise da magnitude da corrente de falta (curto-circuito) apresentam-se como um eficaz princípio de proteção. Dentre os equipamentos que se utilizam da análise desta grandeza elétrica é possível citar o relé de sobrecorrente, que por apresentar características simples de operação e atuação comprovadamente eficazes é um dos tipos de relés amplamente utilizado na proteção de SEP. Como o próprio nome o descreve, o relé de sobrecorrente é capaz de comandar aberturas de disjuntores específicos no sistema de acordo com a magnitude da corrente observada, isolando por completo a porção defeituosa do SEP. O relé de sobrecorrente pode ser aplicado para a proteção da maioria dos elementos do SEP, como, por exemplo, linhas de transmissão, transformadores e geradores (COURY; OLESKOVICZ; GIOVANINI, 2007).

A proteção de Linhas de Transmissão (LT) empregando relés de sobrecorrente pode ser considerada como uma alternativa viável e eficaz, desde que as linhas a serem protegidas configurem um sistema elétrico cujas características de operação sejam estritamente radiais com fontes presentes em apenas um dos lados. Em sistemas elétricos malhados, a corrente de falta pode ser resultante da contribuição de correntes provenientes de direções distintas e, por essa razão, o uso exclusivo de relés de magnitude, como o caso do relé de sobrecorrente, é de difícil concepção, além de se mostrar uma estratégia ineficaz de proteção das LT. Logo, para uma adequada proteção das LT pertencentes à SEP malhados, é recomendado o uso de relés com unidades direcionais, como é o caso dos Relés Direcionais de Sobrecorrente (RDS), amplamente utilizados na proteção de sistemas com características não radiais. Os relés direcionais são capazes de distinguir o fluxo de corrente em uma ou outra direção, isto é, em posição à frente ou reversa em relação à localização física dos mesmos nas LT. Em um circuito de corrente alternada isso é feito pelo reconhecimento do ângulo de fase entre a corrente e a grandeza de polarização (ou de referência) que é geralmente associada à tensão elétrica (COURY; OLESKOVICZ; GIOVANINI, 2007).

Como filosofia adotada para a proteção de um SEP qualquer, sabe-se que os dispositivos que integram um SP não devem atuar de forma independente, ou seja, devem respeitar uma sequência de operação existente entre os mesmos de maneira a garantir o correto funcionamento do SP como um todo. Ao se considerar dois elementos de proteção dispostos em série, por exemplo, afirma-se que os mesmos estão coordenados se seus ajustes são tais que permitam ao elemento de proteção mais próximo do defeito atuar prioritariamente para eliminá-lo. Caso este elemento falhe em extinguir o defeito elétrico, o dispositivo de proteção mais próximo da fonte deve atuar subsequentemente para proteger o SEP (CAMINHA, 1977). 
Ressalta-se que em sistemas malhados a determinação do ajuste correto para os RDS caracteriza uma tarefa não trivial, pois pode envolver o ajuste simultâneo e coordenado de uma quantidade considerável de equipamentos presentes no SP. Além disso, para efetuar o ajuste correto dos relés de proteção, faz-se necessário o conhecimento acerca do perfil das possíveis faltas (situações de curtos-circuitos e/ou defeitos) que podem ocorrer na área a ser protegida, de diferentes configurações topológicas a que estão sujeitas o SEP, das condições operativas dos equipamentos instalados, além das opções de ajustes dos relés, respeitando-se a filosofia de proteção adotada. A análise destas informações é imprescindível para alcançar a seletividade e a coordenação correta entre os diversos dispositivos de proteção existentes no SEP.

De fato, diante do exposto, afirma-se que o problema de parametrização resultante da análise das informações supracitadas é de difícil solução, cuja complexidade aumenta na medida em que o sistema elétrico a ser analisado cresce em tamanho, número de equipamentos e dispositivos de proteção.

Neste contexto, o problema de coordenação mencionado pode ser qualificado como um problema de otimização do tipo combinatório de significativa complexidade que exige o emprego de ferramentas computacionais para sua solução. Entretanto, dentre os softwares mais difundidos há, predominantemente, os que dão ênfase às funções de verificação dos ajustes propostos pelo engenheiro de proteção e disponibilização de ferramentas que possibilitam a coordenação manual de relés, exigindo para tanto, estudos preliminares intensivos acerca do problema de coordenação no âmbito mencionado.

\section{1 - JUSTIFICATIVAs E OBJETIVOS DA PESQUiSA}

Considerando-se os entraves referentes à coordenação da proteção em sistemas elétricos malhados e a importância em garantir uma adequada atuação do SP, esta pesquisa tem como objetivo apresentar um método para a coordenação dos RDS associados a um sistema de proteção de um Sistema Elétrico de Potência (SEP) malhado.

O método consiste em obter os ajustes de tempo e de corrente de partida dos RDS via um algoritmo híbrido que combina Programação Linear (PL) e Algoritmo Genético (AG) de tal maneira a se alcançar a coordenação entre todos os RDS envolvidos no SP. 
Após a obtenção de uma solução factível de coordenação dos relés, caso ocorram ou estejam previstas determinadas mudanças na configuração topológica do SEP em estudo, será conduzida a avaliação da solução de coordenação pré-existente, isto é, válida para a configuração principal do sistema. Como resultado da avaliação, caso necessário, o engenheiro de proteção será alertado para proceder a uma nova parametrização dos relés que venha a atendar à nova configuração do sistema elétrico, sendo esta também fornecida pelo algoritmo híbrido de coordenação.

Conforme mencionado anteriormente, salienta-se que os ajustes dos dispositivos de proteção, fornecidos e analisados pela metodologia proposta nesta pesquisa, devem ser tais que proporcionem rapidez na eliminação das faltas e atendam aos critérios de coordenação e seletividade pré-estabelecidos.

Através de estudos de curtos-circuitos realizados via software CAPE (ComputerAided Protection Engineering) (ELECTROCON INTERNATIONAL INCORPORATED, 2013) os ajustes encontrados pelo algoritmo de coordenação serão validados, verificando-se a existência da coordenação entre os RDS. Este software é amplamente empregado para análises e aplicações em SEP, incluindo as que se referem à proteção, e possibilita, de maneira rápida e eficiente, gerar situações de defeitos elétricos de modo a verificar a consistência da coordenação em função dos ajustes propostos pelo algoritmo desenvolvido.

O sistema elétrico em estudo e utilizado para testes é um sistema de subtransmissão real conectado à rede básica brasileira de concessão da Companhia de Transmissão de Energia Elétrica Paulista (CTEEP). Este sistema será manipulado via software CAPE a partir da base de dados, para estudos de curtos-circuitos, disponibilizada pelo Operador Nacional do Sistema (ONS) (ONS, 2013). Pelo CAPE serão realizados diversos estudos de curtos-circuitos necessários para a obtenção e avaliação da coordenação dos pares de RDS, tanto para a topologia principal, como para outras configurações de operação caracterizadas principalmente pela alteração topológica do SEP. É importante destacar que é objetivo da pesquisa a obtenção de uma metodologia de mais ampla aplicação que possa ser utilizada em outros SEP, não se restringindo a apenas ao referido sistema elétrico da CTEEP.

Vale ressaltar que esta pesquisa está atrelada a um projeto de Pesquisa e Desenvolvimento (P\&D) firmado entre a CTEEP, o Instituto de Engenharia de Sistemas e Computadores do Porto (INESC Porto) e a Escola de Engenharia de São Carlos da Universidade de São Paulo (EESC - USP), cujos principais objetivos contemplam o desenvolvimento de algoritmos fundamentados em técnicas inteligentes e aplicados na coordenação de RDS em SEP malhados (CTEEP-PD-0068-0020/2011, 2011). 


\section{2 - CONTRIBUiÇÕES DESTA PESQUiSA}

O algoritmo híbrido desenvolvido e implementado nesta pesquisa toma por base o trabalho de Noghabi, Sadeh e Masshadi (2009), que propõe a aplicação de PL conjuntamente com AG, de modo a obter a parametrização adequada para todos os RDS do sistema elétrico considerado. Além disso, destaca-se que o emprego de AG no algoritmo híbrido de coordenação, deve-se também à comprovada capacidade desta ferramenta inteligente em encontrar soluções mais próximas do ótimo global, uma vez que processa informações depreendidas da exploração do espaço de busca para se aproximar de tais soluções proximamente ótimas a cada geração (NARA et al., 1992; LINDEN, 2006).

Ressalta-se que em Noghabi, Sadeh e Masshadi (2009) as possíveis variações topológicas devido às saídas de LT são consideradas diretamente no processo de otimização, isto é, o algoritmo proposto busca por ajustes de tempo e corrente que sejam capazes proporcionar coordenação caso qualquer uma das LT do sistema saia de operação (considerando sempre o sistema remanescente operando com uma LT a menos). Diferentemente do proposto por Noghabi, Sadeh e Masshadi (2009), o algoritmo híbrido de coordenação aqui apresentado considera a topologia de operação vigente no sistema, ou seja, caso seja evidenciada uma alteração topológica, a validade de coordenação deve ser revisada, e se classificada como inconsistente, o algoritmo híbrido de coordenação é novamente executado para encontrar uma parametrização válida para a nova topologia. Esta abordagem procura melhor atender a uma aplicação em campo do algoritmo híbrido de coordenação, pois em situações práticas a alteração de topologia, quando prevista, é bem definida, como acontece, por exemplo, devido à saída de uma LT para manutenção ou manobras efetuadas pela concessionária de energia.

Outro aspecto que esta pesquisa considera é a obtenção da coordenação dos RDS respeitando a atuação da proteção primária de distância, enquanto que em Noghabi, Sadeh e Masshadi (2009) os ajustes de MT e de pick-up obtidos não preveem a atuação de um nível prioritário de atuação.

Pode-se destacar ainda que a o algoritmo híbrido apresentado neste documento prevê uma análise mais detalhada com relação à definição do espaço de busca das soluções, principalmente no que concerne a delimitação da faixa de ajuste da corrente de partida, que vai além de uma verificação direta dos ajustes disponíveis no relé, da corrente de carga 
máxima e das correntes mínimas curtos-circuitos, conforme exposto em Noghabi, Sadeh e Masshadi (2009).

\section{3- ORGANIZAÇÃO DO DOCUMENTO}

Neste documento, o capítulo 2 traz uma revisão sobre os principais conceitos da proteção de sobrecorrente direcional em SEP, os princípios de coordenação de RDS em sistemas elétricos malhados, e, por fim, a apresentação de alguns trabalhos técnicos relacionados à solução do problema de coordenação de RDS em SEP que envolvem o emprego de técnicas de otimização e metaheurísticas, dentre outras.

No capítulo 3 será realizada uma exposição mais detalhada a respeito da metodologia e procedimentos a serem adotados para a solução do problema de coordenação dos RDS em sistemas malhados.

O capítulo 4 apresenta informações detalhadas referentes à concepção e funcionamento do algoritmo híbrido de coordenação da proteção no contexto da metodologia desenvolvida e do sistema elétrico teste considerado.

No capítulo 5, serão apresentados e analisados os ajustes fornecidos pelo algoritmo de coordenação para os RDS referentes à topologia principal de operação do sistema teste. Além disso, a avaliação de tais ajustes e eventuais atualizações dos mesmos, perante certas situações de alterações na topologia do sistema teste, será aplicada e demonstrada.

As considerações e conclusões depreendidas do desenvolvimento da pesquisa, assim como as indicações de trabalhos futuros e a relação de trabalhos publicados estão apresentadas no capítulo 6 .

Após as conclusões estão apresentadas as referências bibliográficas consultadas que auxiliaram no desenvolvimento deste trabalho.

Finalizando, as seções de anexos e apêndices trazem tabelas contendo dados do SEP utilizado como teste e resultados decorrentes da análise da aplicação da metodologia para alterações na topologia de operação do sistema teste, respectivamente. 


\section{2 - REVISÃo BIBLIOGRÁFICA}

Neste capítulo, será apresentada uma breve introdução sobre os aspectos mais importantes relacionados à proteção direcional de sobrecorrente e do problema de coordenação dos RDS. Além disso, para o item 2.3 reserva-se um levantamento bibliográfico com alguns dos trabalhos recentemente desenvolvidos e relacionados à coordenação dos RDS em sistemas malhados.

\section{1 - ProteÇÃo DireCiOnAL DE SOBRECORRENTE}

Quando um sistema elétrico possui características não radiais, um simples relé de sobrecorrente pode não ser capaz de promover uma proteção adequada (PHADKE; THORP, 1990). Esta questão pode ser mais bem compreendida considerando-se, por exemplo, duas LT paralelas que interconectam dois sistemas elétricos que contenham cada um, fontes de correntes de falta, conforme ilustra a Figura 1. Para que os relés estejam coordenados, faz-se necessária a manutenção de um intervalo de tempo, antes que a proteção de retaguarda possa atuar, caso uma falha da proteção primária ocorra. Pelo exemplo da Figura 1, é necessário manter-se um intervalo de tempo específico entre os relés adjacentes, uma vez que tais relés não apresentam unidades direcionais. Logo, para uma falta na linha $A-B$, infere-se que:

$$
\begin{aligned}
& t_{A<} t_{C} \\
& t_{B<} t_{D}
\end{aligned}
$$

em que $t$ é o tempo de atuação do relé para uma dada magnitude de corrente de falta, e os índices $A, B, C$ e $D$ identificam a localização do relé no esquema ilustrado na Figura 1. Analogamente, se a falta está presente na linha $C$ - $D$, tem-se para uma coordenação apropriada:

$$
\begin{aligned}
& t_{A>} t_{C} \\
& t_{B}>t_{D}
\end{aligned}
$$




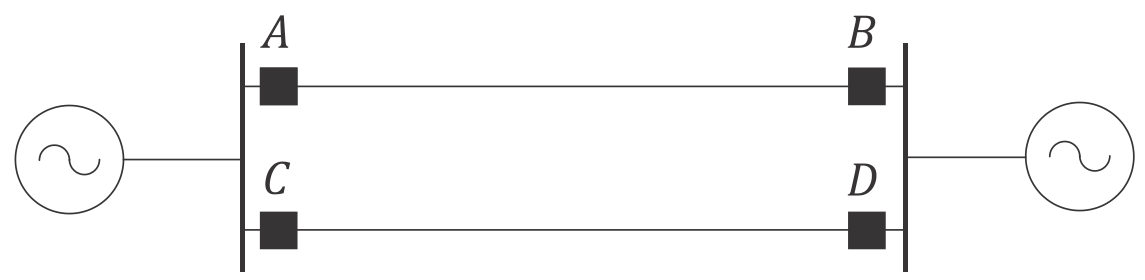

Figura 1 - Sistemas com fontes geradoras interligadas por linhas de transmissão paralelas.

Fonte: Adaptado de Anderson (1999).

Nota-se que o conjunto de restrições construído é inconsistente, uma vez que não é possível satisfazer ambas as situações de faltas descritas utilizando-se exclusivamente relés de sobrecorrente. É evidente, portanto, que estes dispositivos não são capazes de estabelecer a proteção do sistema elétrico em questão, ou seja, os relés operam de forma descoordenada deixando o sistema vulnerável à ocorrência de curtos-circuitos.

Conforme já comentado, a maneira de se conseguir a seletividade desejada para o relé de sobrecorrente em sistemas elétricos malhados se faz com a adição do elemento direcional. Este fato implica na ampla utilização de RDS para a proteção de SEP malhados, objeto de estudo desta pesquisa, já que estes relés são capazes de propiciar uma proteção eficaz em sistemas deste tipo.

A atuação dos RDS é resultante da combinação das unidades direcional e de sobrecorrente, sendo que esta última é inoperante independentemente da magnitude da corrente de falta, a menos que a corrente tenha o mesmo sentido que o ajustado na unidade direcional (MASON, 1956).

Na Figura 2 tem-se uma representação unifilar simplificada de um RDS para a fase $A$ de um sistema trifásico. Por esta figura é possível observar que o RDS possui duas bobinas em quadratura, uma de corrente e outra de tensão. A bobina de corrente é alimentada pela corrente de operação $\dot{I}_{A}$. Já a bobina de tensão é alimentada pela tensão de polarização $\dot{V}_{p o l}$.

$\mathrm{Na}$ Figura 3, tem-se o diagrama fasorial das grandezas envolvidas em uma polarização do RDS dita em quadratura ou a $90^{\circ}$, sendo elas: (i) corrente da fase $\dot{I}_{A}$; (ii) fluxo magnético $\Phi_{I_{A}}$ da bobina de corrente; (iii) tensão $\dot{V}_{A N}$ da fase $A$ em relação ao neutro do sistema, (iv) tensão $\dot{V}_{p o l}$ de polarização aplicada à bobina de tensão, ( $v$ ) corrente de polarização $\dot{I}_{p o l}$ que passa pela bobina de potencial devido a aplicação de $\dot{V}_{p o l}$, (vi) fluxo magnético $\Phi_{I_{p o l}}$ da bobina de tensão em função da corrente $\dot{I}_{p o l}$. 


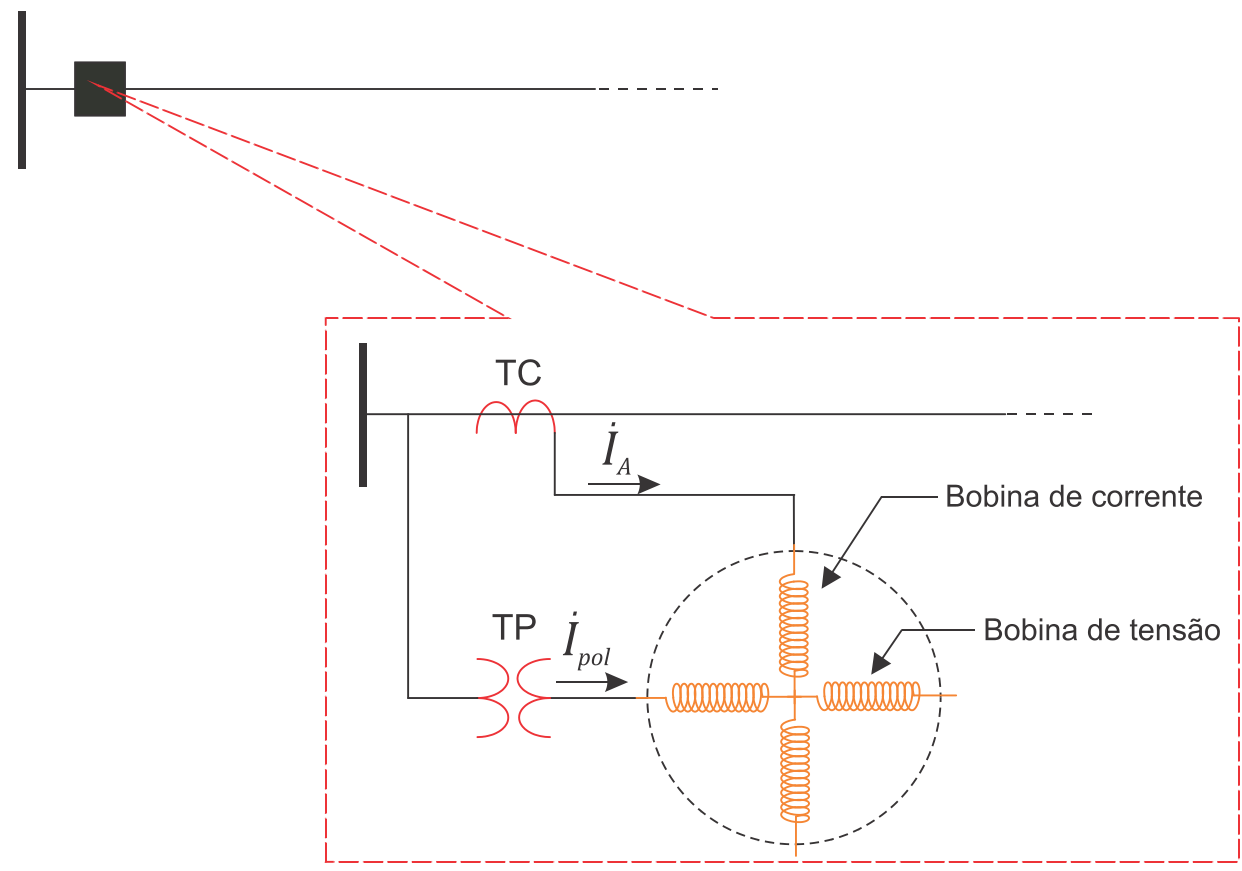

Figura 2 - Representação unifilar simplificada de um RDS. Fonte: Adaptado de Kindermann (2005).

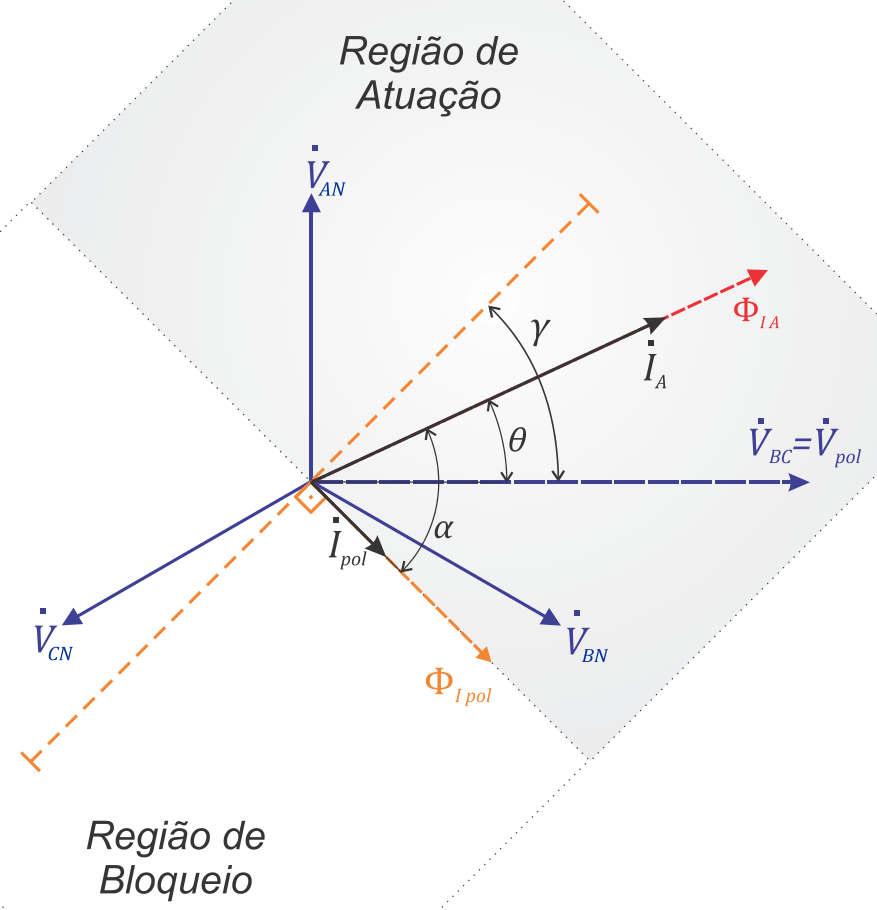

Figura 3 - Diagrama fasorial para estudo da direcionalidade de um RDS. Fonte: Adaptado de Kindermann (2005). 
Conforme exposto por Kindermann (2005), o conjugado do relé é dado pela Equação 5.

$$
\tau=K I_{A} V_{p o l} \sin \alpha
$$

em que $\alpha$ é o ângulo entre os fluxos $\Phi_{I_{A}}$ e $\Phi_{I_{p o l}}$ e $K$ é uma constante de proporcionalidade.

Pelo diagrama da Figura 3, tem-se que $\alpha=90^{\circ}-(\gamma-\theta)$, em que $\gamma$ é o ângulo de máximo conjugado definido pelo fabricante do relé e $\theta$ é o ângulo entre a corrente da fase $A \mathrm{e}$ a tensão de polarização. Logo, a Equação 5 pode ser reescrita conforme a Equação 6.

$$
\tau=K I_{A} V_{p o l} \cos (\gamma-\theta)
$$

O conjugado do relé será nulo para $\theta=\gamma \pm 90^{\circ}$, e máximo para $\theta=\gamma$, denotando a região de atuação do relé (conjugado positivo) em torno da linha de conjugado máximo, isto é, $90^{\circ}$ a direta e $90^{\circ}$ a esquerda da linha de conjugado máximo, conforme indicado pela região definida no semi-plano superior à linha de conjugado nulo na Figura 3. Fora da região de atuação o relé possui conjugado negativo, caracterizando assim a região de não atuação, localizada no semi-plano inferior à linha de conjugado nulo, conforme indicado na Figura 3. A definição destas duas regiões confere aos relés a característica de atuação direcional desejada.

\section{2 - COORDENAÇÃO DA PROTEÇÃo EM Sistemas MALHAdos UtILIZANDO RDS}

Conforme já exposto, os dispositivos que integram um SP não devem atuar de forma independente, ou seja, devem respeitar uma sequência de operação existente entre os mesmos de maneira a garantir o correto funcionamento de todo o sistema.

Ao se considerar dois elementos de proteção dispostos em série, por exemplo, afirma-se que os mesmos estão coordenados se seus ajustes são tais que permitam ao elemento de proteção mais próximo do defeito atuar prioritariamente para eliminá-lo. Caso este elemento falhe em extinguir a falta elétrica, o dispositivo de proteção mais próximo da fonte deve atuar subsequentemente para proteger o sistema elétrico (CAMINHA, 1977). O tempo de espera para a atuação do segundo elemento de proteção é chamado de Intervalo de 
Tempo de Coordenação (ITC), e seu valor é dependente do tipo do relé (dispositivo eletromecânico ou micro processado), velocidade das chaves seccionadoras e outros parâmetros do SP. Tipicamente, o intervalo usado para relés eletromecânicos é de 0,3 a 0,4s, enquanto para relés de proteção baseados em micro processadores é da ordem de 0,1 a $0,2 \mathrm{~s}$ (MANSOUR; MEKHAMER; EL-KHARBAWE, 2007).

No contexto desta pesquisa, os RDS são coordenados de maneira que respeitem a atuação preferencial da proteção de distância, isto é, os RDS são utilizados como elementos de retaguarda da proteção primária de distância. $\mathrm{O}$ tempo total de espera $\Delta T_{\text {dist }}$ pela atuação da proteção de distância compreende, em geral, a soma do tempo de zona $1\left(T_{z 1}\right)$, em que se tem atuação instantânea do relé para até $80 \%$ da LT à jusante do relé, e do tempo de zona 2 $\left(T_{z 2}\right)$, em que o relé atuará de forma temporizada para $100 \%$ da LT à jusante do relé mais $50 \%$ a $60 \%$ da LT seguinte (KINDERMANN, 2005). Além disso, também é importante salientar que o tempo de abertura $T_{a}$ dos disjuntores associados também devem ser computados, bem como a margem de segurança, ou folga, $T_{s}$ (KINDERMANN, 2005), sendo assim, o tempo de espera $\Delta T_{\text {dist }}$ é computado pela Equação 7.

$$
\Delta T_{\text {dist }}=T_{z 1}+T_{z 2}+T_{a}+T_{s}
$$

A proteção de retaguarda é então realizada pelos RDS em dois níveis, chamados de Proteção de Retaguarda Local (PRL) e Proteção de Retaguarda Remota (PRR). O relé de PRR atua como sendo o backup do relé de PRL em caso de falha na atuação deste. Por essa razão, o tempo de atuação do relé de PRR $\left(T_{P R R}\right)$ deve ser maior do que o tempo de atuação do relé de PRL $\left(T_{P R L}\right)$, ou seja, é necessário respeitar o ITC entre estes RDS conforme expresso na Equação 8.

$$
T_{P R R}-T_{P R L} \geq I T C
$$

Conforme mencionado, o tempo de atuação $T_{P R L}$ deve respeitar o tempo $\Delta T_{\text {dist }}$, logo, tem-se que:

$$
T_{P R L}>\Delta T_{\text {dist }}
$$

Além das restrições impostas pelas Equações de 7 a 9, o processo de coordenação da proteção deve respeitar outros requisitos que serão detalhados no capítulo 3 . 
Em geral, os RDS são relés de tempo inverso, ou seja, possuem tempo de atuação inversamente proporcional à corrente de falta observada, atuando em tempos cada vez menores na medida em que o valor da corrente de falta aumenta, a partir de um valor de corrente ajustado, denominado corrente de partida ou corrente de pick-up. Conforme detalhado por Kindermann (2005) a corrente de pick-up é a menor de todas as correntes que conduzem o relé ao limiar de operação, e constitui um dos dois ajustes de um RDS.

As curvas padronizadas mais utilizadas para o tempo de atuação $T$ seguem o padrão definido pelo ANSI (American National Standards Institute) (IEEE Std. C37.112 (1996)) e IEC (International Electrotechnical Commission) (IEC 60255-3 (1989)), sendo que a expressão genérica para tais curvas pode ser representada pela Equação 10, conforme a norma IEEE Std. C37.112 (1996):

$$
T=M T \times\left[\frac{\mathrm{A}}{\left(M^{\mathrm{P}}-1\right)}+B\right]
$$

em que $A, P, B$ são constantes definidas pelas normas, $M$ é o múltiplo da corrente de partida (ou corrente de pickup) e MT é o múltiplo de tempo do relé.

Cada valor de ajuste do Múltiplo de Tempo (MT) produzirá uma curva distinta, transladada verticalmente sobre o gráfico tempo $\times$ corrente (tempo de atuação do relé $T$ versus múltiplo $M$ da corrente de pick-up), que, complementarmente, à corrente de pick-up, compõe o outro ajuste disponível no RDS (CAMINHA, 1977; KINDERMANN, 2005).

A Tabela 1 contém as constantes referentes aos três principais tipos de curva de tempo inverso definido pelos padrões ANSI (IEEE Std. C37.112 (1996)) e IEC (IEC 60255-3 (1989)).

Tabela 1 - Constantes de tempo inverso definidas pelos padrões $A N S I$ e IEC.

\begin{tabular}{ccccc}
\hline Norma & Tipo de Curva & A & P & B \\
\hline \multirow{3}{*}{ IEC 60255-3 (1989) } & Normal Inversa & 0,14 & 0,02 & 0 \\
& Muito Inversa & 13,5 & 1,0 & 0 \\
& Extremamente Inversa & 80 & 2,0 & 0 \\
& Moderadamente Inversa & 0,0515 & 0,002 & 0,114 \\
IEEE Std. C37.112 (1996) & Muito Inversa & 19,61 & 2,0 & 0,491 \\
& Extremamente inversa & 28,2 & 2,0 & 0,1217 \\
\hline
\end{tabular}


Com o intuito de ilustrar o comportamento das curvas de tempo inverso, apresenta-se na Figura 4 a curva do tipo normal inversa segundo a norma IEC 60255-3 (1989) para MT com os seguintes valores: 0,$1 ; 0,5 ; 1 ; 1,5 ; 2 ; 2,5 ; 3 ; 3,5$ e 4 . Nesta figura, as curvas correspondentes à MT = 0,1 e MT = 4 são a mais próxima e a mais distante do eixo abscissas, respectivamente. Entre estas duas curvas, estão situadas as demais curvas referentes aos valores intermediários de MT, na mesma ordem em que foram supracitados.

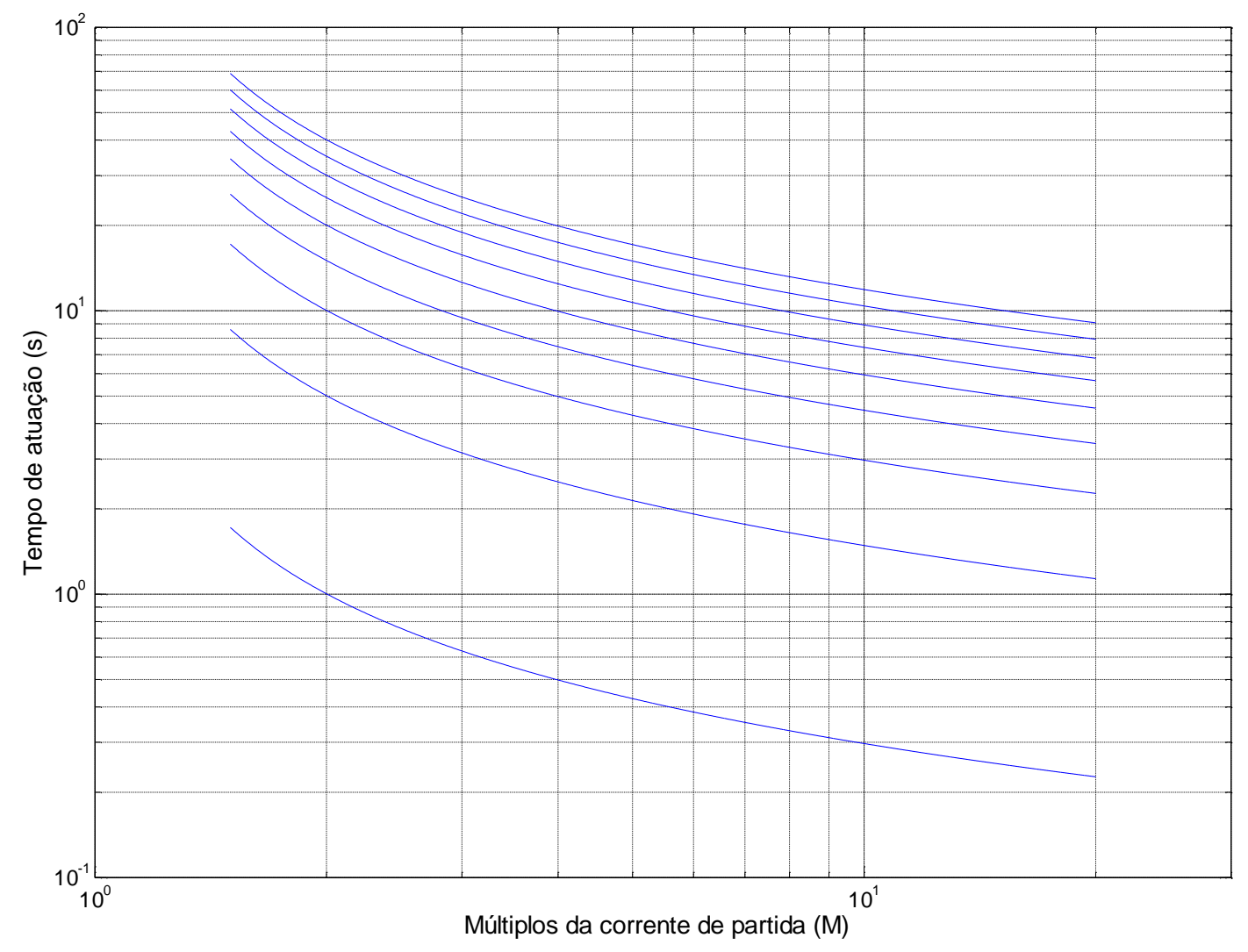

Figura 4 - Curvas de tempo do tipo normal inversa segundo a norma IEC 60255-3 (1989).

Conforme será exposto no item 2.3, para atingir a coordenação de RDS aplicados a sistemas malhados, observa-se, na maioria dos trabalhos revisados, a minimização do tempo de atuação para cada relé através da minimização de uma função objetivo (função de custo) a ser tratada por métodos computacionais de Programação Linear (PL), Programação Não Linear (PNL) e /ou ferramentas inteligentes, dentre outros, já que a coordenação individual de cada relé de proteção se torna inviável em SEP malhados.

Diante deste cenário, a metodologia de coordenação desenvolvida e a ser apresentada nesta pesquisa também visa modelar o problema de coordenação dos RDS em sistemas malhados, incluindo-se todas as restrições a serem atendidas, como um processo de 
minimização do tempo de atuação dos RDS, mais especificamente da PRL, que conduzirá à obtenção da coordenação entre os mesmos.

\section{3 - Trabalhos Relacionados ao Tema Desta Pesquisa}

Visando coordenar a atuação dos RDS de forma automática e otimizada em sistemas elétricos malhados, diversas soluções são propostas na literatura técnica.

Pelos trabalhos encontrados até o momento, verifica-se o emprego de técnicas inteligentes de otimização para tratar do problema de coordenação dos RDS. Entre as técnicas inteligentes, têm-se a aplicação do algoritmo Particle Swarm Optimization (PSO) (KENNEDY; EBERHART, 1995a; KENNEDY; EBERHART, 1995b) e de AG (LINDEN, 2006; NARA et al., 1992; GOLDBERG, 1989; GEN; CHENG, 1997), quando a formulação adotada é concebida como um caso de otimização com o objetivo de minimizar o tempo de atuação da PRL por meio dos ajustes da corrente de pick-up e do MT. Normalmente a aplicação destas técnicas é realizada em conjunto com PL e PNL, caracterizando o desenvolvimento de metodologias fundamentadas em algoritmos híbridos que visam aprimorar soluções obtidas, de maneira independente, pelas técnicas de otimização tradicionais e inteligentes (BASHIR et. al, 2010; BEDKAR; BHIDE, 2011b; NOGHABI; SADEH; MASSHADI, 2009).

Em Zeineldin, Saadany e Salama (2004), os autores apresentam um método que leva em consideração a introdução de valores discretos (inteiros) da corrente de pick-up no processo de minimização do tempo de atuação da PRL, uma vez que na prática esta é a condição de ajuste da maioria dos relés existentes, quando somente ajustes discretos estão disponíveis. Nesse sentido, é introduzida na formulação do problema de coordenação uma variável binária associada a uma restrição específica que mantém os ajustes da corrente de pick-up em valores discretos predeterminados. Neste trabalho, os autores utilizaram o programa General Algebraic Modeling System (GAMS), o qual é capaz de modelar a função objetivo através de sentenças algébricas relacionadas às restrições impostas pelo problema de coordenação do SP. Ao longo do trabalho a relevância da abordagem mencionada para a formulação do problema de coordenação é ressaltada, pois, em geral, o que se encontra na literatura é a prática de se arredondar os valores do ajuste de corrente, obtidos do processo de otimização, para o seu valor inteiro mais próximo. Contudo, este procedimento pode levar a 
soluções não factíveis no espaço de busca, invalidando o processo de otimização realizado caso não seja apropriadamente conduzido. Como alternativa a este tipo de formulação, visando à qualidade da solução disponibilizada, é possível utilizar técnicas de PL, obtendo-se o valor otimizado para o ajuste do MT, que em geral permite o ajuste em termos de valores contínuos a partir de correntes de pick-up previamente fixadas. Pelos resultados apresentados, a abordagem proposta parece contornar os efeitos indesejáveis advindos do arredondamento posterior (após a solução final ser encontrada) da variável associada ao ajuste de corrente.

Na pesquisa de Miranda e Fonseca (2002), assim como na grande maioria dos trabalhos estudados, observa-se o uso de técnicas inteligentes aplicadas em problemas de otimização. Neste último trabalho citado, os autores evidenciam as características evolutivas do algoritmo de otimização PSO, conforme inicialmente observado pelos seus idealizadores, quando novas soluções são geradas em diferentes posições do espaço de busca por uma lei de movimento. Esta interpretação amplia o entendimento acerca do algoritmo já que não é exclusivamente estudado em termos de movimentos de partículas (soluções). Sendo assim, é apresentada uma versão modificada do algoritmo PSO denominada Evolutionary Particle Swarm Optimization (EPSO) que reúne conceitos de algoritmos evolutivos ao tradicional PSO. Os autores salientam que o algoritmo EPSO é um algoritmo evolutivo com características auto adaptativas. No EPSO, os pesos (ou parâmetros) iniciais sofrem mutação pela aplicação de uma variável gaussiana $(N \sim(0,1))$, assim como a posição do mínimo e o máximo global. Além disso, em relação às suas características evolutivas, o EPSO incorpora ao operador de recombinação o conceito de movimento de partícula associado ao algoritmo PSO clássico. A eficiência do algoritmo desenvolvido é apresentada por meio de uma aplicação ao problema de regulação de tensão e minimização de perdas em SEP, comparando os resultados obtidos com as respectivas soluções encontradas via algoritmo de Simulated Annealing (SA). Os principais resultados alcançados com o algoritmo EPSO, e que merecem destaque, incluem: (i) a solução é obtida mais rapidamente em termos de números de iterações, (ii) melhores soluções são encontradas, incluindo casos em que o algoritmo SA não foi capaz de fornecer soluções factíveis e (iii) o desvio padrão encontrado para as soluções obtidas, em relação à solução ótima, foi de cerca de 5 vezes menor quando comparadas às fornecidas pelo algoritmo SA. Entretanto, comparado ao algoritmo SA, o algoritmo EPSO exige maior esforço computacional, o que pode representar empecilhos quando aplicações online (em tempo real) são consideradas. Contudo, cabe colocar que o algoritmo desenvolvido por Miranda e Fonseca, (2002) se apresenta como uma importante ferramenta de 
metaheurística aplicada na otimização de problemas de elevada complexidade, como observado na pesquisa de Leite et al. (2010).

Em Leite, Barros e Miranda (2010), os pesquisadores apresentam uma aplicação do algoritmo de otimização EPSO com o objetivo de resolver o caso de PNL concernente à coordenação de RDS em um sistema de distribuição malhado. Na formulação adotada, os parâmetros a serem ajustados nos RDS são a corrente de pick-up e o ajuste do MT, com o intuito de se minimizar o tempo de atuação da PRL, garantindo a coordenação de todos os RDS do sistema elétrico em questão. Para avaliar a qualidade dos resultados alcançados pelo algoritmo EPSO, os autores apresentam a solução obtida pela aplicação do algoritmo Simplex em que se torna fixa a corrente de pick-up, já que sob esta imposição, o problema de coordenação mencionado pode ser tratado por PL. Segundo os autores, o valor da função objetivo para as soluções encontradas pelo algoritmo EPSO foi menor quando comparado ao método Simplex, revelando que soluções mais próximas do ponto de ótimo global foram encontradas. Sendo assim, é possível constatar, pelo apresentado, que a ferramenta metaheurística EPSO fornece resultados satisfatórios quando aplicada ao problema de coordenação não linear de RDS.

A utilização do algoritmo PSO, aplicado ao problema de coordenação dos RDS também é observada no trabalho de Mansour, Mekhamer e El-Kharbawe (2007). Neste, o problema é abordado como sendo um caso de PL, isto é, os ajustes da corrente de pick-up são predeterminados a fim de se obter, via algoritmo PSO, os valores para o MT. No decorrer do trabalho revisado, muitos pontos são abordados com detalhes, especialmente acerca da obtenção da função objetivo a ser minimizada (soma do tempo de atuação da PRL). Além disso, os autores ainda descrevem como adequaram o algoritmo PSO para tratar das restrições impostas pela coordenação dos relés em questão, uma vez que originalmente o algoritmo PSO é um processo de otimização irrestrito. Para tanto, ao invés de utilizar uma função de penalização, comumente observada na literatura técnica correlata, uma modificação nas velocidades das partículas é realizada no momento que as soluções violem as restrições predefinidas no problema de coordenação da proteção. $\mathrm{O}$ algoritmo foi testado em vários sistemas elétricos modelados computacionalmente, e os resultados obtidos foram comparados com uma ferramenta de PL existente no software Matlab ${ }^{\circledR}$. Depreende-se dos resultados apresentados que o uso do algoritmo PSO se mostrou adequado à obtenção da coordenação ótima dos RDS, e, em certos casos de teste, mostrou-se superior ao processo de PL realizado no $M a t l a b^{\circledR}$, uma vez que nestes casos, não foi possível de se encontrar soluções factíveis por esta última aplicação. O tempo de convergência para a solução do algoritmo PSO modificado 
mostrou-se maior em comparação ao método de PL do Matlab ${ }^{\circledR}$, sendo este um ponto levantado pelos próprios autores e que merece mais cuidadosa análise.

Na pesquisa de Bashir et al. (2010) os autores propõem um algoritmo híbrido cujo intuito é o de otimizar o tempo de atuação da PRL em função do ajuste ótimo da corrente de pick-up e do MT. O algoritmo híbrido apresentado tem os valores de corrente de pick-up inicializados aleatoriamente dentro de um conjunto de valores discretos e possíveis, determinados pelas características dos relés analisados. No que segue, o valor do ajuste do MT é calculado por um método de PL, já que se fixou inicialmente o valor de pick-up. Passada esta fase, os valores do ajuste de corrente são atualizados por meio das regras fundamentais do movimento de partículas inerente ao algoritmo PSO, e pelas restrições impostas pelo problema de coordenação dos RDS. Os valores atualizados da corrente de pickup são quantizados, de forma a se obter valores inteiros, e, ainda na mesma iteração, o novo valor do ajuste de tempo é obtido mais uma vez por PL. O processo ocorre de forma iterativa até que se atinja o critério de parada. Para validar o método, os autores utilizam um sistema malhado que contém 14 RDS. Além disso, os resultados do algoritmo híbrido foram confrontados com valores encontrados por outros dois métodos, sendo um inteiramente baseado no método de PL, e o outro, em AG. Pelos resultados apresentados, o algoritmo híbrido atingiu um melhor desempenho, mostrando-se como uma alternativa eficaz para a solução do problema de coordenação.

Assim como os algoritmos PSO e EPSO, o uso de AG também é eficazmente aplicado ao problema de coordenação dos RDS, como se observa na pesquisa de Razavi et al. (2008). O caso é tratado como sendo um caso de PL ao se pré-fixar a corrente de pick-up, atribuindo-se ao AG a tarefa de encontrar os valores ótimos para os MT dos RDS associados ao sistema. Os riscos de se aproximar as soluções obtidas após o processo de otimização para valores inteiros, nos casos em que o ajuste de tempo dos relés é discreto, é discutida, assim como em Zeineldin, El-Saadany e Salama (2004), e levada em consideração na formulação do algoritmo proposto. Para tanto, os valores para o ajuste de tempo são inicializados com valores contínuos (números reais), sendo que ao final de cada iteração, e antes de se avaliar a função de aptidão, estes valores são aproximados para os valores inteiros mais próximos permitidos (de acordo com o ajuste discreto de tempo disponível no relé), para posteriormente dar continuidade ao processo de otimização. Uma vez que o uso do AG configura essencialmente um método de otimização irrestrita, os autores introduzem uma parcela de penalização na função objetivo, ou seja, quando soluções não factíveis são encontradas pelo AG o valor da função objetivo se eleva, e, por consequência, os indivíduos associados a tais 
soluções estarão sujeitos a não sobreviverem às próximas gerações. Da maneira como foi concebido, este método de penalização permite o ajuste de certos parâmetros de tal modo a se priorizar a redução do tempo de atuação dos relés ou garantir ao máximo a obtenção de soluções factíveis que eleva inevitavelmente o tempo de atuação dos relés.

A utilização de AG para tratar o problema de coordenação da proteção também é observada na pesquisa de Bedkar e Bhide (2011a). Neste trabalho, os autores defendem a utilização de números reais ao invés de se adotar uma codificação binária para os cromossomos representativos dos ajustes do MT. Este tratamento, segundo os autores, justifica-se pelo fato de resultar em um menor esforço computacional relacionado à execução do AG, já que não há necessidade de conversão da representação binária para a correspondente decimal. Além disso, os autores afirmam que é possível alcançar uma maior precisão, em termos da busca pela resposta ótima, sem a necessidade de aumentar significativamente o tamanho dos cromossomos, como o que pode ocorrer na utilização da representação binária. Cabe salientar que o problema de coordenação ótima dos RDS foi concebido como sendo um problema de PL, em função do ajuste de corrente ser prefixado. Os testes realizados em sistemas elétricos modelados computacionalmente mostram que o uso do AG, com as características mencionadas acima, é adequado, fornecendo soluções consistentes para a coordenação da proteção. É importante destacar que a comparação entre o AG utilizado pelos autores, e o AG que usa a codificação binária para representar seus cromossomos eventualmente poderia evidenciar a superioridade nas soluções apresentadas no que diz respeito aos pontos mencionados pelos autores, tais como: menor esforço computacional e qualidade das soluções encontradas no espaço de busca das soluções factíveis.

A abordagem da coordenação ótima dos RDS como sendo um caso de PNL, em que tanto os ajustes de corrente como o de tempo são otimizados, é realizada na pesquisa de Bedkar e Bhide (2011b). Nesta pesquisa, é observado o uso de AG juntamente com uma técnica de PL, justificada pelos autores na medida em que o AG possui maior capacidade em explorar um espaço de soluções amplo, evitando-se assim que as soluções se restrinjam a mínimos locais. Ressalta-se, conforme explicitado pelos pesquisadores, que os métodos de PNL tradicionais podem convergir para a solução ótima global caso a escolha inicial seja adequada, sendo uma característica bastante útil na obtenção da coordenação ótima dos RDS. Nesse sentido, os autores propõem um algoritmo híbrido que consiste em executar primeiramente o AG de modo a fornecer um ponto de partida adequado a um método de PNL disponível no software Matlab ${ }^{\circledR}$. As soluções encontradas por este algoritmo híbrido 
mostram-se superiores àquelas disponibilizadas por AG e o método de PNL, quando estes são utilizados separadamente.

Nos trabalhos supracitados, constata-se a elevada quantidade de restrições a serem atendidas pelos processos de otimização empregados, sejam estes resolvidos por técnicas computacionais tradicionais ou inteligentes. Com o intuito de reduzir o esforço computacional advindo da formulação do problema de coordenação ótima dos RDS, é possível destacar a pesquisa de Karegar et al. (2005), em que os autores apresentam um método de préprocessamento aplicado ao conjunto de restrições provenientes do processo de coordenação mencionado. As restrições eliminadas da formulação são referentes àquelas que são redundantes e/ou possam inviabilizar o processo de otimização modelado. O método de préprocessamento proposto consiste em verificar os limites operacionais dos MT dos RDS a fim de se delimitar a região possível de soluções. Esta região é pertencente ao plano bidimensional (plano $-x_{i} x_{j}$ ) que correlaciona as variáveis referentes aos ajustes de tempo dos pares de relés principais $x_{i}$ e de retaguarda $x_{j}$, sendo delimitada por seus valores máximos e mínimos (limites operacionais dos relés). Sobre este plano também é traçada uma reta, denominada linha de restrição, que representa os limites impostos pelo ITC entre os pares de relés analisados, que deve ser respeitado de maneira a assegurar uma coordenação consistente da proteção. Analisando-se a posição relativa da linha de restrição sobre a região possível de soluções, define-se uma sub-região que contém as soluções factíveis, ou seja, uma vez conhecidos os limites do MT e o ITC dos relés em questão, o espaço de busca das soluções é delimitado. Ao aplicar o referido algoritmo de pré-processamento, o espaço de busca é reduzido às soluções que são relevantes e factíveis para o problema de coordenação, evitando, por conseguinte, esforço computacional desnecessário decorrente de restrições redundantes e não válidas. Diante dos resultados apresentados, ao se considerar dois SEP para o teste do desempenho do algoritmo, constata-se que houve uma redução da ordem de $50 \%$ a $60 \%$ do número de restrições a serem atendidas para a obtenção do ajuste dos RDS. É apropriado destacar que, no trabalho estudado, o problema foi configurado como um caso de PL, já que os ajustes de corrente dos relés foram pré-fixados. Além disso, alterações específicas na topologia do sistema elétrico foram consideradas com o intuito de tornar a coordenação válida também para estas variações, além da topologia principal.

A consideração de variações referentes à topologia dos sistemas elétricos também é verificada na pesquisa de Noghabi, Sadeh e Masshadi (2009), em que autores abordam mais especificamente a importância de obter a coordenação do SP que seja, sob determinadas condições, imunes às mudanças na configuração do sistema elétrico decorrentes de situações 
de contingência ou paradas programadas. As diferentes configurações topológicas são modeladas no processo de otimização por meio da adição de novas restrições, o que pode elevar significativamente a complexidade do problema. Logo, para lidar com a elevada quantidade de restrições a serem simultaneamente satisfeitas, aprimorando a eficiência computacional, os autores propõem um algoritmo híbrido em que se utiliza a técnica de PL tradicional atuando conjuntamente com AG. A justificativa em subdividir o problema de coordenação, ou seja, aplicar AG para encontrar os ajustes de corrente e, posteriormente, PL para os ajustes de tempo é pertinente, uma vez que o espaço de busca das soluções é significativamente reduzido, quando comparado ao uso do AG convencional em que ambos os ajustes (corrente e tempo) são otimizados simultaneamente. $\mathrm{O}$ algoritmo desenvolvido pelos autores foi validado por meio de simulações computacionais sobre um sistema elétrico de 8 barras, sendo que os resultados obtidos foram comparados aos apresentados pelo método que emprega o AG convencional. Pelos resultados apresentados, constata-se que o algoritmo híbrido se mostrou mais eficiente, tanto em termos de esforço computacional, como em relação à capacidade de convergência quando as múltiplas topologias de operação são consideradas no processo de otimização. Observa-se que o algoritmo híbrido desenvolvido apresenta-se com sendo mais adequado para fornecer a solução otimizada da coordenação dos RDS quando o espaço de busca das soluções factíveis é aumentado pela inclusão da análise de múltiplas topologias de operação.

$\mathrm{Na}$ pesquisa de Noghabi, Masshadi e Sadeh (2010) aspectos de modificações topológicas de operação também são considerados. Neste trabalho os autores apresentam casos em que o comprometimento da coordenação é detectado em decorrência de uma alteração topológica do sistema, em particular, quando uma LT é retirada de operação. A descoordenação dos RDS, e a consequente atuação inadequada do SP, devem-se ao fato de apenas a topologia principal de operação do SEP ter sido levada em conta no processo de coordenação dos relés. Nesse sentido, os autores apresentam uma metodologia alternativa capaz de contemplar as múltiplas topologias no processo de coordenação de maneira a eliminar a ocorrência dos casos de não coordenação mencionados, assim como observado em Noghabi, Sadeh e Masshadi (2009). Entretanto, conforme já mencionado, ao se introduzir a análise das várias topologias, o número de restrições a serem atendidas na formulação da função objetivo do problema de otimização, associadas a cada uma das configurações da rede elétrica, cresce significativamente, o que pode inviabilizar a aplicação da técnica em função do esforço computacional exigido. Contudo, os autores demostram com sua pesquisa que é possível reduzir o número das referidas restrições à mesma quantidade de restrições que se 
obtém ao se considerar uma topologia fixa para o sistema. Esta redução é alcançada por meio da aplicação de resultados provenientes de uma teoria para a análise dos intervalos, que possibilita a substituição de todas as matrizes de restrições, que contém os coeficientes referentes ao intervalo de tempo de coordenação entre os pares de RDS de PRL e PRR, resultantes de todas as possíveis configurações topológicas consideradas, por apenas uma única matriz de restrição. Isto é, as matrizes de restrições, que compõem o processo de otimização e contém todas as topologias consideradas, é substituída por uma única matriz, definida como uma matriz de intervalo. A partir da matriz de intervalo construída, e considerando-se os resultados da abordagem matemática adotada, o problema de coordenação para múltiplas topologias é formulado como um problema de PL padrão, já que os valores do ajuste de corrente são assumidos fixos, possuindo o mesmo número de restrições para o caso de topologia única. Os resultados provenientes da aplicação da metodologia em sistemas testes mostram que o método conseguiu eliminar os casos de descoordenação relativos às variações topológicas.

Conforme exposto neste capítulo, verifica-se que as ferramentas inteligentes vêm sendo amplamente utilizadas no processo de coordenação dos RDS em sistemas elétricos malhados. Além disso, o uso de metaheurísticas também é observado para a coordenação de sistemas malhados contendo mais de um tipo de relé de proteção, como é o caso da pesquisa de Sadeh, Aminotojari e Bashir (2011) que por meio de um algoritmo híbrido, similar ao exposto por outros trabalhos aqui mencionados, obtém-se a coordenação da proteção em que estão presentes RDS e relés de distância. 


\section{3 - Metodologia de Parametrização e Avaliação da COORDENAÇÃo}

Os pontos centrais da metodologia e procedimentos empregados nesta pesquisa estão apresentados neste capítulo.

A Figura 5 e a Figura 6 mostram os fluxogramas representativos da metodologia desenvolvida, sendo que seus blocos constituintes serão explicados com maiores detalhes nos itens subsequentes, enfatizando-se as questões técnicas mais relevantes abordadas no desenvolvimento de cada um.

É importante ressaltar que os fluxogramas supracitados representam dois momentos distintos da mesma metodologia de parametrização dos RDS. O fluxograma da Figura 5 é referente à parametrização dos RDS para a topologia principal de operação quando se parte do pressuposto de um SP inicialmente descoordenado. Já o fluxograma da Figura 6 é referente a uma alteração topológica específica no SEP frente à topologia principal. Neste segundo caso, parte-se da parametrização anteriormente obtida (como indica o bloco "Parametrização Principal" da Figura 6) para a configuração principal do sistema elétrico, e, quando necessário, uma nova solução para a coordenação é calculada em função da topologia vigente.

Sendo assim, primeiramente os blocos funcionais do fluxograma da Figura 5 serão detalhados do item 3.1 ao item 3.4, e, posteriormente, no item 3.5, são explicados os blocos funcionais adicionais do fluxograma da Figura 6 que descrevem a situação da parametrização dos RDS para uma variação topológica evidenciada.

Estes fluxogramas foram elaborados com o intuito de reunir e organizar as principais etapas necessárias ao desenvolvimento da metodologia de parametrização proposta. Para tanto, todos os trabalhos pertinentes à coordenação otimizada dos RDS em sistemas malhados, com variações topológicas ou não, foram considerados de maneira a contemplar todas as principais variáveis de interesse para esta pesquisa.

\section{1 - INSPEÇÃO TOPOLÓGICA}

Inicialmente é necessário analisar a topologia do SEP cuja parametrização do SP será obtida. Neste procedimento é determinada a topologia de operação do sistema, assim como a verificação e atribuição dos pares de RDS que serão coordenados. 
A construção do conjunto dos pares de relés é feita com base na técnica apresentada por Braga e Saraiva (1996), em que uma matriz, denominada de matriz de incidência $\left(\boldsymbol{M}_{\boldsymbol{I}}\right)$, é obtida, e, posteriormente interpretada, de maneira a sistematizar a atribuição dos pares de RDS em sistemas malhados. Esta matriz possui dimensão $n \times m$, sendo $n$ o número de barras dos ramos no SEP que possuem RDS, e $m$ o número de relés envolvidos na coordenação. A informação sobre a quantidade de barras e RDS do SEP são provenientes do software CAPE, conforme explicado mais adiante no item 3.2.1.

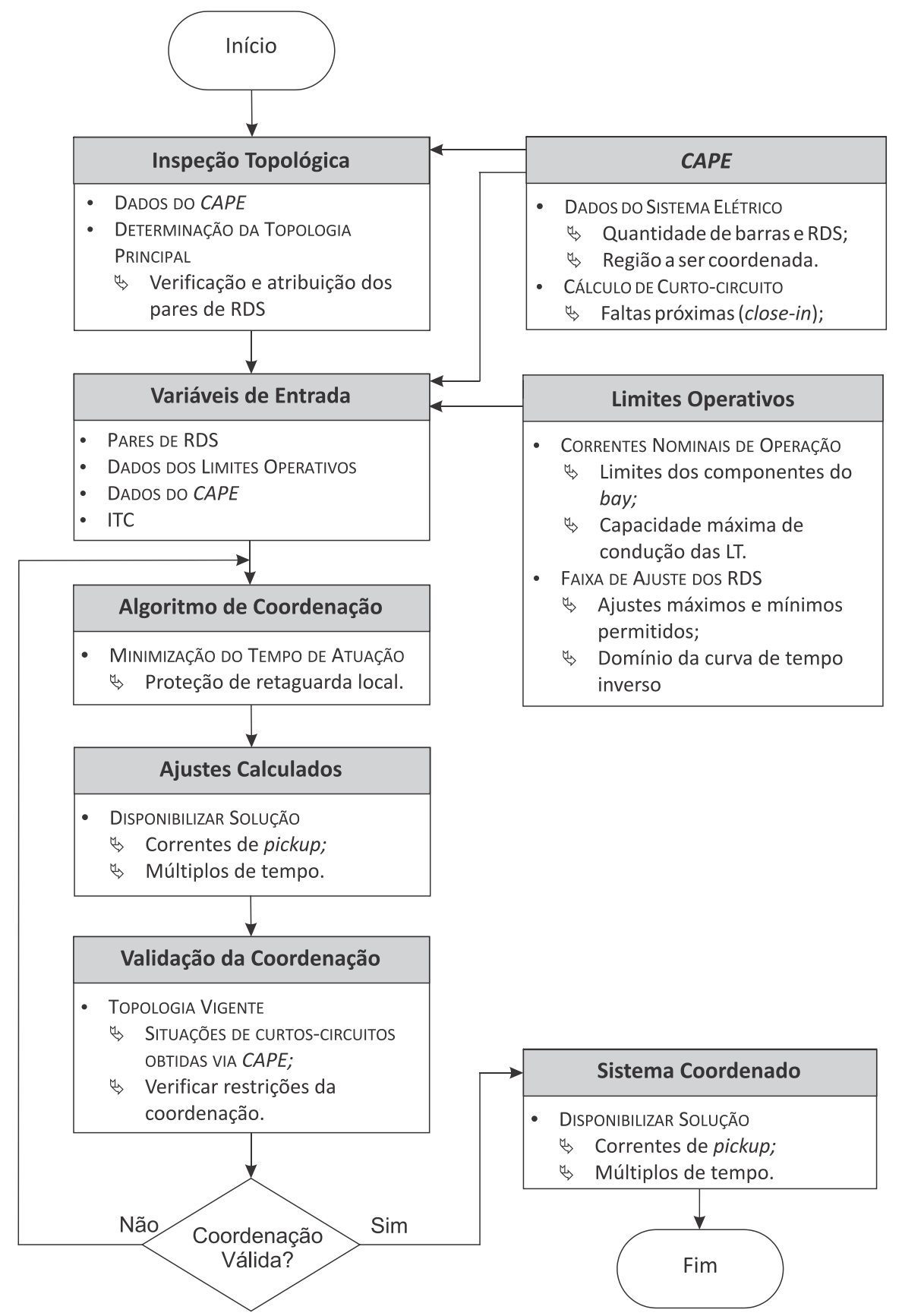

Figura 5 - Fluxograma referente à metodologia de parametrização e avaliação da coordenação do SP para a desejada operação da topologia principal. 


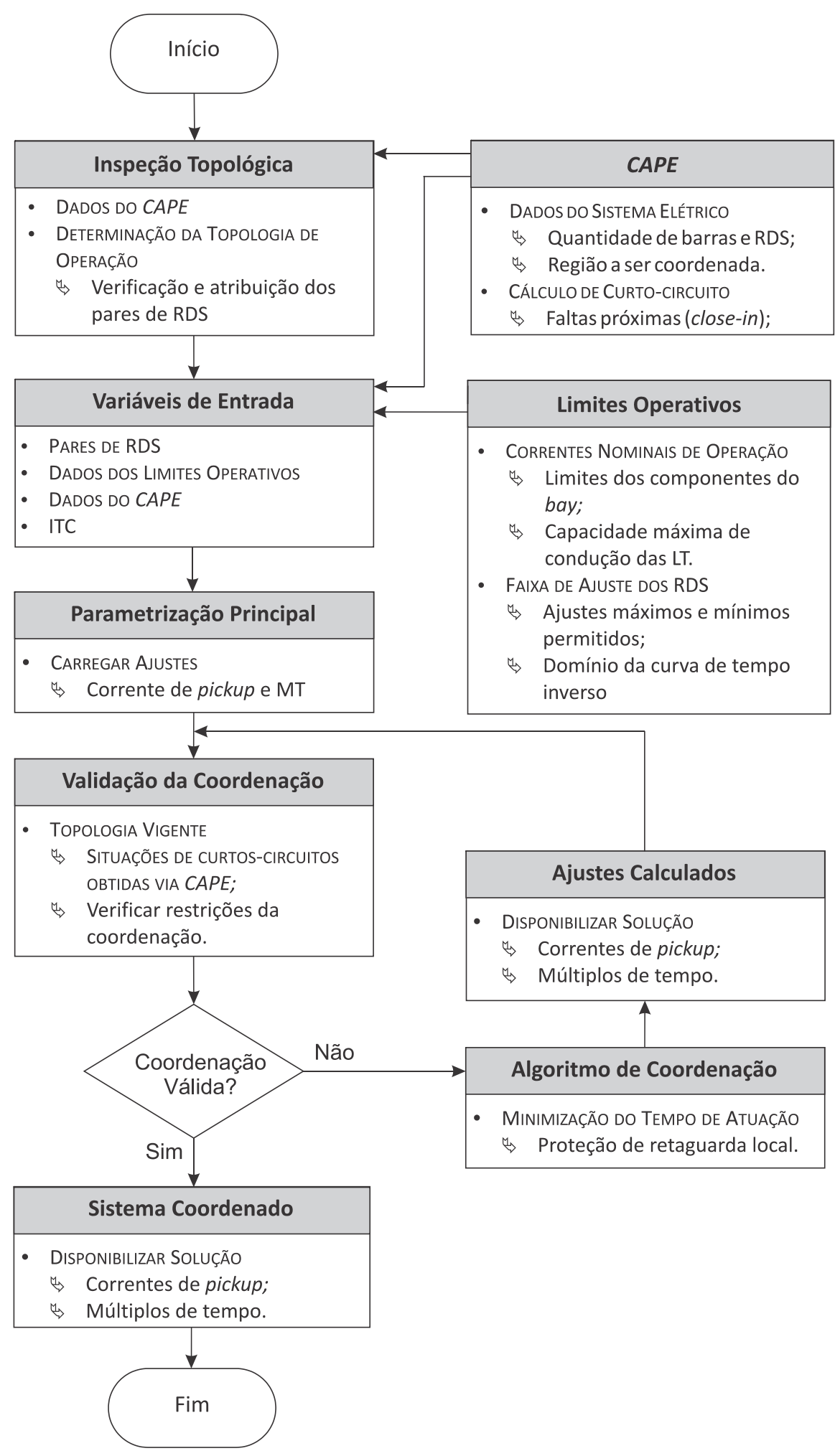

Figura 6 - Fluxograma referente à metodologia de parametrização e avaliação da coordenação do SP para uma alteração na operação da topologia principal do SEP.

Cada linha de $\boldsymbol{M}_{\boldsymbol{I}}$ identifica uma barra $b$ do sistema que possui uma determinada quantidade de barras adjacentes $b_{a d j}$ interconectadas diretamente por LT. Os relés associados à barra $b$, assim como às barras $b_{a d j}$ são identificados, e recebem valor +1 se estão com suas 
unidades direcionais ajustadas no sentido de $b$ para $b_{a d j}$, e recebem valor -1 se o sentido é de $b_{a d j}$ para $b$. Como as colunas da matriz $\boldsymbol{M}_{\boldsymbol{I}}$ representam cada relé do sistema, aqueles que não foram identificados para a barra $b$, e nem para as respectivas barras adjacentes $b_{a d j}$, recebem valor nulo. Dessa maneira, todos os elementos de matriz são determinados, estendendo para todas as $m$ barras do SEP o procedimento descrito acima para a barra $b$.

Para melhor ilustrar a formação da matriz $\boldsymbol{M}_{\boldsymbol{I}}$, considere o sistema malhado simplificado de 3 barras da Figura 7.

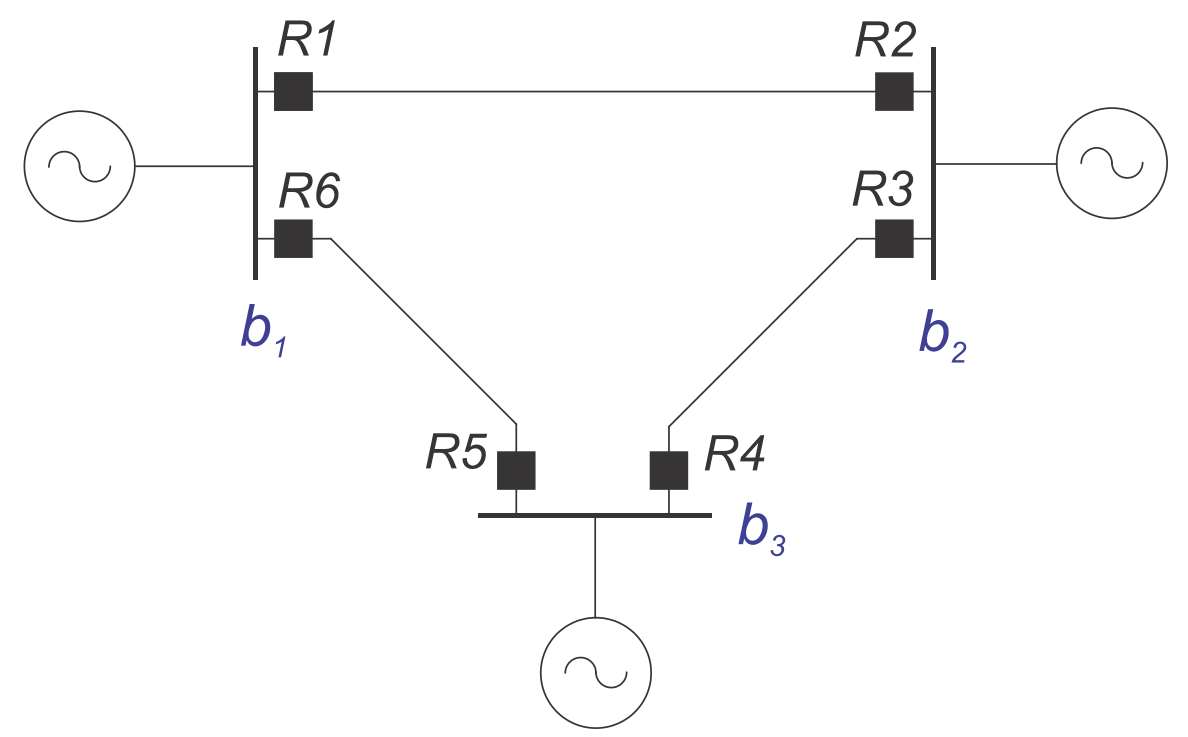

Figura 7 - Sistema elétrico malhado de 3 barras.

Aplicando-se o procedimento descrito anteriormente obtém-se a matriz $\left[\boldsymbol{M}_{\boldsymbol{I}}\right]_{3 \times 6}$ como mostra a Equação 11.

$$
\boldsymbol{M}_{\boldsymbol{I}}=\left[\begin{array}{cccccc}
1 & -1 & 0 & 0 & -1 & 1 \\
-1 & 1 & 1 & -1 & 0 & 0 \\
0 & 0 & -1 & 1 & 1 & -1
\end{array}\right]
$$

Com a matriz $\boldsymbol{M}_{\boldsymbol{I}}$ determinada, o conjunto dos pares de RDS é construído aplicandose o seguinte procedimento: $(i)$ para a $n$-ésima coluna de $\boldsymbol{M}_{\boldsymbol{I}}$ percorre-se se as $m$ linhas até que se encontre o valor +1 ; ( $i i$ ) fixa-se a linha em que se verificou o valor +1 no passo $(i)$ e observa-se as colunas que possuem valor -1 ; ( $i i i)$ as colunas identificadas com valor -1 em (ii) representam os RDS que são retaguarda remota do $n$-ésimo RDS de retaguarda local, desde que não pertençam ao circuito da barra associada à linha identificada no passo (i) (BRAGA; SARAIVA, 1996). 
Para ilustrar o procedimento descrito, considere o relé $R 1$ de retaguarda local do mesmo sistema de 3 barras da Figura 7. Pela matriz de incidência dada pela Equação (11), tem-se que o relé $R 5$ será a retaguarda remota de $R 1$ já que o relé $R 2$ pertence ao mesmo circuito de $R 1$. O mesmo raciocínio é empregado nas demais linhas, e o conjunto de pares de RDS, para o sistema da Figura 7, é dado pela Tabela 2.

Tabela 2 - Conjunto de pares de RDS definidos pela matriz $M_{I}$ para o sistema da Figura 7

\begin{tabular}{cc}
\hline PRL & PRR \\
\hline R1 & R5 \\
R2 & R4 \\
R3 & R1 \\
R4 & R6 \\
R5 & R3 \\
R6 & R2 \\
\hline
\end{tabular}

É importante destacar que o conjunto de pares de RDS determinado pelo procedimento supracitado deve ser avaliado pelo engenheiro de proteção, verificando assim se tal conjunto vai ao encontro da filosofia de proteção adotado para o SEP em estudo.

\section{2 - VARIÁVEIS DE ENTRADA}

As variáveis de entrada para o algoritmo de coordenação são principalmente provenientes de simulações computacionais do SEP real modelado e de suas características técnicas e operacionais. As simulações compreendem dados obtidos do módulo de curtocircuito do programa CAPE, que disponibiliza informações sobre o comportamento do SEP em análise quando ocorrem situações específicas de curtos-circuitos para a configuração de operação vigente.

A delimitação do espaço de busca das soluções que representam uma parametrização adequada para o SP e, por conseguinte, asseguram a coordenação entre os RDS do sistema elétrico é de suma importância para o bom desempenho do algoritmo de coordenação e qualidade das soluções disponibilizadas. Logo, o máximo de informação a respeito dos relés, do SEP, da filosofia de proteção adotada (incluindo margens de ajuste e operação do sistema praticado pela concessionária de energia elétrica), além das restrições ao problema de 
coordenação, devem ser consideradas e reunidas nas variáveis de entrada, formando assim o espaço das soluções factíveis a ser explorado pelo algoritmo híbrido de coordenação.

Estas variáveis, conforme ilustra a Figura 5, estão agrupadas em quatro principais grupos, sendo eles: (i) dados dos pares de RDS; (ii) dados do programa CAPE; (iii) dados dos limites operativos; e (iv) valor do ITC, que pode variar de um sistema elétrico para outro, sendo necessário fixar um valor que atenda à filosofia de proteção da concessionária de energia e /ou que seja conveniente para a análise do sistema elétrico em questão.

\subsection{1-CAPE}

Os dados provenientes do software CAPE, reunidos no bloco CAPE (Figura 5), são referentes ao número de barras e relés envolvidos na região do SEP em estudo que será coordenado, constituindo informações importantes para a determinação dos pares de RDS, conforme explicado anteriormente no item 3.1. Além dessas informações, os dados do CAPE também compreendem estudos de curtos-circuitos necessários à execução do algoritmo de coordenação.

O programa CAPE permite carregar toda a base de dados para estudos de de curtocircuito disponibilizado pelo ONS no formato do programa de cálculo de curtos-circuitos ANAFAS (Análise de Faltas Simultâneas), desenvolvido pelo Centro de Pesquisa de Energia Elétrica (CEPEL), (CEPEL, 2011). Esta base de dados considera a rede brasileira simulada com a sua configuração completa e com todos os seus componentes em operação.

No CAPE é possível que o usuário selecione graficamente apenas as barras de interesse a serem estudadas dentre toda a rede brasileira. Logo, embora o sistema teste, conforme será mostrado mais adiante, contenha apenas 46 barras, todos os cálculos de curtoscircuitos necessários para o estudo da coordenação dos RDS envolvidos consideram a influência do restante do sistema elétrico brasileiro, sem a necessidade de executar cálculo do equivalente elétrico correspondente. Cabe salientar ainda que o CAPE possui o módulo de redução de curto-circuito, de maneira que é possível o cálculo automático do equivalente elétrico, retendo-se as barras de interesse, quando conveniente e /ou necessário.

Pelo software CAPE, também é executado um estudo de curtos-circuitos incidentes proximamente a cada relé de PRL a ser coordenado, isto é, são simuladas situações de curtoscircuitos trifásicos francos à terra do tipo close-in a $1 \%$ da distância à jusante do relé em 
questão. Como consequência, correntes circularão pelas LT para suprir as faltas elétricas aplicadas, o que possibilita construir um conjunto de dados que é utilizado na coordenação dos RDS através do algoritmo desenvolvido. As características do tipo de curto-circuito estudado implicam nas contribuições de correntes de curto-circuito mais significativas, ou seja, as magnitudes de tais correntes são as mais elevadas dentre outros tipos de curtoscircuitos, possibilitando a análise do comportamento do SP em salvaguardar o SEP perante a condição mais severa de curto-circuito incidente em uma LT.

Este banco de dados é constituído por correntes observadas por cada par de RDS a ser coordenado, ou seja, mede-se a corrente de curto-circuito observada no relé de PRL, denotada por $I_{C C, l o c a l}$, e no respectivo relé de PRR, denotada por $I_{C C, \text { rem }}$. A Figura 8 ilustra, para um par de RDS, como se configura um cenário de curto-circuito que é simulado para compilar o conjunto de dados com os valores de curtos-circuitos para todos os pares de relés.

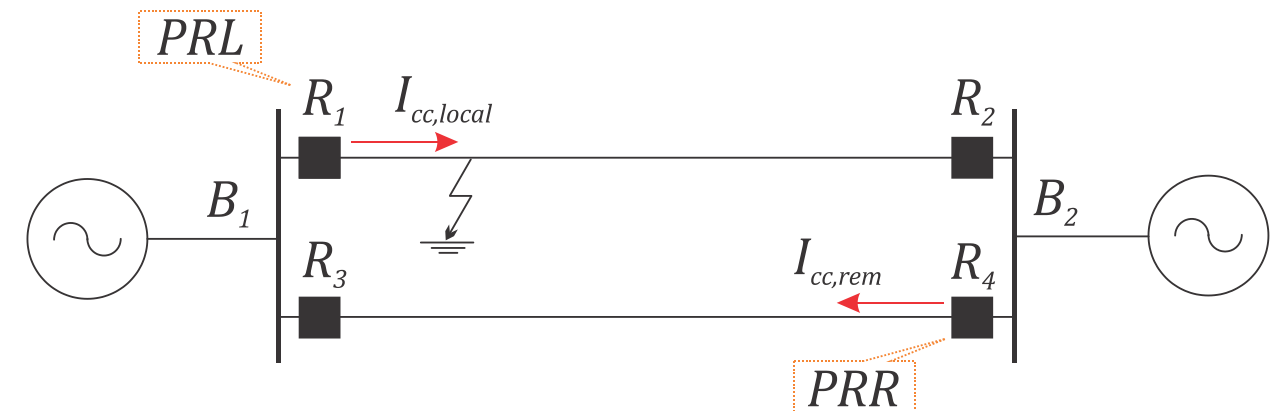

Figura 8 - Ilustração de um cenário de curto-circuito para um par de RDS $\left(R_{1}\right.$ e $\left.R_{4}\right)$ em um SEP simplificado, evidenciando as correntes mensuradas pelos relés de PRL e PRR.

\subsection{2 - LIMITES OPERATIVOS}

Neste item, tem-se explicado a maneira como as variáveis de entrada relacionadas aos limites operativos do sistema foram organizadas para serem apresentadas ao algoritmo de coordenação, determinando, portanto, a faixa de ajuste do múltiplo da corrente de partida $(M)$ e da faixa de ajuste do MT para os relés em questão.

A delimitação da faixa de ajuste da corrente de pick-up é dependente, incialmente, do tipo de RDS utilizado, que possui valores de tap específicos para ajuste, e também do valor da relação de transformação $(R T C)$ do transdutor de corrente atribuído a este relé. 
De acordo com Kindermann (2005), a corrente de pick-up do RDS $\left(I_{p}^{R D S}\right)$ é definida em função da $R T C$ e do tap, dado em ampère (A), do relé, como denota a Equação 12:

$$
I_{p}^{R D S}=\operatorname{tap} \times R T C
$$

Dessa maneira, a mínima e a máxima corrente de partida que podem ser ajustadas no RDS são determinadas, respectivamente, pelas Equações 13 e 14:

$$
\begin{gathered}
I_{p, \min }^{R D S}=\operatorname{tap}_{\min } \times R T C, \\
I_{p, \text { max }}^{R D S}=\operatorname{tap}_{\max } \times R T C,
\end{gathered}
$$

onde $t a p_{\min }$ e $t a p_{\max }$ são os valores máximo e mínimo do tap do RDS em questão.

Embora os RDS possuam uma faixa de ajuste de corrente dada pelas Equações 13 e 14, eles devem estar parametrizados de tal maneira que sejam sensíveis às situações de curtoscircuitos indesejáveis, mas não devem atuar para condições normais de operação do SEP. Sendo assim, é necessário fixar o valor de corrente que corresponda a uma situação normal de carregamento, para que o ajuste de pick-up seja sempre superior a este, evitando a incorreta atuação dos relés de proteção.

O cálculo da corrente que corresponde à situação normal de operação do sistema é feito analisando-se as capacidades nominais dos componentes constituintes de cada LT e seus respectivos bays. O menor valor de corrente nominal dentre estes elementos analisados, denominado $I_{\text {nom, RDS }}$, conforme mostra a Equação 15, será o fator limitante de um determinado trecho do SEP, e deve ser interpretado pelos respectivos RDS como sendo a corrente evidenciada numa situação de operação normal do sistema. Os elementos a serem analisados, tipicamente, são:

- Corrente nominal do disjuntor: $I_{\text {nom,disj }}$

- Corrente nominal da seccionadora: $I_{\text {nom,secc }}$

- Corrente nominal da bobina de bloqueio: $I_{\text {nom,bloq }}$

- Corrente primária nominal do TC: $I_{\text {nom,TC }}$

- Corrente nominal do condutor do bay: $I_{\text {nom,cond }}$ 


$$
I_{\text {nom }, R D S}=\min \left(I_{\text {nom }, \text { disj }}, I_{\text {nom }, \text { secc }}, I_{\text {nom }, \text { bloq }}, I_{\text {nom }, T C}, I_{\text {nom }, \text { cond }}\right)
$$

Por procedimentos adotados pela concessionária de energia no SEP em estudo (sistema teste), que refletem certos pontos centrais da filosofia de proteção adotada, este valor mínimo deve ainda respeitar uma margem de segurança de $20 \%$ acima do valor nominal determinado para um dado trecho do SEP em análise (Equação 16). Caso o relé possua passos discretos de ajuste da corrente de partida, o valor de corrente calculado pela Equação 16 deve ser aproximado para o inteiro superior mais próximo dado em função da RTC e tap associados ao respectivo RDS, de maneira a respeitar a margem de segurança estabelecida.

$$
I_{n o m, R D S}^{20 \%}=1,2 \times I_{\text {nom }, R D S}
$$

Por limitações técnicas da maioria dos relés de tempo inverso, é necessário encontrar o valor mínimo para o intervalo de ajuste da corrente de partida, uma vez que este valor influenciará diretamente na magnitude do máximo múltiplo desta corrente $\left(M_{\max }\right)$ que será possível ajustar em função da curva padronizada do relé. Múltiplos com magnitudes maiores do que $M_{\max }$ estão situados na região em que a curva de tempo inverso não está definida. Nesta região o relé é comumente ajustado para atuar com tempo definido, deixando de imprimir sua característica de tempo inverso. Em geral, as curvas padronizadas são definidas para múltiplos de até 20 vezes da corrente de pick-up (Figura 9), como determina a norma IEC 60255-3 (1989), porém pode variar de acordo com a especificação do fabricante do relé.

Portanto, a mínima corrente de partida que garantirá ao algoritmo fornecer correntes de ajuste (pick-up), cujos múltiplos não ultrapassem $M_{\max }$ é calculado aplicando-se a Equação 17.

$$
I_{M_{\max }}=\frac{I_{C C, \text { local }}}{M_{\max }}
$$

onde $I_{C C, \text { local }}$ é a corrente do curto-circuito que está prevista para o RDS medir quando desempenhar a função de PRL. Cabe ressaltar que em caso de passos discretos de ajuste da corrente de pick-up, o valor de $I_{M_{\max }}$ é aproximado para o inteiro superior mais próximo dado 
em função da $R T C$ e tap associados ao respectivo RDS para garantir que não se ultrapasse $M_{\max }$.

Por fim, o limite inferior da faixa de ajuste da corrente de partida é definido como sendo o máximo valor entre $I_{\text {nom,RDS }}^{20 \%}$ e $I_{M_{\max }}$, conforme mostra a Equação 18.

$$
I_{p, \min }=\max \left(I_{n o m, R D S}^{20 \%}, I_{M_{\max }}\right)
$$

Convém alertar que o valor de $I_{p, \min }$, definido pela Equação 18, pode, eventualmente, ser menor do que o máximo ajuste de pick-up disponível no relé (Equação 14), inevitavelmente resultando em múltiplos de corrente superiores a $M_{\max }$. Neste caso, entende-se que o relé será ajustado com tempo definido e receberá tratamento a parte para estar corretamente parametrizado perante aos demais RDS do SP.

O extremo superior do intervalo da corrente de pick-up de cada relé, em oposição ao extremo inferior, implicará no múltiplo mínimo $M_{\min }$ da corrente de pick-up. A magnitude de $M_{\min }$ pode variar de 1,5 a 2 vezes (Figura 9), ou conforme especificação do fabricante, pois para valores menores do que estes, em geral, a curva de tempo inversa não está definida (IEC 60255-3 (1989); IEEE Std. C37.112 (1996)), ou então, o relé atuará em um tempo demasiadamente longo, como se infere da análise matemática do denominador da equação geral da curva de tempo inverso (Equação 10). Dessa maneira, o ajuste da corrente de partida jamais deverá ultrapassar o valor de corrente dado pela Equação 19.

$$
I_{M_{\min }}=\frac{I_{C C, r e m}}{M_{\min }}
$$

onde $I_{C C \text {,rem }}$ é a mínima corrente de curto-circuito prevista para um RDS atuar quando exercer a função de PRR. É importante salientar que, analogamente ao procedimento de arredondamento de $I_{M_{\max }}$, a corrente calculada pela Equação 19 é aproximada para o valor inteiro inferior mais próximo dado em função da RTC e tap associados ao respectivo RDS para garantir que não se obtenham múltiplos abaixo de $M_{\min }$.

Cabe destacar que um dado RDS, em sua função de PRR, pode constituir mais de um par de relés a serem coordenados simultaneamente. Logo, deve-se considerar $I_{C C, \text { rem }}$, na Equação 19, como sendo a mínima corrente do RDS dentre todos os pares formados, garantindo assim sua sensibilização em todos os casos. 
Em certos casos, alguns RDS, podem não atuar como PRR, pois os mesmos não seriam sensibilizados devido à baixa corrente de curto-circuito mensurada. Isto é, a corrente que circularia pelo relé seria inferior a $I_{p, \min }$ (Equação 18), ou então, sua magnitude seria insuficiente para que a relação de $I_{C C, \text {,rem }}$ sobre $I_{p, \min }$ (múltiplo da corrente de partida em questão) fosse maior ou igual a $I_{M_{\min }}$. Sendo assim, para garantir o múltiplo mínimo $M_{\min }$ da PRL, a Equação 19 é reescrita conforme mostra a Equação 20.

$$
I_{M_{\min }}=\frac{I_{C C, \text { local }}}{M_{\min }}
$$

onde $I_{C C, \text { local }}$ é a corrente de curto-circuito que está prevista para o RDS medir quando desempenhar a função de PRL. É importante observar que o processo de arredondamento da corrente calculada pela Equação 20 é o mesmo realizado para a Equação 19.

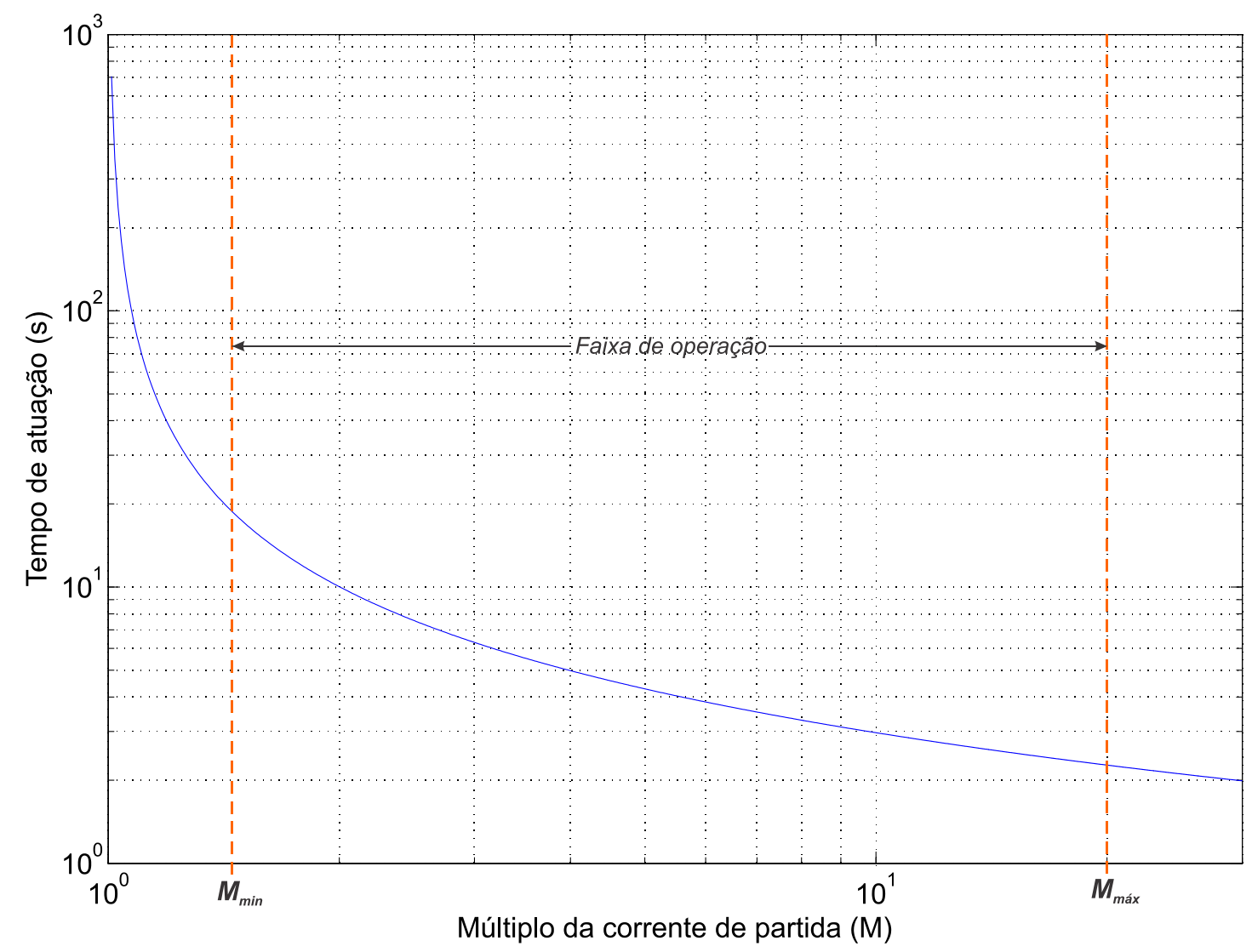

Figura 9 - Limites dos múltiplos $M_{\min }$ e $M_{\max }$ sobre a curva do tipo normal inversa segundo a norma IEC 60255-3 (1989) para MT = 1. 
Contudo, o extremo superior da faixa de ajuste ainda dependerá da máxima corrente de partida que se pode ajustar, dada pela Equação 14. De fato, a máxima corrente de partida que se pode ajustar será o valor mínimo entre $I_{p, \max }^{R D S}$ e $I_{M_{\min }}$, como mostra a Equação 21.

$$
I_{p, \max }=\min \left(I_{p, \max }^{R D S}, I_{M_{\min }}\right)
$$

Portanto, a faixa de ajuste da corrente de partida, é o intervalo I, dado pela Equação 22, cujos valores são dependentes de cada RDS a ser coordenado. É importante salientar que esta faixa é calculada e determinada para cada um dos RDS presentes no sistema, já que tais relés podem apresentar características distintas de ajuste da corrente de partida.

$$
I=\left[I_{p, \min }, I_{p, \max }\right]
$$

Definida a faixa de ajuste da corrente de partida, o intervalo correspondente ao ajuste do MT também deve ser obtido. Neste caso, a PRL e a PRR, conforme mencionado anteriormente no item 2.2, deve atuar para tempos superiores ao tempo de atuação da proteção primária, designada aos relés de distância, conforme registrado na Equação (9).

A condição de permitir que a proteção de retaguarda aguarde a atuação da proteção de distância (Equação 9) pode ser incluída no processo de coordenação dos relés como restrições a serem atendidas, isto é, os ajustes do MT de cada RDS, encontrados pelo algoritmo, devem ser tais que proporcionem tempo de atuação superior a $\Delta T_{\text {dist }}$ e atendam aos ITC estabelecidos entre os pares de RDS.

Entretanto, com o intuito de melhorar o desempenho do algoritmo de coordenação desenvolvido, estas restrições são consideradas implicitamente na delimitação do espaço de busca das soluções factíveis. Ou seja, através de uma análise preliminar dos ajustes dos MT disponíveis nos relés, conjuntamente com os múltiplos da corrente de pick-up, é possível restringir a busca das soluções em um conjunto de curvas de tempo específico para cada relé, garantindo que a atuação dos mesmos seja sempre superior a $\Delta T_{\text {dist }}$ para toda a faixa de ajuste da corrente de partida determinada pelo intervalo de corrente $I$ da Equação 22.

O limite inferior da faixa de ajuste de tempo será então o valor mínimo do MT que garanta a atuação do relé ser maior do que $\Delta T_{\text {dist }}$ para toda a faixa de $M$ disponível para ajuste. 
Para tanto, como as curvas de atuação dos RDS são de tempo inverso, basta verificar qual o MT que garante atuação em tempos superiores a $\Delta T_{\text {dist }}$ quando se utiliza a máxima corrente de curto-circuito que se espera sensibilizar o relé $\left(I_{C C, l o c a l}\right)$, fixando-se a mínima corrente de pick-up disponível $\left(I_{p, \min }\right)$. Partindo da expressão geral padronizada da curva de tempo inversa (Equação 10), com tempo de atuação pré-definido em $\Delta T_{\text {dist }}$, e o múltiplo da corrente de pick-up $M=\left(I_{C C, \text { local }} / I_{p, \min }\right)$, o MT mínimo $\left(M T_{\min }\right)$ para cada relé é obtido pela Equação 23.

$$
M T_{\text {min }}=\frac{\Delta T_{\text {dist }}}{\frac{A}{\left(\frac{I_{C C, \text { local }}}{I_{p, \text { min }}}\right)^{P}-1}+B}
$$

De fato, o valor de $M T_{\min }$ restringe o espaço de busca das soluções a ser explorado pelo algoritmo de coordenação, descartando todos aqueles valores para a AT que possuem magnitudes inferiores e, portanto, acarretarão em tempos de atuação menores do que $\Delta T_{\text {dist }}$, infringindo assim a restrição imposta pela condição de atuação da proteção de distância.

Cabe ressaltar que uma vez $M T_{\min }$ calculado para o máximo múltiplo da corrente de partida do RDS, todos os outros múltiplos de corrente de partida possíveis fornecerão tempos de atuação superiores a $\Delta T_{\text {dist }}$.

Logo, a delimitação da faixa de valores do MT disponíveis para o ajuste dos RDS é dada pela Equação 24 .

$$
M T=\left[M T_{\min }, M T_{\max }\right]
$$

em que $M T_{\text {max }}$ é o máximo valor para o MT disponível para ajuste no RDS considerado.

\section{3 - Algoritmo Híbrido de CoORdenação e Ajustes CAlCulados}

Após a definição de todas as variáveis de entrada, como explicado no item 3.2, o bloco do algoritmo híbrido de coordenação é executado na sequência, como mostra a Figura 
5. Neste bloco, encontra-se o algoritmo de coordenação propriamente dito, que deve estar apto a calcular os ajustes que permitam uma coordenação adequada entre os RDS do sistema.

Maiores detalhes sobre este algoritmo serão fornecidos no capítulo 4, já que este constitui uma das etapas mais importantes desta pesquisa. Contudo, vale adiantar que o tratamento dado para o problema de coordenação considera que ambos os ajustes de corrente de partida e MT sejam obtidos ao fim da execução do algoritmo de coordenação. Sendo assim, a estratégia utilizada para a resolução do problema de coordenação foi o emprego de um algoritmo híbrido, que combina PL e AG.

Após a convergência do algoritmo híbrido de coordenação, a solução encontrada é disponibilizada. Isto é, os valores para os ajustes da corrente de partida e do MT de cada RDS são calculados, conforme indica o bloco denominado “Ajustes Calculados” (Figura 5).

\section{4 - VALIDAÇÃo dA COORDENAÇÃO E SisTEMA COORDENADO}

Com os ajustes de corrente e tempo calculados, que representam a coordenação obtida, é necessário conduzir um procedimento de validação dos mesmos. A validação é bem sucedida se há confirmação da integridade da coordenação proposta pelo algoritmo através da análise do tempo de atuação entre os pares de RDS coordenados, considerando os níveis de curtos-circuitos calculados via o software CAPE para a topologia de operação vigente. Além disso, a parametrização proposta deve respeitar os intervalos definidos na Equação 22 e Equação 24.

Caso a solução de coordenação calculada seja considerada válida, os ajustes são então disponibilizados e os RDS podem ser parametrizados de forma a garantir a coordenação que atenda a todas as restrições impostas inicialmente, como indica o bloco denominado "Sistema Coordenado" (Figura 5). Caso contrário, se a coordenação violar as restrições impostas, todo o processo de coordenação deve ser continuado a partir do bloco "Algoritmo de Coordenação" (item 3.3), assumindo-se uma nova solução inicial aleatoriamente escolhida dentro do espaço das soluções factíveis. 


\section{5 - AlteraÇão da TOPOlOGia EM RelaÇão À Principal}

Eventualmente, após a coordenação dos RDS para a topologia principal de operação, conforme procedimento explicado do item 3.1 ao item 3.4, é necessária a avaliação da coordenação quando evidenciada uma alteração topológica, como, por exemplo, a saída de uma LT para manutenção. Esta alteração do sistema em relação à sua configuração principal de operação pode acarretar em uma descoordenação dos RDS, já que os níveis de curtoscircuitos podem assumir valores muito distintos dos incialmente calculados. Sendo assim, a solução anteriormente calculada (para a topologia principal) deve ser validada novamente frente à nova topologia de operação evidenciada, como indica o fluxograma da Figura 6.

Assim como no procedimento de coordenação do sistema para a topologia principal, quando evidenciada uma alteração na configuração do sistema, é necessário realizar uma nova inspeção topológica da mesma maneira como explicado no item 3.1, já que os pares de RDS deverão inevitavelmente ser atualizados. Além disso, todas as variáveis de entrada devem ser atualizadas para a nova topologia vigente, empregando-se a mesma metodologia descrita no item 3.2 .

Com os pares de RDS, dados de curtos-circuitos, limites operativos e ITC atualizados para a nova topologia de operação, carrega-se a parametrização anteriormente calculada para os relés do sistema e executa-se o bloco de validação da coordenação, seguindo o procedimento já explicado no item 3.4. Caso a parametrização anterior (topologia principal) se adeque às condições da nova topologia considerada, afirma-se que o sistema está coordenado e não é necessário o cálculo de uma nova solução. Entretanto, se alguma restrição da coordenação for violada, o algoritmo de coordenação deve ser novamente executado, como descrito no item 3.3. A nova parametrização, calculada para a alteração topológica evidenciada, segue então novamente para a etapa de validação (item 3.4), em que a necessidade de uma reinicialização do algoritmo de coordenação é verificada, até que a solução obtida atenda a todas as restrições impostas, garantindo assim a coordenação do SP para a nova topologia vigente. 


\section{4 - Algoritmo Híbrido de COORDENAÇÃo}

Conforme anteriormente mencionado, optou-se por adotar um algoritmo híbrido para tratar o problema de coordenação de RDS em sistemas malhados. Os resultados da aplicação conjunta de técnicas de otimização indicam a obtenção de soluções de maior qualidade e esforço computacional satisfatório, conforme apresentado pelos trabalhos revisados no capítulo 2.

A Figura 10 ilustra o fluxograma do algoritmo de coordenação híbrido desenvolvido, onde está destacada a parcela da PL e a parcela em que se utiliza o AG. Pela natureza do algoritmo híbrido, ambas as parcelas mencionadas são interdependentes. Ou seja, o resultado da otimização linear (bloco PL) será entrada para a otimização não linear (bloco AG), e viceversa. A cada iteração, tanto os ajustes de tempo, bem como os ajustes das correntes de partida de cada um dos relés participantes da coordenação são processados e otimizados, de maneira que após a convergência do algoritmo, obtém-se uma parametrização que busca atender todas as restrições impostas inicialmente pelo problema de coordenação.

\section{2 - BLOCO DA PL}

Conforme explicado anteriormente, e como é possível observar na Equação 10, é necessário fixar a corrente de partida para configurar o problema de PL que será responsável pela determinação dos MT otimizados. Logo, o bloco da PL é primeiramente alimentado por valores de corrente de partida e MT inicializados aleatoriamente, respeitando-se os intervalos definidos pelas Equações 22 e 24, respectivamente. Conforme será explicado mais adiante no item 4.3, vale ressaltar que as correntes de pick-up seguem uma representação cromossômica binária específica, já que serão manipuladas pelos operadores genéticos no bloco do AG.

Com as correntes de partida pré-fixadas para cada relé, e valores dos MT inicializados, a PL resume-se a encontrar os ajustes de tempo tais que respeitem o ITC e o próprio intervalo definido para o MT (Equação 24) de cada RDS.

Segundo Rao (2009), no problema de PL em sua forma padrão, uma função de custo

linear, chamada de função objetivo $\left(F_{o b j}\right)$, é minimizada (Equação 25$)$ sujeita a um conjunto de restrições (Equação 26). 


$$
\begin{gathered}
\text { minimize } F_{o b j}\left(x_{1}, x_{2}, \ldots x_{n}\right)=\sum_{j}^{n} c_{j} x_{j} \\
\text { sujeito } a\left\{\begin{array}{c}
a_{11} x_{1}+a_{12} x_{2}+\cdots+a_{1 n} x_{n}=b_{1} \\
a_{21} x_{1}+a_{22} x_{2}+\cdots+a_{2 n} x_{n}=b_{2} \\
\vdots \\
a_{m 1} x_{1}+a_{m 2} x_{2}+\cdots+a_{m n} x_{n}=b_{n} \\
x_{j} \geq 0, j=1,2, \ldots, n
\end{array}\right.
\end{gathered}
$$

Onde $c_{j}, b_{j}, a_{i j}(i=1,2, \ldots, m ; j=1,2, \ldots, n)$ são constantes conhecidas; e $x_{j}$ representa as $n$ variáveis de decisão do problema.

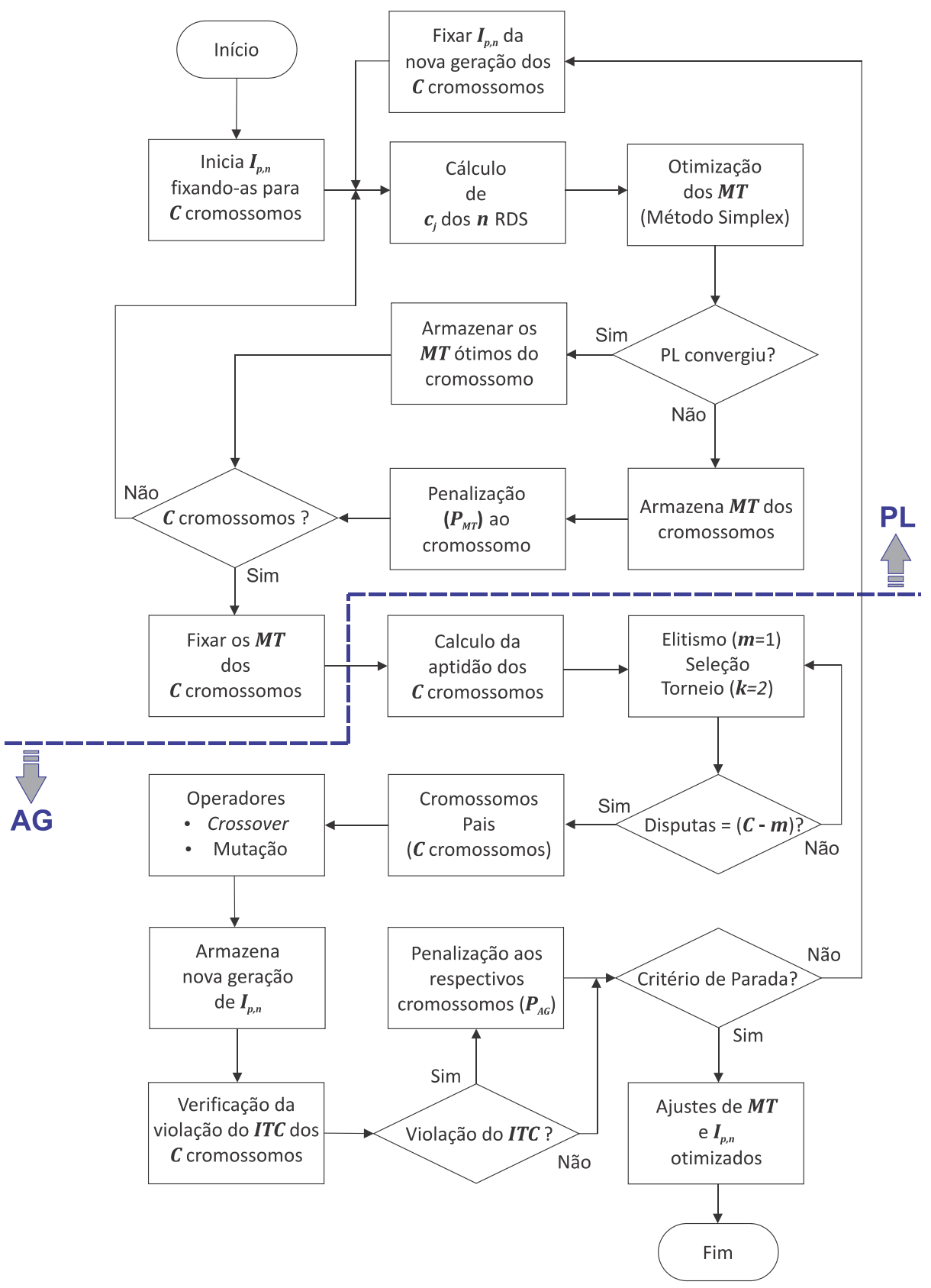

Figura 10 - Fluxograma do algoritmo híbrido de coordenação desenvolvido. 
Se as restrições do problema de otimização (Equação 26) se encontram sob a forma de inequações do tipo "menor ou igual" ou então "maior ou igual", a forma padrão pode ser obtida introduzindo-se variáveis de folga ou excesso, respectivamente (RAO, 2009).

Aplicando a PL descrita acima ao problema de coordenação dos relés em um sistema malhado, e partindo da Equação 10 da curva de tempo inverso padronizada, tem-se que as $n$ variáveis de decisões são exatamente os MT dos $n$ RDS do sistema elétrico estudado. Cada constante $c_{j}$ compreende toda a parcela constante da Equação 10 que é estabelecida pelo múltiplo de corrente fixado para o $n$ - ésimo RDS, como mostra a Equação 27.

$$
c_{j}=\frac{\mathrm{A}}{M_{j}^{\mathrm{P}}-1}+B, \quad j=1, \cdots, n
$$

Cabe destacar que no algoritmo híbrido de coordenação desenvolvido nesta pesquisa, considera-se apenas um tipo de curva de tempo inverso, de maneira que todas as constantes que a definem permanecem idêntica para todos os relés coordenados. É importante salientar que os múltiplos $M_{j}$ utilizados na Equação 27 consideram as correntes de curto-circuito do tipo close-in incidentes proximamente aos relés de PRL.

Neste contexto, fica claro que a função objetivo representa a soma do tempo de atuação da PRL. Logo, cada $b_{j}$ é igual ao ITC estabelecido para o $m$ - ésimo par de RDS configurado no sistema a ser coordenado.

Logo, adotando-se a curva de tempo normal inversa (IEC 60255-3 (1989)) a PL tem como objetivo encontrar os ajustes de tempo que minimizem a somatória do tempo de atuação da PRL (Equação 28), respeitando o ITC e o próprio intervalo definido pela Equação 24 para os MT do $i$-ésimo RDS (Equação 29).

$$
\begin{gathered}
F_{\text {obj }}^{P L}\left(x_{1}, x_{2}, \ldots, x_{n}\right)=\operatorname{minimize}\left[\sum_{j=1}^{n} c_{j} x_{j}\right]=\text { minimize }\left[\sum_{j=1}^{n}\left(\frac{0,14}{M_{j}^{0,02}-1}\right) x_{j}\right] \\
\text { sujeito } a\left\{\begin{array}{c}
M T_{\min }^{j} \leq x_{j} \leq M T_{\max }^{j} \\
\left(T_{P R R}-T_{P R L}\right)^{i} \geq I T C^{i} \\
i=1,2, \cdots, m \\
j=1,2, \ldots, n
\end{array}\right.
\end{gathered}
$$

Onde $M T_{\text {min }}^{j}$ e $M T_{\max }^{j}$ são os limites do intervalo dos MT dos $n$ RDS definido pela Equação 24; $\left(T_{P R R}-T_{P R L}\right)^{i}$ caracterizam os ITC dados como função da variável de decisão $x_{j}$, isto é, 
os MT, dos $m$ pares de RDS configurados; e $I T C^{i}$ são os valores dos ITC atribuídos aos $m$ pares de RDS a serem coordenados.

Para a aplicação no algoritmo de coordenação desenvolvido nesta pesquisa, utilizouse de uma função pré-definida de otimização linear do software Matlab ${ }^{\circledR}$, denominada linprog (MATHWORKS, 2013). Esta função foi configurada de maneira a executar o método simplex (RAO, 2009) para encontrar as variáveis de decisão do problema de coordenação formulado.

Na execução do método simplex, é possível que uma solução básica factível não seja encontrada na fase I, ou ainda a solução na fase II pode ser ilimitada (unbounded solution) (RAO, 2009). Nestes casos é implícito o não atendimento às restrições do problema de coordenação configurado, e um valor de penalização é calculado de maneira a compor a função de avaliação processada no bloco de AG, conforme será explicado no item 4.3.2.

A não convergência da execução do método simplex é indicada pela função linprog através de sinalizadores específicos, a partir dos quais é possível executar a rotina de penalização da solução associada a um dado cromossomo. O valor de penalização atribuído é um fator multiplicativo, determinado empiricamente, que pondera a magnitude da penalização aplicada conforme a Equação 30.

$$
P_{M T}=\lambda, \lambda \in \mathbb{R}
$$

Cabe ressaltar que o uso da função de penalização no algoritmo de coordenação híbrido desenvolvido, será explicado no item 4.3.2, conforme mencionado anteriormente.

\section{3-BLOCO DO AG}

Após a execução do bloco de PL, inicia-se a execução do bloco de AG, em que os MT dos relés são agora fixados e as correntes de partida são modificadas através da execução do AG. É importante frisar que, diferentemente do bloco de PL, em que se encontra a solução ótima quando o método simplex converge (RAO, 2009), os AG constituem uma heurística capaz de encontrar soluções adequadas e eventualmente próximas da ótima a cada execução, porém, tais soluções podem variar e não serem necessariamente as mesmas a cada execução (LINDEN, 2006).

Conforme pode ser constatado, analisando-se a Equação 10 da curva padronizada de tempo inverso, a aplicação do AG no problema de coordenação de RDS consiste em um caso 
de PNL, cujo objetivo é encontrar ajustes de correntes de pick-up tais que proporcionem a minimização do tempo de atuação da PRL (Equação 31), considerando os valores dos MT fixados e o intervalo de corrente definido pela Equação 22 de cada RDS (Equação 32).

$$
\begin{gathered}
F_{o b j}^{A G}\left(x_{1}, x_{2}, \ldots, x_{n}\right)=\min \left[\sum_{j=1}^{n} \frac{0,14}{\left[\left(\frac{I_{c c, l o c a l}}{x_{j}}\right)^{0,02}-1\right]} M T_{j}\right] \\
\text { sujeito a }\left\{\begin{array}{c}
I_{p, \min }^{j} \leq x_{j} \leq I_{p, \max }^{j} \\
\left(T_{P R R}-T_{P R L}\right)^{i} \geq I T C^{i} \\
i=1,2, \ldots, m \\
j=1,2, \ldots, n
\end{array}\right.
\end{gathered}
$$

Onde $I_{p, \text { min }}^{j}$ e $I_{p, \text { max }}^{j}$ são os limites do intervalo das correntes de partida dos $n$ RDS definidos pela Equação 22; $\left(T_{P R R}-T_{P R L}\right)^{i}$ caracterizam os ITC dados como função da variável de decisão $x_{j}$, isto é, as correntes de pick-up, dos $m$ pares de RDS configurados; e $I T C^{j}$ são os valores dos ITC atribuídos aos $m$ pares de RDS a serem coordenados.

Inicialmente um AG deve ter sua população de indivíduos (cromossomos) inicializada, e cada indivíduo deve ser avaliado por uma função de aptidão (função de fitness) de modo a serem selecionados para serem os pais dos indivíduos da nova geração.

Para formar a população da nova geração, são aplicados sobre os indivíduos selecionados (pais) os operadores genéticos de recombinação (crossover) e mutação. Os novos cromossomos resultantes da recombinação e mutação são inseridos na população em substituição a seus pais, constituindo assim a nova geração. Por fim, todos os indivíduos da nova população são avaliados segundo a função de fitness, de maneira que possam ser selecionados como os novos pais da geração seguinte. Este processo continua até que se atinja um número máximo de gerações inicialmente pré-determinado, ou então, até que o melhor cromossomo da população satisfaça as restrições e desempenhos almejados para o problema modelado (GOLDBERG, 1989; NARA et al., 1992; GEN; CHENG, 1997; LINDEN, 2006).

A Figura 11 ilustra o funcionamento básico do AG por blocos funcionais, conforme descrito acima.

Transferindo o princípio básico de funcionamento de um AG para o problema de coordenação da proteção no contexto desta pesquisa, tem-se em que cada cromossomo da população estão codificados os ajustes da corrente de partida dos $n$ RDS que serão 
coordenados no sistema elétrico considerado. Sendo assim, ao término de cada geração (iteração) do AG, novos valores para as correntes de pick-up dos relés são encontrados. Logo, no decorrer das gerações, espera-se que o AG encontre cromossomos que melhor minimizem o tempo de atuação da PRL, respeitando as restrições inerentes do problema de coordenação estudado. É importante salientar que sendo híbrido o algoritmo de coordenação desenvolvido (PL em conjunto com AG), toda nova geração de indivíduos (correntes de pick-up dos RDS) será entrada para o bloco de PL, em que serão otimizados os valores dos MT associados, antes que o valor de fitness de cada indivíduo seja calculado e siga para o módulo de seleção para gerar a próxima população, conforme ilustrado pelo fluxograma da Figura 10.

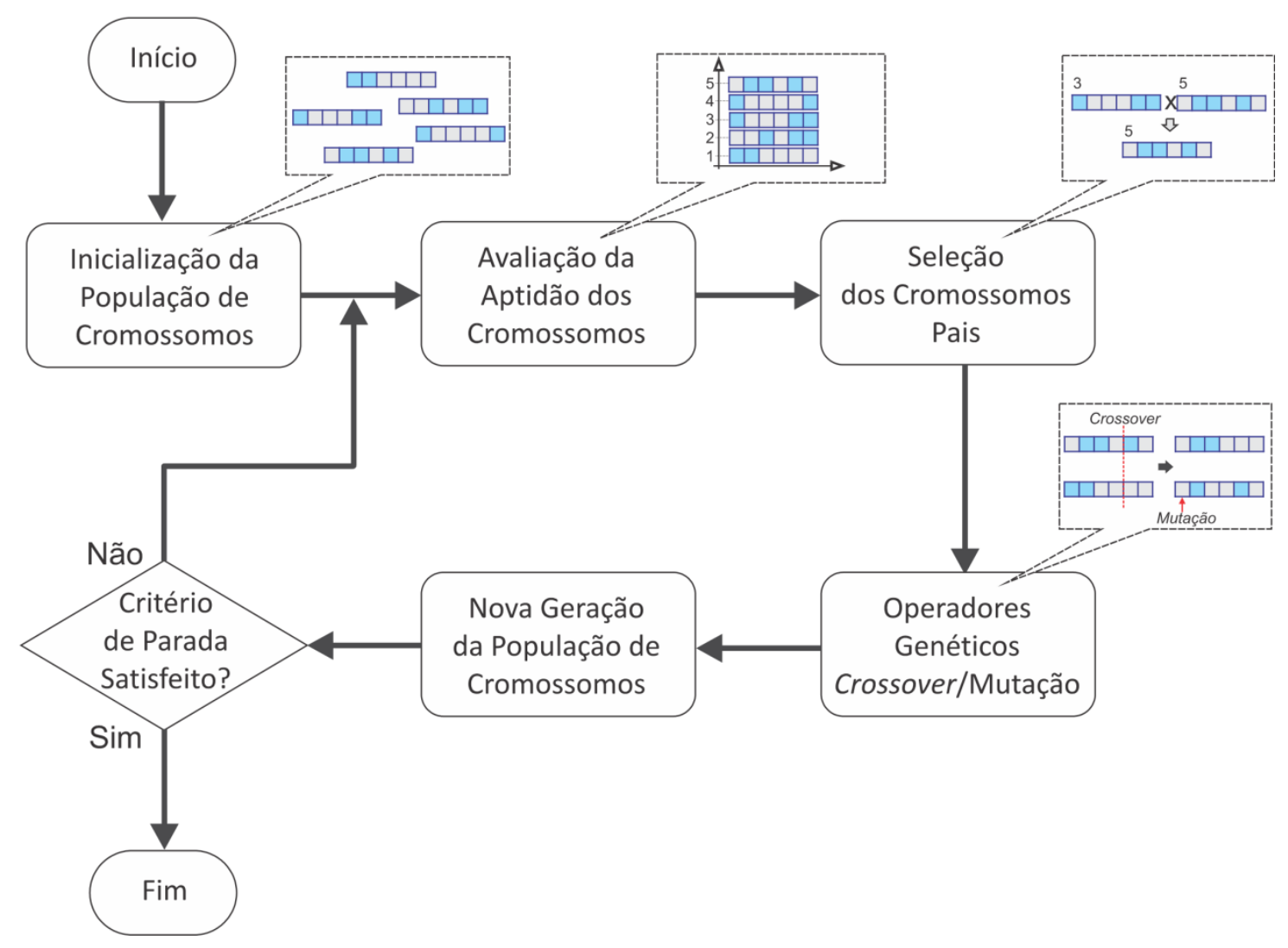

Figura 11 - Blocos funcionais ilustrando o funcionamento básico de um AG.

Ressalta-se que a opção por um algoritmo híbrido com as características descritas toma como base os resultados encontrados na literatura técnica correlata apresentada no capítulo 2, especialmente na pesquisa de Noghabi, Sadeh e Mashhadi (2009), que indicam o bom desempenho deste tipo de algoritmo. Além disso, a adoção de AG como heurística visa à ampla busca direcionada e inteligente pelo espaço das soluções factíveis que esta técnica oferece (GOLDBERG, 1989; NARA et al., 1992; GEN; CHENG, 1997; LINDEN, 2006). 
Nos itens subsequentes, serão explicados os principais módulos utilizados no bloco do AG (seleção, elitismo, crossover e mutação), além da maneira como se procedeu à representação cromossômica das correntes de partida dos RDS, construção da função de aptidão e função de penalidade.

\subsection{1 - REPRESENTAÇÃO CROMOSSÔMICA}

Conforme mencionado anteriormente, a corrente de pick-up do $n$-ésimo RDS, denotada por $I_{p, n}$, é codificada nos cromossomos que sofrerão recombinação (crossover) e mutação. A disposição destas variáveis é feita de maneira sequencial no cromossomo, de tal forma que este contém a informação de $n$ valores de corrente de pick-up associados aos $n$ relés que participam do processo de coordenação. Levando em consideração a disposição sequencial das variáveis que representam as correntes de pick-up dos relés, e utilizando uma codificação binária, afirma-se que estas são representadas por uma sequência definida de bits, como ilustra a Figura 12.

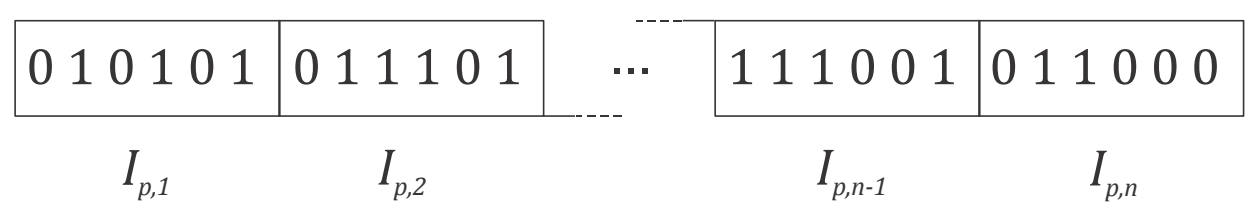

Figura 12 - Exemplo da disposição das correntes de pick-up $I_{p, n}$ binariamente codificadas em uma estrutura cromossômica sequencial.

Os valores de $I_{p, n}$, que serão codificados binariamente devem preencher os requisitos de precisão desejados (precisão do tap do relé) e a faixa de operação definida pela Equação 22. Estes parâmetros definem a quantidade $b$ de bits utilizados para cada uma das variáveis que representam os ajustes da corrente de partida (Equação 33) e a transformação que deve ser aplicada aos números binários para haver correspondência com o intervalo de busca das correntes de pick-up, como expressa a Equação 34 (LINDEN, 2006; RAO, 2009).

$$
2^{b} \geq\left(I_{p, \max }-I_{p, \min }\right) \times 10^{\varepsilon}
$$


Onde $I_{p, \min }$ e $I_{p, \max }$ são, respectivamente, os valores de máximo e mínimo da corrente de partida permitida associada ao $n$ - ésimo RDS; e $\varepsilon$ é a precisão das casas decimais que se deseja para a variável decimal da corrente de partida $I_{p, n}$ de cada RDS.

$$
I_{p, n}=I_{p, \min }+\frac{\left(I_{p, \max }-I_{p, \min }\right) \times I_{p, n}^{b i n}}{2^{b}-1}
$$

Onde $I_{p, \min }$ e $I_{p, \max }$ são, respectivamente, os valores de máximo e mínimo da corrente de partida permitida associada ao $n$ - ésimo $\operatorname{RDS} ; I_{p, n}^{b i n}$ é o número na base decimal calculado a partir da sequência binária relacionada à posição na estrutura cromossômica referente à corrente de pick-up do $n$ - ésimo RDS.

Uma vez que se utiliza a transformação expressa na Equação 34, não há possibilidade de que existam cromossomos cujas sequências binárias resultem em correntes de partida fora do intervalo definido pela Equação 22. Esta situação proporcionada pela representação cromossômica é conveniente, pois indivíduos que correspondam aos valores de corrente de partida que são proibidos não podem ser representados, quaisquer que sejam as ações provocadas pelo processo de inicialização aleatória da população e pelos operadores genéticos de recombinação e mutação. Com essa abordagem, a necessidade de se verificar a factibilidade com relação aos valores da corrente de pick-up, a cada geração do AG, é evitada.

Embora existam diferentes relações de transformação dos TC associados aos RDS considerados nesta pesquisa, resultando em diferentes valores discretos nos passos de corrente de pickup, como será exposto no capítulo 5 , foi utilizada uma mesma precisão $\varepsilon$, associada a sequencia binária correspondente a cada RDS. Desta maneira, possibilita-se um adequado arredondamento das variáveis independentemente do tamanho do passo da corrente de pick-up e pelo seu respectivo TC.

\subsection{2 - FUNÇÃO DE AVALIAÇÃO}

A formação da população que sofrerá os efeitos da recombinação e mutação genéticas implica na determinação dos indivíduos pais de tal população. Para tanto, é necessário que se estabeleça uma métrica que avalie a aptidão de cada cromossomo ao problema formulado, ou seja, que reflita a qualidade da solução (cromossomo) perante o problema estudado. Tal métrica pode ser realizada via uma função de fitness $\left(F_{\text {fitness. }}\right)$, 
também chamada de aptidão ou avaliação, que atribui um valor a ser utilizado como parâmetro para a seleção dos indivíduos pais, que propiciarão a formação da nova população.

Em suma, a função de fitness processa a informação armazenada nos cromossomos e retorna um valor numérico que é atribuído a uma métrica de qualidade/ aptidão da solução (cromossomo) em questão. Por exemplo, para um problema de maximização o cromossomo possuirá maior aptidão se o valor de sua avaliação for maior do que um cromossomo considerado de menor aptidão (LINDEN, 2006).

No caso do algoritmo de coordenação desenvolvido, serão considerados indivíduos mais aptos aqueles que conseguirem melhor minimizar a somatória do tempo de atuação de todos os $n$ relés de PRL. De fato, tem-se caracterizado implicitamente um problema de minimização, ou seja, é desejável que o AG explore o espaço de busca no sentido de disponibilizar cromossomos que contenham valores de $I_{p, n}$ tais que minimizem o tempo de atuação $\left(T_{P R L}\right)$ dos $n$ relés de PRL.

No âmbito do problema de minimização considerado, a métrica principal utilizada para avaliar os indivíduos é a própria somatória dos tempos de atuação dos relés de PRL, já que menores valores retornados pela função de avaliação representam indivíduos mais aptos. Contudo, a função de fitness possui ainda termos referentes à penalização das restrições eventualmente violadas no decorrer da busca pela solução de coordenação, tanto em relação ao bloco da PL $\left(P_{M T}\right)$, como referente ao bloco do AG propriamente dito, como é descrito no que segue.

A função de penalização $P_{A G}$, processada no bloco do $\mathrm{AG}$, calcula a violação relacionada à restrição imposta pelo ITC (Equação 8 do capítulo 2) entre os $i$ - ésimos pares de RDS de PRL e PRR. Logo, o valor de $P_{A G}$ atribuído a um dado cromossomo da população é calculado conforme a Equação 35.

$$
P_{A G}=\sum_{i}^{m} \mu\left(I T C-I T C_{i}{ }^{\prime}\right)
$$

Em que $\mu \in \mathbb{R}$ é um fator multiplicativo, determinado empiricamente, que pondera a magnitude da penalização aplicada e $I T C_{i}{ }^{\prime}$ é o valor calculado do ITC dos $m$ pares de RDS para um dado cromossomo associado. 
Agregando as funções de penalização do bloco da PL (Equação 28) e do bloco do AG (Equação 35) à função de avaliação $F_{\text {fitness. }}$, tem-se, para um dado cromossomo, o valor relativo à sua aptidão calculado pela Equação 36.

$$
F_{\text {fitness }}=\left(\sum_{j=1}^{n} T_{P R L_{j}}\right)+P_{M T}+P_{A G}
$$

Onde $T_{P R L_{j}}$ é o tempo de atuação do j-ésimo relé de PRL.

De acordo com o exposto, os termos referentes às penalizações na Equação 36, que tratam as violações das restrições inerentes ao processo de coordenação dos RDS, acabam por aumentar o valor retornado por $F_{\text {fitness }}$, e, no contexto do problema de minimização considerado, implicará em indivíduos avaliados como menos aptos à solução. Caso as restrições não sejam violadas, os valores de penalização, dados por $P_{M T}$ e $/ o u P_{A G}$ serão ambos nulo.

\subsection{3 - SELEÇÃo, ELITISMO, CROSSOVER E MUTAÇÃo}

O método de seleção utilizado no algoritmo híbrido de coordenação é o método do torneio, que consiste em eleger, aleatoriamente, uma série de indivíduos da população para competirem entre si, com o intuito de conquistarem o status de pais dos indivíduos da próxima geração. Um importante parâmetro deste método de seleção é o tamanho do torneio, denotado por $k$, que reflete a quantidade de indivíduos que competirão entre si a cada disputa. A quantidade de disputas é igual ao número de indivíduos da população, ou seja, para uma população com $c$ cromossomos, $k$ indivíduos serão selecionados aleatoriamente para disputarem $c$ vezes o status de serem pais da próxima geração (LINDEN, 2006).

Os cromossomos mais aptos vencem a disputa entre seus concorrentes, ou seja, a depender do valor de fitness atribuído a tais cromossomos pela função da Equação 36, um vencedor será determinado. Considerando o problema de minimização do tempo de atuação da PRL como meio para a obtenção da coordenação entre os RDS de um sistema malhado, e a maneira como foi formulada a função de avaliação (Equação 36), fica claro que o indivíduo mais apto, que consequentemente vencerá uma disputa, é o que melhor minimiza o valor da somatória dos tempos de atuação da PRL. 
Em geral, o método do torneio é mais eficiente comparado ao método da roleta viciada, o mais simples dos métodos de seleção, especialmente quando se utiliza o tamanho do torneio com dois indivíduos. O torneio mostra-se superior principalmente por ser pouco sensível a questões de escala da função de avaliação, quando os cromossomos possuem valores de avaliação muito próximos (LINDEN, 2006). Diante do exposto, adotou-se para o algoritmo de coordenação desenvolvido um tamanho de torneio $k=2$.

Após o processo de seleção, o tamanho da população permanece inalterado, sendo que ao longo das gerações tem-se a mesma quantidade de indivíduos inicialmente estabelecida. Ademais, é importante destacar que o conceito de elitismo, intimamente relacionado à formação na nova população, assim como o processo de seleção, foi aplicado no algoritmo desenvolvido, uma vez que pode oferecer benefícios na convergência do AG ao longo das gerações. O elitismo estabelece que os $m$ melhores indivíduos (em geral $m=1$ ) são necessariamente reproduzidos na próxima geração, visando garantir que seus genomas sejam preservados, aumentando o componente de memória para as boas soluções encontradas pelo AG (LINDEN, 2006). Partindo do pressuposto de não se alterar o tamanho $c$ da população, será possível gerar somente $(c-m)$ novos filhos para a próxima população.

Selecionados os pais, os operadores genéticos são aplicados, originando dessa forma os cromossomos da nova geração (filhos). Os operadores utilizados no algoritmo desta pesquisa é o operador de crossover de um ponto e o operador de mutação.

O operador de crossover de um ponto realiza o intercâmbio de uma determinada quantidade de genes entre os indivíduos pais, a depender do ponto de corte selecionado na estrutura do cromossomo, originando dois novos indivíduos com características distintas. Um indivíduo que possua $g$ genes em sua estrutura terá $(g-1)$ pontos de corte, a partir dos quais é possível separar o material genético em duas partes que serão permutadas entre os indivíduos pais. A ilustração da Figura 13 mostra como se dá a troca de material genético entre estes cromossomos.

A taxa de crossover entre os indivíduos pais é normalmente alta, possuindo uma probabilidade de $60 \%$ a $100 \%$. A principal função do operador de crossover é a combinação do material genético dos indivíduos mais aptos (pais) com o intuito de produzir soluções que contenham componentes de informações já exploradas no espaço de busca, fato que diferencia o AG de uma técnica de busca aleatória (GOLDBERG, 1989; NARA et al., 1992; GEN; CHENG, 1997; LINDEN, 2006).

Após a operação de recombinação genética entre os indivíduos pais, realizada pelo crossover de um ponto, uma pequena porcentagem, da ordem de 0,3\% a 0,5\% (NARA et al., 
1992; LINDEN, 2006), dos indivíduos filhos sofrerá uma mutação em um de seus genes. Nesta ação, o valor do gene em questão é alterado, modificando a aptidão do indivíduo afetado para a solução do problema formulado. Esta mutação tende a proporcionar a manutenção da diversidade genética ao longo das gerações do AG, atuando como uma heurística exploratória. A Figura 14 ilustra a operação de mutação gênica.

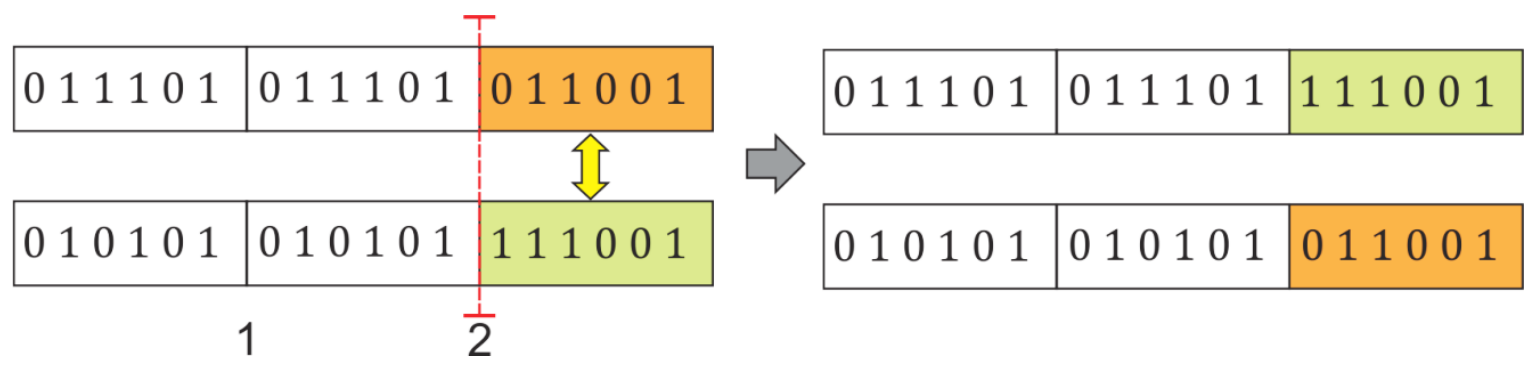

Figura 13 - Ilustração de um processo de crossover entre dois cromossomos de três genes $(g=3)$ e dois pontos de corte $(g-1)$.

Após o término da atuação de ambos os operadores genéticos está formada a nova população, que, no contexto do algoritmo híbrido desenvolvido, servirá de entrada para o bloco da PL a fim de se obter os valores otimizados para os MT. Com estes valores atualizados para os MT, os cromossomos com as correntes de pick-up mais recentes (referentes à última execução do AG antes da chamada do bloco da PL) são avaliados pela função de fitness e dá-se prosseguimento à aplicação dos operadores genéticos para a compilação da nova população, que servirá novamente como entrada para o bloco da PL na próxima geração (Figura 10). Este processo é repetido até que o número máximo de iterações estabelecido seja atingido, ou até que ambos os ajustes, de tempo e de corrente, impliquem em um valor da soma dos tempos de atuação da PRL que se estabilize com o passar das iterações.

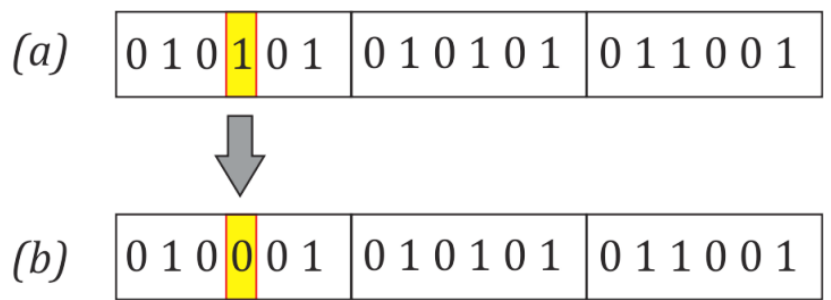

Figura 14 - Efeito da mutação sobre um bit de um dos genes do cromossomo, (a) antes da mutação; (b) após a mutação. 
Conforme mencionado anteriormente os ajustes calculados pelo algoritmo de coordenação devem respeitar os eventuais valores discretos disponíveis para ajuste dos RDS, principalmente os relés digitais. Logo, o algoritmo prevê o arredondamento para o valor inteiro mais próximo disponível para ajuste, de modo que sua factibilidade é verificada, antes da atribuição do valor de fitness pela a cada iteração.

Ademais, é válido destacar que a otimização combinada da PL e do AG proporciona uma melhor exploração no espaço de busca das soluções factíveis, uma vez que é uma característica inerente aos AG utilizarem informações de soluções analisadas nas gerações passadas. Portanto, a probabilidade de convergência para mínimos locais, como acontece em certos métodos tradicionais, é reduzida. Além disso, a modelagem matemática do problema de coordenação pode ser facilmente realizada, uma vez que é implicitamente considerado no processo evolutivo do AG. 


\section{5 - RESUltadOS}

Neste capítulo, o sistema elétrico utilizado para testes é apresentado com maiores detalhes. No item 5.1.1 encontra-se o conjunto de dados referente aos cálculos de curtoscircuitos realizados via o software CAPE, utilizado para obtenção e validação da coordenação da topologia principal de operação. Já no item 5.1.2, tem-se todos os cálculos referentes aos limites operativos do SEP teste, como discutido anteriormente no item 3.2.2. Em seguida, no item 5.1.3, apresenta-se a análise efetuada para a definição dos parâmetros do algoritmo híbrido de coordenação em relação à sua função de fitness, bem como a investigação acerca do tamanho da população de cromossomos e estudo da convergência para a solução de coordenação factível, disponibilizada pelo algoritmo híbrido de coordenação.

Para o item 5.1.4, reserva-se a verificação da consistência da parametrização obtida para a topologia principal de operação. A avaliação do emprego desta parametrização frente às variações topológicas consideradas é discutida no item 5.1.5. Por fim, no item 5.1.6, tem-se a proposição de novos ajustes para uma variação da topologia, dentre as 11 avaliadas, em relação à principal.

\section{1 - SiSTEMA ELÉTRICO TESTE}

O sistema elétrico utilizado para teste e desenvolvimento do algoritmo de coordenação diz respeito a uma área específica de um sistema de subtransmissão de $138 \mathrm{kV}$ conectado à rede básica brasileira sob concessão da CTEEP. Este sistema teste possui 43 barras (incluindo-se as barras de derivações e barras auxiliares), 11 LT e 22 RDS.

A Figura 15 proporciona uma visão geral do diagrama unifilar do sistema teste, obtido por meio da interface gráfica do software CAPE em conjunto com a base de dados de curtos-circuitos no formato ANAFAS disponibilizada pelo ONS. Cabe ressaltar que embora na Figura 15 estejam representadas barras de derivações e auxiliares do sistema, estas não são relevantes para o estudo da coordenação dos RDS. Sendo assim, para uma melhor visualização do sistema teste estudado, na Figura 16, tem-se uma versão simplificada da representação do diagrama unifilar, em que se identificam as LT (de L1 a LT11) com os respectivos 22 RDS associados (R1 a R22). Além disso, conforme mencionado anteriormente, 
o sistema teste possui conexões com o restante da rede básica brasileira que, embora não explicitadas nos digramas unifilares da Figura 15 e da Figura 16, estas sim exercerão influência nos resultados dos estudos de curtos-circuitos utilizados no processo de coordenação dos RDS.

Todos os dados referentes ao sistema elétrico analisado podem ser encontrados na versão $B R 1206 B$ da base de dados para estudos de curto-circuito do ONS disponibilizada no formato ANAFAS (ONS, 2013). Entretanto, para uma apresentação mais adequada dos dados do sistema, tais como, os dados de linha, dados de barra e das impedâncias mútuas, foram realizados os cálculos para a obtenção do equivalente do restante da rede básica do sistema via CAPE, retendo-se as 34 barras de interesse relevantes para o estudo de coordenação. Os dados do sistema, fornecidos pelo CAPE no formato ANAFAS (CEPEL, 2011) estão apresentados na seção Anexos (Anexo A, B e C), pelas Tabelas 30, 31 e 32, respectivamente.

A partir da inspeção topológica referente à configuração principal de operação realizada no sistema teste, utilizando a matriz de incidência, explicada no item 3.1, obtém-se os pares de RDS que serão coordenados. Estes pares de RDS estão apresentados na Tabela 3, sendo a primeira coluna referente aos relés de PRL e a segunda referente aos relés de PRR. Para o relé R16 de PRL, tem-se, por exemplo, os seguintes pares: R16 e R11; R16 e R13 e R16 e R19.

Tabela 3 - Pares de RDS calculados para a topologia principal de operação do sistema teste.

\begin{tabular}{cc}
\hline PRL & PRR \\
\hline R1 & R4 \\
R2 & R3, R6, R10, R12, R14 \\
R3 & R2 \\
R4 & R1, R6, R10, R12, R14 \\
R5 & R1, R3, R10, R12, R14 \\
R6 & R5 \\
R7 & R9 \\
R8 & $\mathrm{R}$ R1, R3, R6, R14 \\
R9 & $\mathrm{R} 1, \mathrm{R} 3, \mathrm{R} 6, \mathrm{R} 10, \mathrm{R} 14$ \\
R10 & $\mathrm{R} 13, \mathrm{R} 15, \mathrm{R} 19$ \\
R11 & $\mathrm{R} 1, \mathrm{R} 3, \mathrm{R} 6, \mathrm{R} 10, \mathrm{R} 12$ \\
R12 & $\mathrm{R} 11, \mathrm{R} 15, \mathrm{R} 19$ \\
R13 & $\mathrm{R} 17$ \\
R14 & $\mathrm{R} 11, \mathrm{R} 13, \mathrm{R} 19$ \\
R15 & $\mathrm{R} 22$ \\
R16 & $\mathrm{R} 16$ \\
R17 & $\mathrm{R} 21$ \\
R18 & $\mathrm{R} 11, \mathrm{R} 13, \mathrm{R} 15$ \\
R19 & $\mathrm{R} 18$ \\
R20 & $\mathrm{R} 20$ \\
R21
\end{tabular}




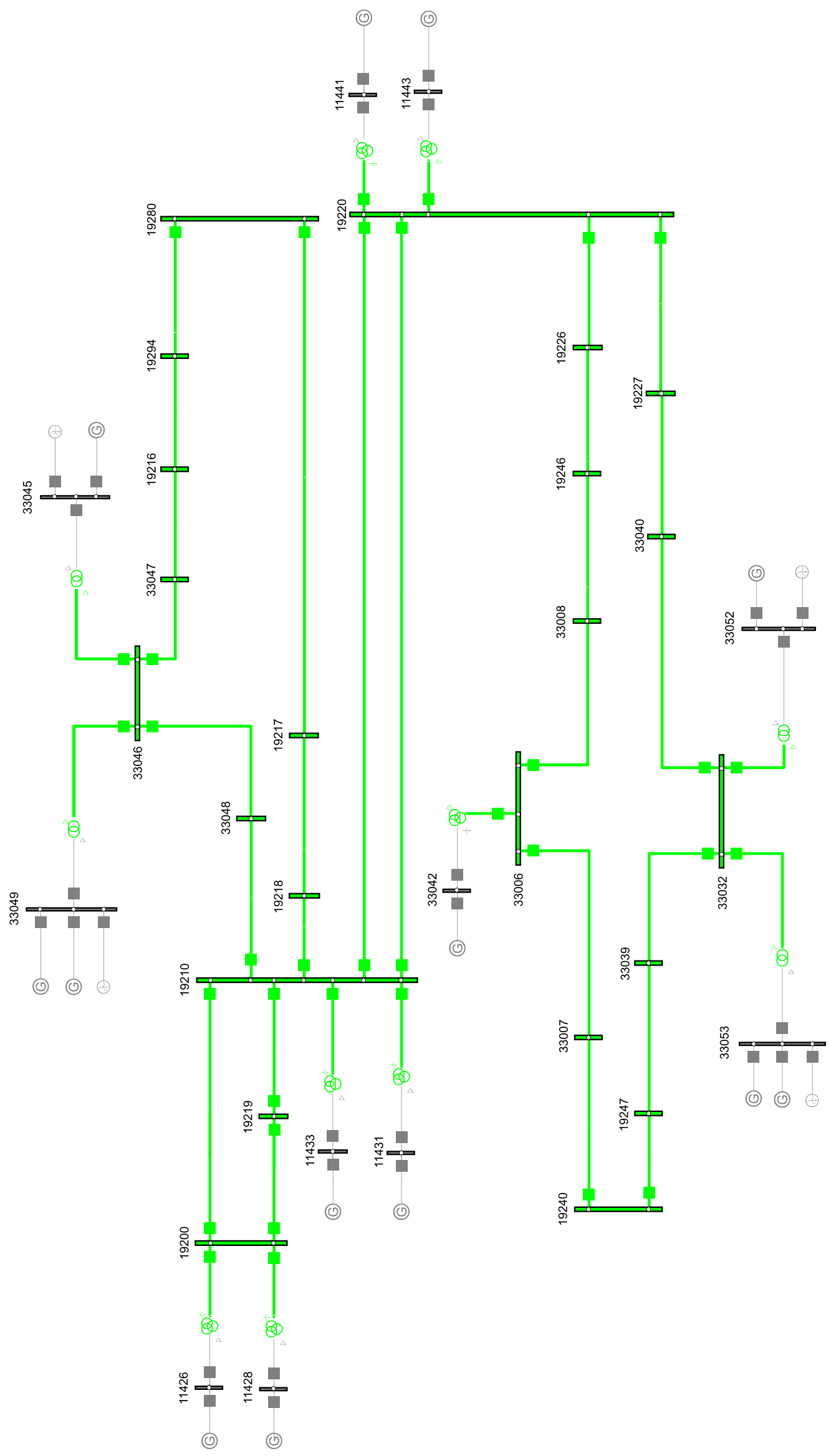

Figura 15 - Diagrama unifilar do sistema teste referente à porção de um sistema de subtransmissão de 138 $\mathrm{kV}$ conectado à rede básica brasileira sob concessão da CTEEP. 


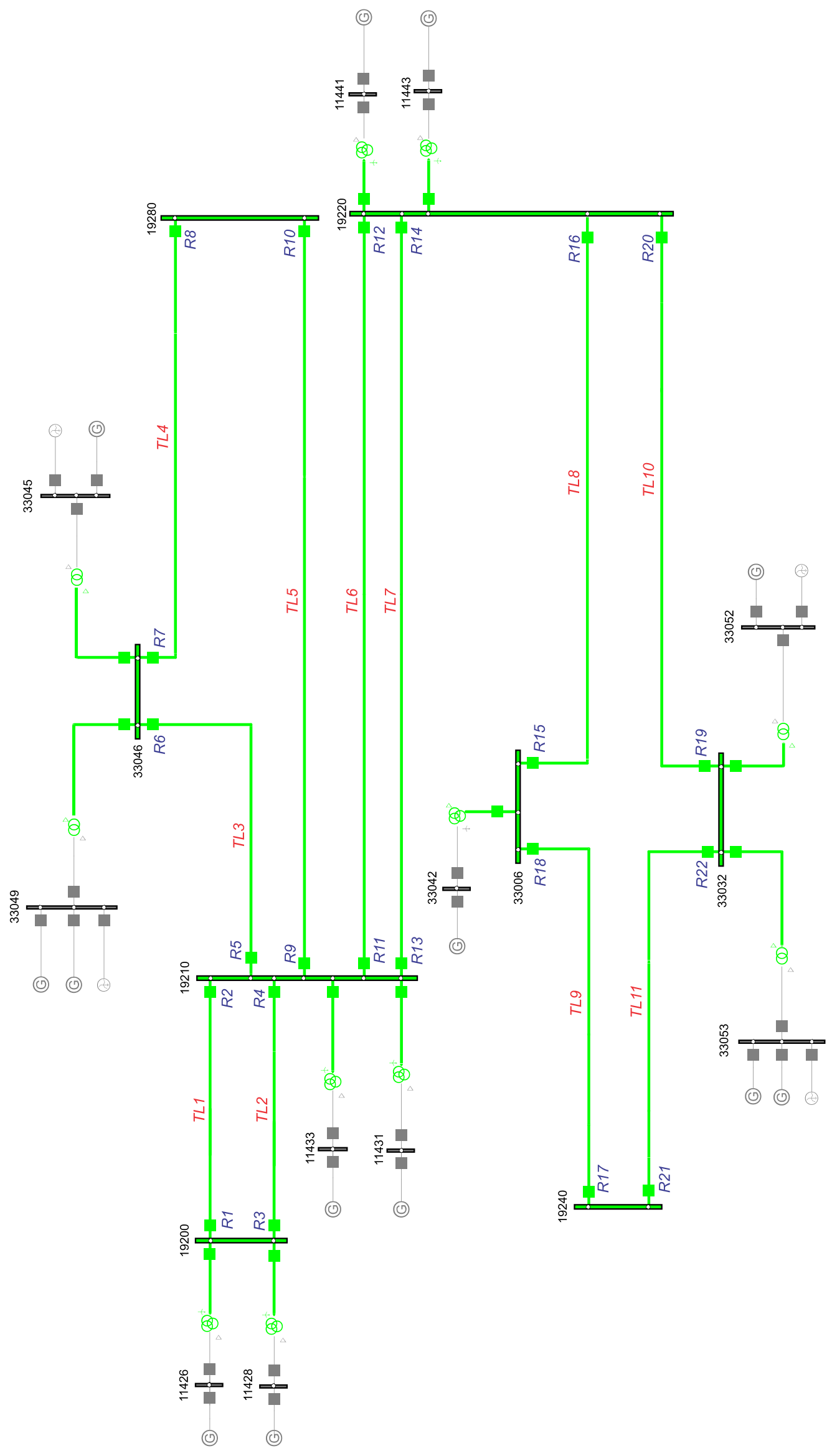

Figura 16 - Representação simplificada do diagrama unifilar do sistema teste em que se identificam as 11 LT e os 22 RDS envolvidos no processo de coordenação. 
Conforme mencionado, o sistema elétrico teste possui 22 RDS. Para este trabalho, considerou-se que todos os relés possuem faixas de ajustes idênticas, tanto para a corrente de partida como para o MT. Tomando como base as principais características de ajuste de um modelo de relé digital, o tap para ajuste da corrente de pickup varia de 0,5 a 20, com passos discretos de 0,01. Já o MT varia de 0,05 a 3,2 em passos discretos de 0,01 (SIEMENS, 2007). Cabe ressaltar que embora neste trabalho os relés considerados para o teste possuam faixas de ajustes idênticas, o algoritmo desenvolvido é capaz de tratar faixas de ajustes distintas para cada relé com passos uniformes, porém, não necessariamente idênticos. Além disso, é importante destacar que as curvas de tempo inverso dos relés mencionados são do tipo normal inversa, obedecendo à norma IEC 60255-3 (1989), como mostrado na Tabela 1.

Diante do valor do passo dos intervalos das correntes de partida e dos MT, adotou-se uma precisão de duas casas decimais $(\varepsilon=2)$ para a representação binária dos cromossomos (Equação 30).

\subsection{1 - CÁlCULO DAS CORRENTES DE CURTOS-CIRCUITOS}

Conforme anteriormente discutido, o módulo de curto-circuito do programa $C A P E$ foi utilizado para o cálculo das situações de curtos-circuitos consideradas para a obtenção da coordenação entre os pares de RDS via algoritmo híbrido de coordenação. Cabe destacar que para todos os estudos de curtos-circuitos a tensão de pré-falta é de $1 \angle 0^{\circ}$ p.u.

A Tabela 4, que foi dividida em duas partes para uma melhor visualização, revela as correntes de curtos-circuitos medidas tanto pelos relés de PRL como de PRR, dados os pares de RDS, identificados nas quatro colunas preenchidas com a cor cinza na mesma tabela, para a topologia principal de operação.

A mínima condição de sensibilização de um dado relé é determinada pela mínima

corrente de partida que se pode ajustar $\left(I_{p, \min }\right)$. Isto é, dada à ocorrência de um curto-circuito, a respectiva corrente medida pelo relé precisa ser suficientemente elevada para que resulte em um múltiplo de corrente mínimo de 1,5 vezes a corrente $I_{p, \min }$. Caso contrário, se a corrente de curto-circuito resultar em um múltiplo de corrente de partida inferior a 1,5, o relé pode ter seu tempo de atuação demasiadamente prolongado. Esta situação deve ser verificada, principalmente, quando o relé atua como PRR, pois nesta condição estará sujeito a correntes de curtos-circuitos menos intensas e que se aproximam de $I_{p, \min }$. 
Para melhor expor a situação de mínima condição de sensibilização, a Tabela 5 revela as mínimas correntes de sensibilização $\left(I_{\min , s}\right)$ que cada relé deve estar sujeito para participar do processo de coordenação.

Levando em conta os valores das correntes de mínima sensibilização, afirma-se que os pares cujos relés de PRR e /ou de PRL observem uma corrente menor do que $I_{\min , s}$ serão excluídos do processo de coordenação. Sendo assim, os pares de relés efetivamente considerados no processo de coordenação estão mostrados na Tabela 6.

Tabela 4 - Valor das correntes de curtos-circuitos obtido via CAPE para a topologia principal de operação.

\begin{tabular}{|c|c|c|c|c|c|c|c|}
\hline PRL & PRR & $\begin{array}{c}I_{C C, \text { local }} \\
\text { (A) }\end{array}$ & $\begin{array}{c}I_{C C, \text { rem }} \\
\text { (A) }\end{array}$ & PRL & PRR & $\begin{array}{c}I_{C C, \text { local }} \\
\text { (A) }\end{array}$ & $\begin{array}{l}I_{C C, \text { rem }} \\
\text { (A) }\end{array}$ \\
\hline R1 & R4 & $3.137,2$ & $2.120,2$ & R11 & R3 & 8.152 & 470,8 \\
\hline R2 & R3 & $9.201,1$ & 420,1 & R11 & R6 & 8.152 & $1.775,9$ \\
\hline R2 & R6 & $9.201,1$ & $1.742,8$ & R11 & R10 & 8.152 & 2.120 \\
\hline R2 & R10 & $9.201,1$ & $2.080,5$ & R11 & R14 & 8.152 & $1.640,4$ \\
\hline R2 & $\mathrm{R} 12$ & $9.201,1$ & $1.654,5$ & $\mathrm{R} 12$ & R13 & $6.461,2$ & $2.796,6$ \\
\hline R2 & R14 & $9.201,1$ & $1.654,5$ & $\mathrm{R} 12$ & R15 & $6.461,2$ & $1.752,8$ \\
\hline R3 & R2 & $3.137,2$ & $2.120,2$ & $\mathrm{R} 12$ & R19 & $6.461,2$ & $1.518,9$ \\
\hline $\mathrm{R} 4$ & R1 & $9.201,1$ & 420,1 & $\mathrm{R} 13$ & R1 & 8.152 & 470,8 \\
\hline $\mathrm{R} 4$ & R6 & $9.201,1$ & $1.742,8$ & $\mathrm{R} 13$ & R3 & 8.152 & 470,8 \\
\hline $\mathrm{R} 4$ & R10 & $9.201,1$ & $2.080,5$ & $\mathrm{R} 13$ & R6 & 8.152 & $1.775,9$ \\
\hline R4 & R12 & $9.201,1$ & $1.654,5$ & R13 & $\mathrm{R} 10$ & 8.152 & 2.120 \\
\hline R4 & R14 & $9.201,1$ & $1.654,5$ & R13 & $\mathrm{R} 12$ & 8.152 & $1.640,4$ \\
\hline R5 & R1 & $7.960,2$ & 462,3 & R14 & R11 & $6.461,2$ & $2.796,6$ \\
\hline R5 & R3 & $7.960,2$ & 462,3 & R14 & R15 & $6.461,2$ & $1.752,8$ \\
\hline R5 & R10 & $7.960,2$ & $2.074,4$ & R14 & R19 & $6.461,2$ & $1.518,9$ \\
\hline R5 & $\mathrm{R} 12$ & $7.960,2$ & $1.655,3$ & R15 & $\mathrm{R} 17$ & $5.878,5$ & $5.326,2$ \\
\hline R5 & R14 & $7.960,2$ & $1.655,3$ & R16 & R11 & $7.416,4$ & $2.775,1$ \\
\hline R6 & R8 & $4.545,9$ & $3.775,6$ & R16 & R13 & $7.416,4$ & $2.775,1$ \\
\hline R7 & R5 & $3.101,5$ & $2.321,1$ & R16 & R19 & $7.416,4$ & $1.478,2$ \\
\hline R8 & R9 & $15.980,3$ & $1.515,5$ & $\mathrm{R} 17$ & R22 & $11.993,4$ & 1.521 \\
\hline R9 & R1 & $7.596,3$ & 460 & R18 & R16 & $2.508,8$ & $1.941,4$ \\
\hline R9 & R3 & $7.596,3$ & 460 & R19 & R21 & 4.489 & $3.691,6$ \\
\hline R9 & R6 & $7.596,3$ & 1.726 & R20 & R11 & $7.627,6$ & $2.769,5$ \\
\hline R9 & $\mathrm{R} 12$ & $7.596,3$ & $1.647,1$ & R20 & R13 & $7.627,6$ & $2.769,5$ \\
\hline R9 & R14 & $7.596,3$ & $1.647,1$ & R20 & R15 & $7.627,6$ & $1.703,1$ \\
\hline R10 & R7 & $15.525,7$ & $1.426,6$ & R21 & R18 & $1.2072,8$ & $1.736,2$ \\
\hline R11 & R1 & 8.152 & 470,8 & R22 & R20 & $2.706,4$ & $1.919,3$ \\
\hline
\end{tabular}


Tabela 5 - Condição mínima de sensibilização dos RDS para a topologia principal de operação.

\begin{tabular}{cc}
\hline RDS & $\boldsymbol{I}_{\boldsymbol{m i n}, \boldsymbol{s}}(\mathbf{A})$ \\
\hline R1 & 603 \\
R2 & 693 \\
R3 & 603 \\
R4 & 693 \\
R5 & 597,6 \\
R6 & 520,2 \\
R7 & 520,2 \\
R8 & $1.198,8$ \\
R9 & 599,4 \\
R10 & $1.166,4$ \\
R11 & 612 \\
R12 & 520,8 \\
R13 & 612 \\
R14 & 520,8 \\
R15 & 600 \\
R16 & 600 \\
R17 & 900 \\
R18 & 542,4 \\
R19 & 600 \\
R20 & 600 \\
R21 & 906,3 \\
R22 & 540 \\
\hline &
\end{tabular}

Tabela 6 - Valor das correntes de curtos-circuitos obtido via $C A P E$ para a topologia principal de operação considerando a condição mínima de sensibilização dos RDS.

\begin{tabular}{|c|c|c|c|c|c|c|c|}
\hline$P R L$ & $P R R$ & $\begin{array}{c}I_{C C, \text { local }} \\
\text { (A) }\end{array}$ & $\begin{array}{l}I_{C C, \text { rem }} \\
\text { (A) }\end{array}$ & $P R L$ & PRR & $\begin{array}{c}I_{C C, \text { local }} \\
\text { (A) }\end{array}$ & $\begin{array}{c}I_{C C, \text { rem }} \\
\text { (A) }\end{array}$ \\
\hline R1 & $\mathrm{R} 4$ & $3.137,2$ & $2.120,2$ & R11 & R14 & 8.152 & $1.640,4$ \\
\hline R2 & R6 & $9.201,1$ & $1.742,8$ & R12 & $\mathrm{R} 13$ & $6.461,2$ & $2.796,6$ \\
\hline R2 & R10 & $9.201,1$ & $2.080,5$ & R12 & R15 & $6.461,2$ & $1.752,8$ \\
\hline R2 & $\mathrm{R} 12$ & $9.201,1$ & $1.654,5$ & R12 & R19 & $6.461,2$ & $1.518,9$ \\
\hline R2 & R14 & $9.201,1$ & $1.654,5$ & R13 & R6 & 8.152 & $1.775,9$ \\
\hline R3 & R2 & $3.137,2$ & $2.120,2$ & R13 & $\mathrm{R} 10$ & 8.152 & 2.120 \\
\hline $\mathrm{R} 4$ & R6 & $9.201,1$ & $1.742,8$ & $\mathrm{R} 13$ & $\mathrm{R} 12$ & 8.152 & $1.640,4$ \\
\hline $\mathrm{R} 4$ & $\mathrm{R} 10$ & $9.201,1$ & $2.080,5$ & R14 & R11 & $6.461,2$ & $2.796,6$ \\
\hline $\mathrm{R} 4$ & $\mathrm{R} 12$ & $9.201,1$ & $1.654,5$ & R14 & $\mathrm{R} 15$ & $6.461,2$ & $1.752,8$ \\
\hline $\mathrm{R} 4$ & $\mathrm{R} 14$ & $9.201,1$ & $1.654,5$ & R14 & R19 & $6.461,2$ & $1.518,9$ \\
\hline R5 & R10 & $7.960,2$ & $2.074,4$ & $\mathrm{R} 15$ & R17 & $5.878,5$ & $5.326,2$ \\
\hline R5 & $\mathrm{R} 12$ & $7.960,2$ & $1.655,3$ & R16 & R11 & $7.416,4$ & $2.775,1$ \\
\hline R5 & $\mathrm{R} 14$ & $7.960,2$ & $1.655,3$ & R16 & R13 & $7.416,4$ & $2.775,1$ \\
\hline R6 & $\mathrm{R} 8$ & $4.545,9$ & $3.775,6$ & R16 & R19 & $7.416,4$ & $1.478,2$ \\
\hline $\mathrm{R} 7$ & R5 & $3.101,5$ & $2.321,1$ & $\mathrm{R} 17$ & $\mathrm{R} 22$ & $11.993,4$ & 1.521 \\
\hline $\mathrm{R} 8$ & R9 & $15.980,3$ & $1.515,5$ & $\mathrm{R} 18$ & $\mathrm{R} 16$ & $2.508,8$ & $1.941,4$ \\
\hline R9 & R6 & $7.596,3$ & 1.726 & R19 & $\mathrm{R} 21$ & 4.489 & $3.691,6$ \\
\hline R9 & $\mathrm{R} 12$ & $7.596,3$ & $1.647,1$ & R20 & R11 & $7.627,6$ & $2.769,5$ \\
\hline R9 & $\mathrm{R} 14$ & $7.596,3$ & $1.647,1$ & R20 & $\mathrm{R} 13$ & $7.627,6$ & $2.769,5$ \\
\hline $\mathrm{R} 10$ & R7 & $15.525,7$ & $1.426,6$ & R20 & $\mathrm{R} 15$ & $7.627,6$ & $1.703,1$ \\
\hline R11 & R6 & 8.152 & $1.775,9$ & $\mathrm{R} 21$ & $\mathrm{R} 18$ & $12.072,8$ & $1.736,2$ \\
\hline $\mathrm{R} 11$ & $\mathrm{R} 10$ & 8.152 & 2.120 & $\mathrm{R} 22$ & $\mathrm{R} 20$ & $2.706,4$ & $1.919,3$ \\
\hline
\end{tabular}




\subsection{2 - CÁLCULO DOS LIMITES OPERATIVOS}

Conforme descrito no item 3.2.2, a definição dos limites operativos é essencial para a delimitação do espaço de busca das soluções factíveis. No que segue, estão apresentados os cálculos necessários à formação do intervalo da corrente de pick-up (Equação 21) e do intervalo dos MT (Equação 23). Cabe ressaltar que todos os valores calculados e apresentados neste item respeitam os intervalos discretos presentes no modelo de RDS escolhido para o sistema teste, ou seja, são considerados os valores inteiros mais próximos, tanto para o tap de corrente de partida como para os MT.

Considerando-se as características dos relés apresentadas no item 5.2 dos RDS utilizados para o sistema teste, calculam-se as correntes de partida mínima $\left(I_{p, \text { min }}^{R D S}\right)$ e máxima $\left(I_{p, \max }^{R D S}\right)$ que podem ser ajustadas no RDS, utilizando-se, respectivamente, a Equação 13 e a Equação 14. Os resultados destes cálculos estão apresentados na Tabela 7, em que se tem na primeira coluna a identificação do relé, na segunda coluna o valor da $R T C$ associada e, nas duas últimas colunas, os valores da mínima e máxima corrente de partida, respectivamente.

Os dados da Tabela 8 trazem informações acerca das capacidades nominais das LT, e seus respectivos bays, identificados na primeira e segunda coluna, que compõem o sistema teste deste trabalho. Ainda na Tabela 8, da terceira coluna até a sétima coluna, tem-se a capacidade nominal dos componentes do bays em questão, conforme mencionado no item 3.2.2. Ressalta-se que estes valores foram obtidos por meio de relatórios técnicos necessários ao desenvolvimento desta pesquisa e do projeto de P\&D firmado com a CTEEP (CTEEP-PD0068-0020/2011). Além disso, conforme é possível constatar, alguns condutores que compõem os bays das extremidades de certas LT possuem capacidades nominais distintas, indicando que a LT é composta por segmentos distintos e/ou possui derivações ao longo de seu comprimento. Utilizando a Equação 15 é possível determinar qual o máximo de corrente que se admite circular em cada LT em uma condição de operação do sistema considerada normal $\left(I_{\text {nom,RDS }}\right)$. Estes valores estão registrados na oitava coluna da Tabela 8. Na última coluna da Tabela 8 tem-se aplicada a margem de segurança de $20 \%$ sobre $I_{\text {nom,RDS }}$, como determinado pela Equação 16. Entre parênteses nesta mesma coluna estão os valores referentes à aproximação para o valor inteiro superior mais próximo, dado em função da $R T C$ e tap associados ao respectivo RDS. 
Tabela 7 - RTC de cada RDS, corrente mínima e máxima de partida que podem ser ajustadas.

\begin{tabular}{cccc}
\hline RDS & $\boldsymbol{R T C}$ & $\boldsymbol{I}_{\boldsymbol{p}, \boldsymbol{m i n}}^{\boldsymbol{R D \boldsymbol { S }}}(\mathbf{A})$ & $\boldsymbol{I}_{\boldsymbol{p}, \boldsymbol{m} \boldsymbol{m} \boldsymbol{a x}}(\mathrm{A})$ \\
\hline $\mathrm{R} 1$ & $600 / 1$ & 300 & 12.000 \\
$\mathrm{R} 2$ & $600 / 1$ & 300 & 12.000 \\
$\mathrm{R} 3$ & $600 / 1$ & 300 & 12.000 \\
$\mathrm{R} 4$ & $600 / 1$ & 300 & 12.000 \\
$\mathrm{R} 5$ & $600 / 5$ & 60 & 2.400 \\
$\mathrm{R} 6$ & $600 / 5$ & 60 & 2.400 \\
$\mathrm{R} 7$ & $600 / 5$ & 60 & 2.400 \\
$\mathrm{R} 8$ & $1200 / 5$ & 120 & 4.800 \\
$\mathrm{R} 9$ & $600 / 5$ & 60 & 2.400 \\
$\mathrm{R} 10$ & $800 / 5$ & 80 & 3.200 \\
$\mathrm{R} 11$ & $600 / 1$ & 300 & 12.000 \\
$\mathrm{R} 12$ & $400 / 5$ & 40 & 1.600 \\
$\mathrm{R} 13$ & $600 / 1$ & 300 & 12.000 \\
$\mathrm{R} 14$ & $400 / 5$ & 40 & 1.600 \\
$\mathrm{R} 15$ & $1600 / 5$ & 160 & 6.400 \\
$\mathrm{R} 16$ & $400 / 5$ & 40 & 1.600 \\
$\mathrm{R} 17$ & $600 / 5$ & 60 & 2.400 \\
$\mathrm{R} 18$ & $1600 / 5$ & 160 & 6.400 \\
$\mathrm{R} 19$ & $400 / 5$ & 40 & 1.600 \\
$\mathrm{R} 20$ & $400 / 5$ & 40 & 1.600 \\
$\mathrm{R} 21$ & $600 / 5$ & 60 & 2.400 \\
$\mathrm{R} 22$ & $400 / 5$ & 40 & 1.600 \\
\hline
\end{tabular}

Para a coordenação dos RDS do sistema teste foi escolhido um múltiplo mínimo da corrente de pick-up de 1,5 $\left(M_{\min }=1,5\right)$ e, para o múltiplo máximo, fixou-se o mesmo em 20 $\left(M_{\max }=20\right)$. Logo, aplicando a Equação 17, encontra-se a mínima corrente de ajuste que limita o máximo múltiplo da corrente de partida $\left(I_{M_{\max }}\right)$ que o algoritmo híbrido pode calcular. Em seguida, com a Equação 18, tem-se a delimitação do extremo inferior do intervalo da corrente de partida $\left(I_{p, \min }\right)$, que é o mínimo entre $I_{\text {nom,RDS }}^{20 \%}$ considerando-se os valores já aproximados para o inteiro superior mais próximo e $I_{M_{\max }}$. A Tabela 9 traz estas informações da segunda até a quarta coluna, sendo que, na terceira coluna, entre parênteses, estão registrados os valores aproximados para o inteiro mais próximo a partir das correntes calculadas pela Equação 16.

Analogamente, empregando-se a Equação 19, ou a Equação 20, conforme condições explicadas no item 3.2.2, tem-se o valor da corrente de partida $I_{M_{\min }}$ que garante o mínimo múltiplo para corrente de partida $M_{\min }$. Por fim, pela Equação 21, encontra-se o limite 
superior do intervalo da corrente de partida $\left(I_{p, \max }\right)$, que é exatamente o mínimo valor entre $I_{p, \max }^{R D S}\left(\right.$ Tabela 7) e $I_{M_{\min }}$. A Tabela 9 traz estas informações nas três últimas colunas.

Tabela 8 - Capacidades nominais das LT e seus respectivos bays.

\begin{tabular}{|c|c|c|c|c|c|c|c|c|}
\hline $\mathbf{L T}$ & $\begin{array}{l}\text { Bay/ } \\
\text { RDS }\end{array}$ & $\begin{array}{l}I_{\text {nom,disj }} \\
\text { (A) }\end{array}$ & $\begin{array}{c}I_{\text {nom,secc }} \\
\text { (A) }\end{array}$ & $\begin{array}{c}I_{\text {nom }, \text { bloq }} \\
\text { (A) }\end{array}$ & $\begin{array}{l}I_{\text {nom } T C} \\
\text { (A) }\end{array}$ & $\begin{array}{l}I_{\text {nom,cond }} \\
\text { (A) }\end{array}$ & $\begin{array}{c}I_{\text {nom }, R D S} \\
\text { (A) }\end{array}$ & $\begin{array}{l}I_{\text {nom }, R D S}^{20 \%} \\
\text { (A) }\end{array}$ \\
\hline \multirow{2}{*}{ LT1 } & 1 & 1.000 & 600 & 630 & 600 & 333 & \multirow{2}{*}{333} & $399,6(402)$ \\
\hline & 2 & 1.000 & 600 & 630 & 600 & 333 & & $399,6(402)$ \\
\hline \multirow{2}{*}{ LT2 } & 3 & 1.000 & 600 & 630 & 600 & 333 & \multirow{2}{*}{333} & $399,6(402)$ \\
\hline & 4 & 1.000 & 600 & 630 & 600 & 333 & & $399,6(402)$ \\
\hline \multirow{2}{*}{ LT3 } & 5 & 1.000 & 600 & 1.250 & 600 & 289 & \multirow{2}{*}{289} & $346,8(346,8)$ \\
\hline & 6 & 2.000 & 2.000 & 1.250 & 600 & 860 & & $346,8(346,8)$ \\
\hline \multirow{2}{*}{ LT4 } & 7 & 2.000 & 2.000 & 1.250 & 600 & 860 & \multirow{2}{*}{289} & $346,8(346,8)$ \\
\hline & 8 & 3.150 & 800 & - & 800 & 289 & & $346,8(348)$ \\
\hline \multirow{2}{*}{ LT5 } & 9 & 1.000 & 600 & 630 & 600 & 333 & \multirow{2}{*}{333} & $399,6(399,6)$ \\
\hline & 10 & 3.150 & 800 & 630 & 800 & 333 & & $399,6(400)$ \\
\hline \multirow{2}{*}{ LT6 } & 11 & 1.000 & 600 & - & 600 & 289 & \multirow{2}{*}{289} & $346,8(348)$ \\
\hline & 12 & 1.600 & 500 & - & 400 & 289 & & $346,8(346,8)$ \\
\hline \multirow{2}{*}{ LT7 } & 13 & 1.000 & 600 & 400 & 600 & 289 & \multirow{2}{*}{289} & $346,8(348)$ \\
\hline & 14 & 1.600 & 500 & 400 & 400 & 289 & & $346,8(346,8)$ \\
\hline \multirow{2}{*}{ LT8 } & 15 & 2.000 & 2.000 & - & 400 & 860 & \multirow{2}{*}{333} & $399,6(400)$ \\
\hline & 16 & 1.600 & 500 & 630 & 400 & 333 & & $399,6(400)$ \\
\hline \multirow{2}{*}{ LT9 } & 17 & 2.000 & 2.000 & - & 1.600 & 380 & \multirow{2}{*}{300} & $360(360)$ \\
\hline & 18 & 1.000 & 600 & 630 & 300 & 333 & & $360(361,6)$ \\
\hline \multirow{2}{*}{ LT10 } & 19 & 1.600 & 500 & 630 & 400 & 333 & \multirow{2}{*}{333} & $399,6(400)$ \\
\hline & 20 & 2.000 & 2.000 & - & 400 & 860 & & $399,6(400)$ \\
\hline \multirow{2}{*}{ LT11 } & 21 & 1.000 & 600 & 630 & 300 & 333 & \multirow{2}{*}{300} & $360(360)$ \\
\hline & 22 & 2.000 & 2.000 & 1.250 & 400 & 860 & & $360(360)$ \\
\hline
\end{tabular}

Definidas as faixas de ajuste da corrente de partida para cada relé, definem-se os intervalos de ajuste dos MT. Pela Equação 22, obtém-se o limite inferior do intervalo $\left(M T_{\min }\right.$, que respeita todas as condições impostas pela atuação prioritária da proteção de distância (proteção primária), como discutido no item 2.2 e no item 3.2.2. O limite superior para o intervalo de ajuste dos MT é, simplesmente, determinado segundo o máximo valor disponível para ajuste no RDS em questão $\left(M T_{\max }\right)$.

A Tabela 10 registra os valores que determinam a faixa de ajuste dos MT para todos os relés presentes no sistema em análise. 
Tabela 9 - Definição dos limites da faixa de ajuste da corrente de partida para a topologia principal de operação.

\begin{tabular}{|c|c|c|c|c|c|c|}
\hline RDS & $I_{M_{\max }}(\mathrm{A})$ & $I_{n o m, R D S}^{20 \%}(\mathrm{~A})$ & $I_{p, \min }(\mathrm{A})$ & $I_{p, \max }^{R D S}(\mathrm{~A})$ & $I_{M_{\min }}(\mathrm{A})$ & $I_{p, \max }(\mathrm{A})$ \\
\hline R1 & 162 & $399,6(402)$ & 402 & 12.000 & 2.088 & 2.088 \\
\hline $\mathrm{R} 2$ & 462 & $399,6(402)$ & 462 & 12.000 & 1.410 & 1.410 \\
\hline R3 & 162 & $399,6(402)$ & 402 & 12.000 & 2.088 & 2.088 \\
\hline $\mathrm{R} 4$ & 462 & $399,6(402)$ & 462 & 12.000 & 1.410 & 1.410 \\
\hline R5 & 398,4 & $346,8(346,8)$ & 398,4 & 2.400 & $1.546,8$ & $1.546,8$ \\
\hline R6 & 228 & $346,8(346,8)$ & 346,8 & 2.400 & $1.149,6$ & $1.149,6$ \\
\hline R7 & 156 & $346,8(346,8)$ & 346,8 & 2.400 & 950,4 & 950,4 \\
\hline R8 & 799,2 & $346,8(348)$ & 799,2 & 4.800 & $2.515,2$ & $2.515,2$ \\
\hline R9 & 380,4 & $399,6(399,6)$ & 399,6 & 2.400 & $1.009,2$ & $1.009,2$ \\
\hline $\mathrm{R} 10$ & 777,6 & $399,6(400)$ & 777,6 & 3.200 & $1.382,4$ & $1.382,4$ \\
\hline $\mathrm{R} 11$ & 408 & $346,8(348)$ & 408 & 12.000 & 1.842 & 1.842 \\
\hline $\mathrm{R} 12$ & 323,2 & $346,8(346,8)$ & 347,2 & 1.600 & $1.093,6$ & $1.093,6$ \\
\hline $\mathrm{R} 13$ & 408 & $346,8(348)$ & 408 & 12.000 & 1.842 & 1.842 \\
\hline R14 & 323,2 & $346,8(346,8)$ & 347,2 & 1.600 & $1.093,6$ & $1.093,6$ \\
\hline $\mathrm{R} 15$ & 294,4 & $399,6(400)$ & 400 & 6.400 & $1.132,8$ & $1.132,8$ \\
\hline R16 & 371,2 & $399,6(400)$ & 400 & 1.600 & $1.293,6$ & $1.293,6$ \\
\hline $\mathrm{R} 17$ & 600 & $360(360)$ & 600 & 2.400 & $3.550,8$ & 2.400 \\
\hline R18 & 128 & $360(361,6)$ & 361,6 & 6.400 & $1.155,2$ & $1.155,2$ \\
\hline R19 & 224,8 & $399,6(400)$ & 400 & 1.600 & 984,8 & 984,8 \\
\hline $\mathrm{R} 20$ & 381,6 & $399,6(400)$ & 400 & 1.600 & $1.279,2$ & $1.279,2$ \\
\hline $\mathrm{R} 21$ & 604,2 & $360(360)$ & 604,2 & 2.400 & $2.460,6$ & 2.400 \\
\hline $\mathrm{R} 22$ & 136 & $360(360)$ & 360 & 1.600 & $1.013,6$ & $1.013,6$ \\
\hline
\end{tabular}

Tabela 10 - Definição dos limites da faixa de ajuste dos MT.

\begin{tabular}{ccc}
\hline RDS & $\boldsymbol{M T}_{\boldsymbol{m i n}}$ & $\boldsymbol{M T}_{\boldsymbol{m a x}}$ \\
\hline R1 & 0,15 & 3,2 \\
R2 & 0,23 & 3,2 \\
R3 & 0,15 & 3,2 \\
R4 & 0,23 & 3,2 \\
R5 & 0,23 & 3,2 \\
R6 & 0,19 & 3,2 \\
R7 & 0,16 & 3,2 \\
R8 & 0,23 & 3,2 \\
R9 & 0,22 & 3,2 \\
R10 & 0,23 & 3,2 \\
R11 & 0,23 & 3,2 \\
R12 & 0,22 & 3,2 \\
R13 & 0,23 & 3,2 \\
R14 & 0,22 & 3,2 \\
R15 & 0,2 & 3,2 \\
R16 & 0,22 & 3,2 \\
R17 & 0,23 & 3,2 \\
R18 & 0,15 & 3,2 \\
R19 & 0,18 & 3,2 \\
R20 & 0,22 & 3,2 \\
R21 & 0,23 & 3,2 \\
R22 & 0,15 & 3,2 \\
\hline
\end{tabular}




\subsection{3 - PARÂMETROS DO ALGORITMO HÍBRIDO DE COORDENAÇÃO}

Para o adequado desempenho do algoritmo híbrido de coordenação desenvolvido, faz-se necessário o ajuste dos parâmetros relacionados à função de aptidão, da taxa de crossover e de mutação, e definição do tamanho da população de cromossomos. Salienta-se que os fatores multiplicativos $\mu$ e $\lambda$, conforme explicado anteriormente, ponderam a magnitude da penalização das soluções não factíveis (Equação 30 e Equação 35).

Da maneira como implementado o algoritmo híbrido, a taxa de crossover empregada foi de $90 \%$, uma vez que se deseja uma boa diversidade genética ao longo das gerações do algoritmo. Além disso, este valor também foi selecionado com base na literatura técnica correlata, em que se reporta a utilização de taxas de crossover entre $60 \%$ a 100\% (NARA et al., 1992; GEN; CHENG, 1997; LINDEN, 2006).

Conforme mencionado anteriormente, é esperado um valor significativamente baixo para a taxa de mutação, em geral variando de 0,3\% a 0,5\% (NARA et al., 1992; GEN; CHENG, 1997; LINDEN, 2006; RAO, 2009). Sendo assim, para o algoritmo híbrido de coordenação desta pesquisa foi adotada uma taxa de mutação de $0,3 \%$.

Partindo-se de uma população de 100 indivíduos (cromossomos), cuja codificação é descrita no item 4.3, conduziu-se uma análise para se determinar qual o valor adequado para o fator multiplicativo da função de penalização $\left(P_{A G}\right)$ referente ao bloco de $\mathrm{AG}$ (Equação 35). É importante frisar que a escolha inicial de 100 indivíduos foi baseada nos resultados apresentados por Noghabi, Sadeh e Masshadi (2009), cujo algoritmo desenvolvido apresentou melhor desempenho com este tamanho de população, conforme relatam os autores. Contudo, vale adiantar que uma investigação acerca do melhor tamanho da população a ser adotado para o algoritmo de coordenação foi realizado, conforme será mostrado mais adiante.

Neste contexto, para verificar a influência do fator $\mu$ e $\lambda$, respectivamente, na convergência do algoritmo de coordenação, fixou-se, primeiramente, $\lambda=1$ e variou-se gradativamente o valor de $\mu\left(\mu_{1}=0,1 ; \mu_{2}=1 ; \mu_{3}=10 ; \mu_{4}=30 ; \mu_{5}=50 ; \mu_{6}=100\right)$. Em seguida, fixou-se o melhor valor encontrado para o fator $\mu$ e alterou-se o valor de $\lambda$ $\left(\lambda_{1}=0,1 ; \lambda_{2}=1 ; \lambda_{3}=10 ; \lambda_{4}=30 ; \lambda_{5}=50 ; \lambda_{6}=100\right)$. Em ambos os casos mencionados, monitorou-se a quantidade de restrições não atendidas ao fim da execução do algoritmo de coordenação, sendo estas referentes ao atendimento do ITC $\left(R_{I T C}\right)$, intervalo definido para os MT $\left(R_{M T}\right)$ e intervalo delimitado para a corrente de partida $\left(R_{I p}\right)$. Também foram verificados os valores finais da somatória dos tempos de atuação das $\operatorname{PRL}\left(S_{T}\right)$, bem como seu comportamento no decorrer das gerações transcorridas. 
Para comparar os resultados observados ao se variar os parâmetros $\mu$ e $\lambda$ e verificar a influência dos mesmos no desempenho do algoritmo de coordenação, foram considerados os valores médios (média aritmética) das variáveis monitoradas $\left(\overline{R_{I T C}}, \overline{R_{A T}}, \overline{R_{I p}}\right.$, e $\left.\overline{S_{T}}\right)$. O valor médio foi considerado, pois, a cada execução do algoritmo de coordenação, parte-se de pontos incialmente distintos e escolhidos aleatoriamente dentro do espaço de busca, definido no item 5.1.2, o que pode conduzir a soluções de coordenação possivelmente diferentes entre si, dificultando a observação da influência dos parâmetros $\mu$ e $\lambda$ no desempenho geral do algoritmo, quando estes são variados como anteriormente comentado.

A Tabela 11 registra os valores médios das variáveis monitoradas referentes a 30 execuções do algoritmo híbrido de coordenação para $\lambda=1$ e variações de $\mu\left(\mu_{1}=0,1 ; \mu_{2}=\right.$ $\left.1 ; \mu_{3}=10 ; \mu_{4}=30 ; \mu_{5}=50 ; \mu_{6}=100\right)$. Ressalta-se que a quantidade mencionada de execuções do algoritmo foi determinada empiricamente para se analisar o desvio do valor final de $S_{T}$, a cada execução, em relação ao valor médio $\left(\overline{S_{T}}\right)$, como denota o desvio padrão $\left(\sigma_{S_{T}}\right)$ na última coluna da Tabela 11.

Cada execução do algoritmo de coordenação foi limitada em um total de 2.000 gerações, tendo em vista o comportamento assintótico observado do valor de $S_{T}$ a partir desta geração, visto que o valor de $S_{T}$ sofre pouca alteração, indicando a estabilização de sua minimização.

Tabela 11 - Valores médios das variáveis monitoradas para estudo do fator $\boldsymbol{\mu}$.

\begin{tabular}{cccccc}
\hline $\boldsymbol{\mu}$ & $\overline{\boldsymbol{R}_{\boldsymbol{I T C}}}$ & $\overline{\boldsymbol{R}_{\boldsymbol{M T}}}$ & $\overline{\boldsymbol{R}_{\boldsymbol{I} \boldsymbol{p}}}$ & $\overline{\boldsymbol{S}_{\boldsymbol{T}}}(\mathbf{s})$ & $\boldsymbol{\sigma}_{\boldsymbol{S}_{\boldsymbol{T}}}$ \\
\hline $\mathbf{0 , 1}$ & 3,8 & 0 & 0 & 11,6746 & 0,0516 \\
$\mathbf{1}$ & 1,6667 & 0 & 0 & 11,6728 & 0,0456 \\
$\mathbf{1 0}$ & 0,0333 & 0 & 0 & 11,7795 & 0,0599 \\
$\mathbf{3 0}$ & 0,0333 & 0 & 0 & 11,7783 & 0,0755 \\
$\mathbf{5 0}$ & 0 & 0 & 0 & 11,8149 & 0,0665 \\
$\mathbf{1 0 0}$ & 0 & 0 & 0 & 11,8173 & 0,0550 \\
\hline
\end{tabular}

Como é possível observar da Tabela 11 , ao se adotar o fator multiplicativo $\mu=0,1$, aproximadamente 4 dos pares de RDS estão descoordenados ao término da execução do algoritmo $\left(\overline{R_{I T C}}=3,8\right)$. Como será exposto em maiores detalhes no item 5.1.4, para o sistema teste são configurados 44 pares de RDS. Logo, a solução disponibilizada pelo algoritmo de coordenação ao fim das 2.000 gerações apresentará, em média, aproximadamente 8,6\% dos pares de RDS descoordenados para $\mu=0,1$ e $\lambda=1$. 
Ao se incrementar o valor de $\mu$, a quantidade de pares descoordenados ao fim das 2.000 gerações do algoritmo híbrido de coordenação decresce, passando a ser nula a partir de $\mu=50$. Isto é, $100 \%$ dos RDS do sistema teste atingem a coordenação.

De fato, pelos resultados registrados na Tabela 11, observa-se que há uma elevação, embora pouco significativa, no valor médio da soma dos tempos de atuação da PRL $\left(\overline{S_{T}}\right)$ em função do aumento do valor do fator $\mu$. Este comportamento reflete a existência de cromossomos na população que são capazes de minimizar mais rapidamente a soma dos tempos de atuação da PRL, quando um baixo valor do fator $\mu$ adotado, ao custo de violarem a restrição inerente ao ITC, uma vez que estes cromossomos não foram adequadamente penalizados.

De acordo com a terceira e quarta colunas da Tabela 11, nenhuma violação referente ao intervalo definido para os MT e ao intervalo das correntes de partida foi observada. Cabe afirmar que a não violação do intervalo dos MT, deve-se à convergência da solução encontrada pelo método simplex empregado no bloco da PL (item 4.2), já que esta parcela é diretamente responsável por encontrar os ajustes dos MT a cada geração. Além disso, o respeito ao intervalo determinado para as correntes de partida confirma a correta representação dos cromossomos no bloco do $\mathrm{AG}$, não permitindo a representação de correntes de pick-up infactíveis, como previsto no item 4.3.1.

Além dos pontos supracitados, constata-se que o desvio padrão de $S_{T}$, denotado por $\sigma_{S_{T}}$ na quinta coluna da Tabela 11, é relativamente baixo, indicando que o algoritmo híbrido de coordenação sempre fornece parametrizações com valores de $S_{T}$ próximos entre si, independentemente da população inicialmente definida.

Diante deste cenário, o fator $\mu=50$ foi eleito como sendo o mais adequado para o algoritmo híbrido de coordenação desenvolvido.

Analogamente ao apresentado pela Tabela 11, a Tabela 12 traz os valores médios das 30 execuções do algoritmo híbrido de coordenação para $\mu=50$ em que se alterou o valor de $\lambda\left(\lambda_{1}=0,1 ; \lambda_{2}=1 ; \lambda_{3}=10 ; \lambda_{4}=30 ; \lambda_{5}=50 ; \lambda_{6}=100\right)$. Pelos dados apresentados nesta tabela, constata-se que a variação do fator $\lambda$ não exerceu influência sobre o desempenho geral do algoritmo híbrido de coordenação. Os valores das variáveis observadas indicam comportamento semelhante ao observado na Tabela 11 ao se empregar $\mu=50$ e $\lambda=1$.

A observação da não influência do valor de $\lambda$ sobre o desempenho do algoritmo de coordenação nas situações estudadas é explicado pelo fato da convergência nas duas fases do método simplex, geração a geração. Ou seja, ao longo da execução do algoritmo híbrido de 
coordenação, o bloco da PL obteve sucesso ao fornecer soluções factíveis e ótimas no intervalo dos MT considerados segundo as restrições impostas (Equação 29). Fato este que produziu um valor nulo de penalização aos cromossomos para todos os valores de $\lambda$ investigados. Sendo assim, adotou-se o valor de $\lambda=1$.

Ressalta-se que embora não tenha havido violação relacionada ao problema de PL, o algoritmo híbrido de coordenação estará apto a processar a penalização do cromossomo associado a uma eventual violação de tal intervalo, conforme descrito no item 4.2 (Equação 30). É importante destacar que $\lambda$ é um parâmetro livre do algoritmo híbrido de coordenação, sendo possível, caso necessário, seu reajuste para obtenção de um melhor desempenho do algoritmo de coordenação.

De fato, a definição inicial do intervalo dos MT, assim como das correntes de partida, da forma como explicado no item 3.2.2, contribui significativamente para a convergência do algoritmo de otimização empregado no bloco da PL. Pelo procedimento de definição dos referidos intervalos, evitam-se possíveis parametrizações que resultem em tempos de atuação indesejados, principalmente devido ao efeito de múltiplos da corrente de partida muito baixos, os quais acarretam tempos de atuação demasiadamente elevados ou até mesmo negativos.

Tabela 12 - Valores médios das variáveis monitoradas para estudo do fator $\lambda$.

\begin{tabular}{cccccc}
\hline $\boldsymbol{\lambda}$ & $\overline{\boldsymbol{R}_{\boldsymbol{I T C}}}$ & $\overline{\boldsymbol{R}_{\boldsymbol{A T}}}$ & $\overline{\boldsymbol{R}_{\boldsymbol{I p}}}$ & $\overline{\boldsymbol{S}_{\boldsymbol{T}}}(\mathbf{s})$ & $\boldsymbol{\sigma}_{\boldsymbol{S}_{\boldsymbol{T}}}$ \\
\hline $\mathbf{0 , 1}$ & 0 & 0 & 0 & 11,8159 & 0,0617 \\
$\mathbf{1}$ & 0 & 0 & 0 & 11,7977 & 0,0572 \\
$\mathbf{1 0}$ & 0 & 0 & 0 & 11,7875 & 0,0643 \\
$\mathbf{3 0}$ & 0 & 0 & 0 & 11,8211 & 0,0570 \\
$\mathbf{5 0}$ & 0 & 0 & 0 & 11,7980 & 0,0784 \\
$\mathbf{1 0 0}$ & 0 & 0 & 0 & 11,8079 & 0,0681 \\
\hline
\end{tabular}

O comportamento assintótico da minimização de $S_{T}$ ao longo das gerações para $\mu=50$ e $\lambda=1$, está representado no gráfico da Figura 17, em que é traçada a curva média de $S_{T}$ até a geração 2.000 para as 30 execuções do algoritmo híbrido de coordenação. A análise da curva média de $S_{T}$ e dos resultados observados na Tabela 11 e Tabela 12, confirmam a convergência para uma solução de coordenação factível e proximamente ótima.

Além do estudo dos fatores $\mu$ e $\lambda$, uma investigação sobre o tamanho da população foi realizada, mantendo-se $\mu=50$ e $\lambda=1$. Conforme explicado anteriormente, partiu-se de uma população de 100 indivíduos, e, posteriormente, estudou-se a influência de outros 
tamanhos $(P)$ da população $\left(50,150,200\right.$ e 300 indivíduos) no valor final de $S_{T}$, e no respeito às restrições impostas pelo problema de coordenação.

Analogamente ao efetuado no estudo dos fatores $\mu$ e $\lambda$, para cada novo tamanho da população inicial, foram realizadas 30 execuções em que se monitoraram as mesmas variáveis discutidas anteriormente $\left(\overline{R_{I T C}}, \overline{R_{A T}}, \overline{R_{I p}}\right.$, e $\left.\overline{S_{T}}\right)$, além do valor médio do tempo de processamento computacional $\overline{t_{c o m p}}$, e seu respectivo desvio padrão, denotado por $\sigma_{t_{c o m p}}$. Os valores obtidos para as variáveis mencionadas estão organizados na Tabela 13, cuja primeira coluna contém os cinco tamanhos $P$ de populações estudadas. É importante colocar que o hardware utilizado para a execução do algoritmo é referente ao uso de um microcomputador Dell Optiplex 790 com processador Intel ${ }^{\circledR}$ Core $^{\mathrm{TM}} i 7-2600$ de 3,40 GHz e $8 \mathrm{~Gb}$ de memória RAM.

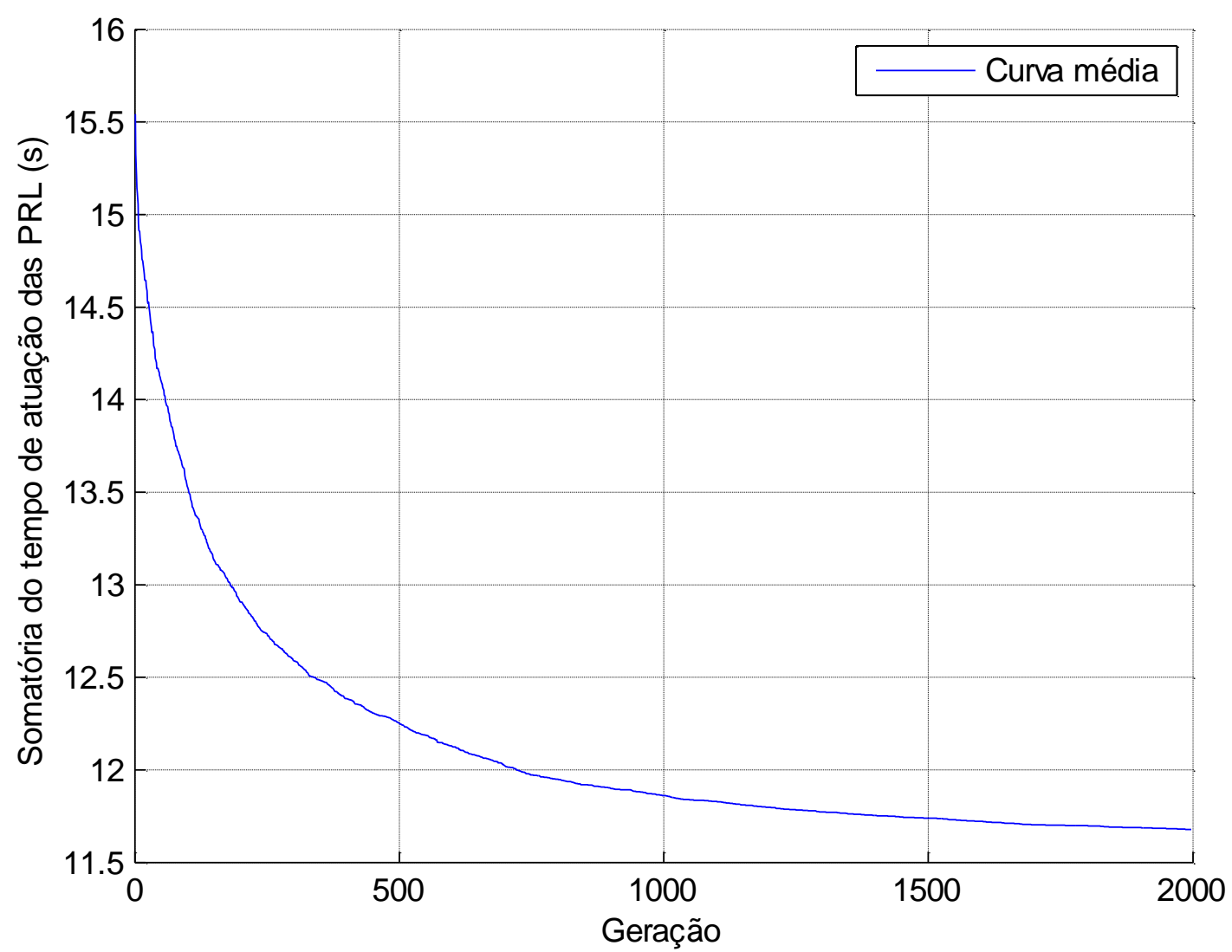

Figura 17 - Comportamento de $\overline{S_{T}}$ (curva média) para as 30 execuções do algoritmo utilizando-se $P=50$, fator $\mu=50$ e $\lambda=1$.

Através da Tabela 13, é possível observar que o incremento do tamanho da população exerce pouca influência no valor médio final da soma dos tempos de atuação da PRL $\left(\overline{S_{T}}\right)$, porém, constata-se uma elevação deste valor ao se definir populações iniciais de maior tamanho. 
Tabela 13 - Variáveis monitoradas para a determinação do tamanho da população inicial de cromossomos.

\begin{tabular}{cccccccc}
\hline $\boldsymbol{P}$ & $\overline{\boldsymbol{R}_{\boldsymbol{I T C}}}$ & $\overline{\boldsymbol{R}_{\boldsymbol{A T}}}$ & $\overline{\boldsymbol{R}_{\boldsymbol{I} \boldsymbol{p}}}$ & $\overline{\boldsymbol{S}_{\boldsymbol{T}}}(\mathbf{s})$ & $\boldsymbol{\sigma}_{\boldsymbol{S}_{\boldsymbol{T}}}$ & $\begin{array}{c}\overline{\boldsymbol{t}_{\text {comp }}} \\
\text { (minutos) }\end{array}$ & $\boldsymbol{\sigma}_{\boldsymbol{t}_{\boldsymbol{c o m p} \boldsymbol{p}}}$ \\
\hline $\mathbf{5 0}$ & 0 & 0 & 0 & 11,6770 & 0,0418 & 18,3145 & 0,2433 \\
$\mathbf{1 0 0}$ & 0 & 0 & 0 & 11,8149 & 0,0665 & 38,9246 & 0,5712 \\
$\mathbf{1 5 0}$ & 0 & 0 & 0 & 11,9133 & 0,0968 & 57,3508 & 0,3754 \\
$\mathbf{2 0 0}$ & 0,0333 & 0 & 0 & 11,9505 & 0,0669 & 76,8403 & 0,7994 \\
$\mathbf{3 0 0}$ & 0,0333 & 0 & 0 & 12,1491 & 0,1522 & 116,2544 & 0,5463 \\
\hline
\end{tabular}

A análise da segunda coluna indica que com o aumento da população, a partir de $P=200$, em média, algumas restrições referentes ao ITC dos pares de RDS $\left(\overline{R_{I T C}}\right)$ não são atendidas ao final da geração 2000. Este comportamento pode ser explicado devido a uma maior diversidade genética da população inicial que proporcionará uma maior probabilidade da existência de cromossomos que violem as restrições impostas, após a ação dos operadores genéticos a cada geração.

O gráfico da Figura 18 ilustra o comportamento de $\left(\overline{S_{T}}\right)$ para os cinco tamanhos de populações iniciais estudadas, em que é possível verificar o aumento de seu valor final à medida que a quantidade de indivíduos cresce na população inicial. Levando em consideração o aspecto assintótico da convergência de $\left(\overline{S_{T}}\right)$, afirma-se que uma população com $P=50$ cromossomos fornecerá, em média, parametrizações cujos valores da soma dos tempos de atuação da PRL é otimizado mais rapidamente a cada geração em relação a populações mais numerosas.

Além das constatações supracitadas que sugerem a adoção de $P=50$ cromossomos na população inicial, é importante notar o aumento no tempo de processamento médio $\left(\overline{t_{\text {comp }}}\right)$ em função do tamanho da população inicial $P$, constituindo uma relação praticamente linear conforme pode ser observado na sexta coluna da Tabela 13. Este fato reforça a opção em se definir a população inicial em $P=50$ cromossomos, uma vez que será possível obter uma solução de coordenação factível mais rapidamente em relação a populações mais numerosas. 


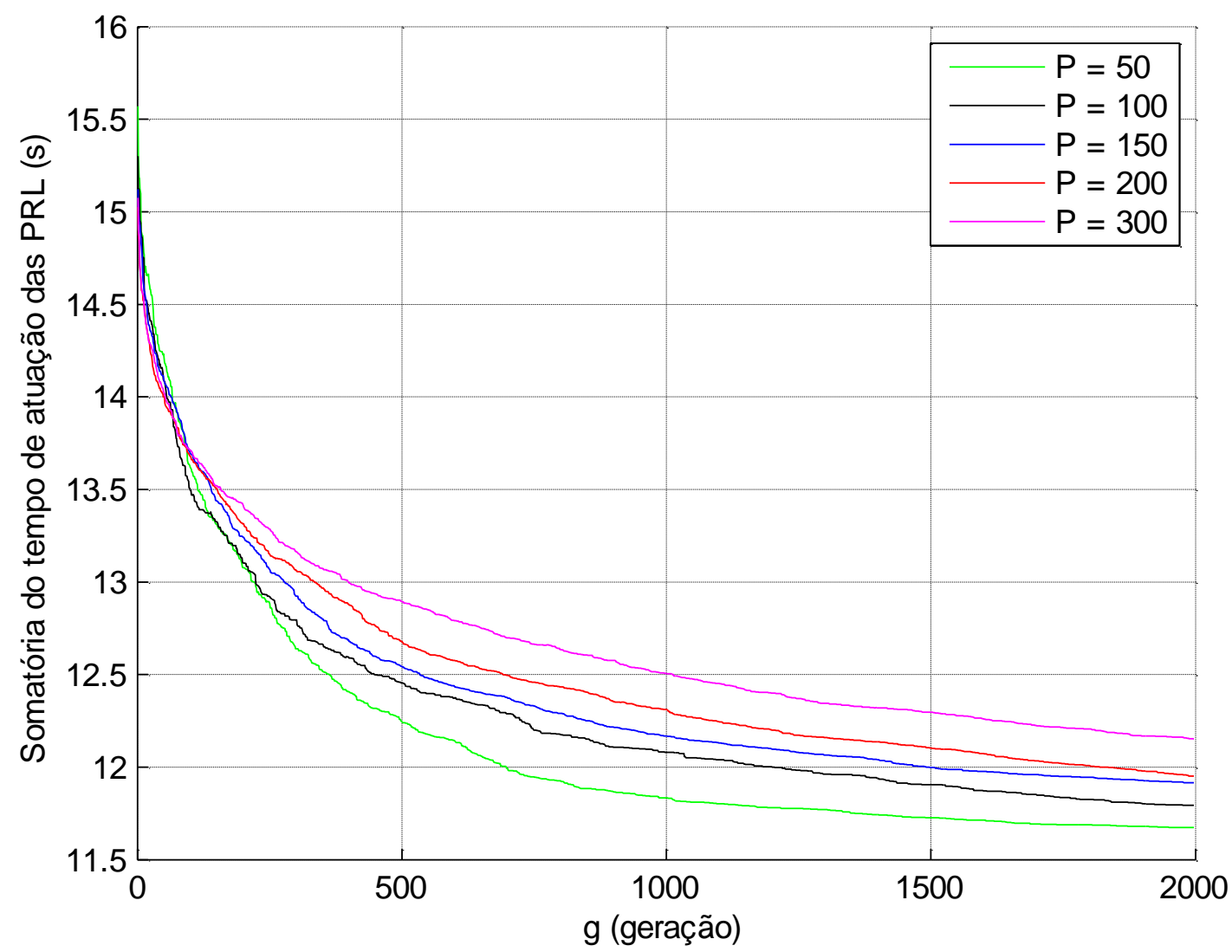

Figura 18 - Gráfico contendo as curvas médias para as 30 execuções do algoritmo híbrido de coordenação variando-se o tamanho populacional de 50 a 300 cromossomos.

A redução do número de cromossomos da população inicial, quando comparado à quantidade de indivíduos utilizada no trabalho de Noghabi, Sadeh e Masshadi (2009), adotada como referência para as análises iniciais desta pesquisa, deve-se principalmente ao fato da menor quantidade de restrições de coordenação a serem atendidas. De fato, conforme mencionado anteriormente no item 2.3, o trabalho de Noghabi, Sadeh e Masshadi (2009) considera a obtenção de uma solução única para mais de uma alteração topológica do sistema, o que eleva consideravelmente a quantidade de restrições de coordenação, consequentemente, há a necessidade de uma população com maior diversidade genética, fato que pode ser refletido em uma população mais numerosa.

Para investigar o comportamento da minimização do valor de $S_{T}$ em decorrência de uma quantidade maior de gerações, executou-se novamente o algoritmo híbrido de coordenação com $\mu=50$ e $\lambda=1$ até 10.000 gerações. Como pode ser observado no gráfico da Figura 19, o valor de $S_{T}$ tende a se estabilizar a partir da geração 2.000, em que assume o valor de $S_{T}=11,6918 \mathrm{~s}$. Transcorridas mais 1.000 gerações o valor de $S_{T}$ decai $82 \mathrm{~ms}$ 
$\left(S_{T}=11,6035 \mathrm{~s}\right)$, mantendo-se praticamente constante até o final da execução do algoritmo, quando após mais 7.000 gerações, é verificada uma diminuição de aproximadamente $28 \mathrm{~ms}$ $\left(S_{T}=11,5757 s\right)$.

Assim como mostrado anteriormente, ao final da geração 2.000, observou-se o atendimento de todas as restrições de coordenação impostas, sendo que nas gerações subsequentes obtém-se uma parametrização que proporciona tempos de atuação levemente mais rápidos aos RDS. Contudo, vale frisar que este fato não invalida as investigações concernentes aos parâmetros do algoritmo desenvolvido apresentadas até o momento.

A Tabela 14 mostra o tempo de processamento decorrido $\left(t_{c o m p}\right)$ e o valor de $S_{T}$ a cada 1.000 gerações do algoritmo híbrido de coordenação. O tempo de processamento adicional, correspondente a 8.000 gerações a mais em relação à geração 2.000 , é de aproximadamente 82 minutos.

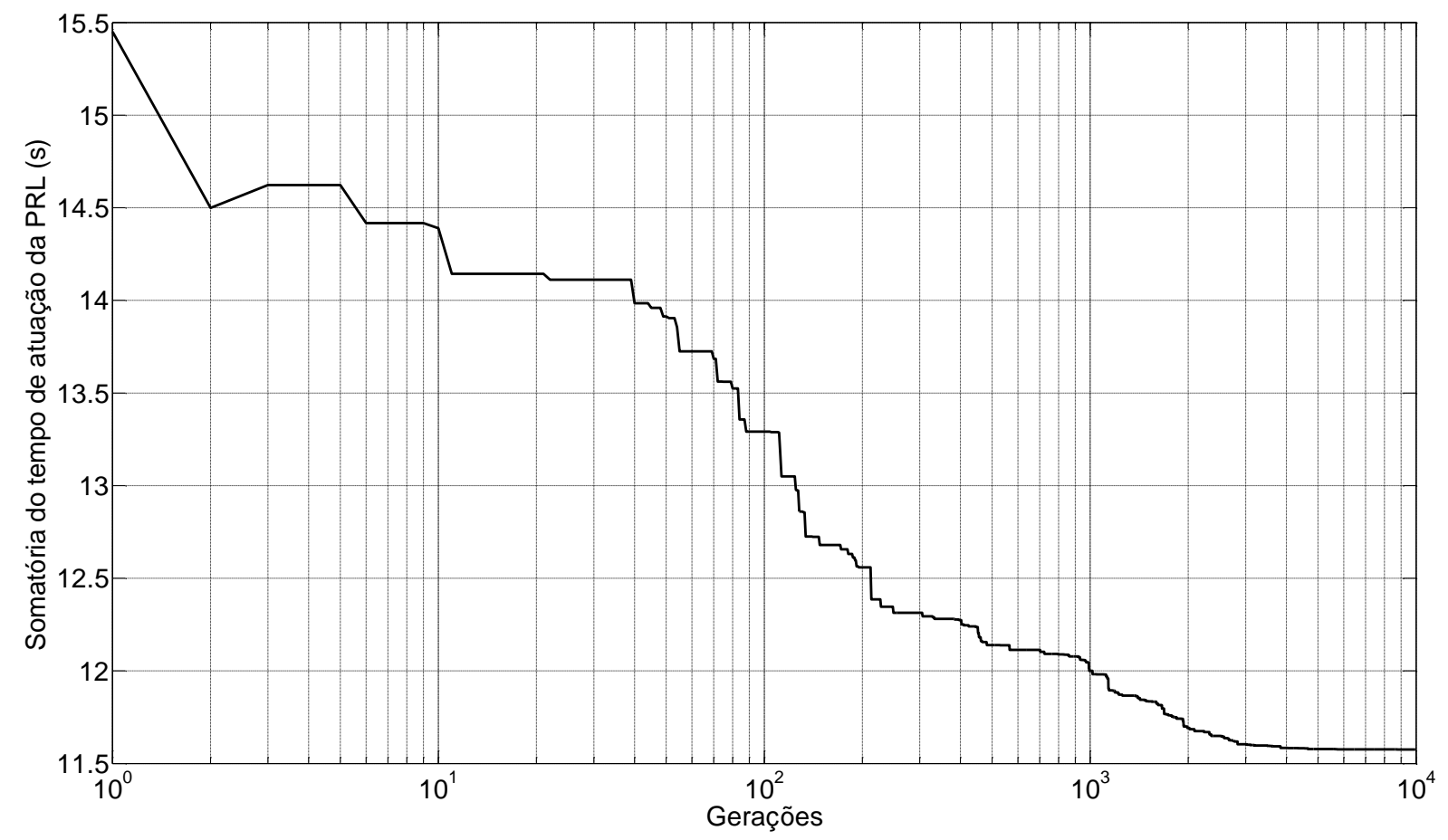

Figura 19 - Comportamento do valor de $S_{T}$ para 10.000 gerações utilizando-se $P=50$, fator $\mu=50$ e $\lambda=1$.

Como critério de parada para a execução do algoritmo é possível que se limite um valor máximo de gerações sucessivas em que se verifica a estabilização do valor de $S_{T}$, como pode ser observado entre as gerações 2.000 e 3.000 . 
Tabela 14 - Valores de tempo computacional e $S_{T}$ a cada 1.000 gerações utilizando-se $P=50$, fator $\mu=50$ e $\lambda=1$.

\begin{tabular}{ccc}
\hline Geração & $\begin{array}{c}\boldsymbol{t}_{\text {comp }} \\
\text { (minutos) }\end{array}$ & $\boldsymbol{S}_{\boldsymbol{T}}(\mathbf{s})$ \\
\hline 1.000 & 9,0626 & 12,0001 \\
2.000 & 18,3133 & 11,6918 \\
3.000 & 28,0550 & 11,6035 \\
4.000 & 37,9305 & 11,5845 \\
5.000 & 47,8568 & 11,5780 \\
6.000 & 57,9909 & 11,5763 \\
7.000 & 68,1147 & 11,5763 \\
8.000 & 78,3836 & 11,5763 \\
9.000 & 88,9329 & 11,5757 \\
10.000 & 99,4937 & 11,5757 \\
\hline
\end{tabular}

Cabe salientar que a obtenção manual de uma solução de coordenação entre todos os 22 RDS presentes no SEP, que respeite todas as restrições inerentes ao problema de coordenação, e que, além disso, minimize o tempo de atuação da PRL, pode custar muitas horas de trabalho ao engenheiro de proteção, mesmo que este possua prontamente os estudos de curtos-circuitos e informações dos equipamentos envolvidos na coordenação. Como exposto, através do algoritmo híbrido de coordenação, utilizando o hardware considerado, foi possível obter uma parametrização que atenda a todos os requisitos mencionados de 18 a 28 minutos, aproximadamente, para 2.000 e 3.000 gerações, respectivamente. Este fato indica que o uso do algoritmo poderá reduzir significativamente o tempo dispensado para a elaboração do estudo de coordenação dos RDS.

\subsection{4 - COORDENAÇÃO OBTIDA ENTRE OS RDS PARA TOPOLOGIA PRINCIPAL DE OPERAÇÃO}

A parametrização obtida via algoritmo híbrido de coordenação, considerando a topologia principal de operação, está registrada na Tabela 15, em que se encontram as correntes de pick-up, em termos do tap (segunda coluna) e seu respectivo valor em ampères (terceira coluna), e MT (quarta coluna), para todos os RDS coordenados no sistema teste.

Ainda na mesma tabela (Tabela 15), na última coluna, têm-se os valores correspondentes aos tempos de atuação da PRL $\left(T_{P R L}\right)$, que além de serem minimizados pelo 
algoritmo híbrido de coordenação devem respeitar a atuação preferencial da proteção primária (proteção de distância), como denotado pela Equação 9 no item 2.2.

Uma vez estabelecido que o tempo de atuação da proteção primária $\Delta T_{\text {dist }}$ deve ser maior do que $500 \mathrm{~ms}$, tempo este correspondente a $400 \mathrm{~ms}$ referentes ao respeito do tempo de zona 1 e zona 2, e 100ms relacionados ao tempo de abertura dos disjuntores e margem de segurança (Equação 7), afirma-se que o algoritmo forneceu uma parametrização para todos os RDS que respeita tal tempo (última coluna da Tabela 15). Na mesma coluna em que estão listados os tempos de atuação da PRL $\left(T_{P R L}\right)$, tem-se na última linha, a soma dos tempos de atuação da PRL $\left(S_{T}\right)$, que é relativa ao valor final encontrado na geração 3.000 como mostrado no gráfico da Figura 19.

Cabe lembrar que a parametrização apresentada foi obtida ao final de 3.000 gerações, utilizando-se uma população de 50 cromossomos, fator $\mu=50$ e fator $\lambda=1$. O tempo de processamento para a obtenção da mesma foi de aproximadamente 28 minutos, utilizando-se o hardware apresentado no item 5.2.3.

Tabela 15 - Ajustes da corrente de partida, ajustes dos MT e tempos de atuação das PRL para a topologia principal de operação.

\begin{tabular}{ccccc}
\hline RDS & $\boldsymbol{I}_{\boldsymbol{p}}(\boldsymbol{t a p})$ & $\boldsymbol{I}_{\boldsymbol{p}}(\mathbf{A})$ & $\boldsymbol{M} \boldsymbol{T}$ & $\boldsymbol{T}_{\boldsymbol{P R} \boldsymbol{L}}(\mathbf{s})$ \\
\hline R1 & 0,67 & 402 & 0,15 & 0,5006 \\
R2 & 0,78 & 468 & 0,23 & 0,5246 \\
R3 & 0,68 & 408 & 0,15 & 0,5043 \\
R4 & 0,77 & 462 & 0,23 & 0,5222 \\
R5 & 3,44 & 412,8 & 0,23 & 0,5281 \\
R6 & 3,02 & 362,4 & 0,19 & 0,5127 \\
R7 & 3,23 & 387,6 & 0,16 & 0,5274 \\
R8 & 3,33 & 799,2 & 0,23 & 0,5215 \\
R9 & 3,49 & 418,8 & 0,22 & 0,5161 \\
R10 & 4,9 & 784 & 0,23 & 0,5233 \\
R11 & 0,68 & 408 & 0,23 & 0,5217 \\
R12 & 4,34 & 347,2 & 0,22 & 0,5115 \\
R13 & 0,68 & 408 & 0,23 & 0,5217 \\
R14 & 4,35 & 348 & 0,22 & 0,5119 \\
R15 & 1,25 & 400 & 0,2 & 0,5070 \\
R16 & 5 & 400 & 0,22 & 0,5121 \\
R17 & 13,14 & 788,4 & 0,23 & 0,5755 \\
R18 & 1,54 & 492,8 & 0,15 & 0,6347 \\
R19 & 5 & 400 & 0,18 & 0,5086 \\
R20 & 5,02 & 401,6 & 0,22 & 0,5078 \\
R21 & 10,07 & 604,2 & 0,23 & 0,5217 \\
R22 & 5,86 & 468,8 & 0,15 & 0,5885 \\
\hline & & & & $S_{T}=11,6035$ \\
\hline
\end{tabular}


Pelos valores da parametrização calculada, nota-se que os valores dos MT, mostrados na quarta coluna da Tabela 15 , são iguais aos valores mínimos $\left(M T_{\min }\right)$ estabelecidos pelo intervalo definido através da Equação 23 (valores listados na Tabela 10).

De fato, na medida em que se diminui o valor dos MT é natural se esperar tempos de atuação mais rápidos, como pode ser inferido pela relação diretamente proporcional na expressão da curva de tempo inversa (Equação 10).

Com respeito às correntes de partida encontradas pelo algoritmo híbrido de coordenação, verifica-se um comportamento semelhante, já que os valores para tais correntes, mostrados na terceira coluna da Tabela 15 , aproximam-se do extremo inferior $\left(I_{p, \min }\right)$ do intervalo definido pela Equação 21 (valores registrados na Tabela 9).

Assim como nos casos dos ajustes dos MT, este fato é esperado, já que magnitudes menores para a corrente de partida tendem a aumentar o valor do múltiplo $M$, situado no denominador da expressão da curva de tempo inverso dos RDS (Equação 10). Sendo assim, múltiplos com valores mais elevados deverão resultar em tempos de atuação mais rápidos para os relés.

Como é possível observar na terceira coluna da Tabela 16, os valores dos ITC para todos os 44 pares de RDS configurados foram respeitados. Ou seja, todos os relés de PRR estarão sempre atuando para tempos acima de 300ms em relação à atuação dos relés de PRL, como estabelecido pela Equação 8, e mostrado na quinta coluna da Tabela 16.

Cabe destacar que uma vez respeitado o intervalo definido pela Equação 22 para a corrente de partida, os valores dos respectivos múltiplos também estarão dentro da faixa inicialmente estabelecida, que, neste trabalho, é definida com base nas normas IEC 60255-3 (1989) e IEEE Std. C37.112 (1996), conforme comentado anteriormente no item 3.2.2.

A sexta e sétima colunas da Tabela 16 trazem os valores máximos $\left(M_{P R L}\right)$ e mínimos $\left(M_{P R L}\right)$ dos múltiplos da corrente de partida obtidos para os relés atuando como PRL e PRR, respectivamente, dada a parametrização calculada.

Diante deste cenário, afirma-se que o algoritmo híbrido de coordenação é capaz de fornecer uma solução de coordenação adequada e dentro dos limites operativos inicialmente definidos para os RDS do SEP malhado em estudo (sistema teste). Além disso, ressalta-se que os critérios para se atingir a validação da coordenação foram satisfeitos, já que toda a análise realizada é decorrente do conjunto de dados de curtos-circuitos obtidos inicialmente pelo módulo de curto-circuito do programa CAPE. 
Tabela 16 - Pares de RDS, dada a condição mínima de sensibilização, e seus respectivos valores de ITC, tempo de atuação da PRL e da PRR e múltiplos máximo e mínimo da PRL e PRR.

\begin{tabular}{|c|c|c|c|c|c|c|}
\hline$P R L$ & PRR & $I T C(\mathrm{~s})$ & $T_{P R L}(\mathrm{~s})$ & $T_{P R R}(\mathrm{~s})$ & $M_{P R L}$ & $M_{P R R}$ \\
\hline $\mathrm{R} 1$ & $\mathrm{R} 4$ & 0,54 & 0,5006 & 1,0406 & 7,80 & 4,59 \\
\hline R2 & R6 & 0,309 & 0,5246 & 0,8336 & 19,66 & 4,81 \\
\hline $\mathrm{R} 2$ & R10 & 1,109 & 0,5246 & 1,6336 & 19,66 & 2,65 \\
\hline $\mathrm{R} 2$ & R12 & 0,4464 & 0,5246 & 0,9710 & 19,66 & 4,77 \\
\hline $\mathrm{R} 2$ & R14 & 0,4479 & 0,5246 & 0,9725 & 19,66 & 4,75 \\
\hline R3 & $\mathrm{R} 2$ & 0,5453 & 0,5043 & 1,0496 & 7,69 & 4,53 \\
\hline R4 & R6 & 0,3114 & 0,5222 & 0,8336 & 19,92 & 4,81 \\
\hline $\mathrm{R} 4$ & R10 & 1,1114 & 0,5222 & 1,6336 & 19,92 & 2,65 \\
\hline R4 & R12 & 0,4488 & 0,5222 & 0,9710 & 19,92 & 4,77 \\
\hline $\mathrm{R} 4$ & R14 & 0,4503 & 0,5222 & 0,9725 & 19,92 & 4,75 \\
\hline R5 & R10 & 1,1105 & 0,5281 & 1,6386 & 19,28 & 2,65 \\
\hline R5 & R12 & 0,4426 & 0,5281 & 0,9707 & 19,28 & 4,77 \\
\hline R5 & R14 & 0,4441 & 0,5281 & 0,9722 & 19,28 & 4,76 \\
\hline R6 & R8 & 0,5082 & 0,5127 & 1,0209 & 12,54 & 4,72 \\
\hline $\mathrm{R} 7$ & $\mathrm{R} 5$ & 0,3889 & 0,5274 & 0,9163 & 8,00 & 5,62 \\
\hline $\mathrm{R} 8$ & R9 & 0,6606 & 0,5215 & 1,1821 & 19,99 & 3,62 \\
\hline R9 & R6 & 0,3228 & 0,5161 & 0,8389 & 18,14 & 4,76 \\
\hline R9 & R12 & 0,4577 & 0,5161 & 0,9738 & 18,14 & 4,74 \\
\hline R9 & R14 & 0,4592 & 0,5161 & 0,9753 & 18,14 & 4,73 \\
\hline $\mathrm{R} 10$ & R7 & 0,3251 & 0,5233 & 0,8484 & 19,80 & 3,68 \\
\hline $\mathrm{R} 11$ & R6 & 0,3019 & 0,5217 & 0,8236 & 19,98 & 4,90 \\
\hline $\mathrm{R} 11$ & R10 & 1,0807 & 0,5217 & 1,6024 & 19,98 & 2,70 \\
\hline $\mathrm{R} 11$ & R14 & 0,4562 & 0,5217 & 0,9779 & 19,98 & 4,71 \\
\hline $\mathrm{R} 12$ & R13 & 0,3089 & 0,5115 & 0,8204 & 18,61 & 6,85 \\
\hline $\mathrm{R} 12$ & R15 & 0,4221 & 0,5115 & 0,9336 & 18,61 & 4,38 \\
\hline $\mathrm{R} 12$ & R19 & 0,4203 & 0,5115 & 0,9318 & 18,61 & 3,80 \\
\hline $\mathrm{R} 13$ & R6 & 0,3019 & 0,5217 & 0,8236 & 19,98 & 4,90 \\
\hline $\mathrm{R} 13$ & R10 & 1,0807 & 0,5217 & 1,6024 & 19,98 & 2,70 \\
\hline $\mathrm{R} 13$ & R12 & 0,4547 & 0,5217 & 0,9764 & 19,98 & 4,72 \\
\hline R14 & R11 & 0,3085 & 0,5119 & 0,8204 & 18,57 & 6,85 \\
\hline $\mathrm{R} 14$ & $\mathrm{R} 15$ & 0,4217 & 0,5119 & 0,9336 & 18,57 & 4,38 \\
\hline R14 & R19 & 0,4199 & 0,5119 & 0,9318 & 18,57 & 3,80 \\
\hline $\mathrm{R} 15$ & $\mathrm{R} 17$ & 0,3198 & 0,5070 & 0,8268 & 14,70 & 6,76 \\
\hline R16 & R11 & 0,3117 & 0,5121 & 0,8238 & 18,54 & 6,80 \\
\hline $\mathrm{R} 16$ & R13 & 0,3117 & 0,5121 & 0,8238 & 18,54 & 6,80 \\
\hline R16 & R19 & 0,4393 & 0,5121 & 0,9514 & 18,54 & 3,70 \\
\hline $\mathrm{R} 17$ & R22 & 0,3062 & 0,5755 & 0,8817 & 15,21 & 3,24 \\
\hline $\mathrm{R} 18$ & R16 & 0,3248 & 0,6347 & 0,9595 & 5,09 & 4,85 \\
\hline R19 & $\mathrm{R} 21$ & 0,3649 & 0,5086 & 0,8735 & 11,22 & 6,11 \\
\hline $\mathrm{R} 20$ & R11 & 0,3169 & 0,5078 & 0,8247 & 18,99 & 6,79 \\
\hline $\mathrm{R} 20$ & $\mathrm{R} 13$ & 0,3169 & 0,5078 & 0,8247 & 18,99 & 6,79 \\
\hline $\mathrm{R} 20$ & $\mathrm{R} 15$ & 0,4446 & 0,5078 & 0,9524 & 18,99 & 4,26 \\
\hline $\mathrm{R} 21$ & $\mathrm{R} 18$ & 0,3016 & 0,5217 & 0,8233 & 19,98 & 3,52 \\
\hline $\mathrm{R} 22$ & $\mathrm{R} 20$ & 0,3807 & 0,5885 & 0,9692 & 5,77 & 4,78 \\
\hline
\end{tabular}


De maneira a melhor apresentar e ilustrar a solução de coordenação obtida via algoritmo híbrido desenvolvido, são traçados os coordenogramas para cinco relés da PRL e seus respectivos relés da PRR, como mostrado na Tabela 17. A escolha dos pares de RDS se deu com o intuito de demonstrar a coordenação obtida em regiões distintas do SEP (Figura 16), uma vez que cada região está inerentemente sujeita a diferentes níveis de curtos-circuitos.

Tabela 17 - Relés de PRL e seus respectivos relés de PRR associados.

\begin{tabular}{cc}
\hline $\boldsymbol{P} \boldsymbol{R} \boldsymbol{L}$ & $\boldsymbol{P R} \boldsymbol{R}$ \\
\hline R3 & $\mathrm{R} 2$ \\
R6 & $\mathrm{R} 8$ \\
R12 & $\mathrm{R} 13, \mathrm{R} 15, \mathrm{R} 19$ \\
R14 & $\mathrm{R} 11, \mathrm{R} 15, \mathrm{R} 19$ \\
R15 & $\mathrm{R} 17$ \\
\hline
\end{tabular}

A Figura 20 mostra os coordenogramas traçados para os relés R3 e R2. Por estes gráficos é possível confirmar o tempo de atuação preferencial da PRL sobre a PRR, respeitando-se o ITC, dada as respectivas correntes de curtos-circuitos mensuradas. De fato, as correntes de contribuição devido ao curto-circuito trifásico franco aplicado a $1 \%$ da distância de R3 resulta em um múltiplo da corrente de partida de 7,69 para R3 e 4,53 para R2, desencadeando um tempo de atuação de 0,5453 s para R3 e 1,0496 s para R2.

De maneira semelhante, como pode ser verificado nos coordenogramas da Figura 21, aplicando-se um curto-circuito trifásico franco a $1 \%$ da distância de R6, observa-se a correta atuação do par de RDS formado por R6 (PRL) e R8 (PRR), sendo de 0,5127s para o relé R6 e 1,0209s para o relé R8, uma vez que os múltiplos das correntes de pick-up são, respectivamente para $\mathrm{R} 6$ e $\mathrm{R} 8$, iguais a 12,54 e 4,72.

A Figura 22 e a Figura 23 trazem, respectivamente, os coordenogramas traçados para todos os pares formados pelos relés R12 e R14, ambos de PRL. Os tempos de atuação, múltiplos de corrente, ITC de cada um deles, devido à aplicação de um curto-circuito, com as mesmas características dos casos anteriores, podem ser encontrados na Tabela 16. Pela análise dos coordenogramas e dos valores da referida tabela é possível observar que os comportamentos dos pares de R12 e R14 são muito semelhantes entre si, dada a situação de curto-circuito simulada. Este fato ocorre devido às linhas LT6 e LT7 do sistema teste serem 
linhas paralelas. Esta situação também se reflete na parametrização muito próxima entre este par de relés, como visto na Tabela 15.

O último exemplo apresentado para ilustrar a parametrização obtida via algoritmo híbrido de coordenação compreende o par de relés formado por R15 (PRL) e R17 (PRR). O ITC atingido entre estes dois relés foi de 0,3197 s, uma vez que o tempo de atuação do relé R15 foi de 0,5070 s para um múltiplo de corrente de partida de 14,70. Já o tempo de atuação de R17 foi de $0,8268 s$ devido à caracterização de um múltiplo de corrente de 6,76.

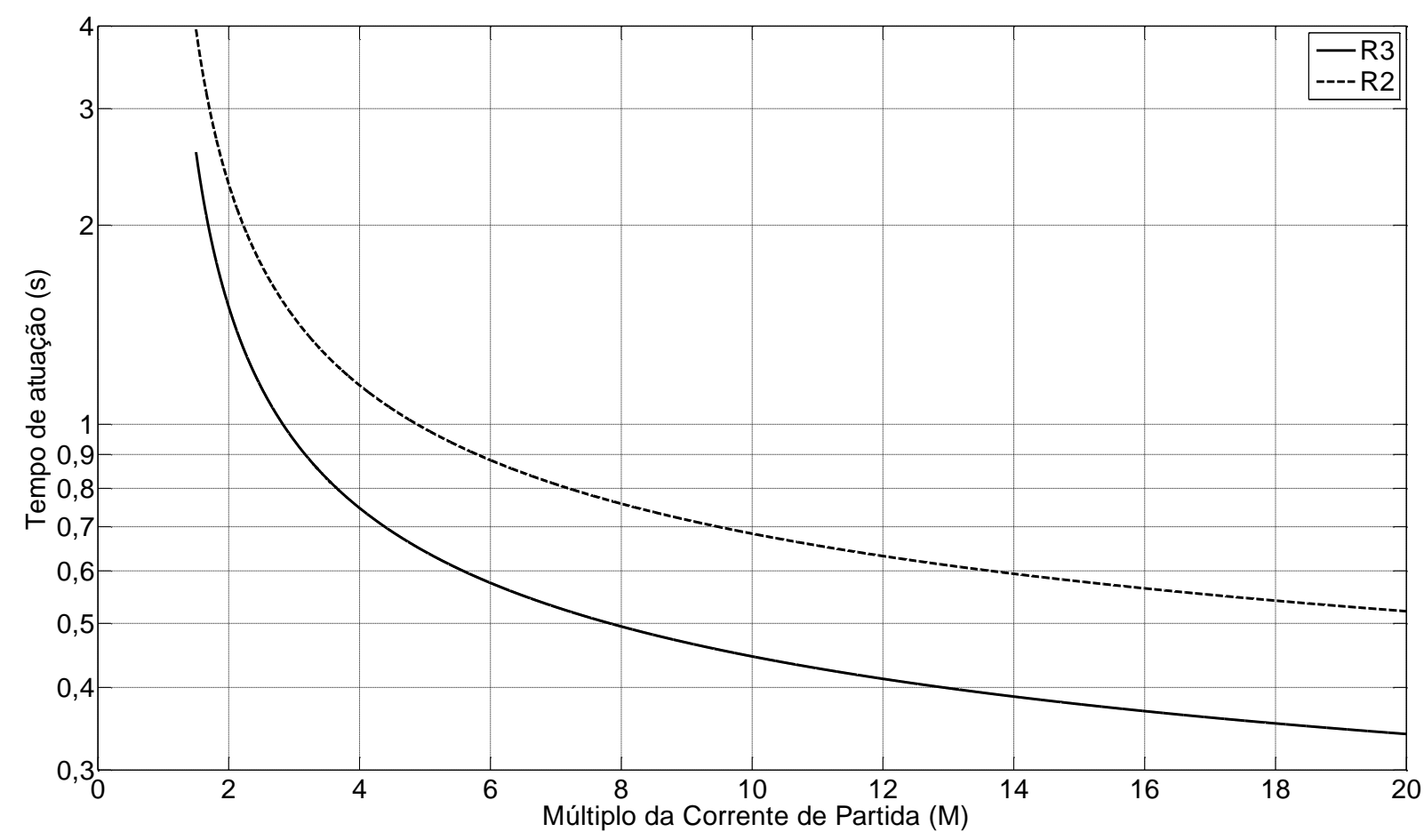

Figura 20 - Coordenogramas do relé R3 (PRL) e relé R2 (PRR).

Conforme mencionado, todos os pares de RDS tiveram o ITC atendido, ficando próximos de 0,3 s. Para os casos em que se observa um ITC acima de $1 \mathrm{~s}$, verifica-se que o tempo de atuação da PRR é mais tardio, principalmente em função da relativa baixa corrente de curto-circuito circulante. Porém, tais valores ainda denotam a coordenação obtida entre os pares de relés envolvidos. Contudo cabe salientar que um ITC muito maior indicaria a atuação demasiadamente demorada da PRR, caso a mesma fosse solicitada, sendo esta uma situação que não é desejada em um SP. 


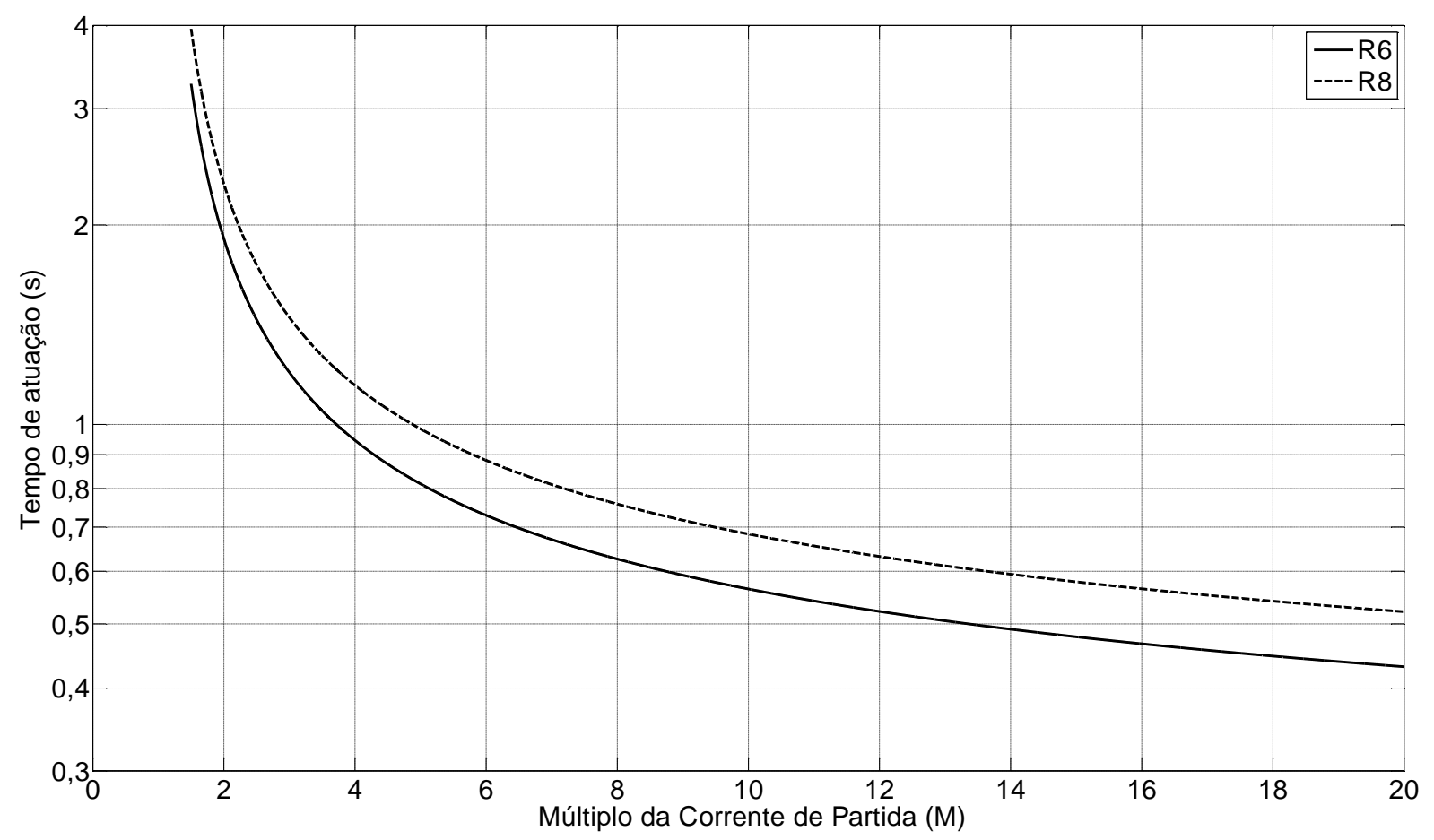

Figura 21 - Coordenogramas do relé R6 (PRL) e relé R8 (PRR).

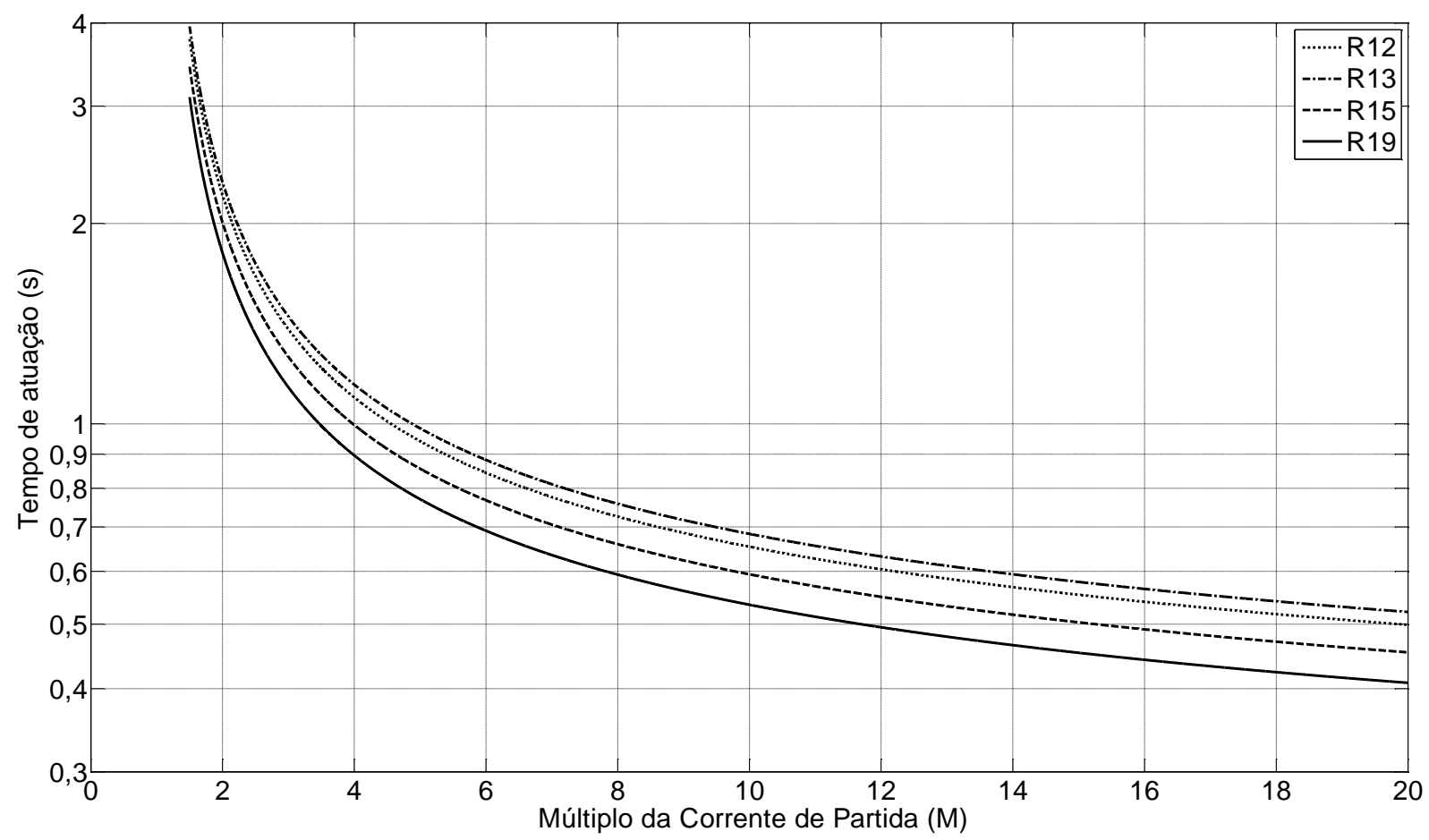

Figura 22 - Coordenogramas do relé R12 (PRL) e relés R13, R15 e R19 (PRR). 


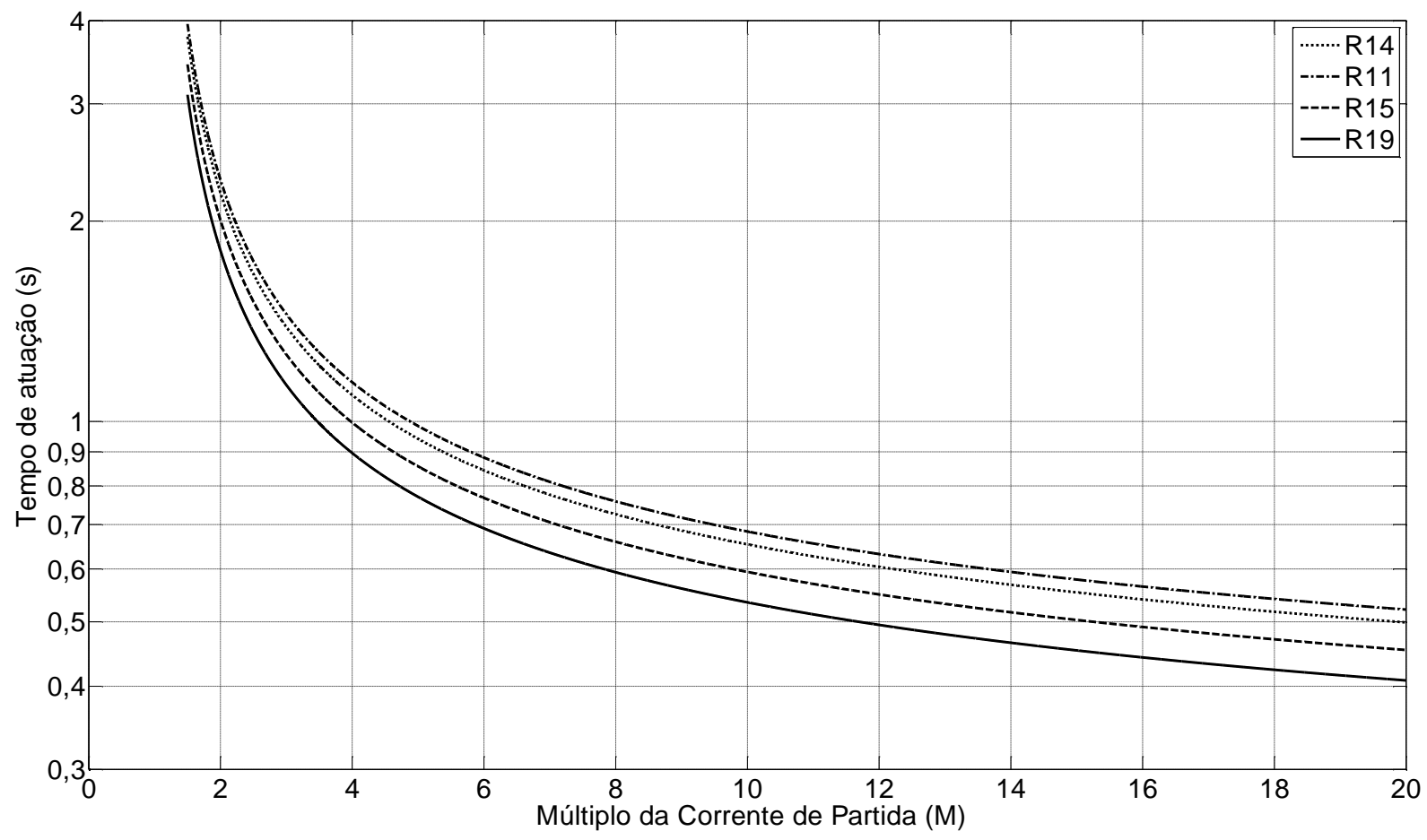

Figura 23 - Coordenogramas do relé R14 (PRL) e relés R11, R15 e R19 (PRR).

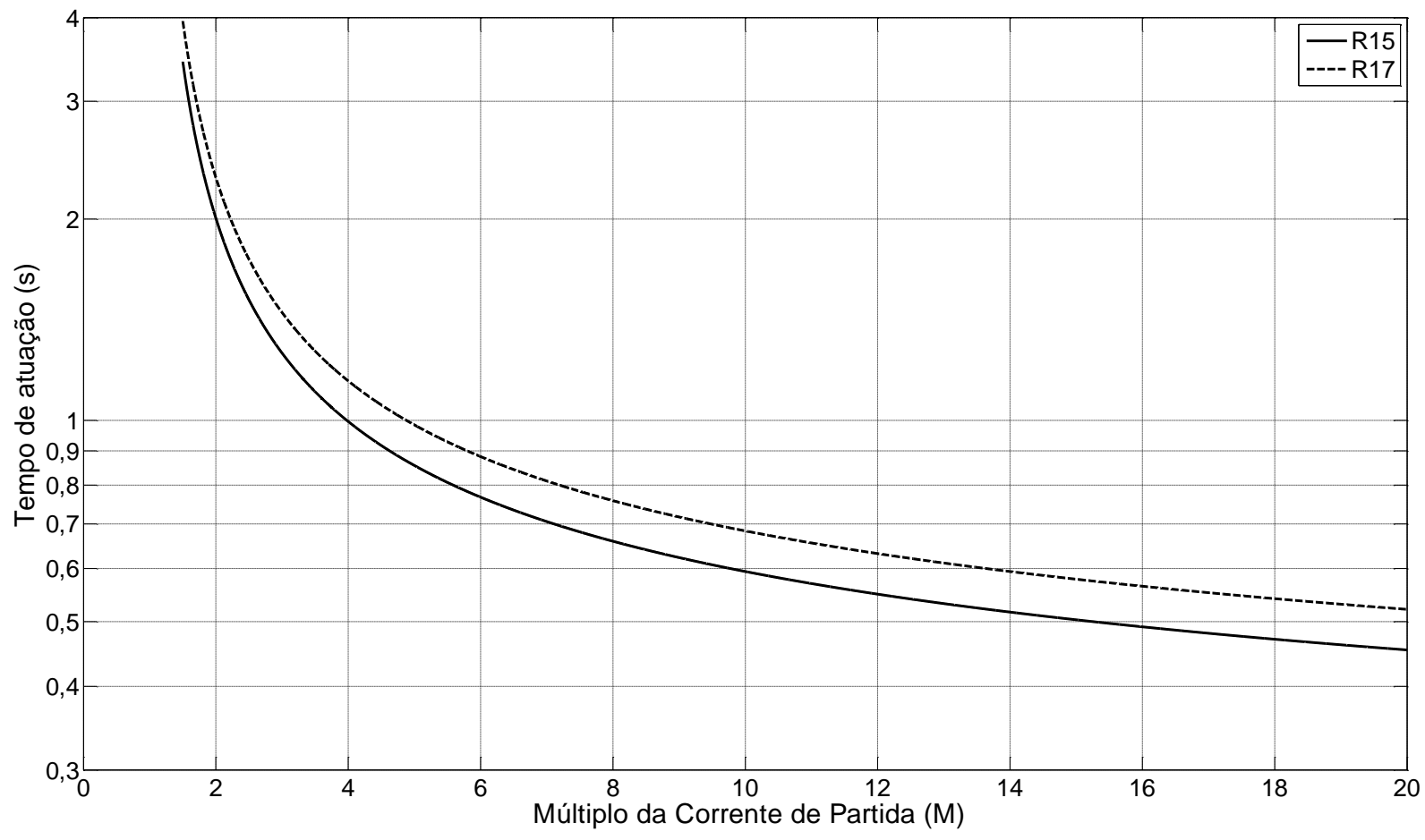

Figura 24 - Coordenogramas do relé R15 (PRL) e relé R17 (PRR). 


\subsection{5 - AVALIAÇÃO DA PARAMETRIZAÇÃO FRENTE A VARIAÇÕES TOPOLÓGICAS}

Com a parametrização obtida para os RDS do sistema teste em que se considera a topologia principal de operação, conforme apresentado no item 5.1.4, novas condições topológicas de operação foram estudadas com o intuito de se avaliar a aplicabilidade da referida parametrização, elucidando a necessidade ou não de um novo processo de otimização. Estas modificações na topologia de operação consistem na saída de operação de uma determinada LT, isto é, o sistema passa a operar com uma LT a menos em relação à topologia principal.

Nesta pesquisa, a consistência da solução de coordenação incialmente obtida foi investigada perante a saída de todas as 11 LT, uma de cada vez. Logo, foram estudados 11 novos cenários em que o sistema passou a operar com uma LT a menos em relação à sua configuração principal.

Os cenários estudados preveem, por exemplo, a necessidade da saída das LT para manutenção e/ou manobras previstas e realizadas pela concessionária de energia elétrica. Neste contexto, o estudo prévio da consistência da solução de coordenação principal é de significativa valia, uma vez que a obtenção de uma nova parametrização para atender à nova topologia pode ser considerada para melhor resguardar o SEP como um todo.

A saída de operação de uma LT tende a provocar alterações nas magnitudes das contribuições das correntes de curtos-circuitos, provocando desvios nos tempos de atuação da PRL e da PRR em relação ao calculado para a configuração principal de operação.

Para realizar a análise supracitada é necessária a atualização do conjunto de dados referente ao cálculo das correntes de curtos-circuitos medidas pelos RDS nas novas configurações topológicas, utilizando-se para tanto o módulo de curto-circuito do programa CAPE. Contudo, estes novos cálculos dependem da determinação dos novos pares de RDS, através da matriz de incidência (item 3.1).

Como objetivo de ilustrar a situação supracitada, serão apresentadas e discutidas em detalhes duas variações topológicas. Uma que consiste na saída da LT1 e a outra na retirada da LT6.

Como anteriormente explicado, cabe ressaltar que foram estudadas as saídas de todas as LT, sendo os respectivos dados organizados em tabelas (Tabela 33 à Tabela 62) e apresentados na seção de apêndices deste trabalho. 
A Tabela 18 traz o registro dos pares de RDS determinados para a topologia relativa à saída da linha LT1 de operação. Ainda na mesma tabela, têm-se os valores das correntes observadas pelas PRL $\left(I_{C C, \text { local }}\right)$ e as correntes observadas pela PRR $\left(I_{C C, \text { rem }}\right)$.

Considerando-se os pares formados após a verificação da condição de sensibilização (Tabela 5) dos relés de PRR, a Tabela 19 reúne os valores de ITC entre os pares de relés, do tempo de atuação da PRL $\left(T_{P R L}\right)$, da PRR $\left(T_{P R R}\right)$, assim como os múltiplos das correntes de partida da PRL $\left(M_{P R L}\right)$ e da PRR $\left(M_{P R R}\right)$ para a saída de LT1.

Tabela 18 - Valor das correntes de curtos-circuitos obtido via $C A P E$ para a topologia sem a operação da linha LT1.

\begin{tabular}{|c|c|c|c|c|c|c|c|}
\hline$P R L$ & $P R R$ & $\begin{array}{c}I_{C C, \text { local }} \\
\text { (A) }\end{array}$ & $\begin{array}{l}I_{C C, \text { rem }} \\
\text { (A) }\end{array}$ & PRL & PRR & $\begin{array}{c}I_{C C, \text { local }} \\
\text { (A) }\end{array}$ & $\begin{array}{c}I_{C C, \text { rem }} \\
\text { (A) }\end{array}$ \\
\hline $\mathrm{R} 4$ & R6 & $8.801,5$ & $1.744,5$ & R12 & R15 & $6.428,1$ & $1.752,8$ \\
\hline R4 & R10 & $8.801,5$ & $2.082,5$ & R12 & R19 & $6.428,1$ & $1.518,9$ \\
\hline $\mathrm{R} 4$ & $\mathrm{R} 12$ & $8.801,5$ & $1.656,1$ & R13 & R3 & $8.066,2$ & 848,5 \\
\hline $\mathrm{R} 4$ & R14 & $8.801,5$ & $1.656,1$ & R13 & R6 & $8.066,2$ & 1.776 \\
\hline R5 & R3 & $7.876,6$ & 833,3 & R13 & $\mathrm{R} 10$ & $8.066,2$ & $2.120,1$ \\
\hline R5 & $\mathrm{R} 10$ & $7.876,6$ & $2.074,9$ & R13 & $\mathrm{R} 12$ & $8.066,2$ & $1.640,9$ \\
\hline R5 & R12 & $7.876,6$ & $1.655,7$ & R14 & R11 & $6.428,1$ & $2.763,3$ \\
\hline $\mathrm{R} 5$ & R14 & $7.876,6$ & $1.655,7$ & R14 & $\mathrm{R} 15$ & $6.428,1$ & $1.752,8$ \\
\hline R6 & $\mathrm{R} 8$ & 4.544 & $3.773,6$ & R14 & R19 & $6.428,1$ & $1.518,9$ \\
\hline $\mathrm{R} 7$ & R5 & $3.091,4$ & $2.311,2$ & R15 & $\mathrm{R} 17$ & $5.876,5$ & $5.324,2$ \\
\hline $\mathrm{R} 8$ & R9 & $15.969,1$ & $1.504,9$ & R16 & $\mathrm{R} 11$ & $7.352,2$ & $2.742,8$ \\
\hline R9 & R3 & $7.512,8$ & 829,3 & R16 & $\mathrm{R} 13$ & $7.352,2$ & $2.742,8$ \\
\hline R9 & R6 & $7.512,8$ & $1.726,5$ & R16 & R19 & $7.352,2$ & $1.478,5$ \\
\hline R9 & $\mathrm{R} 12$ & $7.512,8$ & $1.647,6$ & R17 & $\mathrm{R} 22$ & $11.988,1$ & $1.516,1$ \\
\hline R9 & R14 & $7.512,8$ & $1.647,6$ & R18 & $\mathrm{R} 16$ & $2.501,9$ & $1.934,6$ \\
\hline R10 & $\mathrm{R} 7$ & $15.518,8$ & $1.419,1$ & R19 & $\mathrm{R} 21$ & $4.487,5$ & $3.690,1$ \\
\hline R11 & R3 & $8.066,2$ & 848,5 & R20 & $\mathrm{R} 11$ & $7.563,8$ & $2.737,3$ \\
\hline R11 & R6 & $8.066,2$ & 1776 & R20 & $\mathrm{R} 13$ & $7.563,8$ & $2.737,3$ \\
\hline R11 & $\mathrm{R} 10$ & $8.066,2$ & $2.120,1$ & R20 & $\mathrm{R} 15$ & $7.563,8$ & $1.703,5$ \\
\hline R11 & R14 & $8.066,2$ & $1.640,9$ & R21 & $\mathrm{R} 18$ & $12.066,4$ & $1.730,1$ \\
\hline R12 & $\mathrm{R} 13$ & $6.428,1$ & $2.763,3$ & R22 & $\mathrm{R} 20$ & $2.700,4$ & $1.913,4$ \\
\hline
\end{tabular}

Pela Tabela 19 é possível verificar que o ITC para todos os pares de RDS determinados foram respeitados, permanecendo sempre acima dos $300 \mathrm{~ms}$ pré-fixados. Além disso, pela observação das magnitudes dos múltiplos das correntes de partida, tanto para as PRL como para as PRR (sexta e sétima colunas da Tabela 19) conclui-se que todos os relés são sensibilizados no momento da ocorrência dos curtos-circuitos estudados, respeitando os limites para $M_{\max }=20$ e $M_{\min }=1,5$ adotados. 
Tabela 19 - Pares de RDS e seus respectivos valores de ITC, tempo de atuação da PRL e da PRR, múltiplos de máximo e mínimo da PRL e PRR, dada a parametrização principal frente à saída de LT1.

\begin{tabular}{|c|c|c|c|c|c|c|}
\hline$P R L$ & $P R R$ & $I T C(\mathrm{~s})$ & $T_{P R L}(\mathrm{~s})$ & $T_{P R R}(\mathrm{~s})$ & $M_{P R L}$ & $M_{P R R}$ \\
\hline $\mathrm{R} 4$ & R6 & 0,3509 & 0,5328 & 0,8837 & 18,81 & 4,41 \\
\hline $\mathrm{R} 4$ & R10 & 1,0992 & 0,5328 & 1,6320 & 18,81 & 2,66 \\
\hline $\mathrm{R} 4$ & R12 & 0,439 & 0,5328 & 0,9718 & 18,81 & 4,76 \\
\hline $\mathrm{R} 4$ & R14 & 0,439 & 0,5328 & 0,9718 & 18,81 & 4,76 \\
\hline R5 & R3 & 0,932 & 0,5279 & 1,4599 & 19,31 & 2,04 \\
\hline R5 & R10 & 1,1103 & 0,5279 & 1,6382 & 19,31 & 2,65 \\
\hline R5 & R12 & 0,4441 & 0,5279 & 0,9720 & 19,31 & 4,76 \\
\hline R5 & R14 & 0,4441 & 0,5279 & 0,9720 & 19,31 & 4,76 \\
\hline R6 & $\mathrm{R} 8$ & 0,4913 & 0,5319 & 1,0232 & 11,47 & 4,71 \\
\hline $\mathrm{R} 7$ & R5 & 0,3856 & 0,5267 & 0,9123 & 8,03 & 5,66 \\
\hline $\mathrm{R} 8$ & R9 & 0,6719 & 0,5222 & 1,1941 & 19,92 & 3,57 \\
\hline R9 & R3 & 0,9506 & 0,5192 & 1,4698 & 17,84 & 2,03 \\
\hline R9 & R6 & 0,3708 & 0,5192 & 0,8900 & 17,84 & 4,36 \\
\hline R9 & R12 & 0,4559 & 0,5192 & 0,9751 & 17,84 & 4,73 \\
\hline R9 & R14 & 0,4559 & 0,5192 & 0,9751 & 17,84 & 4,73 \\
\hline R10 & R7 & 0,3243 & 0,5234 & 0,8477 & 19,79 & 3,68 \\
\hline R11 & R3 & 0,8947 & 0,5289 & 1,4236 & 19,21 & 2,08 \\
\hline $\mathrm{R} 11$ & R6 & 0,3441 & 0,5289 & 0,8730 & 19,21 & 4,48 \\
\hline R11 & R10 & 1,0735 & 0,5289 & 1,6024 & 19,21 & 2,70 \\
\hline R11 & R14 & 0,4488 & 0,5289 & 0,9777 & 19,21 & 4,72 \\
\hline $\mathrm{R} 12$ & R13 & 0,3193 & 0,5128 & 0,8321 & 18,47 & 6,67 \\
\hline R12 & $\mathrm{R} 15$ & 0,4208 & 0,5128 & 0,9336 & 18,47 & 4,38 \\
\hline $\mathrm{R} 12$ & R19 & 0,4204 & 0,5128 & 0,9332 & 18,47 & 3,79 \\
\hline R13 & R3 & 0,8974 & 0,5262 & 1,4236 & 19,48 & 2,08 \\
\hline R13 & R6 & 0,3468 & 0,5262 & 0,8730 & 19,48 & 4,48 \\
\hline R13 & R10 & 1,0762 & 0,5262 & 1,6024 & 19,48 & 2,70 \\
\hline R13 & R12 & 0,4515 & 0,5262 & 0,9777 & 19,48 & 4,72 \\
\hline R14 & R11 & 0,3258 & 0,5128 & 0,8386 & 18,47 & 6,58 \\
\hline R14 & R15 & 0,4208 & 0,5128 & 0,9336 & 18,47 & 4,38 \\
\hline R14 & R19 & 0,4204 & 0,5128 & 0,9332 & 18,47 & 3,79 \\
\hline R15 & RR17 & 0,3195 & 0,5071 & 0,8266 & 14,69 & 6,76 \\
\hline R16 & R11 & 0,325 & 0,5170 & 0,8420 & 18,06 & 6,53 \\
\hline R16 & R13 & 0,3185 & 0,5170 & 0,8355 & 18,06 & 6,63 \\
\hline R16 & R19 & 0,4357 & 0,5170 & 0,9527 & 18,06 & 3,69 \\
\hline R17 & R22 & 0,3593 & 0,5754 & 0,9347 & 15,22 & 3,04 \\
\hline R18 & R16 & 0,3215 & 0,6514 & 0,9729 & 4,89 & 4,75 \\
\hline R19 & $\mathrm{R} 21$ & 0,3656 & 0,5091 & 0,8747 & 11,20 & 6,10 \\
\hline R20 & R11 & 0,3219 & 0,5210 & 0,8429 & 17,67 & 6,52 \\
\hline $\mathrm{R} 20$ & R13 & 0,3154 & 0,5210 & 0,8364 & 17,67 & 6,61 \\
\hline $\mathrm{R} 20$ & $\mathrm{R} 15$ & 0,4313 & 0,5210 & 0,9523 & 17,67 & 4,26 \\
\hline $\mathrm{R} 21$ & R18 & 0,3298 & 0,5221 & 0,8519 & 19,93 & 3,38 \\
\hline $\mathrm{R} 22$ & R20 & 0,4015 & 0,6115 & 1,0130 & 5,41 & 4,47 \\
\hline
\end{tabular}

Outro importante ponto a ser destacado é o respeito ao tempo de atuação da proteção primária (proteção de distância, dado pela Equação 9), como pode ser confirmado na quarta coluna da Tabela 19. 
De fato, com base nos resultados apresentados, afirma-se que a parametrização da topologia principal, calculada anteriormente, é capaz de assegurar a coordenação do sistema de proteção frente à saída de operação de LT1.

Vale afirmar que um comportamento similar ao apresentado para a saída da linha LT1 é observado para a retirada das linhas LT2, LT3 e LT4. Isto é, todos os pares de RDS definidos para as novas topologias estão coordenados e respeitam a atuação preferencial da proteção primária (proteção de distância) ao se utilizar a mesma parametrização obtida para a topologia principal. Este fato pode ser explicado, principalmente, pela pequena alteração nas magnitudes das correntes de contribuição de curto-circuito evidenciadas.

Os dados referentes aos cálculos de curto-circuito e verificação da validade da parametrização para as topologias em que estão inoperantes as linhas LT2, LT3 e LT4, assim como os novos pares de RDS definidos com base na condição de sensibilização determinada para a topologia principal de operação, estão apresentados da Tabela 33 até a Tabela 38 na seção de apêndices deste trabalho (Apêndice A, Apêndice B e Apêndice C).

A segunda alteração topológica a ser apresentada diz respeito à retirada de operação da linha LT6, cujos pares de RDS associados e os valores do estudo de curto-circuito estão organizados na Tabela 20.

Tabela 20 - Valor das correntes de curtos-circuitos obtido via CAPE para a topologia sem a operação de LT6.

\begin{tabular}{|c|c|c|c|c|c|c|c|}
\hline PRR & $P R L$ & $\begin{array}{c}I_{C C, \text { local }} \\
\text { (A) }\end{array}$ & $\begin{array}{c}I_{C C, \text { rem }} \\
\text { (A) }\end{array}$ & $P R R$ & $P R L$ & $\begin{array}{c}I_{C C, \text { local }} \\
\text { (A) }\end{array}$ & $\begin{array}{c}I_{C C, \text { rem }} \\
\text { (A) }\end{array}$ \\
\hline R1 & $\overline{\mathrm{R} 4}$ & $3.109,3$ & $2.092,2$ & R9 & $\overline{R 6}$ & 7.363 & $1.728,8$ \\
\hline R2 & R3 & $8.968,9$ & 421,4 & R9 & R14 & 7.363 & 3.058 \\
\hline $\mathrm{R} 2$ & R6 & $8.968,9$ & 1745 & $\mathrm{R} 10$ & R7 & $15.512,7$ & $1.409,5$ \\
\hline $\mathrm{R} 2$ & RR10 & $8.968,9$ & $2.083,4$ & $\mathrm{R} 13$ & R1 & 6.523 & 471,1 \\
\hline $\mathrm{R} 2$ & $\mathrm{R} 14$ & $8.968,9$ & $3.070,9$ & $\mathrm{R} 13$ & R3 & 6.523 & 471,1 \\
\hline R3 & R2 & $3.109,3$ & $2.092,2$ & R13 & R6 & 6.523 & $1.778,4$ \\
\hline $\mathrm{R} 4$ & $\mathrm{R} 1$ & 8.969 & 421,3 & $\mathrm{R} 13$ & R10 & 6.523 & $2.123,3$ \\
\hline $\mathrm{R} 4$ & R6 & 8.969 & 1745 & R14 & $\mathrm{R} 15$ & $3.674,6$ & $1.757,5$ \\
\hline $\mathrm{R} 4$ & R10 & 8.969 & $2.083,4$ & R14 & R19 & $3.674,6$ & $1.522,7$ \\
\hline $\mathrm{R} 4$ & $\mathrm{R} 14$ & 8.969 & $3.070,9$ & $\mathrm{R} 15$ & $\mathrm{R} 17$ & $5.863,1$ & $5.310,8$ \\
\hline R5 & R1 & $7.725,3$ & 462,6 & R16 & R13 & $6.794,5$ & $4.922,4$ \\
\hline R5 & R3 & $7.725,3$ & 462,6 & $\mathrm{R} 16$ & R19 & $6.794,5$ & $1.483,6$ \\
\hline R5 & R10 & $7.725,3$ & $2.077,6$ & R17 & R22 & $11.953,3$ & $1.477,4$ \\
\hline R5 & R14 & $7.725,3$ & $3.072,6$ & $\mathrm{R} 18$ & R16 & $2.443,4$ & $1.876,2$ \\
\hline R6 & $\mathrm{R} 8$ & $4.542,2$ & $3.771,7$ & R19 & R21 & $4.476,5$ & 3.679 \\
\hline R7 & R5 & $3.076,2$ & $2.295,5$ & $\mathrm{R} 20$ & $\mathrm{R} 13$ & $7.009,2$ & 4.913 \\
\hline R8 & R9 & $15.959,6$ & $1.490,5$ & $\mathrm{R} 20$ & R15 & $7.009,2$ & $1.709,8$ \\
\hline R9 & $\mathrm{R} 1$ & 7.363 & 460,4 & $\mathrm{R} 21$ & R18 & $12.021,5$ & 1.681 \\
\hline R9 & R3 & 7.363 & 460,4 & R22 & R20 & $2.649,2$ & $1.862,2$ \\
\hline
\end{tabular}


A Tabela 21 traz todas as variáveis estudadas que permitem a avaliação da consistência ou não da parametrização obtida para a configuração principal quando aplicada ao novo cenário topológico, assim como feito para o primeiro cenário em que a retirada de LT1 foi estudada.

Tabela 21 - Pares de RDS e seus respectivos valores de ITC, tempo de atuação da PRL e da PRR, múltiplos de máximo e mínimo da PRL e PRR, dada a parametrização principal frente à saída de LT6.

\begin{tabular}{cccrrrr}
\hline $\boldsymbol{P R R}$ & $\boldsymbol{P R \boldsymbol { L }}$ & $\boldsymbol{I} \boldsymbol{T C}(\mathbf{s})$ & $\boldsymbol{T}_{\boldsymbol{P R L}}(\mathbf{s})$ & $\boldsymbol{T}_{\boldsymbol{P R R}}(\mathbf{s})$ & \multicolumn{1}{c}{$\boldsymbol{M}_{\boldsymbol{P R L} \boldsymbol{}}$} & $\boldsymbol{M}_{\boldsymbol{P R R}}$ \\
\hline 1 & 4 & 0,5488 & 0,5103 & 1,0591 & 7,51 & 4,47 \\
2 & 6 & 0,3542 & 0,5293 & 0,8835 & 19,16 & 4,41 \\
2 & 10 & 1,102 & 0,5293 & 1,6313 & 19,16 & 2,66 \\
2 & 14 & 0,1626 & 0,5293 & 0,6919 & 19,16 & 8,82 \\
3 & 2 & 0,5525 & 0,5066 & 1,0591 & 7,62 & 4,47 \\
4 & 6 & 0,3542 & 0,5293 & 0,8835 & 19,16 & 4,41 \\
4 & 10 & 1,102 & 0,5293 & 1,6313 & 19,16 & 2,66 \\
4 & 14 & 0,1626 & 0,5293 & 0,6919 & 19,16 & 8,82 \\
5 & 10 & 1,1045 & 0,5315 & 1,6360 & 18,93 & 2,65 \\
5 & 14 & 0,1603 & 0,5315 & 0,6918 & 18,93 & 8,83 \\
6 & 8 & 0,4917 & 0,5319 & 1,0236 & 11,47 & 4,71 \\
7 & 5 & 0,3881 & 0,5279 & 0,9160 & 7,99 & 5,63 \\
8 & 9 & 0,681 & 0,5223 & 1,2033 & 19,91 & 3,54 \\
9 & 6 & 0,3662 & 0,5230 & 0,8892 & 17,48 & 4,37 \\
9 & 14 & 0,1703 & 0,5230 & 0,6933 & 17,48 & 8,79 \\
10 & 7 & 0,3288 & 0,5234 & 0,8522 & 19,79 & 3,66 \\
13 & 6 & 0,3042 & 0,5680 & 0,8722 & 15,76 & 4,49 \\
13 & 10 & 1,0319 & 0,5680 & 1,5999 & 15,76 & 2,71 \\
14 & 15 & 0,2938 & 0,6381 & 0,9319 & 10,56 & 4,39 \\
14 & 19 & 0,2933 & 0,6381 & 0,9314 & 10,56 & 3,80 \\
15 & 17 & 0,3202 & 0,5075 & 0,8277 & 14,66 & 6,74 \\
16 & 13 & 0,1025 & 0,5319 & 0,6344 & 16,69 & 11,89 \\
16 & 19 & 0,4183 & 0,5319 & 0,9502 & 16,69 & 3,70 \\
17 & 22 & 0,3812 & 0,5761 & 0,9573 & 15,17 & 2,96 \\
18 & 16 & 0,3313 & 0,6614 & 0,9927 & 4,77 & 4,61 \\
19 & 21 & 0,3666 & 0,5096 & 0,8762 & 11,17 & 6,08 \\
20 & 13 & 0,0993 & 0,5356 & 0,6349 & 16,38 & 11,87 \\
20 & 15 & 0,4142 & 0,5356 & 0,9498 & 16,38 & 4,27 \\
21 & 18 & 0,35 & 0,5228 & 0,8728 & 19,86 & 3,28 \\
22 & 20 & 0,4133 & 0,6187 & 1,0320 & 5,31 & 4,35 \\
\hline & & & & & & \\
& & & & & &
\end{tabular}

Através da terceira coluna da Tabela 21, observa-se que em 8 dos 30 pares de RDS (linhas destacadas na Tabela 21), o ITC não é respeitado. Ou seja, é inferior a 0,3 s, o que implica na descoordenação entre os relés considerados. Por esta constatação é suficiente dizer que a solução de coordenação obtida para a topologia principal de operação não é aplicável à nova configuração em que a linha LT6 é retirada de operação, sendo necessário, portanto, considerar o cálculo de outra parametrização que atenda às novas características topológicas. 
Afirma-se que resultados similares foram obtidos ao se estudar a validade da parametrização dos relés, obtida para a topologia principal de operação, frente às saídas das linhas LT5, LT7, LT8, LT9, LT10 e LT11, como pode ser conferido nas tabelas apresentadas na seção de apêndices (Apêndice D ao Apêndice I) deste documento (da Tabela 39 até a Tabela 62).

Pelas tabelas supracitadas é possível constatar, para estas variações topológicas, a necessidade da obtenção de uma nova parametrização, já que os ITC, para os pares de relés configurados, não foram integralmente respeitados utilizando-se a solução de coordenação calculada para a topologia principal de operação.

Pelo exposto neste item fica evidente que um estudo prévio concernente à validade da parametrização obtida para a topologia principal de operação deve ser considerado ao se operar o sistema com outras configurações topológicas, pois é possível que seja necessária a determinação de uma nova solução de coordenação que seja efetivamente eficaz ao proteger o SEP em questão, como será exemplificado no item 5.1.6.

\subsection{6 - COORDENAÇÃO PARA UMA VARIAÇÃO TOPOLÓGICA EM RELAÇÃO À PARAMETRIZAÇÃO PRINCIPAL}

Após a confirmação da necessidade da obtenção de uma nova solução de coordenação, dada uma variação específica na configuração do sistema, o algoritmo híbrido de coordenação pode ser novamente executado a fim de proporcionar uma parametrização que atenda à nova situação de operação vigente para o SEP.

Para exemplificar a situação supracitada, uma nova parametrização para os RDS será calculada via algoritmo de coordenação quando a saída da linha LT6 em relação à topologia de operação principal é considerada.

Uma vez que os relés envolvidos no processo de coordenação para a nova topologia são os mesmos, excluídos os relés associados à linha LT6, retirada de operação, os limites operativos referentes às suas características técnicas permanecem inalterados, assim como registrado na Tabela 7 do item 5.1.2.

Da mesma maneira, o fator limitante de um determinado trecho do SEP, conforme mostra a Equação 15, e que deve ser interpretado pelos respectivos RDS como sendo a corrente evidenciada numa situação de operação normal do sistema $\left(I_{n o m, R D S}\right)$, também permanece inalterado para a nova configuração topológica. Por esta razão, o limite inferior da 
corrente de pick-up (Equação 22) será o mesmo que o calculado para a topologia principal, restando a revisão e atualização do limite superior deste intervalo, pois outros valores para as correntes de curto-circuito podem ser encontrados em decorrência da nova topologia vigente. A nova faixa de ajuste para a corrente de partida, para cada uma dos RDS, dada a topologia sem a linha LT6 é mostrada na Tabela 22, sendo que, na segunda coluna desta tabela, têm-se apresentados entre parênteses os valores aproximados para o inteiro mais próximo, calculados partir das correntes calculadas pela Equação 16.

Tabela 22 - Definição dos limites da faixa de ajuste da corrente de partida para a topologia sem a LT6.

\begin{tabular}{|c|c|c|c|c|c|c|}
\hline RDS & $\begin{array}{c}I_{M_{\max }} \\
(\mathrm{A})\end{array}$ & $\begin{array}{c}I_{n O m, R D S}^{20 \%} \\
\text { (A) }\end{array}$ & $\begin{array}{c}I_{p, \min } \\
\text { (A) }\end{array}$ & $\begin{array}{c}I_{p, \max }^{R D S} \\
(\mathrm{~A})\end{array}$ & $\begin{array}{c}I_{M_{\min }} \\
(\mathrm{A})\end{array}$ & $\begin{array}{c}I_{p, \max } \\
\text { (A) }\end{array}$ \\
\hline $\mathrm{R} 1$ & 156 & $399,6(402)$ & 402 & 12.000 & 2.088 & 2.070 \\
\hline $\mathrm{R} 2$ & 450 & $399,6(402)$ & 450 & 12.000 & 1.392 & 1.392 \\
\hline R3 & 156 & $399,6(402)$ & 402 & 12.000 & 2.088 & 2.088 \\
\hline $\mathrm{R} 4$ & 450 & $399,6(402)$ & 450 & 12.000 & 1.392 & 1.392 \\
\hline R5 & 386,4 & $346,8(346,8)$ & 386,4 & 2.400 & 1.530 & 1.530 \\
\hline R6 & 226,8 & $346,8(346,8)$ & 346,8 & 2.400 & 1.152 & 1.152 \\
\hline R7 & 153,6 & $346,8(346,8)$ & 346,8 & 2.400 & 939,6 & 939,6 \\
\hline $\mathrm{R} 8$ & 799,2 & $346,8(348)$ & 799,2 & 4.800 & $2.512,8$ & $2.512,8$ \\
\hline R9 & 368,4 & $399,6(399,6)$ & 399,6 & 2.400 & 993,6 & 993,6 \\
\hline $\mathrm{R} 10$ & 776 & $399,6(400)$ & 776 & 3.200 & 1.384 & 1.384 \\
\hline $\mathrm{R} 11$ & - & - & - & - & - & - \\
\hline $\mathrm{R} 12$ & - & - & - & - & - & - \\
\hline $\mathrm{R} 13$ & 330 & $346,8(348)$ & 348 & 12.000 & 3.270 & 3.276 \\
\hline $\mathrm{R} 14$ & 184 & $346,8(346,8)$ & 346,8 & 1.600 & $2.038,4$ & 1.600 \\
\hline $\mathrm{R} 15$ & 294,4 & $399,6(400)$ & 400 & 6.400 & $1.139,2$ & $1.139,2$ \\
\hline $\mathrm{R} 16$ & 340 & $399,6(400)$ & 400 & 1.600 & $1.250,4$ & $1.250,4$ \\
\hline $\mathrm{R} 17$ & 598,8 & $360(360)$ & 598,8 & 2.400 & 3.540 & 2.400 \\
\hline $\mathrm{R} 18$ & 124,8 & $360(361,6)$ & 361,6 & 6.400 & 1.120 & 1.120 \\
\hline R19 & 224 & $399,6(400)$ & 400 & 1.600 & 988,8 & 988,8 \\
\hline $\mathrm{R} 20$ & 351,2 & $399,6(400)$ & 400 & 1.600 & $1.240,8$ & $1.240,8$ \\
\hline $\mathrm{R} 21$ & 601,2 & $360(360)$ & 601,2 & 2.400 & $2.452,2$ & 2.400 \\
\hline $\mathrm{R} 22$ & 132,8 & $360(360)$ & 360 & 1.600 & 984,8 & 984,8 \\
\hline
\end{tabular}

Da mesma maneira que a redefinição da faixa de ajuste da corrente de partida é necessária que os valores de ajustes mínimos dos MT sejam atualizados, uma vez que são dependentes das novas correntes de curto-circuito calculadas para a nova topologia, como mostra a Equação 23. Os novos valores calculados estão organizados na Tabela 23.

Conforme mencionado no item 5.2.1, a condição mínima de sensibilização para os RDS do sistema é dependente do intervalo inferior da corrente de partida, logo as correntes $I_{\text {min,s }}$ necessárias para a sensibilização mínima dos relés envolvidos no processo de 
coordenação perante à nova topologia de operação permanecem as mesmas, como mostra a Tabela 24.

Conforme mencionado no capítulo 3, dada uma variação na configuração do sistema é necessário realizar uma nova inspeção topológica para a determinação dos novos pares de RDS, utilizando-se para tanto a matriz de incidência $\boldsymbol{M}_{\boldsymbol{I}}$ (item 3.1).

Tabela 23 - Definição dos limites da faixa de ajuste dos MT para a topologia sem LT6.

\begin{tabular}{ccc}
\hline RDS & $\boldsymbol{A T}_{\boldsymbol{m i n}}$ & $\boldsymbol{A T}_{\boldsymbol{m a x}}$ \\
\hline R1 & 0,18 & 3,2 \\
R2 & 0,23 & 3,2 \\
R3 & 0,18 & 3,2 \\
R4 & 0,23 & 3,2 \\
R5 & 0,23 & 3,2 \\
R6 & 0,19 & 3,2 \\
R7 & 0,16 & 3,2 \\
R8 & 0,23 & 3,2 \\
R9 & 0,22 & 3,2 \\
R10 & 0,23 & 3,2 \\
R11 & - & - \\
R12 & - & - \\
R13 & 0,22 & 3,2 \\
R14 & 0,18 & 3,2 \\
R15 & 0,20 & 3,2 \\
R16 & 0,21 & 3,2 \\
R17 & 0,23 & 3,2 \\
R18 & 0,14 & 3,2 \\
R19 & 0,18 & 3,2 \\
R20 & 0,22 & 3,2 \\
R21 & 0,23 & 3,2 \\
R22 & 0,15 & 3,2 \\
\hline
\end{tabular}

Tabela 24 - Condição mínima de sensibilização dos RDS para a topologia sem LT6.

\begin{tabular}{cc}
\hline RDS & $\boldsymbol{I}_{\boldsymbol{m i n}, \boldsymbol{s}}(\mathbf{A})$ \\
\hline R1 & 603 \\
R2 & 693 \\
R3 & 603 \\
R4 & 693 \\
R5 & 597,6 \\
R6 & 520,2 \\
R7 & 520,2 \\
R8 & $1.198,8$ \\
R9 & 599,4 \\
R10 & $1.166,4$ \\
R11 & - \\
R12 & - \\
R13 & 612 \\
R14 & 520,8 \\
R15 & 600 \\
R16 & 600 \\
R17 & 900 \\
R18 & 542,4 \\
R19 & 600 \\
R20 & 600 \\
R21 & 906,3 \\
R22 & 540 \\
\hline
\end{tabular}

A Tabela 25 contém os novos pares de RDS calculados. É importante destacar que estes pares devem ser atualizados após a verificação da condição mínima de sensibilização dos mesmos.

Os dados referentes às situações de curtos-circuitos consideradas (curtos-circuitos trifásicos francos aplicados a 1\% da distância de PRL) estão organizados na Tabela 16. Cabe destacar que nesta tabela, os pares de RDS já estão atualizados segundo a condição mínima de sensibilização mencionada.

No gráfico da Figura 25 é traçada a evolução da somatória dos tempos de atuação da $\operatorname{PRL}\left(S_{T}\right)$ relativa à nova solução de coordenação calculada. Como é possível constatar por 
este gráfico, e também pela Tabela 27, o valor de $S_{T}$ tende a se estabilizar a partir da geração 2.000, mantendo seu valor praticamente constante para as próximas 8.000 gerações.

Tabela 25 - Pares de RDS determinados via matriz de incidência para a topologia sem LT6.

\begin{tabular}{|c|c|}
\hline PRL & PRR \\
\hline R1 & $\mathrm{R} 4$ \\
\hline R2 & R3, R6, R10, R12, R14 \\
\hline R3 & $\mathrm{R} 2$ \\
\hline R4 & R1, R6, R10, R12, R14 \\
\hline R5 & R1, R3, R10, R12, R14 \\
\hline R6 & $\mathrm{R} 8$ \\
\hline R7 & R5 \\
\hline R8 & R9 \\
\hline R9 & R1, R3, R6, R12, R14 \\
\hline R10 & R7 \\
\hline $\mathrm{R} 13$ & R1, R3, R6, R10, R12 \\
\hline $\mathrm{R} 14$ & $\mathrm{R} 11, \mathrm{R} 15, \mathrm{R} 19$ \\
\hline $\mathrm{R} 15$ & $\mathrm{R} 17$ \\
\hline R16 & $\mathrm{R} 11, \mathrm{R} 13, \mathrm{R} 19$ \\
\hline $\mathrm{R} 17$ & $\mathrm{R} 22$ \\
\hline R18 & R16 \\
\hline R19 & R21 \\
\hline R20 & R11, R13, R15 \\
\hline R21 & R18 \\
\hline R22 & R20 \\
\hline
\end{tabular}

Tabela 26 - Valor das correntes de curtos-circuitos obtido via CAPE para a topologia sem LT6.

\begin{tabular}{|c|c|c|c|c|c|c|c|}
\hline PRL & PRR & $\begin{array}{l}I_{C C, \text { local }} \\
\text { (A) }\end{array}$ & $\begin{array}{c}I_{C C, \text { rem }} \\
(\mathbf{A})\end{array}$ & $P R L$ & PRR & $\begin{array}{c}I_{C C, \text { local }} \\
\text { (A) }\end{array}$ & $\begin{array}{l}I_{C C, \text { rem }} \\
\text { (A) }\end{array}$ \\
\hline R1 & R4 & $3.109,3$ & $2.092,2$ & R10 & R7 & $15.512,7$ & $1.409,5$ \\
\hline R2 & R6 & $8.968,9$ & $1.745,0$ & R13 & R6 & $6.523,0$ & $1.778,4$ \\
\hline R2 & R10 & $8.968,9$ & $2.083,4$ & R13 & R10 & $6.523,0$ & $2.123,3$ \\
\hline R2 & R14 & $8.968,9$ & $3.070,9$ & R14 & R15 & $3.674,6$ & $1.757,5$ \\
\hline R3 & R2 & $3.109,3$ & $2.092,2$ & R14 & R19 & $3.674,6$ & $1.522,7$ \\
\hline R4 & R6 & $8.969,0$ & $1.745,0$ & R15 & R17 & $5.863,1$ & $5.310,8$ \\
\hline R4 & R10 & $8.969,0$ & $2.083,4$ & R16 & R13 & $6.794,5$ & $4.922,4$ \\
\hline R4 & R14 & $8.969,0$ & $3.070,9$ & R16 & R19 & $6.794,5$ & $1.483,6$ \\
\hline R5 & R10 & $7.725,3$ & $2.077,6$ & R17 & R22 & $11.953,3$ & $1.477,4$ \\
\hline R5 & R14 & $7.725,3$ & $3.072,6$ & R18 & R16 & $2.443,4$ & $1.876,2$ \\
\hline R6 & R8 & $4.542,2$ & $3.771,7$ & R19 & R21 & $4.476,5$ & $3.679,0$ \\
\hline R7 & R5 & $3.076,2$ & $2.295,5$ & R20 & R13 & $7.009,2$ & $4.913,0$ \\
\hline R8 & R9 & $15.959,6$ & $1.490,5$ & R20 & R15 & $7.009,2$ & $1.709,8$ \\
\hline R9 & R6 & $7.363,0$ & $1.728,8$ & R21 & R18 & $12.021,5$ & $1.681,0$ \\
\hline R9 & R14 & $7.363,0$ & $3.058,0$ & R22 & $\mathrm{R} 20$ & $2.649,2$ & $1.862,2$ \\
\hline
\end{tabular}




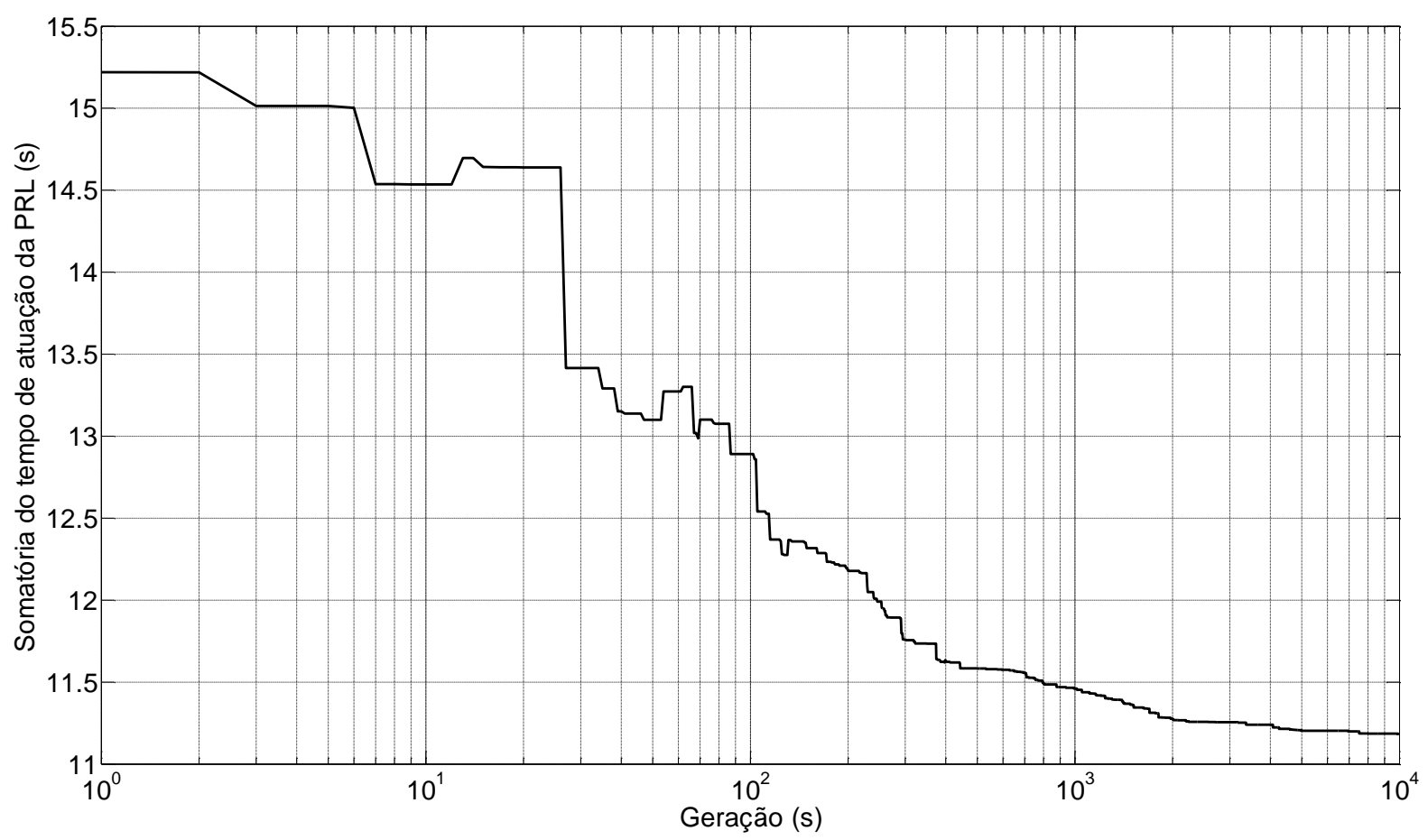

Figura 25 - Comportamento do valor de $S_{T}$ para 10.000 gerações utilizando-se $P=50$, fator $\mu=50$ e $\lambda=1$, dada a alteração na topologia em relação à principal (saída de LT6).

Tabela 27 - Valores de tempo computacional e $S_{T}$ a cada 1.000 gerações utilizando-se $P=50$, fator $\mu=50$ e $\lambda=1$ dada a saída da linha LT6.

\begin{tabular}{ccc}
\hline Geração & $\begin{array}{c}\boldsymbol{t}_{\text {comp }} \\
\text { (minutos) }\end{array}$ & $\boldsymbol{S}_{\boldsymbol{T}}(\mathbf{s})$ \\
\hline 1000 & 8,4966 & 11,4605 \\
2000 & 17,3861 & 11,2761 \\
3000 & 26,4063 & 11,2553 \\
4000 & 35,5096 & 11,2402 \\
5000 & 44,6658 & 11,2032 \\
6000 & 53,8901 & 11,2032 \\
7000 & 63,2794 & 11,2000 \\
8000 & 72,7419 & 11,1866 \\
9000 & 82,3074 & 11,1858 \\
10000 & 91,9427 & 11,1840 \\
\hline
\end{tabular}

Considerando-se a solução obtida ao final da geração 3.000, ponto em que o valor da minimização de $S_{T}$ tende a estabilizar, afirma-se que os respectivos valores calculados para os ajustes da corrente de partida e dos MT dos RDS estão inseridos nas faixas incialmente delimitadas (Tabela 22 e Tabela 23). Uma consequência direta do respeito do intervalo dos MT é garantia da atuação preferencial da proteção primária de distância, como pode ser verificado nos tempos de atuação registrados na última coluna da Tabela 28. 
Tabela 28 - Ajustes da corrente de partida e dos MT e tempos de atuação das PRL para a topologia sem a linha LT6.

\begin{tabular}{ccccc}
\hline RDS & $\boldsymbol{I}_{\boldsymbol{p}}(\boldsymbol{t a p})$ & $\boldsymbol{I}_{\boldsymbol{p}}(\mathbf{A})$ & $\boldsymbol{M} \boldsymbol{T}$ & $\boldsymbol{T}_{\boldsymbol{P R \boldsymbol { L }}}(\mathbf{s})$ \\
\hline R1 & 0,67 & 402 & 0,15 & 0,5028 \\
R2 & 0,75 & 450 & 0,23 & 0,5221 \\
R3 & 0,67 & 402 & 0,15 & 0,5028 \\
R4 & 0,76 & 456 & 0,23 & 0,5245 \\
R5 & 3,22 & 386,4 & 0,23 & 0,5216 \\
R6 & 4,17 & 500,4 & 0,19 & 0,5898 \\
R7 & 3,12 & 374,4 & 0,16 & 0,5207 \\
R8 & 3,34 & 801,6 & 0,23 & 0,5223 \\
R9 & 3,33 & 399,6 & 0,22 & 0,5133 \\
R10 & 4,86 & 777,6 & 0,23 & 0,5219 \\
R11 & - & - & - & - \\
R12 & - & - & - & - \\
R13 & 1,15 & 690 & 0,24 & 0,7312 \\
R14 & 6,16 & 492,8 & 0,22 & 0,7512 \\
R15 & 1,55 & 496 & 0,2 & 0,5529 \\
R16 & 5,75 & 460 & 0,21 & 0,5314 \\
R17 & 13,1 & 786 & 0,24 & 0,6006 \\
R18 & 1,73 & 553,6 & 0,14 & 0,6503 \\
R19 & 5,96 & 476,8 & 0,18 & 0,5501 \\
R20 & 5 & 400 & 0,22 & 0,5225 \\
R21 & 10,02 & 601,2 & 0,23 & 0,5215 \\
R22 & 5,96 & 476,8 & 0,15 & 0,6018 \\
\hline & & & & $S_{T}=11,2553$ \\
\hline
\end{tabular}

Estudando-se os valores da Tabela 29, contata-se que a nova parametrização fornecida pelo algoritmo híbrido de coordenação é capaz de garantir a coordenação do sistema teste quando configurada a nova topologia de operação (sem a linha LT6). Todos os pares de RDS, anteriormente descoordenados em função da vigência da parametrização original (topologia principal de operação), atingiram a coordenação. Além disso, a nova parametrização contempla a atuação preferencial da proteção primária de distância.

Vale salientar que o cálculo da nova parametrização foi realizado em aproximadamente 26 minutos (3.000 gerações), indicando que o algoritmo de coordenação desenvolvido pode contribuir significativamente na redução do tempo de estudo de coordenação de um dado SEP no caso de uma alteração topológica estabelecida.

Conforme anteriormente mencionado, as variações topológicas associadas às saídas de operação das linhas LT5, LT7, LT8, LT9, LT10 e LT11 também implicam na obtenção de uma nova solução de coordenação, já que alguns pares de RDS apresentam-se descoordenados. Para cada um destes casos executou-se novamente o algoritmo de 
coordenação a fim de se obter novas parametrizações que sejam válidas. Estas soluções atualizadas, relativas aos novos ajustes dos MT e das correntes de partida, estão apresentadas em tabelas na seção Apêndices (Apêndice D ao Apêndice I) deste trabalho.

As novas parametrizações obtidas, assim como no exemplo da saída da linha LT6, forneceram ajustes para os RDS que asseguram a correta atuação do SP, fato que comprova a aplicabilidade do algoritmo de coordenação desenvolvido em sistemas malhados com a possibilidade de distintas configurações topológicas.

Tabela 29 - Pares de RDS, dada a condição mínima de sensibilização, seus respectivos valores de ITC, tempo de atuação da PRL e da PRR e múltiplos de máximo e mínimo da PRL e PRR (saída de LT6).

\begin{tabular}{cccrrrr}
\hline $\boldsymbol{P R} \boldsymbol{L}$ & $\boldsymbol{P R R}$ & $\boldsymbol{I T C}(\mathbf{s})$ & $\boldsymbol{T}_{\boldsymbol{P R} \boldsymbol{L}}(\mathbf{s})$ & $\boldsymbol{T}_{\boldsymbol{P R R}}(\mathbf{s})$ & $\boldsymbol{M}_{\boldsymbol{P R} \boldsymbol{L}}$ & $\boldsymbol{M}_{\boldsymbol{P R R}}$ \\
\hline 1 & 4 & 0,5379 & 0,5028 & 1,0408 & 7,73 & 4,59 \\
2 & 6 & 0,5294 & 0,5221 & 1,0515 & 19,93 & 3,49 \\
2 & 10 & 1,0955 & 0,5221 & 1,6176 & 19,93 & 2,68 \\
2 & 14 & 0,3043 & 0,5221 & 0,8264 & 19,93 & 6,23 \\
3 & 2 & 0,5288 & 0,5028 & 1,0317 & 7,73 & 4,65 \\
4 & 6 & 0,5270 & 0,5245 & 1,0515 & 19,67 & 3,49 \\
4 & 10 & 1,0931 & 0,5245 & 1,6176 & 19,67 & 2,68 \\
4 & 14 & 0,3019 & 0,5245 & 0,8264 & 19,67 & 6,23 \\
5 & 10 & 1,1006 & 0,5216 & 1,6222 & 19,99 & 2,67 \\
5 & 14 & 0,3046 & 0,5216 & 0,8261 & 19,99 & 6,23 \\
6 & 8 & 0,4338 & 0,5898 & 1,0236 & 9,08 & 4,71 \\
7 & 5 & 0,3669 & 0,5207 & 0,8876 & 8,22 & 5,94 \\
8 & 9 & 0,6322 & 0,5223 & 1,1545 & 19,91 & 3,73 \\
9 & 6 & 0,5463 & 0,5133 & 1,0595 & 18,43 & 3,45 \\
9 & 14 & 0,3151 & 0,5133 & 0,8283 & 18,43 & 6,21 \\
10 & 7 & 0,3118 & 0,5219 & 0,8337 & 19,95 & 3,76 \\
13 & 6 & 0,3044 & 0,7312 & 1,0356 & 9,45 & 3,55 \\
13 & 10 & 0,8555 & 0,7312 & 1,5867 & 9,45 & 2,73 \\
14 & 15 & 0,3415 & 0,7512 & 1,0927 & 7,46 & 3,54 \\
14 & 19 & 0,3214 & 0,7512 & 1,0726 & 7,46 & 3,19 \\
15 & 17 & 0,3097 & 0,5529 & 0,8626 & 11,82 & 6,76 \\
16 & 13 & 0,3070 & 0,5314 & 0,8383 & 14,77 & 7,13 \\
16 & 19 & 0,5661 & 0,5314 & 1,0975 & 14,77 & 3,11 \\
17 & 22 & 0,3174 & 0,6006 & 0,9180 & 15,21 & 3,10 \\
18 & 16 & 0,3807 & 0,6503 & 1,0311 & 4,41 & 4,08 \\
19 & 21 & 0,3227 & 0,5501 & 0,8728 & 9,39 & 6,12 \\
20 & 13 & 0,3166 & 0,5225 & 0,8392 & 17,52 & 7,12 \\
20 & 15 & 0,5948 & 0,5225 & 1,1173 & 17,52 & 3,45 \\
21 & 18 & 0,3510 & 0,5215 & 0,8726 & 20,00 & 3,04 \\
22 & 20 & 0,3841 & 0,6018 & 0,9859 & 5,56 & 4,66 \\
\hline & & & & & &
\end{tabular}




\section{6 - CONSIDERAÇÕES FINAIS}

\section{$6.1-$ CONCLUSÕES}

O emprego de técnicas computacionais ao processo de obtenção de parametrizações que propiciem a coordenação entre pares de RDS, atuantes como PRL e PRR, em sistemas elétricos malhados é de fundamental importância, pois o cálculo de tais ajustes pode se apresentar como uma tarefa de significativa complexidade.

Como foi verificado no levantamento bibliográfico realizado, o estudo de coordenação mencionado é frequentemente modelado como um problema de otimização combinatória, em que são utilizadas técnicas inteligentes como AG, por exemplo, para a obtenção de parametrizações que assegurem a coordenação dos pares de RDS envolvidos. Além disso, os trabalhos estudados também afirmam que é imprescindível analisar o comportamento do SP quando são previstas variações na topologia de operação do sistema elétrico, já que é possível que a integridade da solução de coordenação se encontre comprometida frente a tais situações.

Neste contexto, a metodologia de parametrização e avaliação da coordenação desenvolvidas nesta pesquisa foi capaz de fornecer resultados satisfatórios quando aplicada ao sistema teste considerado, tanto para a topologia principal de operação como para determinadas variações em relação à mesma.

A manipulação do sistema teste via o software CAPE, referente ao sistema de subtransmissão pertencente à rede básica brasileira, de concessão da CTEEP, permitiu a realização de diversos estudos de curtos-circuitos necessários para a obtenção e avaliação da coordenação dos pares de RDS, tanto para a topologia principal como para outras configurações de operação. Os casos de faltas elétricas estudadas compreendem a aplicação de curtos-circuitos trifásicos francos a $1 \%$ de distância do relé de PRL, e constituem o caso em que se observam as maiores magnitudes das contribuições de corrente de falta.

A adequada definição dos intervalos dos MT e das correntes de pick-up foi necessária para proporcionar o bom desempenho do algoritmo de coordenação, já que este procedimento restringe e melhor delimita o espaço de busca das soluções factíveis ao problema de coordenação estabelecido. Estes mesmos benefícios podem ser atribuídos à apropriada representação cromossômica das correntes de partida de acordo com os valores do 
respectivo intervalo previamente definido, fato que evita a obtenção de ajustes de correntes de pick-up fora dos limites especificados, mesmo após a aplicação dos operadores genéticos de seleção e mutação.

Em particular, a definição do limite inferior do intervalo dos MT garante que todo relé de PRL, e, consequentemente, todo relé de PRR, atue após o tempo de zona 2 da proteção primária de distância, incluindo-se o tempo de abertura dos disjuntores e a folga estabelecida. Sendo assim, o algoritmo de coordenação sempre estará em busca de valores do MT que permitam a atuação preferencial da proteção primária.

$\mathrm{O}$ arredondamento dos valores dos ajustes encontrados pelo algoritmo, antes do cálculo do valor de aptidão dos cromossomos da população, permitiu que ao fim de cada geração, se obtivesse uma potencial parametrização compatível ao que de fato é permitido ajustar nos relés, já que, na prática, os ajustes não são contínuos, com exceção à maioria dos modelos de relés eletromecânicos. De fato, ainda que o ajuste contínuo esteja disponível, seja dos MT e /ou das correntes de pick-up, o algoritmo desenvolvido pode ser aplicado com uma prévia discretização de tais ajustes de acordo com a precisão da escala encontrada no relé, desde que em intervalos igualmente espaçados.

Tendo em vista a qualidade da solução de coordenação disponibilizada pelo algoritmo desenvolvido, afirma-se que a função de avaliação dos cromossomos se mostrou eficaz ao processar as violações referentes ao ITC, já que foi possível a minimização da função objetivo construída atendendo-se as restrições impostas. Sendo assim, é possível afirmar que o emprego do algoritmo híbrido na resolução do problema de coordenação de RDS em sistemas malhados é eficaz, confirmando o apontado em pesquisas correlatas que foram mencionadas neste trabalho.

Os ajustes obtidos pelo algoritmo híbrido de coordenação demonstram que a coordenação dos pares de RDS considerados no sistema teste foi atingida para a topologia principal de operação, isto é, a solução de coordenação disponibilizada garantiu o respeito ao ITC entre os pares de RDS, ao intervalo dos MT e à corrente de pick-up.

Contudo, conforme evidenciado no trabalho, a validade da parametrização principal procedeu em apenas 4 das 11 situações analisadas em que o SEP opera sob configurações topológicas distintas da principal. Conforme apontado, este fato está intrinsecamente relacionado com o grau de alteração das magnitudes das correntes de contribuição de falta observadas pelos RDS. Ou seja, a baixa alteração nos valores das referidas correntes, devido às saídas das linhas de LT1 a LT4, permitiram a manutenção da parametrização principal. No entanto, para as saídas das demais LT do sistema teste (LT5 a LT11), verificou-se uma maior 
modificação das magnitudes das correntes de falta, sendo necessária a obtenção de uma nova solução para a coordenação.

Para as configurações de topologia em que a parametrização tornou-se inconsistente, o algoritmo de coordenação foi executado novamente, fornecendo soluções adequadas e que respeitam as restrições incialmente impostas pelo problema de coordenação formulado.

O tempo de processamento do algoritmo, considerando-se o hardware utilizado, até se atingir a estabilização da minimização da somatória dos tempos de atuação da PRL dá-se em aproximadamente 28 minutos para a topologia principal de operação e, em média, em aproximadamente 26 minutos para as demais topologias de operação consideradas. Este fato indica que o tempo necessário a um estudo de coordenação pode ser significativamente reduzido, tendo em vista a complexidade da execução desta tarefa. Nesse sentido, quando variações na configuração topológica do sistema são consideradas, como o caso da saída de LT para manutenção e /ou manobras previstas pela concessionária de energia, o algoritmo pode fornecer em tempo hábil subsídios ao engenheiro de proteção para a tomada de decisões que garantam a adequada atuação do SP em tais condições operacionais.

Como aprimoramento da metodologia de parametrização e coordenação desenvolvida, cita-se a ampliação do conjunto de dados decorrentes do estudo de curtoscircuitos, incluindo-se, por exemplo, a incidência de faltas nas barras remotas à jusante dos relés de PRL, definindo-se de maneira mais objetiva o alcance de tais relés, potencialmente aumentando a seletividade do SP de retaguarda constituído pelos RDS.

Outro ponto a ser explorado é o aperfeiçoamento do processamento das variações topológicas, incluindo-se, por exemplo, o estudo da conexão e /ou desconexão de unidades geradoras, saída de transformadores, perda de subestações e topologias de operação em que se configurem bays radiais, já que tais alterações possivelmente modificarão as magnitudes das contribuições das correntes de falta, e, consequentemente, poderão afetar a integridade das parametrizações vigentes. Nesse sentido, a inclusão das configurações topológicas mais comumente observadas na operação do SEP, seja através da ampliação da base de dados de curto-circuito e /ou do conjunto de restrições a serem atendidas no processo de otimização, poderá possibilitar a obtenção de uma parametrização mais ampla que atenda a tais configurações específicas de operação. Além disso, também é possível citar como trabalhos futuros a análise de RDS de modelos e características diversificadas, considerar mais de um tipo de curva de tempo inverso no processo de coordenação, e incluir restrições que permitam manter o máximo possível os ajustes já encontrados para a topologia principal quando uma 
alteração topológica for evidenciada, buscando assim minimizar a necessidade de atualização em campo dos ajustes dos relés.

\section{2 - Trabalhos Publicados e Sob Processo de Submissão}

A seguir estão listados três artigos técnico-científicos divulgados e decorrentes do tema de pesquisa apresentado.

[1] BOtTurA, F. B.; NetTO, U. C.; OleSKOVICZ, M.; COURY, D. V.; SOUZA, S. A.; RAMOS, M. J. Avaliação da Coordenação de Relés Direcionais de Sobrecorrente em Sistemas Malhados Frente a Variações na Topologia de Operação. In: 2012 SIXTH IEEE/PES Transmission and Distribution: Latin America Conference and Exposition (T\&D - LA), Montevideo, 2012.

[2] BOtTURA, F.B.; BERNARDES, W. S.; OLESKOVICZ, M.; ASADA, E. N.; SOUZA, S. A.; RAMOS, M. J. Coordination of Directional Overcurrent Relays in Meshed Power Systems Using Hybrid Genetic Algorithm Optimization. In: CONFERENCE ON DEVELOPMENTS IN POWER SYSTEM PROTECTION (DPSP 2014), Copenhagen, 2014.

[3] BOtTurA, F. B.; OLESKOVICZ, M.; COURY, D.V.; SOUZA, S. A.; RAMOS, M. J.; Hybrid Optimization Algorithm for Directional Overcurrent Relay Coordination. In: IEEE POWER \& ENERGY SOCIETY GENERAL MEETING 2014, Washington, DC., 2014 (em processo de revisão). 


\section{REFERÊNCIAS BIBLIOGRÁFICAS}

ANDERSON, P. M. Power system protection. New York: McGraw-Hill, 1999.

BASHIR, M. TAGHIZADEH, M.; SADEH. J.; MASHHADI, H. R. A new hybrid particle swarm optimization for optimal coordination of overcurrent relay. In: INTERNATIONAL CONFERENCE ON POWER SYSTEM TECHNOLOGY (POWERCOM), 2010, Hangzhou. Proceedings... [S.1.] 2010, p1-6. doi: 10.1109/POWERCON.2010.5666600.

BEDKAR, P. P.; BHIDE, R. S. Optimum coordination of overcurrent relay timing using continuous genetic algorithm. Expert Systems with Applications, Elsevier, v.38, n. 9, p. 11286 - 11292, set. 2011a. doi: 10.1016/j.eswa.2011.02.177.

BEDKAR, P. P.; BHIDE, R. S. Optimum coordination of directional overcurrent relays using the hybrid GA-NLP approach. IEEE Transactions on Power Delivery, vol. 26, n. 1, p. 109119, jan. 2011b. doi: 10.1109/TPWRD.2010.2080289.

BRAGA, A. S.; SARAIVA, J. T. Coordination of overcurrent directional relays in meshed networks using the Simplex method. In: $8^{\mathrm{TH}}$ MEDITERRANEAN ELECTROTECHNICAL CONFERENCE, Bari, 1996. Proceedings... [S.1.] v..3, p. 1535 - 1538. doi: 10.1109/MELCON.1996.551243

CAMINHA, A. C. Introdução à proteção dos sistemas elétricos. São Paulo: Edgard Blücher, 1977.

CEPEL - CENTRO DE PESQUISAS DE ENERGIA ELÉTRICA (EMPRESA DO SISTEMA ELETROBRÁS). ANAFAS - Análise de Faltas Simultâneas v6.3: Manual do usuário. Rio de Janeiro: CEPEL, 2011.

COURY, D. V.; OLESKOVICZ, M.; GIOVANINI, R. Proteção digital de sistemas elétricos de potência: dos relés eletromecânicos aos microprocessados inteligentes. São Carlos: Ed. da EESC - USP, 2007. 
CTEEP-PD-0068-0020/2011. Metodologia eficiente para coordenação ótima de relés de sobrecorrente direcionais em sistemas elétricos malhados. ANEEL (Agência Nacional de Energia Elétrica).

ELECTROCON INTERNATIONAL INCORPORATED - Computer Aided Protection Engineering (CAPE). Disponível em < http://www.electrocon.com/> Acesso em 14 de agosto de 2013.

GEN, M.; CHENG, R. Genetic algorithms and engineering design. New York: John Wiley \& Sons Inc., 1997.

GOLDBERG, D. E. Genetic Algorithms, in search, optimization, and machine learning. New York: Addison-Wesley Publishing Company Inc. 1989.

HEWITSON, L. G.; BROWN, M.; BALAKRISHNAN, R. Practical Power Systems Protection. [S.1.]: Elsevier - Newnes, 2005.

INSTITUTE OF ELECTRICAL AND ELECTRONICS ENGINEERS. IEEE Std. C37.112:

IEEE standard inverse-time characteristic equations for overcurrent relays. 1997. doi: 10.1109/IEEESTD.1997.81576.

INTERNATIONAL ELECTROTECHNICAL COMISSION. IEC 60255-3: electrical relays part 3: single input energizing quantity measuring relays with dependent or independent time", 1989.

KAREGAR, H. K.; ABYANEH, H. A.; OHIS, V.; MESHKIN, M. Pre-processing of the optimal coordination of overcurrent relays. Electric Power Systems Research, Elsevier, n. 75, p. 134-141, jun 2005. doi: 10.1016/j.epsr.2005.02.005.

KENNEDY, J.; EBERHART, R. A new optimizer using particle swarm theory. In: $6^{\text {th }}$ SYMP. MICRO MACHINE AND HUMAN SCIENCE, Nagoya, 1995a. Proceedings... [S.1.] p. 3943. doi: 10.1109/MHS.1995.494215. 
KENNEDY, J.; EBERHART, R. Particle Swarm Optimization. In: IEEE INT. CONF. NEURAL NETWORKS. Perth, 1995b. Proceedings... [S.1] v.4, p. 1942-1948. doi: 10.1109/ICNN.1995.488968

KINDERMANN, G. Proteção de Sistemas Elétricos de Potência. Florianópolis: Edição do Autor, v. 1, 2005.

LEITE H.; BARROS, J.; MIRANDA, V. The evolutionary algorithm EPSO to coordinate directional overcurrent relays. In: DEVELOPMENTS IN POWER SYSTEM PROTECTION (DPSP, 2010), 10 th $^{\text {th }}$ IET INTERNATIONAL CONFERENCE, Manchester 2010. Proceedings... [S.1.] p. 1-5. doi: 10.1049/cp.2010.0318

LINDEN, R. Algoritmos Genéticos: uma importante ferramenta da inteligência computacional. Rio de Janeiro: Brasport, 2006.

MANSOUR, M. M.; MEKHAMER, S. F.; EL-KHARBAWE, N. E. A modified particle swarm optimizer for the coordination of directional overcurrent relays. IEEE Transactions on Power Delivery, v. 22, n. 3, p. 1400-1410, jul. 2007. doi: 10.1109/TPWRD.2007.899259.

MASON, C. R. The Art and science of protective relaying. New York: John Wiley and Sons, 1956.

MATHWORKS $^{\circledR}$, Documentation Center, Optimization Toolbox, Minimization, Linear Programming and Binary Integer Programming. Disponível em <http://www.mathworks.com/help/optim/ug/linprog.html> Acesso em: 27 de junho de 2013.

MIRANDA V.; FONSECA, N. EPSO - Evolutionary Particle Swarm Optimization, a new algorithm with applications in power systems. In: IEEE/PES TRANSMISSION AND DISTRIBUTION CONFERENCE AND EXHIBITION, Yokohama, 2002. Proceedings... [S.1.], v. 2, p.745-750. doi: 10.1109/TDC.2002.1177567.

NARA, K.; SHIOSE, A.; KITAGAWA, M.; ISHIHARA, T. Implementation of genetic algorithm for distribution systems loss minimum re-configuration. . IEEE Transactions on Power Systems, v. 7, n. 3, p. 1044-1051, ago. 1992. doi: 10.1109/59.207317. 
NOGHABI, A. S.; SADEH, J.; MASSHADI, H. R. Considering different network topologies in optimal overcurrent relay coordination using hybrid GA. IEEE Transactions on Power Delivery, v. 24, n. 4, p. 1857-1863, out. 2009. doi: 10.1109/TPWRD.2009.2029057.

NOGHABI, A. S.; MASHHADI, H. R.; SADEH, J. Optimal Coordination of Directional Overcurrent Relays Considering Different Network Topologies Using Interval Linear Programming. IEEE Transactions on Power Delivery, v. 25, n. 3, p. 1348-1354, jul. 2010. doi: 10.1109/TPWRD.2010.2041560.

ONS - OPERADOR NACIONAL DO SISTEMA. Disponível em < http://www.ons.org.br/operacao/base_dados_curtoc_referencia.aspx\#dados> Acesso em 14 de agosto de 2013.

PHADKE, A. G.; THORP, J. S. Computer Relaying for Power Systems. Chichester: John Wiley \& Sons Ltd., 1990.

RAO, S. S. Engineering Optimization: theory and practice. Hoboken: John Wiley \& Sons, 2009.

RAZAVI, F.; ABYANEH, H. A.; AL-DABBAGH, M.; MOHAMMADI, R.; TORKAMAN, H.. A new comprehensive genetic algorithm method for optimal overcurrent relays coordination. Electric Power Systems Research. v. 78, n. 4, p. 713-720, abr. 2008. doi: 10.1016/j.epsr.2007.05.013.

SADEH, J.; AMINOTOJARI, V.; BASHIR, M. Optimal Coordination of Overcurrent and Distance Relays with Hybrid Genetic Algorithm. In: $10^{\mathrm{TH}}$ INTERNATIONAL CONFERENCE ON ENVIRONMENT AND ELECTRICAL ENGINEERING, Rome, 2011. Proceedings... [S.1.] p. 1-5, 2011. doi: 10.1109/EEEIC.2011.5874690.

SIEMENS AG (SIPROTEC). Multi-Functional Protection Relay with Local Control 7SJ62/63/64 C53000-G1179-C147-1, [S.1.], [S.n.], 2007. 
ZEINELDIN, H.; EL-SAADANY, E. F.; SALAMA, M. A. A novel problem formulation for directional overcurrent relay coordination. large engineering systems. In: LARGE ENGINEERING CONFERENCE ON POWER ENGINEERING, 2004. Proceedings... [S.1.], p. 48-51. doi: 10.1109/LESCPE.2004.1356265. 


\section{ANEXOS}

Nas tabelas seguintes estão apresentados os dados do sistema teste reduzido. Ressalta-se que estes dados foram obtidos via CAPE considerando-se a retenção das barras da área específica do sistema de subtransmissão de $138 \mathrm{kV}$ sob concessão da CTEEP que estão conectadas ao restante da rede básica brasileira

ANEXO A - DADOS DE LINHA

Tabela 30 - Dados de linha do sistema teste reduzido de 43 barras.

\begin{tabular}{|c|c|c|c|c|c|c|c|c|c|c|c|c|}
\hline $\begin{array}{c}\text { Barra } \\
\text { de }\end{array}$ & $\begin{array}{c}\text { Barra } \\
\text { para }\end{array}$ & Circ. & Tipo & $\begin{array}{c}\mathbf{R 1} \\
\text { (p.u.) }\end{array}$ & $\begin{array}{c}\mathbf{X 1} \\
\text { (p.u.) }\end{array}$ & $\begin{array}{c}\text { R0 } \\
\text { (p.u.) }\end{array}$ & $\begin{array}{c}\mathbf{X 0} \\
\text { (p.u.) }\end{array}$ & $\mathrm{CN}$ & Tap & TB & TC & IA \\
\hline 0 & 11425 & 1 & $\mathrm{~T}$ & 99999 & 99999 & 0 & 8,61 & & & & & 9 \\
\hline 0 & 11426 & 1 & G & 0 & 54,35 & 99999 & 99999 & & & & & 9 \\
\hline 0 & 11427 & 1 & $\mathrm{~T}$ & 99999 & 99999 & 0 & 8,61 & & & & & 9 \\
\hline 0 & 11428 & 1 & G & 0 & 54,35 & 99999 & 99999 & & & & & 9 \\
\hline 0 & 11430 & 1 & $\mathrm{~T}$ & 99999 & 99999 & 0 & 10,4 & & & & & 9 \\
\hline 0 & 11431 & 1 & G & 0 & 64,14 & 99999 & 99999 & & & & & 9 \\
\hline 0 & 11432 & 1 & $\mathrm{~T}$ & 99999 & 99999 & 0 & 3,47 & & & & & 9 \\
\hline 0 & 11433 & 1 & G & 0 & 21,38 & 99999 & 99999 & & & & & 9 \\
\hline 0 & 11440 & 1 & $\mathrm{~T}$ & 99999 & 99999 & 0 & 10,05 & & & & & 9 \\
\hline 0 & 11441 & 1 & G & 0 & 154,28 & 99999 & 99999 & & & & & 9 \\
\hline 0 & 11442 & 1 & $\mathrm{~T}$ & 99999 & 99999 & 0 & 10,05 & & & & & 9 \\
\hline 0 & 11443 & 1 & G & 0 & 154,28 & 99999 & 99999 & & & & & 9 \\
\hline 0 & 19200 & 99 & $\mathrm{~T}$ & 99999 & 99999 & 0 & 65,4 & & & & & 9 \\
\hline 0 & 19210 & 99 & $\mathrm{~T}$ & 99999 & 99999 & 3,91 & 55,97 & & & & & 9 \\
\hline 0 & 19218 & 99 & $\mathrm{~T}$ & 99999 & 99999 & 0 & 44,143 & & & & & 9 \\
\hline 0 & 19226 & 99 & $\mathrm{~T}$ & 99999 & 99999 & 0,01 & 71,84 & & & & & 9 \\
\hline 0 & 19227 & 99 & $\mathrm{~T}$ & 99999 & 99999 & 0,2 & 134,65 & & & & & 9 \\
\hline 0 & 19240 & 99 & G & 1,1357 & 4,0663 & 2,4139 & 9,9727 & & & & & 9 \\
\hline 0 & 19247 & 99 & $\mathrm{~T}$ & 99999 & 99999 & 2,71 & 152,52 & & & & & 9 \\
\hline 0 & 19280 & 99 & G & 0,6111 & 2,8608 & 2,0929 & 9,0173 & & & & & 9 \\
\hline 0 & 19294 & 99 & $\mathrm{~T}$ & 99999 & 99999 & 0 & 102 & & & & & 9 \\
\hline 0 & 33041 & 1 & $\mathrm{~T}$ & 99999 & 99999 & 6301,2 & 16 & & & & & 9 \\
\hline 0 & 33042 & 1 & G & 0 & 38,86 & 6301,2 & 18,24 & & & & & 9 \\
\hline 0 & 33045 & 1 & G & 0 & 92,8 & 0 & 25,6 & & & & & 9 \\
\hline 0 & 33045 & 2 & $\mathrm{~T}$ & 99999 & 99999 & 0 & 35 & & & & & 9 \\
\hline 0 & 33049 & 1 & G & 0 & 92,8 & 3150,6 & 25,6 & & & & & 9 \\
\hline 0 & 33049 & 2 & G & 0 & 108 & 3150,6 & 28 & & & & & 9 \\
\hline 0 & 33049 & 3 & $\mathrm{~T}$ & 99999 & 99999 & 0 & 35 & & & & & 9 \\
\hline 0 & 33052 & 1 & G & 0 & 92,8 & 0 & 25,6 & & & & & 9 \\
\hline 0 & 33052 & 2 & $\mathrm{~T}$ & 99999 & 99999 & 0 & 35 & & & & & 9 \\
\hline
\end{tabular}


Tabela 30 - Continuação

\begin{tabular}{|c|c|c|c|c|c|c|c|c|c|c|c|c|}
\hline $\begin{array}{c}\text { Barra } \\
\text { de }\end{array}$ & $\begin{array}{c}\text { Barra } \\
\text { para }\end{array}$ & Circ. & Tipo & $\begin{array}{c}\mathbf{R 1} \\
\text { (p.u.) }\end{array}$ & $\begin{array}{c}\text { X1 } \\
\text { (p.u.) }\end{array}$ & $\begin{array}{c}\text { R0 } \\
\text { (p.u.) }\end{array}$ & $\begin{array}{c}\mathbf{X 0} \\
\text { (p.u.) }\end{array}$ & CN & Tap & TB & TC & IA \\
\hline 0 & 33053 & 1 & G & 0 & 92,8 & 3150,6 & 25,6 & & & & & 9 \\
\hline 0 & 33053 & 2 & G & 0 & 108 & 3150,6 & 28 & & & & & 9 \\
\hline 0 & 33053 & 3 & $\mathrm{~T}$ & 99999 & 99999 & 0 & 35 & & & & & 9 \\
\hline 19200 & 19210 & 1 & & 3,63 & 9,52 & 10,08 & 33,61 & CTP & & & & 0 \\
\hline 19217 & 19218 & 1 & & 1,77 & 3,84 & 4,23 & 13,4 & CTP & & & & 0 \\
\hline 19210 & 19218 & 1 & & 3,7 & 7,92 & 8,93 & 27,46 & CTP & & & & 0 \\
\hline 19210 & 19220 & 1 & & 0,81 & 1,75 & 1,7 & 6,35 & CTP & & & & 0 \\
\hline 19210 & 19220 & 2 & & 0,81 & 1,75 & 1,7 & 6,35 & CTP & & & & 0 \\
\hline 19220 & 19226 & 1 & & 1,7 & 4,45 & 4,72 & 15,73 & CTP & & & & 0 \\
\hline 19220 & 19227 & 1 & & 3,91 & 10,24 & 10,86 & 36,2 & CTP & & & & 0 \\
\hline 19247 & 19240 & 1 & & 1,3 & 3,42 & 3,62 & 12,07 & CTP & & & & 0 \\
\hline 19226 & 19246 & 1 & & 0,53 & 1,39 & 1,47 & 4,92 & CTP & & & & 0 \\
\hline 19217 & 19280 & 1 & & 0,7 & 1,83 & 1,94 & 6,45 & CTP & & & & 0 \\
\hline 19294 & 19280 & 1 & & 0,8 & 2,08 & 2,13 & 7,43 & CTP & & & & 0 \\
\hline 19216 & 19294 & 1 & & 0,01 & 0,03 & 0,03 & 0,09 & CTP & & & & 0 \\
\hline 19240 & 33007 & 1 & & 1,35 & 3,54 & 3,75 & 12,5 & & & & & 0 \\
\hline 33007 & 33006 & 1 & & 0,0965 & 0,2531 & 0,2681 & 0,8927 & & & & & 0 \\
\hline 33008 & 33006 & 1 & & 0,0965 & 0,2531 & 0,2681 & 0,8927 & & & & & 0 \\
\hline 33008 & 19246 & 1 & & 2,67 & 7,01 & 7,43 & 24,73 & & & & & 0 \\
\hline 19216 & 33047 & 1 & & 1,43 & 3,05 & 3,44 & 10,58 & CTP & & & & 0 \\
\hline 33048 & 19210 & 1 & & 3,93 & 8,43 & 9,5 & 29,21 & CTP & & & & 0 \\
\hline 33048 & 33046 & 1 & & 0,85 & 2,194 & 2,93 & 9 & CTP & & & & 0 \\
\hline 33047 & 33046 & 1 & & 0,85 & 2,194 & 2,93 & 9 & CTP & & & & 0 \\
\hline 19227 & 33040 & 1 & & 0,52 & 1,45 & 1,37 & 4,83 & CTP & & & & 0 \\
\hline 33040 & 33032 & 1 & & 0,83 & 2,06 & 2,06 & 7,75 & CTP & & & & 0 \\
\hline 33032 & 33039 & 1 & & 0,83 & 2,06 & 2,06 & 7,75 & CTP & & & & 0 \\
\hline 33039 & 19247 & 1 & & 0,52 & 1,36 & 1,45 & 4,82 & CTP & & & & 0 \\
\hline 19200 & 19219 & 1 & & 3,01 & 7,9 & 8,37 & 27,89 & CTP & & & & 0 \\
\hline 19219 & 19210 & 1 & & 0,62 & 1,62 & 1,72 & 5,72 & CTP & & & & 0 \\
\hline 11426 & 11425 & 1 & $\mathrm{~T}$ & 0 & 12,3 & 99999 & 99999 & AES & 1 & & & 0 \\
\hline 19200 & 11425 & 1 & $\mathrm{~T}$ & 0 & 12,3 & 0 & 12,3 & AES & 1 & & & 0 \\
\hline 19200 & 11427 & 1 & $\mathrm{~T}$ & 0 & 12,3 & 0 & 12,3 & AES & 1 & & & 0 \\
\hline 11428 & 11427 & 1 & $\mathrm{~T}$ & 0 & 12,3 & 99999 & 99999 & AES & 1 & & & 0 \\
\hline 11431 & 11430 & 1 & $\mathrm{~T}$ & 0 & 15 & 99999 & 99999 & AES & 1 & & & 0 \\
\hline 19210 & 11430 & 1 & $\mathrm{~T}$ & 0 & 15 & 0 & 15 & AES & 1 & & & 0 \\
\hline 19210 & 11432 & 1 & $\mathrm{~T}$ & 0 & 5 & 0 & 5 & AES & 1 & & & 0 \\
\hline 11433 & 11432 & 1 & $\mathrm{~T}$ & 0 & 5 & 99999 & 99999 & AES & 1 & & & 0 \\
\hline 11441 & 11440 & 1 & $\mathrm{~T}$ & 0 & 24,12 & 99999 & 99999 & AES & 1 & & & 0 \\
\hline 19220 & 11440 & 1 & $\mathrm{~T}$ & 0 & 24,12 & 0 & 24,12 & AES & 1 & & & 0 \\
\hline 19220 & 11442 & 1 & $\mathrm{~T}$ & 0 & 24,12 & 0 & 24,12 & AES & 1 & & & 0 \\
\hline 11443 & 11442 & 1 & $\mathrm{~T}$ & 0 & 24,12 & 99999 & 99999 & AES & 1 & & & 0 \\
\hline 33006 & 33041 & 1 & $\mathrm{~T}$ & 0 & 16 & 99999 & 99999 & & 1 & & & 0 \\
\hline 33042 & 33041 & 1 & $\mathrm{~T}$ & 0 & 16 & 0 & 16 & & 1 & & & 0 \\
\hline 33046 & 33045 & 1 & $\mathrm{~T}$ & 0 & 35 & 99999 & 99999 & ELK & 1 & & & 0 \\
\hline 33046 & 33049 & 1 & $\mathrm{~T}$ & 0 & 35 & 99999 & 99999 & ELK & 1 & & & 0 \\
\hline 33032 & 33052 & 1 & $\mathrm{~T}$ & 0 & 35 & 99999 & 99999 & EKT & 1 & & & 0 \\
\hline 33032 & 33053 & 1 & $\mathrm{~T}$ & 0 & 35 & 99999 & 99999 & EKT & 1 & & & 0 \\
\hline 19240 & 19280 & 99 & & 27,232 & 48,685 & 566,11 & 990,81 & EQIV & & & & 9 \\
\hline 14247 & 19217 & 1 & & 0 & 0,001 & 0 & 0,001 & Tie & & & & 9 \\
\hline 14509 & 19294 & 1 & & 0 & 0,001 & 0 & 0,001 & Tie & & & & 9 \\
\hline
\end{tabular}


ANEXO B - DADOS DE BARRA

Tabela 31 - Dados de barra do sistema equivalente de 43 barras.

\begin{tabular}{ccccccc}
\hline Barra & Tipo & Nome & V & Ang & V $_{\text {base }}$ & Área \\
\hline 11425 & 1 & T\#CAC138 13A & 1 & 0 & & 51 \\
11426 & 0 & CAC.G1 13.8 & 1 & 0 & 13.8 & 51 \\
11427 & 1 & T\#CAC138 13B & 1 & 0 & & 51 \\
11428 & 0 & CAC.G2 13.8 & 1 & 0 & 13.8 & 51 \\
11430 & 1 & T\#EUC138 13A & 1 & 0 & & 51 \\
11431 & 0 & EUC.G1 13.8 & 1 & 0 & 13.8 & 51 \\
11432 & 1 & T\#EUC138 13B & 1 & 0 & & 51 \\
11433 & 0 & EUC.G2- 13.8 & 1 & 0 & 13.8 & 51 \\
11440 & 1 & T\#LMO138 13A & 1 & 0 & & 51 \\
11441 & 0 & LMO.G1 13.8 & 1 & 0 & 13.8 & 51 \\
11442 & 1 & T\#LMO138 13B & 1 & 0 & & 51 \\
11443 & 0 & LMO.G2 13.8 & 1 & 0 & 13.8 & 51 \\
14247 & 0 & ELFUSA 138 & 1 & 0 & 138 & 38 \\
14509 & 0 & SJBVIST 138 & 1 & 0 & 138 & 38 \\
19200 & 0 & CACONDE 138 & 1 & 0 & 138 & 9 \\
19210 & 0 & EUCUNHA 138 & 1 & 0 & 138 & 9 \\
19216 & 2 & D\#ASSOF 138 & 1 & 0 & 138 & 9 \\
19217 & 2 & D\#ELFUS 138 & 1 & 0 & 138 & 9 \\
19218 & 2 & D\#VGS 138 & 1 & 0 & 138 & 9 \\
19219 & 0 & SJRPARD 138 & 1 & 0 & 138 & 9 \\
19220 & 0 & LIMOEIR 138 & 1 & 0 & 138 & 9 \\
19226 & 2 & D\#CBRAN 138 & 1 & 0 & 138 & 9 \\
19227 & 2 & D\#SCRUZ 138 & 1 & 0 & 138 & 9 \\
19240 & 0 & P.FERR. 138 & 1 & 0 & 138 & 9 \\
19246 & 2 & D\#CABFE 138 & 1 & 0 & 138 & 9 \\
19247 & 2 & D\#PSS2 138 & 1 & 0 & 138 & 9 \\
19280 & 0 & SJBVIST 138 & 1 & 0 & 138 & 9 \\
19294 & 2 & D\#SJBV1 138 & 1 & 0 & 138 & 9 \\
33006 & 0 & US FERR 138 & 1 & 0 & 138 & 38 \\
33007 & 2 & A\#USFER 138 & 1 & 0 & 138 & 38 \\
33008 & 2 & A\#USFER 138 & 1 & 0 & 138 & 38 \\
33032 & 0 & USABENS 138 & 1 & 0 & 138 & 38 \\
33039 & 2 & A\#USABS 138 & 1 & 0 & 138 & 38 \\
33040 & 2 & A\#USABS 138 & 1 & 0 & 138 & 38 \\
33041 & 1 & T\#FER138 13 & 1 & 0 & & 9 \\
33042 & 0 & FERRARI 13.8 & 1 & 0 & 13.8 & 9 \\
33045 & 0 & S.JOAO 13.8 & 1 & 0 & 13.8 & 38 \\
33046 & 0 & US.ABEN 138 & 1 & 0 & 138 & 38 \\
33047 & 2 & A\#USABS 138 & 1 & 0 & 138 & 38 \\
33048 & 2 & A\#USABS 138 & 1 & 0 & 138 & 38 \\
33049 & 0 & S.JOAO 13.8 & 1 & 0 & 13.8 & 38 \\
33052 & 0 & S.LUIZ 13.8 & 1 & 0 & 13.8 & 38 \\
33053 & 0 & S.LUIZ 13.8 & 1 & 0 & 13.8 & 38 \\
\hline & & & & &
\end{tabular}


ANEXO C - DADOS DAS IMPEDÂNCIAS MÚTUAS

Tabela 32 - Dados das impedâncias mútuas do sistema reduzido de 43 barras.

\begin{tabular}{cccccccc}
\hline Barra de 1 & Barra para 1 & NC1 & Barra de 2 & Barra para 2 & NC2 & Rm & Xm \\
\hline 19200 & 19210 & 1 & 19200 & 19219 & 1 & 536 & 1840 \\
19200 & 19210 & 1 & 19219 & 19210 & 1 & 110 & 377 \\
19217 & 19218 & 1 & 19216 & 19294 & 1 & 2 & 6 \\
19217 & 19218 & 1 & 19216 & 33047 & 1 & 63 & 215 \\
19217 & 19218 & 1 & 33048 & 19210 & 1 & 173 & 593 \\
19210 & 19220 & 2 & 19210 & 19220 & 1 & 92 & 424 \\
19220 & 19226 & 1 & 19220 & 19227 & 1 & 302 & 1038 \\
19226 & 19246 & 1 & 19220 & 19227 & 1 & 94 & 324 \\
19217 & 19280 & 1 & 19294 & 19280 & 1 & 124 & 426 \\
19294 & 19280 & 1 & 19217 & 19218 & 1 & 9 & 67 \\
19240 & 33007 & 1 & 19247 & 19240 & 1 & -232 & -796 \\
33008 & 19246 & 1 & 19220 & 19227 & 1 & -475 & -1634 \\
33008 & 19246 & 1 & 19227 & 33040 & 1 & -93 & -319 \\
33008 & 19246 & 1 & 33039 & 19247 & 1 & -92 & -318 \\
19216 & 33047 & 1 & 19210 & 19218 & 1 & 139 & 478 \\
33048 & 19210 & 1 & 19210 & 19218 & 1 & 385 & 1321 \\
\hline
\end{tabular}




\section{APÊNDICES}

Perante o exposto no item 5.1.5 do capítulo de resultados, estão apresentados no que segue os resultados das avaliações da parametrização dos RDS obtida para a configuração principal de operação do sistema dada às variações topológicas que compreendem as saídas das linhas LT2, LT3, LT4, LT5, LT7, LT8, LT9, LT10 e LT11.

As avaliações estão apresentadas separadamente para cada uma das LT acima listadas, utilizando-se tabelas que contém os valores do estudo de curto-circuito referente às novas configurações de operação evidenciadas, tempo de atuação da PRL e PRR, valor de ITC e múltiplos de corrente obtidos.

Além disso, detectada a descoordenação dos pares de RDS, apresentam-se as novas parametrizações calculadas ao final de 3.000 gerações (ponto de estabilização do valor de $S_{T}$ para a nova topologia de operação, verificando-se e demonstrando-se sua validade). Cabe salientar que com exceção das tabelas que trazem os dados do estudo de curtos-circuitos, as demais tabelas já consideram as condições mínimas de sensibilização de cada RDS.

APÊNDICE A - TOPOLOGIA DE OPERAÇÃO SEM A LINHA LT2

Tabela 33 - Correntes de curto-circuito observadas pela PRL e PRR em função da saída da linha LT2.

\begin{tabular}{|c|c|c|c|c|c|c|c|}
\hline$P R R$ & $P R L$ & $I_{C C, \text { local }}(\mathrm{A})$ & $I_{C C, \text { rem }}(\mathrm{A})$ & $P R R$ & $P R L$ & $I_{C C, \text { local }}(\mathrm{A})$ & $I_{C C, \text { rem }}(\mathrm{A})$ \\
\hline $\mathrm{R} 2$ & R6 & $8.801,5$ & $1.744,5$ & R12 & R15 & $6.428,1$ & $1.752,8$ \\
\hline R2 & $\mathrm{R} 10$ & $8.801,5$ & $2.082,5$ & R12 & R19 & $6.428,1$ & $1.518,9$ \\
\hline R2 & $\mathrm{R} 12$ & $8.801,5$ & $1.656,1$ & R13 & R1 & $8.066,2$ & 848,5 \\
\hline R2 & R14 & $8.801,5$ & $1.656,1$ & R13 & R6 & $8.066,2$ & $1.776,0$ \\
\hline R5 & R1 & $7.876,6$ & 833,3 & R13 & R10 & $8.066,2$ & $2.120,1$ \\
\hline R5 & R10 & $7.876,6$ & $2.074,9$ & R13 & $\mathrm{R} 12$ & $8.066,2$ & $1.640,9$ \\
\hline R5 & $\mathrm{R} 12$ & $7.876,6$ & $1.655,7$ & R14 & R11 & $6.428,1$ & $2.763,3$ \\
\hline R5 & R14 & $7.876,6$ & $1.655,7$ & R14 & R15 & $6.428,1$ & $1.752,8$ \\
\hline R6 & R8 & $4.544,0$ & $3.773,6$ & R14 & R19 & $6.428,1$ & $1.518,9$ \\
\hline R7 & R5 & $3.091,4$ & $2.311,2$ & R15 & R17 & $5.876,5$ & $5.324,2$ \\
\hline R8 & R9 & $15.969,1$ & $1.504,9$ & R16 & R11 & $7.352,2$ & $2.742,8$ \\
\hline R9 & R1 & $7.512,8$ & 829,3 & R16 & R13 & $7.352,2$ & $2.742,8$ \\
\hline R9 & R6 & $7.512,8$ & $1.726,5$ & R16 & R19 & $7.352,2$ & $1.478,5$ \\
\hline R9 & $\mathrm{R} 12$ & $7.512,8$ & $1.647,6$ & R17 & R22 & $11.988,1$ & $1.516,1$ \\
\hline R9 & R14 & $7.512,8$ & $1.647,6$ & R18 & R16 & $2.501,9$ & $1.934,6$ \\
\hline R10 & R7 & $15.518,0$ & $1.419,1$ & R19 & R21 & $4.487,5$ & $3.690,1$ \\
\hline R11 & R1 & $8.066,2$ & 848,5 & R20 & R11 & $7.563,8$ & $2.737,3$ \\
\hline R11 & R6 & $8.066,2$ & $1.776,0$ & R20 & R13 & $7.563,8$ & $2.737,3$ \\
\hline R11 & R10 & $8.066,2$ & $2.120,1$ & R20 & R15 & $7.563,8$ & $1.703,5$ \\
\hline R11 & R14 & $8.066,2$ & $1.640,9$ & R21 & R18 & $12.066,4$ & $1.730,1$ \\
\hline R12 & R13 & $6.428,1$ & $2.763,3$ & R22 & R20 & $2.700,4$ & $1.913,4$ \\
\hline
\end{tabular}


Tabela 34 - Pares de RDS sensibilizados e seus respectivos valores de ITC, tempo de atuação da PRL e da PRR, múltiplos de máximo e mínimo da PRL e PRR, dada a parametrização principal frente à saída de LT2.

\begin{tabular}{|c|c|c|c|c|c|c|}
\hline$P R R$ & $P R L$ & $I T C(\mathrm{~s})$ & $T_{P R L}(\mathrm{~s})$ & $T_{P R R}(\mathrm{~s})$ & $M_{P R L}$ & $M_{P R R}$ \\
\hline $\mathrm{R} 2$ & R6 & 0,3509 & 0,5328 & 0,8837 & 18,81 & 4,41 \\
\hline R2 & R10 & 1,0992 & 0,5328 & 1,6320 & 18,81 & 2,66 \\
\hline R2 & R12 & 0,439 & 0,5328 & 0,9718 & 18,81 & 4,76 \\
\hline R2 & R14 & 0,439 & 0,5328 & 0,9718 & 18,81 & 4,76 \\
\hline R5 & R1 & 0,9626 & 0,5279 & 1,4905 & 19,31 & 2,01 \\
\hline R5 & R10 & 1,1103 & 0,5279 & 1,6382 & 19,31 & 2,65 \\
\hline R5 & R12 & 0,4441 & 0,5279 & 0,9720 & 19,31 & 4,76 \\
\hline R5 & R14 & 0,4441 & 0,5279 & 0,9720 & 19,31 & 4,76 \\
\hline R6 & R8 & 0,4913 & 0,5319 & 1,0232 & 11,47 & 4,71 \\
\hline R7 & R5 & 0,3856 & 0,5267 & 0,9123 & 8,03 & 5,66 \\
\hline R8 & R9 & 0,6719 & 0,5222 & 1,1941 & 19,92 & 3,57 \\
\hline R9 & R1 & 0,9817 & 0,5192 & 1,5009 & 17,84 & 2,00 \\
\hline R9 & R6 & 0,3708 & 0,5192 & 0,8900 & 17,84 & 4,36 \\
\hline R9 & R12 & 0,4559 & 0,5192 & 0,9751 & 17,84 & 4,73 \\
\hline R9 & R14 & 0,4559 & 0,5192 & 0,9751 & 17,84 & 4,73 \\
\hline R10 & R7 & 0,3243 & 0,5234 & 0,8477 & 19,79 & 3,68 \\
\hline R11 & R1 & 0,9238 & 0,5289 & 1,4527 & 19,21 & 2,05 \\
\hline R11 & R6 & 0,3441 & 0,5289 & 0,8730 & 19,21 & 4,48 \\
\hline R11 & R10 & 1,0735 & 0,5289 & 1,6024 & 19,21 & 2,70 \\
\hline R11 & R14 & 0,4488 & 0,5289 & 0,9777 & 19,21 & 4,72 \\
\hline R12 & R13 & 0,3193 & 0,5128 & 0,8321 & 18,47 & 6,67 \\
\hline R12 & R15 & 0,4208 & 0,5128 & 0,9336 & 18,47 & 4,38 \\
\hline R12 & R19 & 0,4204 & 0,5128 & 0,9332 & 18,47 & 3,79 \\
\hline R13 & R1 & 0,9265 & 0,5262 & 1,4527 & 19,48 & 2,05 \\
\hline R13 & R6 & 0,3468 & 0,5262 & 0,8730 & 19,48 & 4,48 \\
\hline R13 & R10 & 1,0762 & 0,5262 & 1,6024 & 19,48 & 2,70 \\
\hline R13 & R12 & 0,4515 & 0,5262 & 0,9777 & 19,48 & 4,72 \\
\hline R14 & R11 & 0,3258 & 0,5128 & 0,8386 & 18,47 & 6,58 \\
\hline R14 & R15 & 0,4208 & 0,5128 & 0,9336 & 18,47 & 4,38 \\
\hline R14 & R19 & 0,4204 & 0,5128 & 0,9332 & 18,47 & 3,79 \\
\hline R15 & R17 & 0,3195 & 0,5071 & 0,8266 & 14,69 & 6,76 \\
\hline R16 & R11 & 0,325 & 0,5170 & 0,8420 & 18,06 & 6,53 \\
\hline R16 & R13 & 0,3185 & 0,5170 & 0,8355 & 18,06 & 6,63 \\
\hline R16 & R19 & 0,4357 & 0,5170 & 0,9527 & 18,06 & 3,69 \\
\hline R17 & R22 & 0,3593 & 0,5754 & 0,9347 & 15,22 & 3,04 \\
\hline R18 & R16 & 0,3215 & 0,6514 & 0,9729 & 4,89 & 4,75 \\
\hline R19 & R21 & 0,3656 & 0,5091 & 0,8747 & 11,20 & 6,10 \\
\hline R20 & R11 & 0,3219 & 0,5210 & 0,8429 & 17,67 & 6,52 \\
\hline R20 & R13 & 0,3154 & 0,5210 & 0,8364 & 17,67 & 6,61 \\
\hline R20 & R15 & 0,4313 & 0,5210 & 0,9523 & 17,67 & 4,26 \\
\hline R21 & R18 & 0,3298 & 0,5221 & 0,8519 & 19,93 & 3,38 \\
\hline R22 & R20 & 0,4015 & 0,6115 & 1,0130 & 5,41 & 4,47 \\
\hline
\end{tabular}


APÊNDICE B - TOPOLOGIA DE OPERAÇÃO SEM A LINHA LT3

Tabela 35 - Correntes de curto-circuito observadas pela PRL e PRR em função da saída da linha LT3.

\begin{tabular}{|c|c|c|c|c|c|c|c|}
\hline$P R R$ & $P R L$ & $I_{C C, \text { local }}(\mathrm{A})$ & $I_{C C, \text { rem }}(\mathrm{A})$ & $P R R$ & $P R L$ & $I_{C C, \text { local }}(\mathrm{A})$ & $I_{C C, \text { rem }}(\mathrm{A})$ \\
\hline R1 & $\mathrm{R} 4$ & $2.950,3$ & $1.929,9$ & R12 & R15 & $5.875,7$ & $1.760,0$ \\
\hline R2 & R3 & $7.732,1$ & 428,0 & R12 & R19 & $5.875,7$ & $1.524,5$ \\
\hline R2 & R10 & $7.732,1$ & $2.316,2$ & R13 & R1 & $6.626,9$ & 471,1 \\
\hline R2 & R12 & $7.732,1$ & $1.667,1$ & R13 & R3 & $6.626,9$ & 471,1 \\
\hline R2 & R14 & $7.732,1$ & $1.667,1$ & R13 & R10 & $6.626,9$ & $2.353,0$ \\
\hline R3 & R2 & $2.950,3$ & $1.929,9$ & R13 & R12 & $6.626,9$ & $1.655,3$ \\
\hline R4 & R1 & $7.732,1$ & 428,0 & R14 & R11 & $5.875,7$ & $2.200,6$ \\
\hline R4 & R10 & $7.732,1$ & $2.316,2$ & R14 & R15 & $5.875,7$ & $1.760,0$ \\
\hline R4 & R12 & $7.732,1$ & $1.667,1$ & R14 & R19 & $5.875,7$ & $1.524,5$ \\
\hline R4 & R14 & $7.732,1$ & $1.667,1$ & R15 & R17 & $5.853,6$ & $5.301,0$ \\
\hline R8 & R9 & $16.291,3$ & $1.824,1$ & R16 & R11 & $6.271,5$ & $2.196,3$ \\
\hline R9 & R1 & $5.936,8$ & 462,8 & R16 & R13 & $6.271,5$ & $2.196,3$ \\
\hline R9 & R3 & $5.936,8$ & 462,8 & R16 & R19 & $6.271,5$ & $1.490,1$ \\
\hline R9 & R12 & $5.936,8$ & $1.663,8$ & R17 & R22 & $11.928,8$ & $1.444,7$ \\
\hline R9 & R14 & $5.936,8$ & $1.663,8$ & R18 & R16 & $2.390,3$ & $1.820,6$ \\
\hline $\mathrm{R} 10$ & R7 & $14.822,1$ & 678,3 & R19 & $\mathrm{R} 21$ & $4.468,1$ & $3.670,2$ \\
\hline $\mathrm{R} 11$ & R1 & $6.626,9$ & 471,1 & $\mathrm{R} 20$ & R11 & $6.487,8$ & $2.192,3$ \\
\hline $\mathrm{R} 11$ & R3 & $6.626,9$ & 471,1 & $\mathrm{R} 20$ & R13 & $6.487,8$ & $2.192,3$ \\
\hline $\mathrm{R} 11$ & R10 & $6.626,9$ & $2.353,3$ & $\mathrm{R} 20$ & $\mathrm{R} 15$ & $6.487,8$ & $1.717,8$ \\
\hline $\mathrm{R} 11$ & R14 & $6.626,9$ & $1.655,3$ & $\mathrm{R} 21$ & R18 & $11.987,7$ & $1.638,9$ \\
\hline $\mathrm{R} 12$ & $\mathrm{R} 13$ & $5.875,7$ & $2.200,6$ & $\mathrm{R} 22$ & $\mathrm{R} 20$ & $2.602,7$ & $1.812,7$ \\
\hline
\end{tabular}

Tabela 36 - Pares de RDS sensibilizados e seus respectivos valores de ITC, tempo de atuação da PRL e da PRR, múltiplos de máximo e mínimo da PRL e PRR, dada a parametrização principal frente à saída de LT3.

\begin{tabular}{cccrrrr}
\hline $\boldsymbol{P R R}$ & $\boldsymbol{P R L}$ & $\boldsymbol{I T C}(\mathbf{s})$ & $\boldsymbol{T}_{\boldsymbol{P R L}}(\mathbf{s})$ & $\boldsymbol{T}_{\boldsymbol{P R R}}(\mathbf{s})$ & $\boldsymbol{M}_{\boldsymbol{P R L} \boldsymbol{}}$ & $\boldsymbol{M}_{\boldsymbol{P R R}}$ \\
\hline $\mathrm{R} 1$ & $\mathrm{R} 4$ & 0,5962 & 0,5242 & 1,1204 & 7,13 & 4,12 \\
R2 & R10 & 0,9121 & 0,5581 & 1,4702 & 16,52 & 2,95 \\
R2 & R12 & 0,4096 & 0,5581 & 0,9677 & 16,52 & 4,79 \\
R2 & R14 & 0,4096 & 0,5581 & 0,9677 & 16,52 & 4,79 \\
R3 & R2 & 0,6001 & 0,5203 & 1,1204 & 7,23 & 4,12 \\
R4 & R10 & 0,9121 & 0,5581 & 1,4702 & 16,52 & 2,95 \\
R4 & R12 & 0,4096 & 0,5581 & 0,9677 & 16,52 & 4,79 \\
R4 & R14 & 0,4096 & 0,5581 & 0,9677 & 16,52 & 4,79 \\
R8 & R9 & 0,5167 & 0,5186 & 1,0353 & 20,32 & 4,33 \\
R9 & R12 & 0,4021 & 0,5668 & 0,9689 & 14,09 & 4,78 \\
R9 & R14 & 0,4021 & 0,5668 & 0,9689 & 14,09 & 4,78 \\
R10 & R7 & 1,4364 & 0,5318 & 1,9682 & 18,91 & 1,76 \\
R11 & R10 & 0,881 & 0,5677 & 1,4487 & 15,78 & 3,00 \\
R11 & R14 & 0,4045 & 0,5677 & 0,9722 & 15,78 & 4,76 \\
R12 & R13 & 0,4181 & 0,5296 & 0,9477 & 16,88 & 5,32 \\
R12 & R15 & 0,4014 & 0,5296 & 0,9310 & 16,88 & 4,40 \\
\hline
\end{tabular}

Continua na próxima página 
Tabela 36 - Continuação

\begin{tabular}{cccrrrr}
\hline $\boldsymbol{P R R}$ & $\boldsymbol{P R \boldsymbol { L }}$ & $\boldsymbol{I T C}(\mathbf{s})$ & $\boldsymbol{T}_{\boldsymbol{P R L}}(\mathrm{s})$ & $\boldsymbol{T}_{\boldsymbol{P R R}}(\mathrm{s})$ & $\boldsymbol{M}_{\boldsymbol{P R L} \boldsymbol{L}}$ & $\boldsymbol{M}_{\boldsymbol{P R R}}$ \\
\hline $\mathrm{R} 12$ & $\mathrm{R} 19$ & 0,401 & 0,5296 & 0,9306 & 16,88 & 3,80 \\
$\mathrm{R} 13$ & $\mathrm{R} 10$ & 0,8843 & 0,5646 & 1,4489 & 16,01 & 3,00 \\
$\mathrm{R} 13$ & $\mathrm{R} 12$ & 0,4076 & 0,5646 & 0,9722 & 16,01 & 4,76 \\
$\mathrm{R} 14$ & $\mathrm{R} 11$ & 0,4265 & 0,5296 & 0,9561 & 16,88 & 5,24 \\
$\mathrm{R} 14$ & $\mathrm{R} 15$ & 0,4014 & 0,5296 & 0,9310 & 16,88 & 4,40 \\
$\mathrm{R} 14$ & $\mathrm{R} 19$ & 0,401 & 0,5296 & 0,9306 & 16,88 & 3,80 \\
$\mathrm{R} 15$ & $\mathrm{R} 17$ & 0,3206 & 0,5079 & 0,8285 & 14,63 & 6,73 \\
$\mathrm{R} 16$ & $\mathrm{R} 11$ & 0,4093 & 0,5479 & 0,9572 & 15,40 & 5,23 \\
$\mathrm{R} 16$ & $\mathrm{R} 13$ & 0,4009 & 0,5479 & 0,9488 & 15,40 & 5,31 \\
$\mathrm{R} 16$ & $\mathrm{R} 19$ & 0,3991 & 0,5479 & 0,9470 & 15,40 & 3,72 \\
$\mathrm{R} 17$ & $\mathrm{R} 22$ & 0,4011 & 0,5765 & 0,9776 & 15,14 & 2,89 \\
$\mathrm{R} 18$ & $\mathrm{R} 16$ & 0,342 & 0,6710 & 1,0130 & 4,67 & 4,47 \\
$\mathrm{R} 19$ & $\mathrm{R} 21$ & 0,3673 & 0,5101 & 0,8774 & 11,15 & 6,06 \\
$\mathrm{R} 20$ & $\mathrm{R} 11$ & 0,4071 & 0,5512 & 0,9583 & 15,16 & 5,22 \\
$\mathrm{R} 20$ & $\mathrm{R} 13$ & 0,3987 & 0,5512 & 0,9499 & 15,16 & 5,30 \\
$\mathrm{R} 20$ & $\mathrm{R} 15$ & 0,3955 & 0,5512 & 0,9467 & 15,16 & 4,29 \\
$\mathrm{R} 21$ & $\mathrm{R} 18$ & 0,3687 & 0,5233 & 0,8920 & 19,80 & 3,20 \\
$\mathrm{R} 22$ & $\mathrm{R} 20$ & 0,4262 & 0,6254 & 1,0516 & 5,21 & 4,24 \\
\hline
\end{tabular}

APÊNDICE C - TOPOLOGIA DE OPERAÇÃO SEM A LINHA LT4

Tabela 37 - Correntes de curto-circuito observadas pela PRL e PRR em função da saída da linha LT4.

\begin{tabular}{|c|c|c|c|c|c|c|c|}
\hline$P R R$ & $P R L$ & $I_{C C, \text { local }}(\mathrm{A})$ & $I_{C C, \text { rem }}(\mathrm{A})$ & $P R R$ & $P R L$ & $I_{C C, \text { local }}(\mathrm{A})$ & $I_{C C, \text { rem }}(\mathrm{A})$ \\
\hline R1 & R4 & $3.036,3$ & $2.015,5$ & R11 & R10 & $7.272,5$ & $2.334,4$ \\
\hline $\mathrm{R} 2$ & R3 & $8.353,8$ & 424,5 & R11 & R14 & $7.272,5$ & $1.651,3$ \\
\hline $\mathrm{R} 2$ & R6 & $8.353,8$ & 663,1 & $\mathrm{R} 12$ & R13 & $6.132,6$ & $2.546,6$ \\
\hline R2 & R10 & $8.353,8$ & $2.294,9$ & R12 & R15 & $6.132,6$ & $1.759,4$ \\
\hline R2 & R12 & $8.353,8$ & $1.664,1$ & $\mathrm{R} 12$ & R19 & $6.132,6$ & $1.524,0$ \\
\hline R2 & R14 & $8.353,8$ & $1.664,1$ & R13 & R1 & $7.272,5$ & 471,0 \\
\hline R3 & R2 & $3.036,3$ & $2.015,5$ & R13 & R3 & $7.272,5$ & 471,0 \\
\hline R4 & R1 & $8.353,8$ & 424,5 & R13 & R6 & $7.272,5$ & 674,5 \\
\hline R4 & R6 & $8.353,8$ & 663,1 & R13 & R10 & $7.272,5$ & $2.334,4$ \\
\hline R4 & R10 & $8.353,8$ & $2.294,9$ & R13 & R12 & $7.272,5$ & $1.651,3$ \\
\hline R4 & R12 & $8.353,8$ & $1.664,1$ & R14 & R11 & $6.132,6$ & $2.459,9$ \\
\hline R4 & R14 & $8.353,8$ & $1.664,1$ & R14 & R15 & $6.132,6$ & $1.759,4$ \\
\hline R5 & R1 & $8.174,8$ & 462,0 & R14 & R19 & $6.132,6$ & $1.524,0$ \\
\hline R5 & R3 & $8.174,8$ & 462,0 & R15 & R17 & $5.868,8$ & $5.316,3$ \\
\hline R5 & $\mathrm{R} 10$ & $8.174,8$ & $2.289,9$ & $\mathrm{R} 16$ & $\mathrm{R} 11$ & $6.772,2$ & $2.448,8$ \\
\hline R5 & $\mathrm{R} 12$ & $8.174,8$ & $1.660,4$ & R16 & $\mathrm{R} 13$ & $6.772,2$ & $2.448,8$ \\
\hline R5 & R14 & $8.174,8$ & $1.660,4$ & R16 & R19 & $6.772,2$ & $1.486,8$ \\
\hline R9 & R1 & $6.581,5$ & 461,8 & R17 & R22 & $11.968,9$ & $1.485,0$ \\
\hline R9 & R3 & $6.581,5$ & 461,8 & R18 & R16 & $2.449,7$ & $1.880,2$ \\
\hline R9 & R6 & $6.581,5$ & 661,4 & R19 & R21 & $4.480,2$ & $3.682,5$ \\
\hline R9 & $\mathrm{R} 12$ & $6.581,5$ & $1.659,5$ & $\mathrm{R} 20$ & R11 & $6.986,3$ & $2.444,2$ \\
\hline R9 & $\mathrm{R} 14$ & $6.581,5$ & $1.659,5$ & $\mathrm{R} 20$ & $\mathrm{R} 13$ & $6.986,3$ & $2.444,2$ \\
\hline R11 & R1 & $7.272,5$ & 471,0 & R20 & R15 & $6.986,3$ & $1.713,9$ \\
\hline R11 & R3 & $7.272,5$ & 471,0 & R21 & R18 & $12.038,2$ & $1.690,0$ \\
\hline R11 & R6 & $7.272,5$ & 674,5 & R22 & R20 & $2.654,3$ & $1.864,7$ \\
\hline
\end{tabular}


Tabela 38 - Pares de RDS sensibilizados e seus respectivos valores de ITC, tempo de atuação da PRL e da PRR, múltiplos de máximo e mínimo da PRL e PRR, dada a parametrização principal frente à saída de LT4.

\begin{tabular}{|c|c|c|c|c|c|c|}
\hline$P R R$ & $P R L$ & $I T C(\mathrm{~s})$ & $T_{P R L}(\mathrm{~s})$ & $T_{P R R}(\mathrm{~s})$ & $M_{P R L}$ & $M_{P R R}$ \\
\hline R1 & R4 & 0,5701 & 0,5165 & 1,0866 & 7,33 & 4,31 \\
\hline R2 & R6 & 2,024 & 0,5427 & 2,5667 & 17,85 & 1,67 \\
\hline R2 & R10 & 0,9403 & 0,5427 & 1,4830 & 17,85 & 2,93 \\
\hline R2 & $\mathrm{R} 12$ & 0,4261 & 0,5427 & 0,9688 & 17,85 & 4,78 \\
\hline R2 & R14 & 0,4261 & 0,5427 & 0,9688 & 17,85 & 4,78 \\
\hline R3 & R2 & 0,5739 & 0,5127 & 1,0866 & 7,44 & 4,31 \\
\hline R4 & R6 & 2,024 & 0,5427 & 2,5667 & 17,85 & 1,67 \\
\hline R4 & R10 & 0,9403 & 0,5427 & 1,4830 & 17,85 & 2,93 \\
\hline R4 & $\mathrm{R} 12$ & 0,4261 & 0,5427 & 0,9688 & 17,85 & 4,78 \\
\hline R4 & R14 & 0,4261 & 0,5427 & 0,9688 & 17,85 & 4,78 \\
\hline R5 & R10 & 0,9648 & 0,5212 & 1,4860 & 20,04 & 2,92 \\
\hline R5 & $\mathrm{R} 12$ & 0,449 & 0,5212 & 0,9702 & 20,04 & 4,77 \\
\hline R5 & R14 & 0,449 & 0,5212 & 0,9702 & 20,04 & 4,77 \\
\hline R9 & R6 & 2,0346 & 0,5450 & 2,5796 & 15,63 & 1,67 \\
\hline R9 & $\mathrm{R} 12$ & 0,4256 & 0,5450 & 0,9706 & 15,63 & 4,77 \\
\hline R9 & R14 & 0,4256 & 0,5450 & 0,9706 & 15,63 & 4,77 \\
\hline R11 & R6 & 1,9355 & 0,5486 & 2,4841 & 17,32 & 1,70 \\
\hline R11 & R10 & 0,9109 & 0,5486 & 1,4595 & 17,32 & 2,98 \\
\hline R11 & R14 & 0,4251 & 0,5486 & 0,9737 & 17,32 & 4,75 \\
\hline R12 & R13 & 0,3487 & 0,5215 & 0,8702 & 17,62 & 6,15 \\
\hline R12 & R15 & 0,4097 & 0,5215 & 0,9312 & 17,62 & 4,40 \\
\hline R12 & R19 & 0,4093 & 0,5215 & 0,9308 & 17,62 & 3,80 \\
\hline R13 & R6 & 1,9383 & 0,5458 & 2,4841 & 17,57 & 1,70 \\
\hline R13 & R10 & 0,9137 & 0,5458 & 1,4595 & 17,57 & 2,98 \\
\hline R13 & $\mathrm{R} 12$ & 0,4279 & 0,5458 & 0,9737 & 17,57 & 4,75 \\
\hline R14 & R11 & 0,3733 & 0,5215 & 0,8948 & 17,62 & 5,86 \\
\hline R14 & R15 & 0,4097 & 0,5215 & 0,9312 & 17,62 & 4,40 \\
\hline R14 & R19 & 0,4093 & 0,5215 & 0,9308 & 17,62 & 3,80 \\
\hline R15 & R17 & 0,3198 & 0,5074 & 0,8272 & 14,67 & 6,75 \\
\hline R16 & R11 & 0,3647 & 0,5325 & 0,8972 & 16,63 & 5,83 \\
\hline R16 & R13 & 0,3573 & 0,5325 & 0,8898 & 16,63 & 5,91 \\
\hline R16 & R19 & 0,4161 & 0,5325 & 0,9486 & 16,63 & 3,71 \\
\hline R17 & R22 & 0,3769 & 0,5758 & 0,9527 & 15,19 & 2,97 \\
\hline R18 & R16 & 0,331 & 0,6603 & 0,9913 & 4,78 & 4,62 \\
\hline R19 & R21 & 0,3662 & 0,5095 & 0,8757 & 11,18 & 6,08 \\
\hline R20 & R11 & 0,3619 & 0,5362 & 0,8981 & 16,32 & 5,82 \\
\hline R20 & $\mathrm{R} 13$ & 0,3545 & 0,5362 & 0,8907 & 16,32 & 5,90 \\
\hline R20 & R15 & 0,412 & 0,5362 & 0,9482 & 16,32 & 4,28 \\
\hline R21 & R18 & 0,3463 & 0,5225 & 0,8688 & 19,88 & 3,30 \\
\hline R22 & R20 & 0,4131 & 0,6180 & 1,0311 & 5,32 & 4,36 \\
\hline
\end{tabular}


APÊNDICE D - TOPOLOGIA DE OPERAÇÃO SEM A LINHA LT5

Tabela 39 - Correntes de curto-circuito observadas pela PRL e PRR em função da saída da linha LT5.

\begin{tabular}{|c|c|c|c|c|c|c|c|}
\hline$P R R$ & $P R L$ & $I_{C C, \text { local }}(\mathrm{A})$ & $I_{C C, \text { rem }}(\mathrm{A})$ & $P R R$ & $P R L$ & $I_{C C, \text { local }}(\mathrm{A})$ & $I_{C C, \text { rem }}(\mathrm{A})$ \\
\hline R1 & $\mathrm{R} 4$ & $2.907,8$ & $1.885,3$ & R12 & R15 & $5.750,5$ & $1.763,4$ \\
\hline R2 & R3 & $7.420,5$ & 429,6 & $\mathrm{R} 12$ & $\mathrm{R} 19$ & $5.750,5$ & $1.527,1$ \\
\hline $\mathrm{R} 2$ & R6 & $7.420,5$ & $1.981,1$ & $\mathrm{R} 13$ & $\mathrm{R} 1$ & $6.305,7$ & 471,2 \\
\hline $\mathrm{R} 2$ & $\mathrm{R} 12$ & $7.420,5$ & $1.671,5$ & $\mathrm{R} 13$ & R3 & $6.305,7$ & 471,2 \\
\hline $\mathrm{R} 2$ & $\mathrm{R} 14$ & $7.420,5$ & $1.671,5$ & $\mathrm{R} 13$ & R6 & $6.305,7$ & $2.011,5$ \\
\hline R3 & R2 & $2.907,8$ & $1.885,3$ & $\mathrm{R} 13$ & $\mathrm{R} 12$ & $6.305,7$ & $1.660,1$ \\
\hline $\mathrm{R} 4$ & $\mathrm{R} 1$ & $7.420,5$ & 429,6 & $\mathrm{R} 14$ & $\mathrm{R} 11$ & $5.750,5$ & $2.072,1$ \\
\hline $\mathrm{R} 4$ & R6 & $7.420,5$ & $1.981,1$ & $\mathrm{R} 14$ & $\mathrm{R} 15$ & $5.750,5$ & $1.763,4$ \\
\hline $\mathrm{R} 4$ & $\mathrm{R} 12$ & $7.420,5$ & $1.671,5$ & $\mathrm{R} 14$ & $\mathrm{R} 19$ & $5.750,5$ & $1.527,1$ \\
\hline $\mathrm{R} 4$ & $\mathrm{R} 14$ & $7.420,5$ & $1.671,5$ & $\mathrm{R} 15$ & $\mathrm{R} 17$ & $5.850,3$ & $5.297,6$ \\
\hline R5 & $\mathrm{R} 1$ & $5.969,5$ & 464,9 & $\mathrm{R} 16$ & $\mathrm{R} 11$ & $6.023,7$ & $2.071,0$ \\
\hline R5 & R3 & $5.969,5$ & 464,9 & R16 & R13 & $6.023,7$ & $2.071,0$ \\
\hline R5 & $\mathrm{R} 12$ & $5.969,5$ & $1.674,4$ & R16 & R19 & $6.023,7$ & $1.494,1$ \\
\hline R5 & R14 & $5.969,5$ & $1.674,4$ & $\mathrm{R} 17$ & R22 & $11.920,8$ & $1.429,3$ \\
\hline R6 & R8 & $4.600,6$ & $3.831,8$ & R18 & R16 & $2.364,2$ & $1.793,3$ \\
\hline R7 & R5 & $3.031,1$ & $2.247,3$ & R19 & R21 & $4.464,9$ & 366,8 \\
\hline R11 & $\mathrm{R} 1$ & $6.305,7$ & 471,2 & R20 & R11 & $6.241,0$ & $2.067,3$ \\
\hline R11 & R3 & $6.305,7$ & 471,2 & R20 & R13 & $6.241,0$ & $2.067,3$ \\
\hline R11 & R6 & $6.305,7$ & $2.011,5$ & R20 & R15 & $6.241,0$ & $1.722,9$ \\
\hline R11 & $\mathrm{R} 14$ & $6.305,7$ & $1.660,1$ & $\mathrm{R} 21$ & $\mathrm{R} 18$ & $11.975,1$ & $1.619,2$ \\
\hline $\mathrm{R} 12$ & $\mathrm{R} 13$ & $5.750,5$ & $2.072,1$ & $\mathrm{R} 22$ & $\mathrm{R} 20$ & $2.579,6$ & $1.788,2$ \\
\hline
\end{tabular}

Tabela 40 - Pares de RDS sensibilizados e seus respectivos valores de ITC, tempo de atuação da PRL e da PRR, múltiplos de máximo e mínimo da PRL e PRR, dada a parametrização principal frente à saída de LT5.

\begin{tabular}{|c|c|c|c|c|c|c|}
\hline PRR & PRL & $I T C(\mathrm{~s})$ & $T_{P R L}(s)$ & $T_{P R R}(\mathrm{~s})$ & $M_{P R L}$ & $M_{P R R}$ \\
\hline R1 & $\overline{\mathrm{R} 4}$ & 0,6112 & 0,5282 & 1,1394 & 7,02 & 4,03 \\
\hline R2 & R6 & 0,2463 & 0,5666 & 0,8129 & 15,86 & 5,00 \\
\hline R2 & $\mathrm{R} 12$ & 0,3994 & 0,5666 & 0,9660 & 15,86 & 4,80 \\
\hline R2 & R14 & 0,3994 & 0,5666 & 0,9660 & 15,86 & 4,80 \\
\hline R3 & R2 & 0,6152 & 0,5242 & 1,1394 & 7,13 & 4,03 \\
\hline R4 & R6 & 0,2463 & 0,5666 & 0,8129 & 15,86 & 5,00 \\
\hline R4 & $\mathrm{R} 12$ & 0,3994 & 0,5666 & 0,9660 & 15,86 & 4,80 \\
\hline R4 & R14 & 0,3994 & 0,5666 & 0,9660 & 15,86 & 4,80 \\
\hline R5 & $\mathrm{R} 12$ & 0,3808 & 0,5841 & 0,9649 & 14,63 & 4,81 \\
\hline R5 & R14 & 0,3808 & 0,5841 & 0,9649 & 14,63 & 4,81 \\
\hline R6 & R8 & 0,484 & 0,5291 & 1,0131 & 11,62 & 4,78 \\
\hline R7 & R5 & 0,3958 & 0,5318 & 0,9276 & 7,87 & 5,51 \\
\hline R11 & R6 & 0,2267 & 0,5784 & 0,8051 & 15,01 & 5,08 \\
\hline R11 & R14 & 0,3919 & 0,5784 & 0,9703 & 15,01 & 4,77 \\
\hline R12 & R13 & 0,4499 & 0,5338 & 0,9837 & 16,52 & 5,01 \\
\hline R12 & R15 & 0,396 & 0,5338 & 0,9298 & 16,52 & 4,41 \\
\hline R12 & R19 & 0,3956 & 0,5338 & 0,9294 & 16,52 & 3,81 \\
\hline
\end{tabular}


Tabela 40 - Continuação

\begin{tabular}{cccrrrr}
\hline $\boldsymbol{P R R}$ & $\boldsymbol{P R \boldsymbol { L }}$ & $\boldsymbol{I T C}(\mathbf{s})$ & $\boldsymbol{T}_{\boldsymbol{P R \boldsymbol { L }}}(\mathrm{s})$ & $\boldsymbol{T}_{\boldsymbol{P R R}}(\mathrm{s})$ & $\boldsymbol{M}_{\boldsymbol{P R L} \boldsymbol{L}}$ & $\boldsymbol{M}_{\boldsymbol{P R R}}$ \\
\hline $\mathrm{R} 13$ & $\mathrm{R} 6$ & 0,2299 & 0,5752 & 0,8051 & 15,23 & 5,08 \\
$\mathrm{R} 13$ & $\mathrm{R} 12$ & 0,3951 & 0,5752 & 0,9703 & 15,23 & 4,77 \\
$\mathrm{R} 14$ & $\mathrm{R} 11$ & 0,4589 & 0,5338 & 0,9927 & 16,52 & 4,93 \\
$\mathrm{R} 14$ & $\mathrm{R} 15$ & 0,396 & 0,5338 & 0,9298 & 16,52 & 4,41 \\
$\mathrm{R} 14$ & $\mathrm{R} 19$ & 0,3956 & 0,5338 & 0,9294 & 16,52 & 3,81 \\
$\mathrm{R} 15$ & $\mathrm{R} 17$ & 0,3208 & 0,5080 & 0,8288 & 14,63 & 6,72 \\
$\mathrm{R} 16$ & $\mathrm{R} 11$ & 0,4368 & 0,5563 & 0,9931 & 14,79 & 4,93 \\
$\mathrm{R} 16$ & $\mathrm{R} 13$ & 0,4277 & 0,5563 & 0,9840 & 14,79 & 5,00 \\
$\mathrm{R} 16$ & $\mathrm{R} 19$ & 0,3887 & 0,5563 & 0,9450 & 14,79 & 3,73 \\
$\mathrm{R} 17$ & $\mathrm{R} 22$ & 0,411 & 0,5767 & 0,9877 & 15,13 & 2,86 \\
$\mathrm{R} 18$ & $\mathrm{R} 16$ & 0,3476 & 0,6759 & 1,0235 & 4,62 & 4,40 \\
$\mathrm{R} 20$ & $\mathrm{R} 11$ & 0,4348 & 0,5594 & 0,9942 & 14,58 & 4,92 \\
$\mathrm{R} 20$ & $\mathrm{R} 13$ & 0,4257 & 0,5594 & 0,9851 & 14,58 & 4,99 \\
$\mathrm{R} 20$ & $\mathrm{R} 15$ & 0,3854 & 0,5594 & 0,9448 & 14,58 & 4,31 \\
$\mathrm{R} 11$ & $\mathrm{R} 18$ & 0,378 & 0,5235 & 0,9015 & 19,78 & 3,16 \\
$\mathrm{R} 22$ & $\mathrm{R} 20$ & 0,4328 & 0,6289 & 1,0617 & 5,17 & 4,18 \\
\hline
\end{tabular}

Tabela 41 - Nova parametrização calculada para a topologia de operação sem a linha LT5; valor do tempo de atuação da PRL e a respectiva soma dos mesmos.

\begin{tabular}{|c|c|c|c|c|}
\hline RDS & $I_{p}(t a p)$ & $I_{p}(\mathrm{~A})$ & $M T$ & $T_{P R L}(\mathrm{~s})$ \\
\hline R1 & 0,67 & 402 & 0,15 & 0,5202 \\
\hline R2 & 0,67 & 402 & 0,22 & 0,5130 \\
\hline R3 & 0,67 & 402 & 0,15 & 0,5202 \\
\hline R4 & 0,67 & 402 & 0,22 & 0,5130 \\
\hline R5 & 3,19 & 382,8 & 0,21 & 0,5206 \\
\hline R6 & 3,15 & 378 & 0,2 & 0,5463 \\
\hline R7 & 2,89 & 346,8 & 0,16 & 0,5055 \\
\hline R8 & 3,03 & 727,2 & 0,23 & 0,5216 \\
\hline R9 & - & - & - & - \\
\hline R10 & - & - & - & - \\
\hline R11 & 0,58 & 348 & 0,22 & 0,5163 \\
\hline $\mathrm{R} 12$ & 4,34 & 347,2 & 0,21 & 0,5091 \\
\hline R13 & 0,58 & 348 & 0,22 & 0,5163 \\
\hline R14 & 4,34 & 347,2 & 0,21 & 0,5091 \\
\hline $\mathrm{R} 15$ & 1,25 & 400 & 0,2 & 0,5080 \\
\hline R16 & 5,62 & 449,6 & 0,2 & 0,5256 \\
\hline R17 & 12,58 & 754,8 & 0,23 & 0,5675 \\
\hline $\mathrm{R} 18$ & 1,57 & 502,4 & 0,14 & 0,6230 \\
\hline R19 & 5,0 & 400 & 0,18 & 0,5098 \\
\hline R20 & 5,0 & 400 & 0,21 & 0,5205 \\
\hline R21 & 9,98 & 598,8 & 0,23 & 0,5215 \\
\hline $\mathrm{R} 22$ & 5,43 & 434,4 & 0,15 & 0,5790 \\
\hline
\end{tabular}


Tabela 42 - Pares de RDS sensibilizados e seus respectivos valores de ITC, tempo de atuação da PRL e da PRR, múltiplos de máximo e mínimo da PRL e PRR, dada a nova parametrização frente à saída de LT5.

\begin{tabular}{|c|c|c|c|c|c|c|}
\hline PRR & $P R L$ & $I T C(\mathrm{~s})$ & $T_{P R L}(\mathrm{~s})$ & $T_{P R R}(\mathrm{~s})$ & $M_{P R L}$ & $M_{P R R}$ \\
\hline R1 & R4 & 0,461 & 0,5202 & 0,9812 & 7,23 & 4,69 \\
\hline R2 & R6 & 0,3182 & 0,5130 & 0,8312 & 18,46 & 5,24 \\
\hline R2 & R12 & 0,4077 & 0,5130 & 0,9207 & 18,46 & 4,81 \\
\hline R2 & R14 & 0,4077 & 0,5130 & 0,9207 & 18,46 & 4,81 \\
\hline $\mathrm{R} 3$ & R2 & 0,461 & 0,5202 & 0,9812 & 7,23 & 4,69 \\
\hline $\mathrm{R} 4$ & R6 & 0,3182 & 0,5130 & 0,8312 & 18,46 & 5,24 \\
\hline $\mathrm{R} 4$ & $\mathrm{R} 12$ & 0,4077 & 0,5130 & 0,9207 & 18,46 & 4,81 \\
\hline $\mathrm{R} 4$ & $\mathrm{R} 14$ & 0,4077 & 0,5130 & 0,9207 & 18,46 & 4,81 \\
\hline $\mathrm{R} 5$ & $\mathrm{R} 12$ & 0,3991 & 0,5206 & 0,9197 & 15,59 & 4,82 \\
\hline $\mathrm{R} 5$ & $\mathrm{R} 14$ & 0,3991 & 0,5206 & 0,9197 & 15,59 & 4,82 \\
\hline R6 & R8 & 0,4065 & 0,5463 & 0,9528 & 12,17 & 5,27 \\
\hline $\mathrm{R} 7$ & $\mathrm{R} 5$ & 0,3104 & 0,5055 & 0,8159 & 8,74 & 5,87 \\
\hline $\mathrm{R} 11$ & R6 & 0,3072 & 0,5163 & 0,8235 & 18,12 & 5,32 \\
\hline $\mathrm{R} 11$ & $\mathrm{R} 14$ & 0,4085 & 0,5163 & 0,9248 & 18,12 & 4,78 \\
\hline $\mathrm{R} 12$ & $\mathrm{R} 13$ & 0,3388 & 0,5091 & 0,8479 & 16,56 & 5,95 \\
\hline $\mathrm{R} 12$ & $\mathrm{R} 15$ & 0,4207 & 0,5091 & 0,9298 & 16,56 & 4,41 \\
\hline $\mathrm{R} 12$ & R19 & 0,4189 & 0,5091 & 0,9280 & 16,56 & 3,82 \\
\hline $\mathrm{R} 13$ & R6 & 0,3072 & 0,5163 & 0,8235 & 18,12 & 5,32 \\
\hline $\mathrm{R} 13$ & $\mathrm{R} 12$ & 0,4085 & 0,5163 & 0,9248 & 18,12 & 4,78 \\
\hline R14 & $\mathrm{R} 11$ & 0,3388 & 0,5091 & 0,8479 & 16,56 & 5,95 \\
\hline R14 & $\mathrm{R} 15$ & 0,4207 & 0,5091 & 0,9298 & 16,56 & 4,41 \\
\hline R14 & R19 & 0,4189 & 0,5091 & 0,9280 & 16,56 & 3,82 \\
\hline $\mathrm{R} 15$ & $\mathrm{R} 17$ & 0,3023 & 0,5080 & 0,8103 & 14,63 & 7,02 \\
\hline R16 & $\mathrm{R} 11$ & 0,3225 & 0,5256 & 0,8481 & 13,40 & 5,95 \\
\hline R16 & $\mathrm{R} 13$ & 0,3225 & 0,5256 & 0,8481 & 13,40 & 5,95 \\
\hline R16 & R19 & 0,418 & 0,5256 & 0,9436 & 13,40 & 3,74 \\
\hline $\mathrm{R} 17$ & $\mathrm{R} 22$ & 0,3037 & 0,5675 & 0,8712 & 15,79 & 3,29 \\
\hline R18 & $\mathrm{R} 16$ & 0,375 & 0,6230 & 0,9980 & 4,71 & 3,99 \\
\hline $\mathrm{R} 20$ & $\mathrm{R} 11$ & 0,3285 & 0,5205 & 0,8490 & 15,60 & 5,94 \\
\hline R20 & $\mathrm{R} 13$ & 0,3285 & 0,5205 & 0,8490 & 15,60 & 5,94 \\
\hline R20 & R15 & 0,4243 & 0,5205 & 0,9448 & 15,60 & 4,31 \\
\hline R21 & R18 & 0,3061 & 0,5215 & 0,8276 & 20,00 & 3,22 \\
\hline $\mathrm{R} 22$ & $\mathrm{R} 20$ & 0,388 & 0,5790 & 0,9670 & 5,94 & 4,47 \\
\hline
\end{tabular}


APÊNDICE E - TOPOLOGIA DE OPERAÇÃO SEM A LINHA LT7

Tabela 43 - Correntes de curto-circuito observadas pela PRL e PRR em função da saída da linha LT7.

\begin{tabular}{|c|c|c|c|c|c|c|c|}
\hline$P R R$ & $P R L$ & $I_{C C, \text { local }}(\mathrm{A})$ & $I_{C C, \text { rem }}(\mathrm{A})$ & $P R R$ & $P R L$ & $I_{C C, \text { local }}(\mathrm{A})$ & $I_{C C, \text { rem }}(\mathrm{A})$ \\
\hline R1 & $\mathrm{R} 4$ & $3.109,3$ & $2.029,2$ & R9 & R6 & $7.363,0$ & $1.728,8$ \\
\hline $\mathrm{R} 2$ & R3 & $8.968,9$ & 421,4 & R9 & R12 & $7.363,0$ & $3.058,0$ \\
\hline R2 & R6 & $8.968,9$ & $1.745,0$ & R10 & R7 & $15.512,7$ & $1.409,5$ \\
\hline R2 & R10 & $8.968,9$ & $2.083,4$ & R11 & R1 & $6.523,0$ & 471,1 \\
\hline R2 & R12 & $8.968,9$ & $3.070,9$ & R11 & R3 & $6.523,0$ & 471,1 \\
\hline R3 & R2 & $3.109,3$ & $2.092,2$ & R11 & R6 & $6.523,0$ & $1.778,4$ \\
\hline $\mathrm{R} 4$ & $\mathrm{R} 1$ & $8.969,0$ & 421,3 & $\mathrm{R} 11$ & $\mathrm{R} 10$ & $6.523,0$ & $2.123,3$ \\
\hline R4 & R6 & $8.969,0$ & $1.745,0$ & $\mathrm{R} 12$ & R15 & $3.674,6$ & $1.757,5$ \\
\hline R4 & R10 & $8.969,0$ & $2.083,5$ & $\mathrm{R} 12$ & R19 & $3.674,6$ & $1.522,7$ \\
\hline R4 & R12 & $8.969,0$ & $3.070,9$ & R15 & R17 & $5.863,1$ & $5.310,8$ \\
\hline R5 & R1 & $7.725,3$ & 462,6 & R16 & R11 & $6.794,5$ & $4.922,4$ \\
\hline R5 & R3 & $7.725,3$ & 462,6 & R16 & R19 & $6.794,5$ & $1.483,6$ \\
\hline R5 & R10 & $7.725,3$ & $2.077,6$ & R17 & R22 & $11.953,3$ & $1.477,4$ \\
\hline R5 & R12 & $7.725,3$ & $3.072,6$ & R18 & R16 & $2.443,4$ & $1.876,2$ \\
\hline R6 & R8 & $4.542,2$ & $3.771,7$ & R19 & R21 & $4.476,5$ & $3.679,0$ \\
\hline R7 & R5 & $3.076,2$ & $2.295,5$ & R20 & R11 & $7.009,2$ & $4.913,0$ \\
\hline R8 & R9 & $15.959,6$ & $1.490,5$ & R20 & R15 & $7.009,2$ & $1.709,8$ \\
\hline R9 & R1 & $7.363,0$ & 460,4 & R21 & R18 & $12.021,5$ & $1.681,0$ \\
\hline R9 & R3 & $7.363,0$ & 460,4 & R22 & R20 & $2.649,2$ & $1.862,2$ \\
\hline
\end{tabular}

Tabela 44 - Pares de RDS sensibilizados e seus respectivos valores de ITC, tempo de atuação da PRL e da PRR, múltiplos de máximo e mínimo da PRL e PRR, dada a parametrização principal frente à saída de LT7.

\begin{tabular}{ccccccc}
\hline $\boldsymbol{P R R}$ & $\boldsymbol{P R \boldsymbol { L }}$ & $\boldsymbol{I T C}(\mathbf{s})$ & $\boldsymbol{T}_{\boldsymbol{P R \boldsymbol { L }}}(\mathbf{s})$ & $\boldsymbol{T}_{\boldsymbol{P R R}}(\mathbf{s})$ & $\boldsymbol{M}_{\boldsymbol{P R} \boldsymbol{L}}$ & $\boldsymbol{M}_{\boldsymbol{P R R}}$ \\
\hline R1 & R4 & 0,5712 & 0,5103 & 1,0815 & 7,51 & 4,34 \\
R2 & R6 & 0,3543 & 0,5293 & 0,8835 & 19,16 & 4,41 \\
R2 & R10 & 1,1020 & 0,5293 & 1,6313 & 19,16 & 2,66 \\
R2 & R12 & 0,1627 & 0,5293 & 0,6919 & 19,16 & 8,82 \\
R3 & R2 & 0,5525 & 0,5066 & 1,0591 & 7,62 & 4,47 \\
R4 & R6 & 0,3543 & 0,5293 & 0,8835 & 19,16 & 4,41 \\
R4 & R10 & 1,1019 & 0,5293 & 1,6312 & 19,16 & 2,66 \\
R4 & R12 & 0,1627 & 0,5293 & 0,6919 & 19,16 & 8,82 \\
R5 & R10 & 1,1045 & 0,5315 & 1,6360 & 18,93 & 2,65 \\
R5 & R12 & 0,1603 & 0,5315 & 0,6918 & 18,93 & 8,83 \\
R6 & R8 & 0,4916 & 0,5319 & 1,0236 & 11,47 & 4,71 \\
R7 & R5 & 0,3881 & 0,5279 & 0,9160 & 7,99 & 5,63 \\
R8 & R9 & 0,6809 & 0,5223 & 1,2033 & 19,91 & 3,54 \\
R9 & R6 & 0,3662 & 0,5230 & 0,8892 & 17,48 & 4,37 \\
R9 & R12 & 0,1703 & 0,5230 & 0,6933 & 17,48 & 8,79 \\
R10 & R7 & 0,3288 & 0,5234 & 0,8522 & 19,79 & 3,66 \\
R11 & R6 & 0,3012 & 0,5710 & 0,8722 & 15,53 & 4,49 \\
R11 & R10 & 1,0289 & 0,5710 & 1,5999 & 15,53 & 2,71 \\
R12 & R15 & 0,2938 & 0,6381 & 0,9319 & 10,56 & 4,39 \\
R12 & R19 & 0,2933 & 0,6381 & 0,9314 & 10,56 & 3,80 \\
\hline & & & & Continua na próxima página
\end{tabular}


Tabela 44 - Continuação

\begin{tabular}{ccccccc}
\hline $\boldsymbol{P R R}$ & $\boldsymbol{P R L}$ & $\boldsymbol{I T C}(\mathbf{s})$ & $\boldsymbol{T}_{\boldsymbol{P R L}}(\mathrm{s})$ & $\boldsymbol{T}_{\boldsymbol{P R R} R}(\mathrm{~s})$ & $\boldsymbol{M}_{\boldsymbol{P R} \boldsymbol{L}}$ & $\boldsymbol{M}_{\boldsymbol{P R R}}$ \\
\hline $\mathrm{R} 15$ & $\mathrm{R} 17$ & 0,3202 & 0,5075 & 0,8277 & 14,66 & 6,74 \\
$\mathrm{R} 16$ & $\mathrm{R} 11$ & 0,1063 & 0,5319 & 0,6382 & 16,69 & 11,72 \\
$\mathrm{R} 16$ & $\mathrm{R} 19$ & 0,4183 & 0,5319 & 0,9502 & 16,69 & 3,70 \\
$\mathrm{R} 17$ & $\mathrm{R} 22$ & 0,3812 & 0,5761 & 0,9573 & 15,17 & 2,96 \\
$\mathrm{R} 18$ & $\mathrm{R} 16$ & 0,3313 & 0,6614 & 0,9927 & 4,77 & 4,61 \\
$\mathrm{R} 19$ & $\mathrm{R} 1$ & 0,3666 & 0,5096 & 0,8762 & 11,17 & 6,08 \\
$\mathrm{R} 20$ & $\mathrm{R} 11$ & 0,1031 & 0,5356 & 0,6387 & 16,38 & 11,70 \\
$\mathrm{R} 20$ & $\mathrm{R} 15$ & 0,4143 & 0,5356 & 0,9498 & 16,38 & 4,27 \\
$\mathrm{R} 21$ & $\mathrm{R} 18$ & 0,3500 & 0,5228 & 0,8728 & 19,86 & 3,28 \\
$\mathrm{R} 22$ & $\mathrm{R} 20$ & 0,4133 & 0,6187 & 1,0320 & 5,31 & 4,35 \\
\hline
\end{tabular}

Tabela 45 - Nova parametrização calculada para a topologia de operação sem a linha LT7; valor do tempo de atuação da PRL e a respectiva soma dos mesmos.

\begin{tabular}{ccccc}
\hline RDS & $\boldsymbol{I}_{\boldsymbol{p}}(\boldsymbol{t a p})$ & $\boldsymbol{I}_{\boldsymbol{p}}(\mathbf{A})$ & $\boldsymbol{M} \boldsymbol{T}$ & $\boldsymbol{T}_{\boldsymbol{P R L}}(\mathbf{s})$ \\
\hline R1 & 0,67 & 402 & 0,15 & 0,5028 \\
R2 & 0,76 & 456 & 0,23 & 0,5245 \\
R3 & 0,67 & 402 & 0,15 & 0,5028 \\
R4 & 0,75 & 450 & 0,23 & 0,5221 \\
R5 & 3,23 & 387,6 & 0,23 & 0,5221 \\
R6 & 4,57 & 548,4 & 0,19 & 0,6159 \\
R7 & 3,07 & 368,4 & 0,16 & 0,5166 \\
R8 & 3,33 & 799,2 & 0,23 & 0,5218 \\
R9 & 3,35 & 402 & 0,22 & 0,5144 \\
R10 & 4,85 & 776 & 0,23 & 0,5216 \\
R11 & 1,21 & 726 & 0,23 & 0,7173 \\
R12 & 8,65 & 692 & 0,18 & 0,7421 \\
R13 & - & - & - & - \\
R14 & - & - & - & - \\
R15 & 1,55 & 496 & 0,2 & 0,5529 \\
R16 & 5,0 & 400 & 0,21 & 0,5044 \\
R17 & 13,91 & 834,6 & 0,23 & 0,5889 \\
R18 & 1,66 & 531,2 & 0,14 & 0,6324 \\
R19 & 5,96 & 476,8 & 0,18 & 0,5501 \\
R20 & 5,08 & 406,4 & 0,22 & 0,5255 \\
R21 & 10,09 & 605,4 & 0,23 & 0,5228 \\
R22 & 5,96 & 476,8 & 0,15 & 0,6018 \\
\hline & & & & \multicolumn{2}{c}{$S_{T}=11,2031$} \\
\hline
\end{tabular}


Tabela 46 - Pares de RDS sensibilizados e seus respectivos valores de ITC, tempo de atuação da PRL e da PRR, múltiplos de máximo e mínimo da PRL e PRR, dada a nova parametrização frente à saída de LT7.

\begin{tabular}{|c|c|c|c|c|c|c|}
\hline$P R R$ & $P R L$ & $I T C(\mathrm{~s})$ & $T_{P R L}(\mathrm{~s})$ & $T_{P R R}(\mathrm{~s})$ & $M_{P R L}$ & $M_{P R R}$ \\
\hline $\mathrm{R} 1$ & $\mathrm{R} 4$ & 0,5501 & 0,5028 & 1,0529 & 7,73 & 4,51 \\
\hline R2 & R6 & 0,6113 & 0,5245 & 1,1358 & 19,67 & 3,18 \\
\hline R2 & R10 & 1,0897 & 0,5245 & 1,6142 & 19,67 & 2,68 \\
\hline R2 & R12 & 0,3085 & 0,5245 & 0,8330 & 19,67 & 4,44 \\
\hline R3 & R2 & 0,538 & 0,5028 & 1,0408 & 7,73 & 4,59 \\
\hline R4 & R6 & 0,6137 & 0,5221 & 1,1358 & 19,93 & 3,18 \\
\hline R4 & R10 & 1,092 & 0,5221 & 1,6141 & 19,93 & 2,68 \\
\hline R4 & $\mathrm{R} 12$ & 0,3109 & 0,5221 & 0,8330 & 19,93 & 4,44 \\
\hline R5 & R10 & 1,0967 & 0,5221 & 1,6188 & 19,93 & 2,68 \\
\hline R5 & $\mathrm{R} 12$ & 0,3106 & 0,5221 & 0,8327 & 19,93 & 4,44 \\
\hline R6 & R8 & 0,4057 & 0,6159 & 1,0216 & 8,28 & 4,72 \\
\hline R7 & R5 & 0,3725 & 0,5166 & 0,8891 & 8,35 & 5,92 \\
\hline R8 & R9 & 0,6381 & 0,5218 & 1,1599 & 19,97 & 3,71 \\
\hline R9 & R6 & 0,6307 & 0,5144 & 1,1451 & 18,32 & 3,15 \\
\hline R9 & $\mathrm{R} 12$ & 0,321 & 0,5144 & 0,8354 & 18,32 & 4,42 \\
\hline R10 & R7 & 0,3019 & 0,5216 & 0,8235 & 19,99 & 3,83 \\
\hline R11 & R6 & 0,4 & 0,7173 & 1,1173 & 8,98 & 3,24 \\
\hline R11 & R10 & 0,8661 & 0,7173 & 1,5834 & 8,98 & 2,74 \\
\hline R12 & R15 & 0,3506 & 0,7421 & 1,0927 & 5,31 & 3,54 \\
\hline R12 & R19 & 0,3305 & 0,7421 & 1,0726 & 5,31 & 3,19 \\
\hline R15 & R17 & 0,3011 & 0,5529 & 0,8540 & 11,82 & 6,36 \\
\hline R16 & R11 & 0,3208 & 0,5044 & 0,8252 & 16,99 & 6,78 \\
\hline R16 & R19 & 0,5931 & 0,5044 & 1,0975 & 16,99 & 3,11 \\
\hline R17 & R22 & 0,3291 & 0,5889 & 0,9180 & 14,32 & 3,10 \\
\hline R18 & R16 & 0,3041 & 0,6324 & 0,9365 & 4,60 & 4,69 \\
\hline R19 & R21 & 0,3261 & 0,5501 & 0,8762 & 9,39 & 6,08 \\
\hline R20 & R11 & 0,3005 & 0,5255 & 0,8260 & 17,25 & 6,77 \\
\hline R20 & R15 & 0,5918 & 0,5255 & 1,1173 & 17,25 & 3,45 \\
\hline R21 & R18 & 0,3181 & 0,5228 & 0,8409 & 19,86 & 3,16 \\
\hline R22 & R20 & 0,3946 & 0,6018 & 0,9964 & 5,56 & 4,58 \\
\hline
\end{tabular}


Tabela 47 - Correntes de curto-circuito observadas pela PRL e PRR em função da saída da linha LT8.

\begin{tabular}{|c|c|c|c|c|c|c|c|}
\hline$P R R$ & $P R L$ & $I_{C C, \text { local }}(\mathrm{A})$ & $I_{C C, \text { rem }}(\mathrm{A})$ & $P R R$ & $P R L$ & $I_{C C, \text { local }}(\mathrm{A})$ & $I_{C C, \text { rem }}(\mathrm{A})$ \\
\hline $\mathrm{R} 1$ & R4 & $2.977,7$ & $1.957,5$ & R9 & R12 & $6.325,5$ & 993,0 \\
\hline R2 & R3 & $7.928,0$ & 426,9 & R9 & R14 & $6.325,5$ & 993,0 \\
\hline R2 & R6 & $7.928,0$ & $1.755,6$ & R10 & R7 & $15.457,3$ & $1.330,7$ \\
\hline R2 & R10 & $7.928,0$ & $2.097,7$ & R11 & $\mathrm{R} 1$ & $7.504,1$ & 470,9 \\
\hline R2 & $\mathrm{R} 12$ & $7.928,0$ & 995,9 & R11 & R3 & $7.504,1$ & 470,9 \\
\hline R2 & R14 & $7.928,0$ & 995,9 & R11 & R6 & $7.504,1$ & $1.783,8$ \\
\hline R3 & R2 & $2.977,7$ & $1.957,5$ & R11 & $\mathrm{R} 10$ & $7.504,1$ & $2.131,4$ \\
\hline R4 & R1 & $7.928,0$ & 426,9 & R11 & R14 & $7.504,1$ & 971,1 \\
\hline R4 & R6 & $7.928,0$ & $1.755,6$ & $\mathrm{R} 12$ & R13 & $4.941,3$ & $2.813,5$ \\
\hline R4 & R10 & $7.928,0$ & $2.097,7$ & $\mathrm{R} 12$ & R19 & $4.941,3$ & $1.733,5$ \\
\hline R4 & $\mathrm{R} 12$ & $7.928,0$ & 995,9 & R13 & R1 & $7.504,1$ & 470,9 \\
\hline R4 & R14 & $7.928,0$ & 995,9 & $\mathrm{R} 13$ & R3 & $7.504,1$ & 470,9 \\
\hline R5 & $\mathrm{R} 1$ & $6.677,9$ & 463,9 & $\mathrm{R} 13$ & R6 & $7.504,1$ & $1.783,8$ \\
\hline R5 & R3 & $6.677,9$ & 463,9 & $\mathrm{R} 13$ & $\mathrm{R} 10$ & $7.504,1$ & $2.131,4$ \\
\hline R5 & $\mathrm{R} 10$ & $6.677,9$ & $2.093,5$ & $\mathrm{R} 13$ & $\mathrm{R} 12$ & $7.504,1$ & 971,1 \\
\hline R5 & $\mathrm{R} 12$ & $6.677,9$ & 996,9 & R14 & R11 & $4.941,3$ & $2.813,5$ \\
\hline R5 & $\mathrm{R} 14$ & $6.677,9$ & 996,9 & R14 & R19 & $4.941,3$ & $1.733,5$ \\
\hline R6 & $\mathrm{R} 8$ & $4.525,6$ & $3.754,7$ & $\mathrm{R} 17$ & R22 & $12.290,1$ & $1.797,8$ \\
\hline R7 & R5 & $2.956,7$ & $2.171,9$ & R19 & $\mathrm{R} 21$ & $4.492,1$ & $3.694,9$ \\
\hline R8 & R9 & $15.868,4$ & $1.373,5$ & R20 & R11 & $5.981,8$ & $2.794,2$ \\
\hline R9 & $\mathrm{R} 1$ & $6.325,5$ & 462,2 & $\mathrm{R} 20$ & R13 & $5.981,8$ & $2.794,2$ \\
\hline R9 & R3 & $6.325,5$ & 462,2 & $\mathrm{R} 21$ & $\mathrm{R} 18$ & $10.913,1$ & 549,6 \\
\hline R9 & R6 & $6.325,5$ & $1.742,5$ & R22 & R20 & $2.709,1$ & $1.921,7$ \\
\hline
\end{tabular}

Tabela 48 - Pares de RDS sensibilizados e seus respectivos valores de ITC, tempo de atuação da PRL e da PRR, múltiplos de máximo e mínimo da PRL e PRR, dada a parametrização principal frente à saída de LT8.

\begin{tabular}{cccrrrr}
\hline $\boldsymbol{P R R}$ & $\boldsymbol{P R L}$ & $\boldsymbol{I T C}(\mathbf{s})$ & $\boldsymbol{T}_{\boldsymbol{P R L}}(\mathbf{s})$ & $\boldsymbol{T}_{\boldsymbol{P R R}}(\mathbf{s})$ & $\boldsymbol{M}_{\boldsymbol{P R L}}$ & $\boldsymbol{M}_{\boldsymbol{P R R}}$ \\
\hline R1 & R4 & 0,5874 & 0,5217 & 1,1091 & 7,19 & 4,18 \\
R2 & R6 & 0,3269 & 0,5530 & 0,8799 & 16,94 & 4,43 \\
R2 & R10 & 1,0668 & 0,5530 & 1,6198 & 16,94 & 2,68 \\
R2 & R12 & 0,8963 & 0,5530 & 1,4493 & 16,94 & 2,86 \\
R2 & R14 & 0,8963 & 0,5530 & 1,4493 & 16,94 & 2,86 \\
R3 & R2 & 0,5913 & 0,5178 & 1,1091 & 7,30 & 4,18 \\
R4 & R6 & 0,3269 & 0,5530 & 0,8799 & 16,94 & 4,43 \\
R4 & R10 & 1,0668 & 0,5530 & 1,6198 & 16,94 & 2,68 \\
R4 & R12 & 0,8963 & 0,5530 & 1,4493 & 16,94 & 2,86 \\
R4 & R14 & 0,8963 & 0,5530 & 1,4493 & 16,94 & 2,86 \\
R5 & R10 & 1,0632 & 0,5600 & 1,6232 & 16,37 & 2,67 \\
R5 & R12 & 0,8879 & 0,5600 & 1,4479 & 16,37 & 2,86 \\
R5 & R14 & 0,8879 & 0,5600 & 1,4479 & 16,37 & 2,86 \\
R6 & R8 & 0,4938 & 0,5328 & 1,0266 & 11,43 & 4,68 \\
\hline & \multicolumn{5}{c}{ Continua na próxima página }
\end{tabular}


Tabela 48 - Continuação

\begin{tabular}{|c|c|c|c|c|c|c|}
\hline$P R R$ & $P R L$ & $I T C(\mathrm{~s})$ & $\boldsymbol{T}_{\boldsymbol{P R L}}(\mathrm{s})$ & $\boldsymbol{T}_{\boldsymbol{P R R}}(\mathrm{s})$ & $M_{P R L}$ & $M_{P R R}$ \\
\hline R7 & R5 & 0,4085 & 0,5384 & 0,9469 & 7,68 & 5,32 \\
\hline R8 & R9 & 0,7642 & 0,5233 & 1,2875 & 19,80 & 3,26 \\
\hline R9 & R6 & 0,3312 & 0,5532 & 0,8844 & 15,02 & 4,40 \\
\hline R9 & $\mathrm{R} 12$ & 0,9002 & 0,5532 & 1,4534 & 15,02 & 2,85 \\
\hline R9 & R14 & 0,9002 & 0,5532 & 1,4534 & 15,02 & 2,85 \\
\hline R10 & R7 & 0,3682 & 0,5241 & 0,8923 & 19,72 & 3,45 \\
\hline R11 & R6 & 0,3279 & 0,5425 & 0,8704 & 17,87 & 4,50 \\
\hline R11 & R10 & 1,0513 & 0,5425 & 1,5938 & 17,87 & 2,72 \\
\hline R11 & R14 & 0,9428 & 0,5425 & 1,4853 & 17,87 & 2,79 \\
\hline R12 & R13 & 0,259 & 0,5652 & 0,8242 & 14,20 & 6,80 \\
\hline R12 & R19 & 0,2827 & 0,5652 & 0,8479 & 14,20 & 4,33 \\
\hline R13 & R6 & 0,3307 & 0,5397 & 0,8704 & 18,13 & 4,50 \\
\hline R13 & R10 & 1,0541 & 0,5397 & 1,5938 & 18,13 & 2,72 \\
\hline R13 & $\mathrm{R} 12$ & 0,9456 & 0,5397 & 1,4853 & 18,13 & 2,79 \\
\hline R14 & R11 & 0,2653 & 0,5652 & 0,8305 & 14,20 & 6,70 \\
\hline R14 & R19 & 0,2827 & 0,5652 & 0,8479 & 14,20 & 4,33 \\
\hline R17 & R22 & 0,2389 & 0,5701 & 0,8090 & 15,60 & 3,60 \\
\hline R19 & R21 & 0,3652 & 0,5089 & 0,8741 & 11,21 & 6,10 \\
\hline R20 & R11 & 0,2649 & 0,5687 & 0,8336 & 13,98 & 6,65 \\
\hline R20 & R13 & 0,2585 & 0,5687 & 0,8272 & 13,98 & 6,75 \\
\hline R22 & R20 & 0,3997 & 0,6104 & 1,0101 & 5,43 & 4,49 \\
\hline
\end{tabular}

Tabela 49 - Nova parametrização calculada para a topologia de operação sem a linha LT8; valor do tempo de atuação da PRL e a respectiva soma dos mesmos.

\begin{tabular}{|c|c|c|c|c|}
\hline RDS & $I_{p}(\operatorname{tap})$ & $I_{p}(\mathrm{~A})$ & $M T$ & $T_{P R L}(\mathrm{~s})$ \\
\hline$\overline{\mathrm{R} 1}$ & 0,67 & 402 & 0,15 & 0,5139 \\
\hline R2 & 0,67 & 402 & 0,22 & 0,5012 \\
\hline R3 & 0,67 & 402 & 0,15 & 0,5139 \\
\hline R4 & 0,67 & 402 & 0,22 & 0,5012 \\
\hline R5 & 2,89 & 346,8 & 0,22 & 0,5054 \\
\hline R6 & 3,75 & 450 & 0,19 & 0,5630 \\
\hline R7 & 2,94 & 352,8 & 0,16 & 0,5157 \\
\hline R8 & 3,31 & 794,4 & 0,23 & 0,5217 \\
\hline R9 & 3,33 & 399,6 & 0,21 & 0,5177 \\
\hline R10 & 4,84 & 774,4 & 0,23 & 0,5218 \\
\hline R11 & 0,79 & 474 & 0,22 & 0,5423 \\
\hline $\mathrm{R} 12$ & 4,34 & 347,2 & 0,2 & 0,5133 \\
\hline $\mathrm{R} 13$ & 0,71 & 426 & 0,23 & 0,5453 \\
\hline R14 & 4,4 & 352 & 0,2 & 0,5161 \\
\hline R15 & - & - & - & - \\
\hline R16 & - & - & - & - \\
\hline $\mathrm{R} 17$ & 10,28 & 616,8 & 0,23 & 0,5222 \\
\hline R18 & 1,13 & 361,6 & 0,05 & 0,7112 \\
\hline R19 & 5,01 & 400,8 & 0,18 & 0,5089 \\
\hline R20 & 5,69 & 455,2 & 0,2 & 0,5297 \\
\hline $\mathrm{R} 21$ & 9,1 & 546 & 0,23 & 0,5216 \\
\hline $\mathrm{R} 22$ & 6,47 & 517,6 & 0,15 & 0,6239 \\
\hline
\end{tabular}


Tabela 50 - Pares de RDS sensibilizados e seus respectivos valores de ITC, tempo de atuação da PRL e da PRR, múltiplos de máximo e mínimo da PRL e PRR, dada a nova parametrização frente à saída de LT8.

\begin{tabular}{|c|c|c|c|c|c|c|}
\hline PRR & $P R L$ & $I T C(\mathrm{~s})$ & $T_{P R L}(\mathrm{~s})$ & $T_{P R R}(\mathrm{~s})$ & $M_{P R L}$ & $M_{P R R}$ \\
\hline R1 & R4 & 0,4436 & 0,5139 & 0,9575 & 7,41 & 4,87 \\
\hline R2 & R6 & 0,4626 & 0,5012 & 0,9638 & 19,72 & 3,90 \\
\hline R2 & R10 & 1,0984 & 0,5012 & 1,5996 & 19,72 & 2,71 \\
\hline R2 & R12 & 0,8134 & 0,5012 & 1,3146 & 19,72 & 2,87 \\
\hline R2 & R14 & 0,831 & 0,5012 & 1,3322 & 19,72 & 2,83 \\
\hline R3 & R2 & 0,4436 & 0,5139 & 0,9575 & 7,41 & 4,87 \\
\hline R4 & R6 & 0,4626 & 0,5012 & 0,9638 & 19,72 & 3,90 \\
\hline R4 & R10 & 1,0984 & 0,5012 & 1,5996 & 19,72 & 2,71 \\
\hline $\mathrm{R} 4$ & $\mathrm{R} 12$ & 0,8134 & 0,5012 & 1,3146 & 19,72 & 2,87 \\
\hline $\mathrm{R} 4$ & $\mathrm{R} 14$ & 0,831 & 0,5012 & 1,3322 & 19,72 & 2,83 \\
\hline R5 & $\mathrm{R} 10$ & 1,0975 & 0,5054 & 1,6029 & 19,26 & 2,70 \\
\hline R5 & R12 & 0,808 & 0,5054 & 1,3134 & 19,26 & 2,87 \\
\hline R5 & $\mathrm{R} 14$ & 0,8255 & 0,5054 & 1,3309 & 19,26 & 2,83 \\
\hline R6 & R8 & 0,4576 & 0,5630 & 1,0206 & 10,06 & 4,73 \\
\hline R7 & R5 & 0,3084 & 0,5157 & 0,8241 & 8,38 & 6,26 \\
\hline R8 & R9 & 0,6543 & 0,5217 & 1,1760 & 19,98 & 3,44 \\
\hline R9 & R6 & 0,4515 & 0,5177 & 0,9692 & 15,83 & 3,87 \\
\hline R9 & $\mathrm{R} 12$ & 0,8006 & 0,5177 & 1,3183 & 15,83 & 2,86 \\
\hline R9 & $\mathrm{R} 14$ & 0,8183 & 0,5177 & 1,3360 & 15,83 & 2,82 \\
\hline $\mathrm{R} 10$ & $\mathrm{R} 7$ & 0,3107 & 0,5218 & 0,8325 & 19,96 & 3,77 \\
\hline $\mathrm{R} 11$ & R6 & 0,4102 & 0,5423 & 0,9525 & 15,83 & 3,96 \\
\hline $\mathrm{R} 11$ & $\mathrm{R} 10$ & 1,0319 & 0,5423 & 1,5742 & 15,83 & 2,75 \\
\hline $\mathrm{R} 11$ & $\mathrm{R} 14$ & 0,8233 & 0,5423 & 1,3656 & 15,83 & 2,76 \\
\hline $\mathrm{R} 12$ & $\mathrm{R} 13$ & 0,3236 & 0,5133 & 0,8369 & 14,23 & 6,60 \\
\hline $\mathrm{R} 12$ & R19 & 0,3346 & 0,5133 & 0,8479 & 14,23 & 4,33 \\
\hline $\mathrm{R} 13$ & R6 & 0,4072 & 0,5453 & 0,9525 & 17,62 & 3,96 \\
\hline $\mathrm{R} 13$ & $\mathrm{R} 10$ & 1,0289 & 0,5453 & 1,5742 & 17,62 & 2,75 \\
\hline R13 & $\mathrm{R} 12$ & 0,8019 & 0,5453 & 1,3472 & 17,62 & 2,80 \\
\hline R14 & $\mathrm{R} 11$ & 0,3333 & 0,5161 & 0,8494 & 14,04 & 5,94 \\
\hline R14 & R19 & 0,3318 & 0,5161 & 0,8479 & 14,04 & 4,33 \\
\hline $\mathrm{R} 17$ & $\mathrm{R} 22$ & 0,3106 & 0,5222 & 0,8328 & 19,93 & 3,47 \\
\hline R19 & $\mathrm{R} 21$ & 0,3171 & 0,5089 & 0,8260 & 11,21 & 6,77 \\
\hline $\mathrm{R} 20$ & $\mathrm{R} 11$ & 0,323 & 0,5297 & 0,8527 & 13,14 & 5,89 \\
\hline $\mathrm{R} 20$ & $\mathrm{R} 13$ & 0,3103 & 0,5297 & 0,8400 & 13,14 & 6,56 \\
\hline $\mathrm{R} 21$ & $\mathrm{R} 18$ & 0,3109 & 0,5216 & 0,8325 & 19,99 & 1,52 \\
\hline R22 & R20 & 0,3342 & 0,6239 & 0,9581 & 5,23 & 4,22 \\
\hline
\end{tabular}


APÊNDICE G - TOPOLOGIA DE OPERAÇÃO SEM A LINHA LT9

Tabela 51 - Correntes de curto-circuito observadas pela PRL e PRR em função da saída da linha LT9.

\begin{tabular}{|c|c|c|c|c|c|c|c|}
\hline$P R R$ & $P R L$ & $I_{C C, \text { local }}(\mathrm{A})$ & $I_{C C, \text { rem }}(\mathrm{A})$ & $P R R$ & $P R L$ & $I_{C C, \text { local }}(\mathrm{A})$ & $I_{C C, \text { rem }}(\mathrm{A})$ \\
\hline $\mathrm{R} 1$ & R4 & $3.034,1$ & $2.013,7$ & R10 & R7 & $15.494,3$ & $1.370,8$ \\
\hline R2 & R3 & $8.341,4$ & 424,6 & R11 & R1 & $7.717,0$ & 470,9 \\
\hline R2 & R6 & $8.341,4$ & $1.753,5$ & R11 & R3 & $7.717,0$ & 470,9 \\
\hline R2 & R10 & $8.341,4$ & $2.095,1$ & R11 & R6 & $7.717,0$ & $1.783,3$ \\
\hline R2 & $\mathrm{R} 12$ & $8.341,4$ & $1.206,2$ & R11 & R10 & $7.717,0$ & $2.130,7$ \\
\hline R2 & R14 & $8.341,4$ & $1.206,2$ & R11 & R14 & $7.717,0$ & $1.184,3$ \\
\hline R3 & R2 & $3.034,1$ & $2.013,7$ & $\mathrm{R} 12$ & R13 & $5.415,0$ & $2.810,4$ \\
\hline R4 & R1 & $8.341,4$ & 424,6 & $\mathrm{R} 12$ & R15 & $5.415,0$ & 496,2 \\
\hline R4 & R6 & $8.341,4$ & $1.753,5$ & $\mathrm{R} 12$ & R19 & $5.415,0$ & $1.722,5$ \\
\hline R4 & $\mathrm{R} 10$ & $8.341,4$ & $2.095,1$ & $\mathrm{R} 13$ & $\mathrm{R} 1$ & $7.717,0$ & 470,9 \\
\hline R4 & $\mathrm{R} 12$ & $8.341,4$ & $1.206,2$ & $\mathrm{R} 13$ & R3 & $7.717,0$ & 470,9 \\
\hline R4 & R14 & $8.341,4$ & $1.206,2$ & $\mathrm{R} 13$ & R6 & $7.717,0$ & $1.783,3$ \\
\hline R5 & R1 & $7.096,4$ & 463,4 & $\mathrm{R} 13$ & R10 & $7.717,0$ & $2.130,7$ \\
\hline R5 & R3 & $7.096,4$ & 463,4 & $\mathrm{R} 13$ & R12 & $7.717,0$ & $1.184,3$ \\
\hline R5 & $\mathrm{R} 10$ & $7.096,4$ & $2.090,4$ & R14 & R11 & $5.415,0$ & $2.810,4$ \\
\hline R5 & $\mathrm{R} 12$ & $7.096,4$ & $1.207,3$ & R14 & R15 & $5.415,0$ & 496,2 \\
\hline R5 & R14 & $7.096,4$ & $1.207,3$ & R14 & R19 & $5.415,0$ & $1.722,5$ \\
\hline R6 & R8 & $4.535,3$ & $3.764,6$ & R16 & R11 & $7.630,1$ & $2.781,0$ \\
\hline R7 & R5 & $3.012,0$ & $2.227,8$ & R16 & R13 & $7.630,1$ & $2.781,0$ \\
\hline R8 & R9 & $15.923,6$ & $1.431,9$ & R16 & R19 & $7.630,1$ & $1.682,9$ \\
\hline R9 & R1 & $6.741,5$ & 461,5 & R19 & R21 & $4.429,0$ & $3.632,0$ \\
\hline R9 & R3 & $6.741,5$ & 461,5 & R20 & R11 & $6.451,0$ & $2.789,2$ \\
\hline R9 & R6 & $6.741,5$ & $1.739,3$ & R20 & R13 & $6.451,0$ & $2.789,2$ \\
\hline R9 & R12 & $6.741,5$ & $1.202,2$ & R20 & R15 & $6.451,0$ & 486,2 \\
\hline R9 & R14 & $6.741,5$ & $1.202,2$ & R22 & $\mathrm{R} 20$ & $2.756,5$ & $1.969,1$ \\
\hline
\end{tabular}

Tabela 52 - Pares de RDS sensibilizados e seus respectivos valores de ITC, tempo de atuação da PRL e da PRR, múltiplos de máximo e mínimo da PRL e PRR, dada a parametrização principal frente à saída de LT9.

\begin{tabular}{cccrrrr}
\hline $\boldsymbol{P R R}$ & $\boldsymbol{P R L}$ & $\boldsymbol{I T C}(\mathbf{s})$ & $\boldsymbol{T}_{\boldsymbol{P R L}}(\mathbf{s})$ & $\boldsymbol{T}_{\boldsymbol{P R R}}(\mathbf{s})$ & $\boldsymbol{M}_{\boldsymbol{P R L} \boldsymbol{}}$ & $\boldsymbol{M}_{\boldsymbol{P R R}}$ \\
\hline R1 & R4 & 0,5706 & 0,5167 & 1,0873 & 7,33 & 4,30 \\
R2 & R6 & 0,3376 & 0,5430 & 0,8806 & 17,82 & 4,43 \\
R2 & R10 & 1,0789 & 0,5430 & 1,6219 & 17,82 & 2,67 \\
R2 & R12 & 0,6806 & 0,5430 & 1,2236 & 17,82 & 3,47 \\
R2 & R14 & 0,6806 & 0,5430 & 1,2236 & 17,82 & 3,47 \\
R3 & R2 & 0,5744 & 0,5129 & 1,0873 & 7,44 & 4,30 \\
R4 & R6 & 0,3376 & 0,5430 & 0,8806 & 17,82 & 4,43 \\
R4 & R10 & 1,0789 & 0,5430 & 1,6219 & 17,82 & 2,67 \\
R4 & R12 & 0,6806 & 0,5430 & 1,2236 & 17,82 & 3,47 \\
R4 & R14 & 0,6806 & 0,5430 & 1,2236 & 17,82 & 3,47 \\
R5 & R10 & 1,0778 & 0,5478 & 1,6256 & 17,39 & 2,67 \\
\hline & & & \multicolumn{3}{c}{ Continua na próxima página }
\end{tabular}


Tabela 52 - Continuação

\begin{tabular}{cccrrrr}
\hline $\boldsymbol{P R R}$ & $\boldsymbol{P R \boldsymbol { L }}$ & $\boldsymbol{I T C}(\mathbf{s})$ & $\boldsymbol{T}_{\boldsymbol{P R \boldsymbol { L }}}(\mathbf{s})$ & $\boldsymbol{T}_{\boldsymbol{P R R} \boldsymbol{R}}(\mathbf{s})$ & $\boldsymbol{M}_{\boldsymbol{P R} \boldsymbol{L}}$ & $\boldsymbol{M}_{\boldsymbol{P R R}}$ \\
\hline R5 & R12 & 0,6749 & 0,5478 & 1,2227 & 17,39 & 3,47 \\
R5 & R14 & 0,6749 & 0,5478 & 1,2227 & 17,39 & 3,47 \\
R6 & R8 & 0,4926 & 0,5323 & 1,0249 & 11,45 & 4,70 \\
R7 & R5 & 0,3989 & 0,5335 & 0,9324 & 7,82 & 5,46 \\
R8 & R9 & 0,7205 & 0,5227 & 1,2432 & 19,86 & 3,40 \\
R9 & R6 & 0,3454 & 0,5401 & 0,8855 & 16,01 & 4,39 \\
R9 & R12 & 0,6868 & 0,5401 & 1,2269 & 16,01 & 3,45 \\
R9 & R14 & 0,6868 & 0,5401 & 1,2269 & 16,01 & 3,45 \\
R10 & R7 & 0,3476 & 0,5236 & 0,8712 & 19,76 & 3,56 \\
R11 & R6 & 0,3335 & 0,5371 & 0,8706 & 18,37 & 4,50 \\
R11 & R10 & 1,0572 & 0,5371 & 1,5943 & 18,37 & 2,72 \\
R11 & R14 & 0,705 & 0,5371 & 1,2421 & 18,37 & 3,40 \\
R12 & R13 & 0,2788 & 0,5458 & 0,8246 & 15,56 & 6,79 \\
R12 & R19 & 0,3058 & 0,5458 & 0,8516 & 15,56 & 4,30 \\
R13 & R6 & 0,3362 & 0,5344 & 0,8706 & 18,64 & 4,50 \\
R13 & R10 & 1,0599 & 0,5344 & 1,5943 & 18,64 & 2,72 \\
R13 & R12 & 0,7077 & 0,5344 & 1,2421 & 18,64 & 3,40 \\
R14 & R11 & 0,2852 & 0,5458 & 0,8310 & 15,56 & 6,69 \\
R14 & R19 & 0,3058 & 0,5458 & 0,8516 & 15,56 & 4,30 \\
R16 & R11 & 0,3255 & 0,5102 & 0,8357 & 18,74 & 6,62 \\
R16 & R13 & 0,3191 & 0,5102 & 0,8293 & 18,74 & 6,72 \\
R16 & R19 & 0,3554 & 0,5102 & 0,8656 & 18,74 & 4,20 \\
R19 & R21 & 0,3706 & 0,5120 & 0,8826 & 11,05 & 6,00 \\
R20 & R11 & 0,282 & 0,5524 & 0,8344 & 15,07 & 6,64 \\
R20 & R13 & 0,2756 & 0,5524 & 0,8280 & 15,07 & 6,74 \\
R22 & R20 & 0,3896 & 0,6041 & 0,9937 & 5,52 & 4,60 \\
\hline & & & & & &
\end{tabular}

Tabela 53 - Nova parametrização calculada para a topologia de operação sem a linha LT9; valor do tempo de atuação da PRL e a respectiva soma dos mesmos.

\begin{tabular}{ccccc}
\hline RDS & $\boldsymbol{I}_{\boldsymbol{p}}(\boldsymbol{t a p})$ & $\boldsymbol{I}_{\boldsymbol{p}}(\mathbf{A})$ & $\boldsymbol{M} \boldsymbol{T}$ & $\boldsymbol{T}_{\boldsymbol{P R \boldsymbol { L }}}(\mathbf{s})$ \\
\hline R1 & 0,67 & 402 & 0,15 & 0,5091 \\
R2 & 0,7 & 420 & 0,22 & 0,5000 \\
R3 & 0,67 & 402 & 0,15 & 0,5091 \\
R4 & 0,7 & 420 & 0,22 & 0,5000 \\
R5 & 2,96 & 355,2 & 0,23 & 0,5217 \\
R6 & 3,15 & 378 & 0,19 & 0,5221 \\
R7 & 3,19 & 382,8 & 0,16 & 0,5318 \\
R8 & 3,35 & 804 & 0,23 & 0,5233 \\
R9 & 3,34 & 400,8 & 0,21 & 0,5062 \\
R10 & 4,87 & 779,2 & 0,23 & 0,5225 \\
R11 & 0,76 & 456 & 0,22 & 0,5292 \\
R12 & 4,34 & 347,2 & 0,21 & 0,5206 \\
R13 & 0,8 & 480 & 0,22 & 0,5392 \\
R14 & 4,36 & 348,8 & 0,21 & 0,5215 \\
R15 & 1,22 & 390,4 & 0,03 & 0,5079 \\
R16 & 5,15 & 412 & 0,22 & 0,5124 \\
\hline \multicolumn{5}{c}{ Continua na próxima página }
\end{tabular}


Tabela 53 - Continuação

\begin{tabular}{ccccc}
\hline RDS & $\boldsymbol{I}_{\boldsymbol{p}}($ tap $)$ & $\boldsymbol{I}_{\boldsymbol{p}}(\mathrm{A})$ & $\boldsymbol{M T}$ & $\boldsymbol{T}_{\boldsymbol{P R \boldsymbol { L }}}(\mathrm{s})$ \\
\hline R17 & - & - & - & - \\
R18 & - & - & - & - \\
R19 & 5,0 & 400 & 0,18 & 0,5115 \\
R20 & 5,02 & 401,6 & 0,21 & 0,5149 \\
R21 & 10,08 & 604,8 & 0,23 & 0,5218 \\
R22 & 4,5 & 360 & 0,15 & 0,5054 \\
\hline & & & \multicolumn{3}{c}{$S_{T}=10,3300$} \\
\hline
\end{tabular}

Tabela 54 - Pares de RDS sensibilizados e seus respectivos valores de ITC, tempo de atuação da PRL e da PRR, múltiplos de máximo e mínimo da PRL e PRR, dada a nova parametrização frente à saída de LT9.

\begin{tabular}{|c|c|c|c|c|c|c|}
\hline$P R R$ & $P R L$ & $I T C(\mathrm{~s})$ & $T_{P R L}(\mathrm{~s})$ & $T_{P R R}(\mathrm{~s})$ & $M_{P R L}$ & $M_{P R R}$ \\
\hline R1 & R4 & 0,4581 & 0,5091 & 0,9672 & 7,55 & 4,79 \\
\hline R2 & R6 & 0,3535 & 0,5000 & 0,8535 & 19,86 & 4,64 \\
\hline R2 & R10 & 1,1117 & 0,5000 & 1,6117 & 19,86 & 2,69 \\
\hline R2 & R12 & 0,6658 & 0,5000 & 1,1658 & 19,86 & 3,47 \\
\hline R2 & R14 & 0,6701 & 0,5000 & 1,1701 & 19,86 & 3,46 \\
\hline R3 & R2 & 0,4581 & 0,5091 & 0,9672 & 7,55 & 4,79 \\
\hline R4 & R6 & 0,3535 & 0,5000 & 0,8535 & 19,86 & 4,64 \\
\hline R4 & R10 & 1,1117 & 0,5000 & 1,6117 & 19,86 & 2,69 \\
\hline R4 & $\mathrm{R} 12$ & 0,6658 & 0,5000 & 1,1658 & 19,86 & 3,47 \\
\hline R4 & R14 & 0,6701 & 0,5000 & 1,1701 & 19,86 & 3,46 \\
\hline R5 & R10 & 1,0937 & 0,5217 & 1,6154 & 19,98 & 2,68 \\
\hline R5 & R12 & 0,6432 & 0,5217 & 1,1649 & 19,98 & 3,48 \\
\hline R5 & R14 & 0,6476 & 0,5217 & 1,1693 & 19,98 & 3,46 \\
\hline R6 & R8 & 0,5048 & 0,5221 & 1,0269 & 12,00 & 4,68 \\
\hline R7 & R5 & 0,3291 & 0,5318 & 0,8609 & 7,87 & 6,27 \\
\hline R8 & R9 & 0,6165 & 0,5233 & 1,1398 & 19,81 & 3,57 \\
\hline R9 & R6 & 0,3519 & 0,5062 & 0,8581 & 16,82 & 4,60 \\
\hline R9 & R12 & 0,6627 & 0,5062 & 1,1689 & 16,82 & 3,46 \\
\hline R9 & R14 & 0,6671 & 0,5062 & 1,1733 & 16,82 & 3,45 \\
\hline $\mathrm{R} 10$ & $\mathrm{R} 7$ & 0,3443 & 0,5225 & 0,8668 & 19,88 & 3,58 \\
\hline $\mathrm{R} 11$ & R6 & 0,3149 & 0,5292 & 0,8441 & 16,92 & 4,72 \\
\hline $\mathrm{R} 11$ & $\mathrm{R} 10$ & 1,0553 & 0,5292 & 1,5845 & 16,92 & 2,73 \\
\hline R11 & R14 & 0,6587 & 0,5292 & 1,1879 & 16,92 & 3,40 \\
\hline $\mathrm{R} 12$ & $\mathrm{R} 13$ & 0,3355 & 0,5206 & 0,8561 & 15,60 & 5,86 \\
\hline $\mathrm{R} 12$ & R19 & 0,3298 & 0,5206 & 0,8504 & 15,60 & 4,31 \\
\hline $\mathrm{R} 13$ & $\mathrm{R} 6$ & 0,3049 & 0,5392 & 0,8441 & 16,08 & 4,72 \\
\hline $\mathrm{R} 13$ & $\mathrm{R} 10$ & 1,0453 & 0,5392 & 1,5845 & 16,08 & 2,73 \\
\hline $\mathrm{R} 13$ & $\mathrm{R} 12$ & 0,6442 & 0,5392 & 1,1834 & 16,08 & 3,41 \\
\hline R14 & $\mathrm{R} 11$ & 0,31 & 0,5215 & 0,8315 & 15,52 & 6,16 \\
\hline R14 & R19 & 0,3289 & 0,5215 & 0,8504 & 15,52 & 4,31 \\
\hline $\mathrm{R} 16$ & $\mathrm{R} 11$ & 0,324 & 0,5124 & 0,8364 & 18,52 & 6,10 \\
\hline $\mathrm{R} 16$ & $\mathrm{R} 13$ & 0,3489 & 0,5124 & 0,8613 & 18,52 & 5,79 \\
\hline $\mathrm{R} 16$ & R19 & 0,352 & 0,5124 & 0,8644 & 18,52 & 4,21 \\
\hline $\mathrm{R} 19$ & $\mathrm{R} 21$ & 0,3706 & 0,5115 & 0,8821 & 11,07 & 6,01 \\
\hline $\mathrm{R} 20$ & $\mathrm{R} 11$ & 0,3201 & 0,5149 & 0,8350 & 16,06 & 6,12 \\
\hline $\mathrm{R} 20$ & R13 & 0,3449 & 0,5149 & 0,8598 & 16,06 & 5,81 \\
\hline $\mathrm{R} 22$ & R20 & 0,4046 & 0,5054 & 0,9100 & 7,66 & 4,90 \\
\hline
\end{tabular}


APÊNDICE H - TOPOLOGIA DE OPERAÇÃO SEM A LINHA LT10

Tabela 55 - Correntes de curto-circuito observadas pela PRL e PRR em função da saída da linha LT10.

\begin{tabular}{|c|c|c|c|c|c|c|c|}
\hline PRR & $P R L$ & $I_{C C, \text { local }}(\mathrm{A})$ & $I_{C C, \text { rem }}(\mathrm{A})$ & $P R R$ & $P R L$ & $I_{C C, \text { local }}(\mathrm{A})$ & $I_{C C, \text { rem }}(\mathrm{A})$ \\
\hline R1 & $\mathrm{R} 4$ & $3.003,2$ & $1.983,7$ & R9 & R12 & $6.518,1$ & $1.093,4$ \\
\hline R2 & R3 & $8.121,1$ & 425,9 & R9 & R14 & $6.518,1$ & $1.093,4$ \\
\hline R2 & R6 & $8.121,1$ & $1.752,9$ & R10 & R7 & $15.464,6$ & $1.345,2$ \\
\hline R2 & $\mathrm{R} 10$ & $8.121,1$ & $2.094,1$ & R11 & R1 & $7.601,1$ & 470,9 \\
\hline R2 & $\mathrm{R} 12$ & $8.121,1$ & $1.096,9$ & R11 & R3 & $7.601,1$ & 470,9 \\
\hline R2 & R14 & $8.121,1$ & $1.096,9$ & R11 & R6 & $7.601,1$ & $1.781,9$ \\
\hline R3 & R2 & $3.003,2$ & $1.983,7$ & R11 & R10 & $7.601,1$ & $2.128,7$ \\
\hline R4 & R1 & $8.121,1$ & 425,9 & R11 & R14 & $7.601,1$ & $1.073,6$ \\
\hline R4 & R6 & $8.121,1$ & $1.752,9$ & $\mathrm{R} 12$ & $\mathrm{R} 13$ & $5.166,9$ & $2.810,3$ \\
\hline R4 & $\mathrm{R} 10$ & $8.121,1$ & $2.094,1$ & $\mathrm{R} 12$ & R15 & $5.166,9$ & $1.964,0$ \\
\hline R4 & $\mathrm{R} 12$ & $8.121,1$ & $1.096,9$ & R13 & R1 & $7.601,1$ & 470,9 \\
\hline R4 & R14 & $8.121,1$ & $1.096,9$ & R13 & R3 & $7.601,1$ & 470,9 \\
\hline R5 & R1 & $6.872,3$ & 463,7 & R13 & R6 & $7.601,1$ & $1.781,9$ \\
\hline R5 & R3 & $6.872,3$ & 463,7 & R13 & R10 & $7.601,1$ & $2.128,7$ \\
\hline R5 & $\mathrm{R} 10$ & $6.872,3$ & $2.089,6$ & $\mathrm{R} 13$ & $\mathrm{R} 12$ & $7.601,1$ & $1.073,6$ \\
\hline R5 & $\mathrm{R} 12$ & $6.872,3$ & $1.097,9$ & R14 & $\mathrm{R} 11$ & $5.166,9$ & $2.810,3$ \\
\hline R5 & $\mathrm{R} 14$ & $6.872,3$ & $1.097,9$ & R14 & $\mathrm{R} 15$ & $5.166,9$ & $1.964,0$ \\
\hline R6 & $\mathrm{R} 8$ & $4.528,2$ & $3.757,4$ & $\mathrm{R} 15$ & $\mathrm{R} 17$ & $5.833,7$ & $5.281,0$ \\
\hline R7 & R5 & $2.979,8$ & $2.196,0$ & $\mathrm{R} 16$ & $\mathrm{R} 11$ & $5.983,8$ & $2.795,0$ \\
\hline $\mathrm{R} 8$ & R9 & $15.882,2$ & $1.395,0$ & $\mathrm{R} 16$ & $\mathrm{R} 13$ & $5.983,8$ & $2.795,0$ \\
\hline R9 & $\mathrm{R} 1$ & $6.518,1$ & 461,8 & $\mathrm{R} 17$ & $\mathrm{R} 22$ & $11.194,1$ & 712,2 \\
\hline R9 & R3 & $6.518,1$ & 461,8 & $\mathrm{R} 18$ & R16 & $2.551,0$ & $1.984,4$ \\
\hline R9 & R6 & $6.518,1$ & $1.739,3$ & R21 & R18 & $12.334,7$ & $1.985,7$ \\
\hline
\end{tabular}

Tabela 56 - Pares de RDS sensibilizados e seus respectivos valores de ITC, tempo de atuação da PRL e da PRR, múltiplos de máximo e mínimo da PRL e PRR, dada a parametrização principal frente à saída de LT10.

\begin{tabular}{|c|c|c|c|c|c|c|}
\hline PRR & $P R L$ & $I T C(\mathrm{~s})$ & $T_{P R L}(\mathrm{~s})$ & $T_{P R R}(\mathrm{~s})$ & $M_{P R L}$ & $M_{P R R}$ \\
\hline $\mathrm{R} 1$ & $\mathrm{R} 4$ & 0,5792 & 0,5195 & 1,0987 & 7,25 & 4,24 \\
\hline R2 & R6 & 0,3326 & 0,5482 & 0,8808 & 17,35 & 4,43 \\
\hline R2 & R10 & 1,0745 & 0,5482 & 1,6227 & 17,35 & 2,67 \\
\hline R2 & R12 & 0,7779 & 0,5482 & 1,3261 & 17,35 & 3,15 \\
\hline R2 & R14 & 0,7779 & 0,5482 & 1,3261 & 17,35 & 3,15 \\
\hline R3 & R2 & 0,5831 & 0,5156 & 1,0987 & 7,36 & 4,24 \\
\hline R4 & R6 & 0,3326 & 0,5482 & 0,8808 & 17,35 & 4,43 \\
\hline R4 & R10 & 1,0745 & 0,5482 & 1,6227 & 17,35 & 2,67 \\
\hline R4 & R12 & 0,7779 & 0,5482 & 1,3261 & 17,35 & 3,15 \\
\hline R4 & R14 & 0,7779 & 0,5482 & 1,3261 & 17,35 & 3,15 \\
\hline R5 & R10 & 1,0721 & 0,5542 & 1,6263 & 16,84 & 2,67 \\
\hline R5 & R12 & 0,7708 & 0,5542 & 1,3250 & 16,84 & 3,15 \\
\hline R5 & R14 & 0,7708 & 0,5542 & 1,3250 & 16,84 & 3,15 \\
\hline
\end{tabular}


Tabela 56 - Continuação

\begin{tabular}{cccrrrr}
\hline $\boldsymbol{P R} \boldsymbol{R}$ & $\boldsymbol{P R \boldsymbol { L }}$ & $\boldsymbol{I} \boldsymbol{T} \boldsymbol{C}(\mathbf{s})$ & $\boldsymbol{T}_{\boldsymbol{P R} \boldsymbol{L}}(\mathbf{s})$ & $\boldsymbol{T}_{\boldsymbol{P R} \boldsymbol{R}}(\mathbf{s})$ & $\boldsymbol{M}_{\boldsymbol{P R} \boldsymbol{L}}$ & $\boldsymbol{M}_{\boldsymbol{P R} \boldsymbol{R}}$ \\
\hline R6 & R8 & 0,4935 & 0,5326 & 1,0261 & 11,43 & 4,69 \\
R7 & R5 & 0,4042 & 0,5363 & 0,9405 & 7,74 & 5,38 \\
R8 & R9 & 0,7474 & 0,5232 & 1,2706 & 19,81 & 3,31 \\
R9 & R6 & 0,3386 & 0,5469 & 0,8855 & 15,48 & 4,39 \\
R9 & R12 & 0,7829 & 0,5469 & 1,3298 & 15,48 & 3,14 \\
R9 & R14 & 0,7829 & 0,5469 & 1,3298 & 15,48 & 3,14 \\
R10 & R7 & 0,3605 & 0,5240 & 0,8845 & 19,73 & 3,49 \\
R11 & R6 & 0,3311 & 0,5400 & 0,8711 & 18,10 & 4,50 \\
R11 & R10 & 1,0558 & 0,5400 & 1,5958 & 18,10 & 2,72 \\
R11 & R14 & 0,8116 & 0,5400 & 1,3516 & 18,10 & 3,09 \\
R12 & R13 & 0,2691 & 0,5556 & 0,8247 & 14,85 & 6,79 \\
R12 & R15 & 0,3103 & 0,5556 & 0,8659 & 14,85 & 4,91 \\
R13 & R6 & 0,3338 & 0,5373 & 0,8711 & 18,36 & 4,50 \\
R13 & R10 & 1,0585 & 0,5373 & 1,5958 & 18,36 & 2,72 \\
R13 & R12 & 0,8143 & 0,5373 & 1,3516 & 18,36 & 3,09 \\
R14 & R11 & 0,2754 & 0,5556 & 0,8310 & 14,85 & 6,69 \\
R14 & R15 & 0,3103 & 0,5556 & 0,8659 & 14,85 & 4,91 \\
R15 & R17 & 0,3217 & 0,5085 & 0,8302 & 14,58 & 6,70 \\
R16 & R11 & 0,2757 & 0,5578 & 0,8335 & 14,69 & 6,65 \\
R16 & R13 & 0,2693 & 0,5578 & 0,8271 & 14,69 & 6,75 \\
R17 & R22 & 2,3536 & 0,5907 & 2,9443 & 14,21 & 1,43 \\
R18 & R16 & 0,3136 & 0,6434 & 0,9570 & 4,98 & 4,87 \\
R21 & R18 & 0,246 & 0,5182 & 0,7642 & 20,37 & 3,88 \\
\hline
\end{tabular}

Tabela 57 - Nova parametrização calculada para a topologia de operação sem a linha LT10; valor do tempo de atuação da PRL e a respectiva soma dos mesmos.

\begin{tabular}{ccccc}
\hline RDS & $\boldsymbol{I}_{\boldsymbol{p}}(\boldsymbol{t a p})$ & $\boldsymbol{I}_{\boldsymbol{p}}(\mathbf{A})$ & $\boldsymbol{M} \boldsymbol{T}$ & $\boldsymbol{T}_{\boldsymbol{P R \boldsymbol { L }}}(\mathbf{s})$ \\
\hline R1 & 0,67 & 402 & 0,15 & 0,5117 \\
R2 & 0,68 & 408 & 0,23 & 0,5224 \\
R3 & 0,68 & 408 & 0,15 & 0,5156 \\
R4 & 0,68 & 408 & 0,23 & 0,5224 \\
R5 & 3,25 & 390 & 0,22 & 0,5215 \\
R6 & 3,34 & 400,8 & 0,19 & 0,5353 \\
R7 & 3,2 & 384 & 0,16 & 0,5355 \\
R8 & 3,31 & 794,4 & 0,23 & 0,5216 \\
R9 & 3,33 & 399,6 & 0,21 & 0,5120 \\
R10 & 4,99 & 798,4 & 0,23 & 0,5273 \\
R11 & 0,76 & 456 & 0,23 & 0,5563 \\
R12 & 4,34 & 347,2 & 0,2 & 0,5046 \\
R13 & 0,82 & 492 & 0,22 & 0,5473 \\
R14 & 4,41 & 352,8 & 0,2 & 0,5077 \\
R15 & 1,26 & 403,2 & 0,2 & 0,5101 \\
R16 & 6,48 & 518,4 & 0,2 & 0,5585 \\
R17 & 11,74 & 704,4 & 0,24 & 0,5908 \\
R18 & 1,51 & 483,2 & 0,17 & 0,7034 \\
R19 & - & - & - & - \\
R20 & - & - & - & - \\
R21 & 10,28 & 616,8 & 0,23 & 0,5215 \\
R22 & 5,57 & 445,6 & 0,06 & 0,6858 \\
\hline \multicolumn{5}{r}{} \\
\hline
\end{tabular}


Tabela 58 - Pares de RDS sensibilizados e seus respectivos valores de ITC, tempo de atuação da PRL e da PRR, múltiplos de máximo e mínimo da PRL e PRR, dada a nova parametrização frente à saída de LT10.

\begin{tabular}{|c|c|c|c|c|c|c|}
\hline PRR & $P R L$ & $I T C(\mathrm{~s})$ & $T_{P R L}(\mathrm{~s})$ & $T_{P R R}(\mathrm{~s})$ & $M_{P R L}$ & $M_{P R R}$ \\
\hline R1 & $\mathrm{R} 4$ & 0,4903 & 0,5117 & 1,0020 & 7,47 & 4,86 \\
\hline R2 & R6 & 0,3657 & 0,5224 & 0,8881 & 19,90 & 4,37 \\
\hline R2 & R10 & 1,1312 & 0,5224 & 1,6536 & 19,90 & 2,62 \\
\hline R2 & R12 & 0,6807 & 0,5224 & 1,2031 & 19,90 & 3,16 \\
\hline R2 & R14 & 0,6978 & 0,5224 & 1,2202 & 19,90 & 3,11 \\
\hline R3 & R2 & 0,4864 & 0,5156 & 1,0020 & 7,36 & 4,86 \\
\hline R4 & R6 & 0,3657 & 0,5224 & 0,8881 & 19,90 & 4,37 \\
\hline R4 & R10 & 1,1312 & 0,5224 & 1,6536 & 19,90 & 2,62 \\
\hline R4 & R12 & 0,6807 & 0,5224 & 1,2031 & 19,90 & 3,16 \\
\hline R4 & R14 & 0,6978 & 0,5224 & 1,2202 & 19,90 & 3,11 \\
\hline R5 & R10 & 1,1358 & 0,5215 & 1,6573 & 17,62 & 2,62 \\
\hline R5 & R12 & 0,6806 & 0,5215 & 1,2021 & 17,62 & 3,16 \\
\hline R5 & R14 & 0,6978 & 0,5215 & 1,2193 & 17,62 & 3,11 \\
\hline R6 & R8 & 0,4848 & 0,5353 & 1,0201 & 11,30 & 4,73 \\
\hline R7 & R5 & 0,3403 & 0,5355 & 0,8758 & 7,76 & 5,63 \\
\hline R8 & R9 & 0,6396 & 0,5216 & 1,1612 & 19,99 & 3,49 \\
\hline R9 & R6 & 0,3809 & 0,5120 & 0,8929 & 16,31 & 4,34 \\
\hline R9 & R12 & 0,6945 & 0,5120 & 1,2065 & 16,31 & 3,15 \\
\hline R9 & R14 & 0,7117 & 0,5120 & 1,2237 & 16,31 & 3,10 \\
\hline R10 & R7 & 0,3549 & 0,5273 & 0,8822 & 19,37 & 3,50 \\
\hline R11 & R6 & 0,3219 & 0,5563 & 0,8782 & 16,67 & 4,45 \\
\hline R11 & R10 & 1,0694 & 0,5563 & 1,6257 & 16,67 & 2,67 \\
\hline R11 & R14 & 0,6878 & 0,5563 & 1,2441 & 16,67 & 3,04 \\
\hline R12 & R13 & 0,3638 & 0,5046 & 0,8684 & 14,88 & 5,71 \\
\hline R12 & R15 & 0,3657 & 0,5046 & 0,8703 & 14,88 & 4,87 \\
\hline R13 & R6 & 0,3309 & 0,5473 & 0,8782 & 15,45 & 4,45 \\
\hline R13 & R10 & 1,0784 & 0,5473 & 1,6257 & 15,45 & 2,67 \\
\hline R13 & R12 & 0,6789 & 0,5473 & 1,2262 & 15,45 & 3,09 \\
\hline R14 & R11 & 0,3616 & 0,5077 & 0,8693 & 14,65 & 6,16 \\
\hline R14 & R15 & 0,3626 & 0,5077 & 0,8703 & 14,65 & 4,87 \\
\hline R15 & R17 & 0,3072 & 0,5101 & 0,8173 & 14,47 & 7,50 \\
\hline R16 & R11 & 0,3135 & 0,5585 & 0,8720 & 11,54 & 6,13 \\
\hline R16 & R13 & 0,3127 & 0,5585 & 0,8712 & 11,54 & 5,68 \\
\hline R17 & R22 & 0,3006 & 0,5908 & 0,8914 & 15,89 & 1,60 \\
\hline R18 & R16 & 0,3256 & 0,7034 & 1,0290 & 5,28 & 3,83 \\
\hline R21 & R18 & 0,3087 & 0,5215 & 0,8302 & 20,00 & 4,11 \\
\hline
\end{tabular}


APÊNDICE I - TOPOLOGIA DE OPERAÇÃO SEM A LINHA LT11

Tabela 59 - Correntes de curto-circuito observadas pela PRL e PRR em função da saída da linha LT11.

\begin{tabular}{|c|c|c|c|c|c|c|c|}
\hline PRR & $P R L$ & $I_{C C, \text { local }}(\mathbf{A})$ & $I_{C C, \text { rem }}(\mathrm{A})$ & $P R R$ & $P R L$ & $I_{C C, \text { local }}(\mathrm{A})$ & $I_{C C, \text { rem }}(\mathrm{A})$ \\
\hline R1 & R4 & $3.072,1$ & $2.052,5$ & R10 & R7 & $15.508,6$ & $1.393,0$ \\
\hline $\mathrm{R} 2$ & R3 & $8.643,2$ & 423,0 & R11 & $\mathrm{R} 1$ & $7.870,3$ & 470,8 \\
\hline $\mathrm{R} 2$ & R6 & $8.643,2$ & $1.750,2$ & R11 & R3 & $7.870,3$ & 470,8 \\
\hline R2 & R10 & $8.643,2$ & $2.090,7$ & R11 & R6 & $7.870,3$ & $1.781,2$ \\
\hline R2 & R12 & $8.643,2$ & $1.362,5$ & R11 & R10 & $7.870,3$ & $2.127,7$ \\
\hline R2 & R14 & $8.643,2$ & $1.362,5$ & R11 & R14 & $7.870,3$ & $1.343,0$ \\
\hline R3 & R2 & $3.072,1$ & $2.052,5$ & $\mathrm{R} 12$ & R13 & $5.773,9$ & $2.806,1$ \\
\hline R4 & R1 & $8.643,2$ & 423,0 & $\mathrm{R} 12$ & R15 & $5.773,9$ & $1.942,1$ \\
\hline R4 & R6 & $8.643,2$ & $1.750,2$ & $\mathrm{R} 12$ & R19 & $5.773,9$ & 642,2 \\
\hline $\mathrm{R} 4$ & $\mathrm{R} 10$ & $8.643,2$ & $2.090,7$ & $\mathrm{R} 13$ & $\mathrm{R} 1$ & $7.870,3$ & 470,8 \\
\hline $\mathrm{R} 4$ & $\mathrm{R} 12$ & $8.643,2$ & $1.362,5$ & $\mathrm{R} 13$ & R3 & $7.870,3$ & 470,8 \\
\hline $\mathrm{R} 4$ & $\mathrm{R} 14$ & $8.643,2$ & $1.362,5$ & $\mathrm{R} 13$ & R6 & $7.870,3$ & $1.781,2$ \\
\hline R5 & $\mathrm{R} 1$ & $7.400,3$ & 463,0 & $\mathrm{R} 13$ & $\mathrm{R} 10$ & $7.870,3$ & $2.127,7$ \\
\hline R5 & R3 & $7.400,3$ & 463,0 & $\mathrm{R} 13$ & $\mathrm{R} 12$ & $7.870,3$ & $1.343,0$ \\
\hline R5 & $\mathrm{R} 10$ & $7.400,3$ & $2.085,5$ & $\mathrm{R} 14$ & $\mathrm{R} 11$ & $5.773,9$ & $2.806,1$ \\
\hline R5 & $\mathrm{R} 12$ & $7.400,3$ & $1.363,5$ & $\mathrm{R} 14$ & $\mathrm{R} 15$ & $5.773,9$ & $1.942,1$ \\
\hline R5 & $\mathrm{R} 14$ & $7.400,3$ & $1.363,5$ & $\mathrm{R} 14$ & R19 & $5.773,9$ & 642,2 \\
\hline R6 & $\mathrm{R} 8$ & $4.539,8$ & $3.769,2$ & $\mathrm{R} 15$ & $\mathrm{R} 17$ & $5.664,9$ & $5.112,8$ \\
\hline $\mathrm{R} 7$ & R5 & $3.046,3$ & $2.263,1$ & $\mathrm{R} 16$ & $\mathrm{R} 11$ & $6.593,9$ & $2.788,6$ \\
\hline $\mathrm{R} 8$ & R9 & $15.948,0$ & $1.464,9$ & $\mathrm{R} 16$ & $\mathrm{R} 13$ & $6.593,9$ & $2.788,6$ \\
\hline R9 & $\mathrm{R} 1$ & $7.042,8$ & 461,0 & $\mathrm{R} 16$ & R19 & $6.593,9$ & 629,8 \\
\hline R9 & R3 & $7.042,8$ & 461,0 & R18 & R16 & $2.616,2$ & $2.049,6$ \\
\hline R9 & R6 & $7.042,8$ & $1.735,1$ & R20 & R11 & $7.823,0$ & $2.773,3$ \\
\hline R9 & $\mathrm{R} 12$ & $7.042,8$ & $2.161,2$ & $\mathrm{R} 20$ & $\mathrm{R} 13$ & $7.823,0$ & $2.773,3$ \\
\hline $\mathrm{R} 9$ & $\mathrm{R} 14$ & $7.042,8$ & $2.161,2$ & $\mathrm{R} 20$ & $\mathrm{R} 15$ & $7.823,0$ & $1.984,0$ \\
\hline
\end{tabular}

Tabela 60 - Pares de RDS sensibilizados e seus respectivos valores de ITC, tempo de atuação da PRL e da PRR, múltiplos de máximo e mínimo da PRL e PRR, dada a parametrização principal frente à saída de LT11.

\begin{tabular}{cccrrrr}
\hline $\boldsymbol{P R R}$ & $\boldsymbol{P R L}$ & $\boldsymbol{I T C}(\mathbf{s})$ & $\boldsymbol{T}_{\boldsymbol{P R L}}(\mathbf{s})$ & $\boldsymbol{T}_{\boldsymbol{P R R}}(\mathbf{s})$ & $\boldsymbol{M}_{\boldsymbol{P R L} L}$ & $\boldsymbol{M}_{\boldsymbol{P R R}}$ \\
\hline R1 & R4 & 0,5595 & 0,5135 & 1,0730 & 7,42 & 4,39 \\
R2 & R6 & 0,3455 & 0,5362 & 0,8817 & 18,47 & 4,42 \\
R2 & R10 & 1,0892 & 0,5362 & 1,6254 & 18,47 & 2,67 \\
R2 & R12 & 0,5768 & 0,5362 & 1,1130 & 18,47 & 3,92 \\
R2 & R14 & 0,5768 & 0,5362 & 1,1130 & 18,47 & 3,92 \\
R3 & R2 & 0,5633 & 0,5097 & 1,0730 & 7,53 & 4,39 \\
R4 & R6 & 0,3455 & 0,5362 & 0,8817 & 18,47 & 4,42 \\
R4 & R10 & 1,0892 & 0,5362 & 1,6254 & 18,47 & 2,67 \\
R4 & R12 & 0,5768 & 0,5362 & 1,1130 & 18,47 & 3,92 \\
R4 & R14 & 0,5768 & 0,5362 & 1,1130 & 18,47 & 3,92 \\
R5 & R10 & 1,09 & 0,5396 & 1,6296 & 18,14 & 2,66 \\
R5 & R12 & 0,5728 & 0,5396 & 1,1124 & 18,14 & 3,92 \\
R5 & R14 & 0,5728 & 0,5396 & 1,1124 & 18,14 & 3,92 \\
\hline & & & \multicolumn{3}{c}{ Continua na próxima página }
\end{tabular}


Tabela 60 - Continuação

\begin{tabular}{cccrrrr}
\hline $\boldsymbol{P R \boldsymbol { R }}$ & $\boldsymbol{P R \boldsymbol { L }}$ & $\boldsymbol{I} \boldsymbol{C} \boldsymbol{( s )}$ & $\boldsymbol{T}_{\boldsymbol{P R} \boldsymbol{L}}(\mathbf{s})$ & $\boldsymbol{T}_{\boldsymbol{P R \boldsymbol { R }}}(\mathbf{s})$ & $\boldsymbol{M}_{\boldsymbol{P R} \boldsymbol{L}}$ & $\boldsymbol{M}_{\boldsymbol{P R} \boldsymbol{R}}$ \\
\hline R6 & R8 & 0,4919 & 0,5321 & 1,0240 & 11,46 & 4,70 \\
R7 & R5 & 0,3932 & 0,5305 & 0,9237 & 7,91 & 5,55 \\
R8 & R9 & 0,6978 & 0,5224 & 1,2202 & 19,90 & 3,48 \\
R9 & R6 & 0,3555 & 0,5315 & 0,8870 & 16,72 & 4,38 \\
R9 & R12 & 0,2965 & 0,5315 & 0,8280 & 16,72 & 6,21 \\
R9 & R14 & 0,2965 & 0,5315 & 0,8280 & 16,72 & 6,21 \\
R10 & R7 & 0,3366 & 0,5235 & 0,8601 & 19,78 & 3,62 \\
R11 & R6 & 0,3379 & 0,5334 & 0,8713 & 18,74 & 4,50 \\
R11 & R10 & 1,0632 & 0,5334 & 1,5966 & 18,74 & 2,71 \\
R11 & R14 & 0,5916 & 0,5334 & 1,1250 & 18,74 & 3,86 \\
R12 & R13 & 0,2923 & 0,5330 & 0,8253 & 16,59 & 6,78 \\
R12 & R15 & 0,3391 & 0,5330 & 0,8721 & 16,59 & 4,86 \\
R12 & R19 & 2,1271 & 0,5330 & 2,6601 & 16,59 & 1,60 \\
R13 & R6 & 0,3405 & 0,5308 & 0,8713 & 19,01 & 4,50 \\
R13 & R10 & 1,0658 & 0,5308 & 1,5966 & 19,01 & 2,71 \\
R13 & R12 & 0,5942 & 0,5308 & 1,1250 & 19,01 & 3,86 \\
R14 & R11 & 0,2987 & 0,5330 & 0,8317 & 16,59 & 6,68 \\
R14 & R15 & 0,3391 & 0,5330 & 0,8721 & 16,59 & 4,86 \\
R14 & R19 & 2,1271 & 0,5330 & 2,6601 & 16,59 & 1,60 \\
R15 & R17 & 0,3305 & 0,5143 & 0,8448 & 14,16 & 6,49 \\
R16 & R11 & 0,2967 & 0,5378 & 0,8345 & 16,19 & 6,64 \\
R16 & R13 & 0,2903 & 0,5378 & 0,8281 & 16,19 & 6,74 \\
R16 & R19 & 2,2376 & 0,5378 & 2,7754 & 16,19 & 1,57 \\
R18 & R16 & 0,3043 & 0,6333 & 0,9376 & 5,11 & 5,03 \\
R20 & R11 & 0,3223 & 0,5147 & 0,8370 & 18,28 & 6,60 \\
R20 & R13 & 0,3158 & 0,5147 & 0,8305 & 18,28 & 6,70 \\
R20 & R15 & 0,3456 & 0,5147 & 0,8603 & 18,28 & 4,96 \\
\hline & & & & & &
\end{tabular}

Tabela 61 - Nova parametrização calculada para a topologia de operação sem a linha LT11; valor do tempo de atuação da PRL e a respectiva soma dos mesmos.

\begin{tabular}{ccccc}
\hline RDS & $\boldsymbol{I}_{\boldsymbol{p}}($ tap $)$ & $\boldsymbol{I}_{\boldsymbol{p}}(\mathbf{A})$ & $\boldsymbol{M} \boldsymbol{T}$ & $\boldsymbol{T}_{\boldsymbol{P R L} \boldsymbol{L}}(\mathbf{s})$ \\
\hline R1 & 0,67 & 402 & 0,15 & 0,5059 \\
R2 & 0,73 & 438 & 0,22 & 0,5011 \\
R3 & 0,67 & 402 & 0,15 & 0,5059 \\
R4 & 0,74 & 444 & 0,22 & 0,5035 \\
R5 & 3,09 & 370,8 & 0,23 & 0,5219 \\
R6 & 3,33 & 399,6 & 0,19 & 0,5341 \\
R7 & 3,2 & 384 & 0,16 & 0,5297 \\
R8 & 3,36 & 806,4 & 0,23 & 0,5235 \\
R9 & 3,34 & 400,8 & 0,22 & 0,5220 \\
R10 & 4,85 & 776 & 0,23 & 0,5216 \\
R11 & 0,72 & 432 & 0,23 & 0,5388 \\
R12 & 4,77 & 381,6 & 0,21 & 0,5265 \\
R13 & 0,74 & 444 & 0,23 & 0,5440 \\
R14 & 4,77 & 381,6 & 0,21 & 0,5265 \\
R15 & 1,27 & 406,4 & 0,2 & 0,5175 \\
\hline \multicolumn{4}{c}{ Continua na próxima página }
\end{tabular}


Tabela 61 - Continuação

\begin{tabular}{ccccc}
\hline RDS & $\boldsymbol{I}_{\boldsymbol{p}}($ tap $)$ & $\boldsymbol{I}_{\boldsymbol{p}}(\mathrm{A})$ & $\boldsymbol{M T}$ & $\boldsymbol{T}_{\boldsymbol{P R \boldsymbol { L }}}(\mathrm{s})$ \\
\hline R16 & 5,01 & 400,8 & 0,21 & 0,5104 \\
$\mathrm{R} 17$ & 12,36 & 741,6 & 0,23 & 0,5625 \\
$\mathrm{R} 18$ & 1,13 & 361,6 & 0,15 & 0,5202 \\
$\mathrm{R} 19$ & 5,0 & 400 & 0,06 & 0,5830 \\
R20 & 5,0 & 400 & 0,22 & 0,5027 \\
R21 & - & - & - & - \\
R22 & - & - & - & - \\
\hline & & & & $S_{T}=10,5012$ \\
\hline
\end{tabular}

Tabela 62 - Pares de RDS sensibilizados e seus respectivos valores de ITC, tempo de atuação da PRL e da PRR, múltiplos de máximo e mínimo da PRL e PRR, dada a nova parametrização frente à saída de LT11.

\begin{tabular}{|c|c|c|c|c|c|c|}
\hline$P R R$ & $P R L$ & $I T C(\mathrm{~s})$ & $T_{P R L}(\mathrm{~s})$ & $T_{P R R}(\mathrm{~s})$ & $M_{P R L}$ & $\overline{M_{P R R}}$ \\
\hline R1 & $\mathrm{R} 4$ & 0,4847 & 0,5059 & 0,9906 & 7,64 & 4,62 \\
\hline R2 & R6 & 0,3861 & 0,5011 & 0,8872 & 19,73 & 4,38 \\
\hline R2 & R10 & 1,1073 & 0,5011 & 1,6084 & 19,73 & 2,69 \\
\hline R2 & $\mathrm{R} 12$ & 0,6393 & 0,5011 & 1,1404 & 19,73 & 3,57 \\
\hline R2 & R14 & 0,6393 & 0,5011 & 1,1404 & 19,73 & 3,57 \\
\hline R3 & R2 & 0,4758 & 0,5059 & 0,9817 & 7,64 & 4,69 \\
\hline R4 & R6 & 0,3837 & 0,5035 & 0,8872 & 19,47 & 4,38 \\
\hline $\mathrm{R} 4$ & $\mathrm{R} 10$ & 1,1049 & 0,5035 & 1,6084 & 19,47 & 2,69 \\
\hline R4 & $\mathrm{R} 12$ & 0,6369 & 0,5035 & 1,1404 & 19,47 & 3,57 \\
\hline $\mathrm{R} 4$ & $\mathrm{R} 14$ & 0,6369 & 0,5035 & 1,1404 & 19,47 & 3,57 \\
\hline R5 & $\mathrm{R} 10$ & 1,0906 & 0,5219 & 1,6125 & 19,96 & 2,69 \\
\hline R5 & $\mathrm{R} 12$ & 0,6178 & 0,5219 & 1,1397 & 19,96 & 3,57 \\
\hline R5 & $\mathrm{R} 14$ & 0,6178 & 0,5219 & 1,1397 & 19,96 & 3,57 \\
\hline R6 & R8 & 0,4940 & 0,5341 & 1,0281 & 11,36 & 4,67 \\
\hline R7 & R5 & 0,3444 & 0,5297 & 0,8741 & 7,93 & 6,10 \\
\hline R8 & R9 & 0,6494 & 0,5235 & 1,1729 & 19,78 & 3,65 \\
\hline R9 & R6 & 0,3705 & 0,5220 & 0,8925 & 17,57 & 4,34 \\
\hline R9 & $\mathrm{R} 12$ & 0,3111 & 0,5220 & 0,8331 & 17,57 & 5,66 \\
\hline R9 & $\mathrm{R} 14$ & 0,3111 & 0,5220 & 0,8331 & 17,57 & 5,66 \\
\hline $\mathrm{R} 10$ & $\mathrm{R} 7$ & 0,3364 & 0,5216 & 0,8580 & 19,99 & 3,63 \\
\hline $\mathrm{R} 11$ & R6 & 0,3379 & 0,5388 & 0,8766 & 18,22 & 4,46 \\
\hline $\mathrm{R} 11$ & $\mathrm{R} 10$ & 1,0414 & 0,5388 & 1,5802 & 18,22 & 2,74 \\
\hline $\mathrm{R} 11$ & $\mathrm{R} 14$ & 0,6149 & 0,5388 & 1,1536 & 18,22 & 3,52 \\
\hline $\mathrm{R} 12$ & R13 & 0,3307 & 0,5265 & 0,8572 & 15,13 & 6,32 \\
\hline $\mathrm{R} 12$ & $\mathrm{R} 15$ & 0,3546 & 0,5265 & 0,8811 & 15,13 & 4,78 \\
\hline $\mathrm{R} 12$ & R19 & 0,3564 & 0,5265 & 0,8829 & 15,13 & 1,61 \\
\hline R13 & R6 & 0,3326 & 0,5440 & 0,8766 & 17,73 & 4,46 \\
\hline $\mathrm{R} 13$ & $\mathrm{R} 10$ & 1,0361 & 0,5440 & 1,5802 & 17,73 & 2,74 \\
\hline $\mathrm{R} 13$ & $\mathrm{R} 12$ & 0,6096 & 0,5440 & 1,1536 & 17,73 & 3,52 \\
\hline $\mathrm{R} 14$ & R11 & 0,3179 & 0,5265 & 0,8444 & 15,13 & 6,50 \\
\hline $\mathrm{R} 14$ & $\mathrm{R} 15$ & 0,3546 & 0,5265 & 0,8811 & 15,13 & 4,78 \\
\hline $\mathrm{R} 14$ & R19 & 0,3564 & 0,5265 & 0,8829 & 15,13 & 1,61 \\
\hline R15 & R17 & 0,3004 & 0,5175 & 0,8179 & 13,94 & 6,89 \\
\hline R16 & R11 & 0,3370 & 0,5104 & 0,8473 & 16,45 & 6,46 \\
\hline R16 & R13 & 0,3498 & 0,5104 & 0,8602 & 16,45 & 6,28 \\
\hline
\end{tabular}


Tabela 62- Continuação

\begin{tabular}{ccccccc}
\hline $\boldsymbol{P R R}$ & $\boldsymbol{P R L}$ & $\boldsymbol{I T C}(\mathbf{s})$ & $\boldsymbol{T}_{\boldsymbol{P R L}}(\mathbf{s})$ & $\boldsymbol{T}_{\boldsymbol{P R R}}(\mathbf{s})$ & $\boldsymbol{M}_{\boldsymbol{P R L}}$ & $\boldsymbol{M}_{\boldsymbol{P R R}}$ \\
\hline $\mathrm{R} 16$ & $\mathrm{R} 19$ & 0,4107 & 0,5104 & 0,9210 & 16,45 & 1,57 \\
$\mathrm{R} 18$ & $\mathrm{R} 16$ & 0,3660 & 0,5202 & 0,8861 & 7,24 & 5,11 \\
$\mathrm{R} 20$ & $\mathrm{R} 11$ & 0,3472 & 0,5027 & 0,8499 & 19,56 & 6,42 \\
$\mathrm{R} 20$ & $\mathrm{R} 13$ & 0,3601 & 0,5027 & 0,8628 & 19,56 & 6,25 \\
$\mathrm{R} 20$ & $\mathrm{R} 15$ & 0,3664 & 0,5027 & 0,8691 & 19,56 & 4,88 \\
\hline
\end{tabular}

